\title{
Nondestructive evaluation of FRP wrapped concrete cylinders using infrared thermography and ground penetrating radar
}

\author{
Shasanka Shekhar Dutta \\ West Virginia University
}

Follow this and additional works at: https://researchrepository.wvu.edu/etd

\section{Recommended Citation}

Dutta, Shasanka Shekhar, "Nondestructive evaluation of FRP wrapped concrete cylinders using infrared thermography and ground penetrating radar" (2006). Graduate Theses, Dissertations, and Problem Reports. 1766.

https://researchrepository.wvu.edu/etd/1766

This Thesis is protected by copyright and/or related rights. It has been brought to you by the The Research Repository @ WVU with permission from the rights-holder(s). You are free to use this Thesis in any way that is permitted by the copyright and related rights legislation that applies to your use. For other uses you must obtain permission from the rights-holder(s) directly, unless additional rights are indicated by a Creative Commons license in the record and/ or on the work itself. This Thesis has been accepted for inclusion in WVU Graduate Theses, Dissertations, and Problem Reports collection by an authorized administrator of The Research Repository @ WVU. For more information, please contact researchrepository@mail.wvu.edu. 


\title{
NONDESTRUCTIVE EVALUATION OF FRP WRAPPED CONCRETE CYLINDERS USING INFRARED THERMOGRAPHY AND GROUND PENETRATING RADAR
}

\author{
Shasanka Shekhar Dutta
}

\author{
Thesis submitted to the \\ College of Engineering and Mineral Resources \\ at West Virginia University \\ in partial fulfillment of the requirements \\ for the degree of
}

Master of Science
in
Civil Engineering

Udaya B. Halabe, Ph.D., P.E., Chair

Hota V. S. GangaRao, Ph.D., P.E.

Hema J. Siriwardane, Ph.D., P.E.

Department of Civil and Environmental Engineering

\author{
Morgantown, West Virginia \\ 2006
}

Keywords: Ground Penetrating Radar, Infrared Thermography, CFRP, GFRP, Debonds, Concrete Cylinder 


\section{ABSTRACT \\ Nondestructive Evaluation of FRP Wrapped Concrete Cylinders Using Infrared Thermography and Ground Penetrating Radar}

\section{Shasanka Shekhar Dutta}

The objectives of this research are: (a) to investigate the feasibility of using Infrared Thermography (IRT) and Ground Penetrating Radar (GPR) for detecting debonds in Fiber Reinforced Polymer (FRP) wrapped columns, and (b) to study the effect of the debonds on reduction in compressive strength of FRP wrapped columns.

All laboratory tests were conducted on concrete cylinders of size 6" x 12' (152.4 $\mathrm{mm} \times 304.8 \mathrm{~mm}$ ) in which air-filled and water-filled debonds of various sizes were inserted. Air-filled debonds were made by cutting plastic sheets into the desired sizes whereas water-filled debonds were made by injecting water in custom made polyethylene pouches. Infrared Thermography and Ground Penetrating Radar techniques were used to locate these simulated discontinuities, and the effectiveness of each technique in identifying these debonds was carefully assessed. Infrared tests were conducted with the help of ThermaCAM ${ }^{\mathrm{TM}} \mathrm{S} 60$ infrared camera manufactured by FLIR Systems, and Ground Penetrating Radar tests were accomplished with a $1.5 \mathrm{GHz}$ ground coupled antenna from Geophysical Survey Systems, Inc (GSSI). As a part of this research, the effect of area of debonds on the axial compressive strength of concrete columns was also studied. Two field trips were made to Moorefield, West Virginia. During these two field trips, debonds in FRP wrapped timber piles of a railroad bridge were located and evaluated through extensive inspection.

The results reveal that a combination of Infrared Thermography and Ground Penetrating Radar can be used as an effective nondestructive evaluating tool in detection of subsurface debonds in concrete columns wrapped with Fiber Reinforced Polymer (FRP) wraps. Also, a significant decrease in axial compressive strength with an increase in area of debonds was observed. 


\section{ACKNOWLEDGEMENTS}

At the outset, I would like to express my sincere gratitude to my academic and research advisor, Dr. Udaya B. Halabe for his valuable guidance and encouragement during my Master of Science in Civil Engineering (M.S.C.E) degree program. I am thankful to Dr. Hota. V. S. GangaRao and Dr. Hema J. Siriwardane, members of the Advisory and Examining Committee, for their help during my research and studies.

I would like to convey thanks to Srinivas Aluri, Reza Sadat Abhari and Ayman Bataineh for helping me in successfully conducting my field trips. I am thankful to Aneesh Bethi, Manjunath Pawar and Sandeep Pyakurel for their help during my research work. The help provided by laboratory technicians, Jerry Nester, David Turner and Douglas F. Cutlip during some of my laboratory work is gratefully acknowledged.

I thank my family who stood beside me and provided the impetus to do my best. Lastly, I thank all of my friends for their help directly or indirectly in my research. 


\section{TABLE OF CONTENTS}

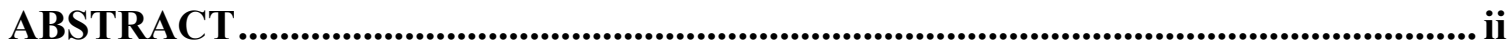

ACKNOWLEDGEMENTS ............................................................................................ii

TABLE OF CONTENTS ..................................................................................... iv

LIST OF FIGURES ................................................................................................................. vii

LIST OF TABLES

Chapter 1 INTRODUCTION ................................................................................................... 1

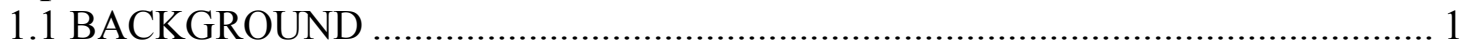

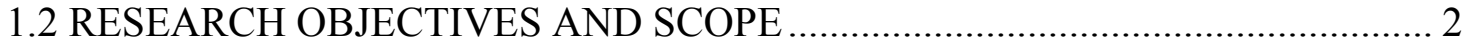

1.3 Failure Modes in Unwrapped and Wrapped Concrete Cylinders .............................. 3

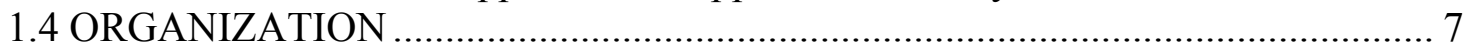

\section{Chapter 2 BASICS OF GROUND PENETRATING RADAR AND INFRARED}

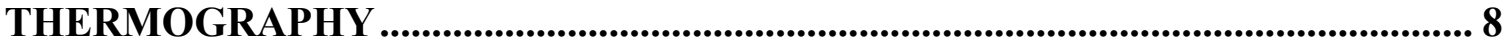

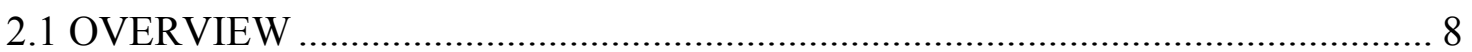

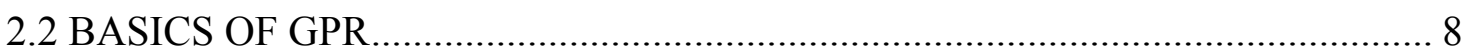

2.2.1 Attenuation of Electromagnetic Waves .................................................. 12

2.2.2 Reflection and Transmission of Radar Waves......................................... 13

2.2.3 Resolution and Polarization ................................................................ 15

2.3 BASICS OF INFRARED THERMOGRAPHY ……........................................ 15

2.3.1 Active and Passive Thermography …………………………………..... 19

2.4 ADVANTAGES AND DISADVANTAGES OF GPR AND IRT ........................ 19

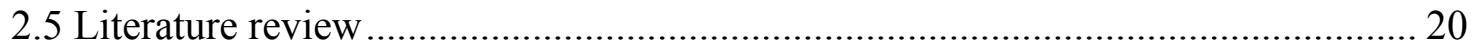

Chapter 3 EQUIPMENT AND EXPERIMENTAL SETUP ...................................... 21

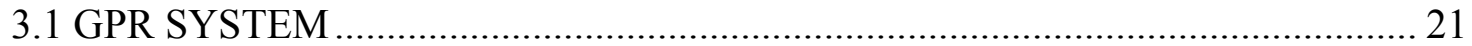

3.1.1 Data Acquisition System................................................................ 22

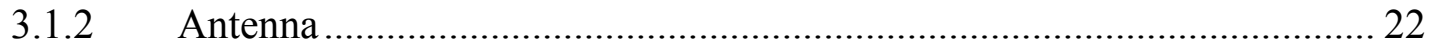

3.1.3 Antenna Deployment Frame and Rotating Table .................................... 25

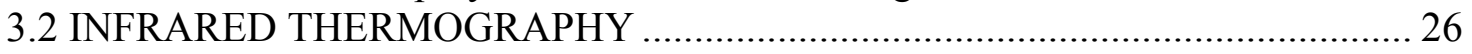

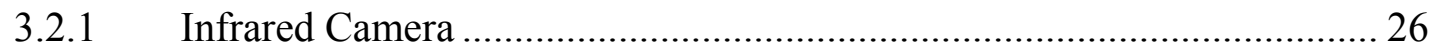

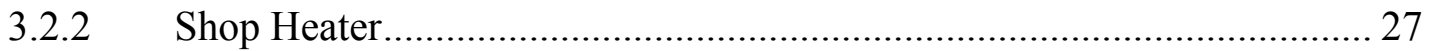

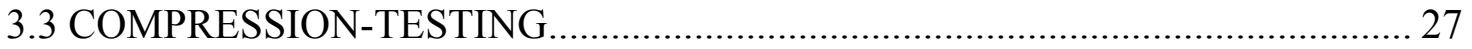

3.3.1 Universal Compression-Testing Machine................................................ 27

Chapter 4 LABORATORY EXPERIMENTS, ANALYSIS AND RESULTS .......... 29

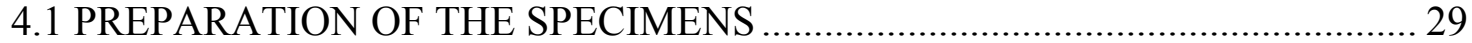

4.1.1 Casting of Concrete Cylinders ............................................................... 29

4.1.2 Making of Debonds............................................................................. 30

4.1.3 Wrapping of Cylinders............................................................................. 31 


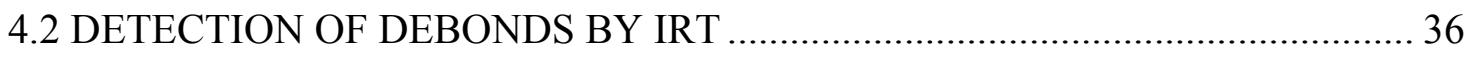

4.2.1 Detection of Debonds in Cylinders Wrapped with GFRP ……………..... 37

4.2.1.1 Detection of 1.4" x 1.4" Air-Filled Debond....................................... 37

4.2.1.2 Detection of 2" ' 2 2" Air-Filled Debond.............................................. 38

4.2.1.3 Detection of 3" x 3"' Air-Filled Debond............................................... 39

4.2.1.4 Detection of Water-Filled Debonds .................................................... 40

4.2.2 Detection of Debonds in Cylinders Wrapped with CFRP ........................ 43

4.2.2.1 Detection of 1.4" x 1.4" Air-Filled Debond........................................ 43

4.2.2.2 Detection of 2" $x$ 2" Air-Filled Debond........................................... 43

4.2.2.3 Detection of 3" x 3" Air-Filled Debond............................................ 44

4.2.2.4 Detection of Water-Filled Debonds ..................................................... 44

4.2.3 Effect of Input of Lower Heat Energy …………................................... 45

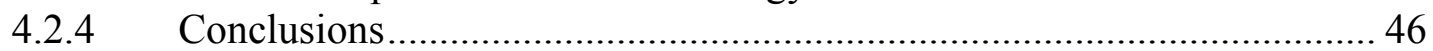

4.3 DETECTION OF DEBONDS BY GPR ……............................................. 46

4.3.1 Detection of Debonds in Cylinders Wrapped with GFRP ........................ 48

4.3.1.1 Detection of Air-Filled Debonds .......................................................... 48

4.3.1.2 Detection of 1.4" x 1.4" Water-Filled Debond .................................... 53

4.3.1.3 Detection of 2" $\times 2$ " Water-Filled Debond ......................................... 55

4.3.1.4 Detection of 3" x 3"' Water-Filled Debond ............................................ 56

4.3.2 Detection of Debonds in Cylinders Wrapped with CFRP ......................... 57

4.3.2.1 Detection of Air-Filled Debonds ........................................................ 57

4.3.2.2 Detection of 1.4" x 1.4" Water-Filled Debond ...................................... 61

4.3.2.3 Detection of 2" ' 2 2" Water-Filled Debond ........................................... 62

4.3.2.4 Detection of 3" " x 3" Water-Filled Debond ............................................ 63

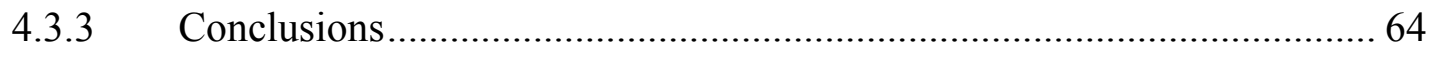

4.4 SURFACE TEMPERATURE CURVES AND THEIR ANALYSIS .................... 64

4.4.1 Surface Temperature versus Time Curves for GFRP Wrapped Cylinders65

4.4.2 Surface Temperature versus Time Curves for CFRP Wrapped Cylinders 72

4.4.3 Thermal Difference versus Time Curves for GFRP Wrapped Cylinders 79

4.4.4 Thermal Difference versus Time Curves for CFRP Wrapped Cylinders. 82

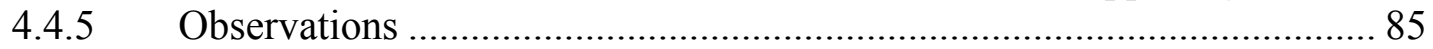

4.5 EFFECT OF DISCONTINUITY ON AXIAL COMPRESSIVE STRENGTH ..... 87

4.5.1 Axial Compressive Strength of Unwrapped Specimens ........................... 87

4.5.2 Axial Compressive Strength of Wrapped Specimens ............................... 88

4.5.3 Axial Compressive Strength of Wrapped Specimens with Simulated

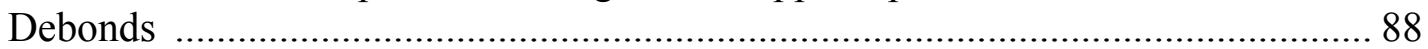

4.5.3.1 Compressive Strength of GFRP Wrapped Cylinders with Air-filled

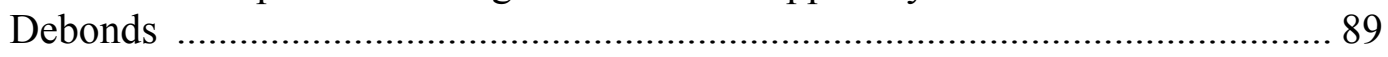

4.5.3.2 Compressive Strength of GFRP Wrapped Cylinders with Water-filled

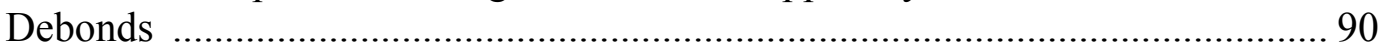

4.5.3.3 Compressive Strength of CFRP Wrapped Cylinders with Air-filled

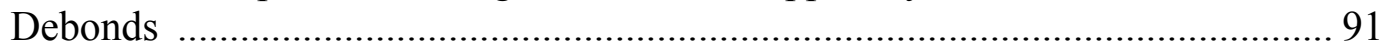

4.5.3.4 Compressive Strength of CFRP Wrapped Cylinders with Water-filled

Debonds .................................................................................................... 91

4.5.3.5 Graphs of Percent Area of Debonds versus Percent Decrease in Compressive Strength 
4.5.3.6 Graphs of Percent Area of Debonds versus Percent Compressive

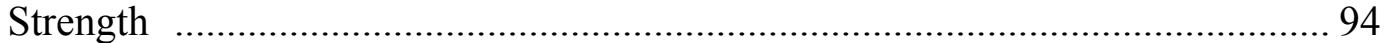

4.5.3.7 Theory of Confinement and Comparison between Analytical and

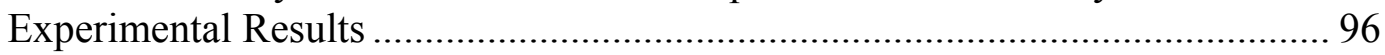

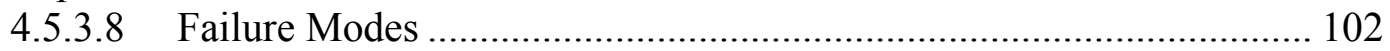

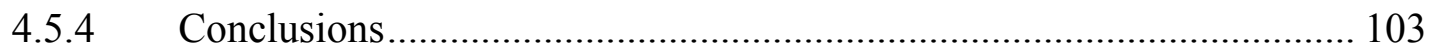

\section{Chapter 5 FIELD TESTING RESULTS USING INFRARED THERMOGRAPHY}

5.1 FIELD TRIP DURING JUNE 7-9, 2005

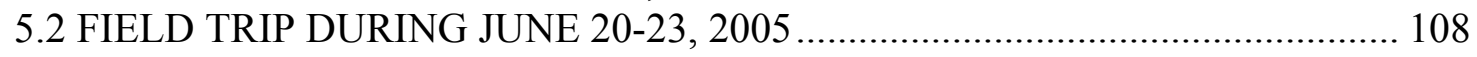

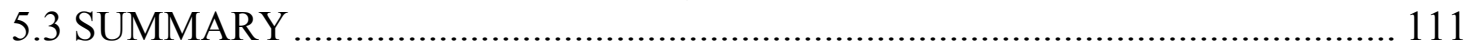

Chapter 6 CONCLUSIONS AND RECOMMENDATIONS ...................................... 112

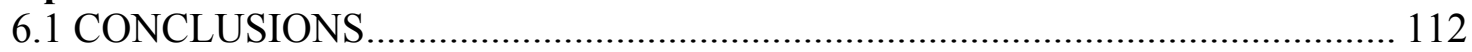

6.2 RECOMMENDATIONS FOR FUTURE RESEARCH.................................... 114

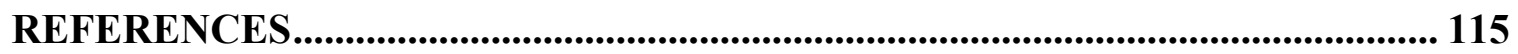




\section{LIST OF FIGURES}

Figure 1-1 Failure of plain (unwrapped) concrete cylinder under compression (Mehta

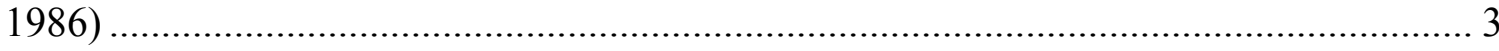

Figure 1-2 Brittle failure of cylinders wrapped with one layer of unidirectional fabric (Buyukozturk et al. 2005) ........................................................................................... 4

Figure 1-3 Brittle failure of cylinders wrapped with one inner layer of unidirectional fabric and one outer layer of angular $\left( \pm 45^{\circ}\right)$ fabric (Buyukozturk et al. 2005) ................. 5 Figure 1-4 Brittle failure of cylinders wrapped with one layer of bidirectional $\left(0^{\circ} / 90^{\circ}\right)$ fabric (Buyukozturk et al. 2005) ................................................................................. 5

Figure 1-5 Ductile failure of cylinders wrapped with one layer of angular $\left( \pm 45^{\circ}\right)$ fabric (Buyukozturk et al. 2005) ........................................................................................... 6

Figure 1-6 Fiber reorientation in angular $\left( \pm 45^{\circ}\right)$ fabrics (Buyukozturk et al. 2005) ......... 6 Figure 1-7 Ductile failure of cylinders wrapped with one inner layer of bidirectional $\left(0^{\circ} / 90^{\circ}\right)$ fabric and one outer layer of angular $\left( \pm 45^{\circ}\right)$ fabric (Buyukozturk et al. 2005) ..... 6 Figure 2-1 Single scan (extracted from sample of scans) with vertical axis showing the strength of the received signal in millivolts $(\mathrm{mV})$ and horizontal axis indicating the two way travel time within the material in nanoseconds (ns) ............................................. 10

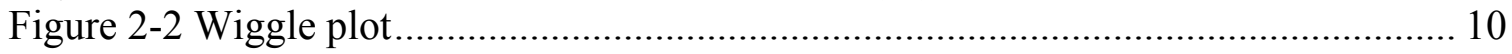

Figure 2-3 Grey scale scan................................................................................. 11

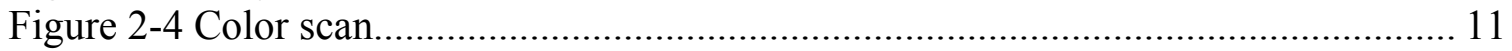

Figure 2-5 Infrared region in electromagnetic spectrum (Kaplan 1999) .......................... 16

Figure 2-6 Blackbody curves at various temperatures (Kreith and Bohn 1993................ 19

Figure 3-1 GPR scanning setup for laboratory testing of FRP wrapped cylinders........... 21

Figure 3-2 Data acquisition system (laptop computer and main frame)........................... 22

Figure 3-3 Ground coupled $1500 \mathrm{MHz}$ antenna ………............................................. 24

Figure 3-4 Antenna deployment frame and rotating table ............................................ 25

Figure 3-5 ThermaCAM ${ }^{\mathrm{TM}} \mathrm{S} 60$ digital infrared camera................................................ 26

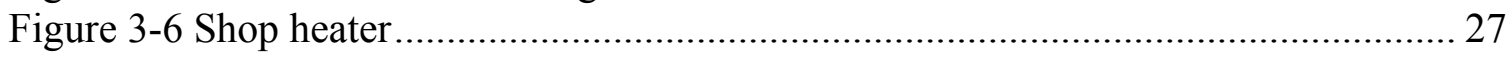

Figure 3-7 Laboratory setup for infrared testing of wrapped cylinders............................ 28

Figure 3-8 Universal compression testing machine..................................................... 28

Figure 4-1 Air-filled debonds ................................................................................ 31

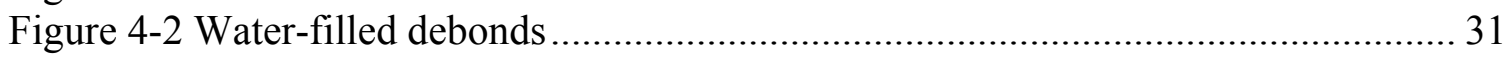

Figure 4-3 Carbon fiber tow sheet ……………………......................................... 32

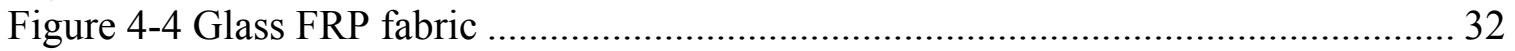

Figure 4-5 Tyfo S Saturant Epoxy (Type A and Type B)............................................. 33

Figure 4-6 Mixing the two parts of the resin with a low speed mixer............................... 34

Figure 4-7 Applying the mixed resin on FRP sheets ....................................................... 34

Figure 4-8 Wrapping the cylinders with FRP sheets .................................................... 34

Figure 4-9 Removing air bubbles ……………………………………………. 35

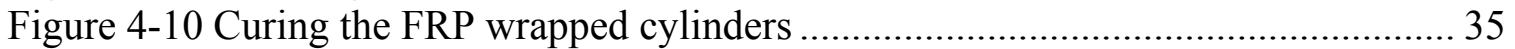

Figure 4-11 Cylinder no 1 with 1.4" x 1.4" air-filled debond at the center .................... 37

Figure 4-12 Infrared image of cylinder no 1 showing the air-filled debond .................... 38

Figure 4-13 Cylinder no 2 with 2" $x$ 2" air-filled debond at the center .......................... 38

Figure 4-14 Infrared image of cylinder no 2............................................................. 39

Figure 4-15 Cylinder no 3 with 3" x 3" air-filled debond at the center .......................... 39 
Figure 4-16 Infrared image of cylinder no 3

Figure 4-17 Cylinder no 8 with 1.4" x 1.4"' water-filled debond at the center ............... 40

Figure 4-18 Cylinder no 9 with 2" $\mathrm{x} 2$ " water-filled debond at the center ..................... 41

Figure 4-19 Cylinder no 10 with 3" $\mathrm{x} 3$ " water-filled debond at the center .................. 41

Figure 4-20 Infrared image of water-filled debonds in (a) cylinder no 8 (1.4" x 1.4"

debond), (b) cylinder no 9 (2" x 2" debond), and (c) cylinder no 10 (3" x 3" debond) ... 42

Figure 4-21 Infrared image of cylinder no 15.............................................................. 43

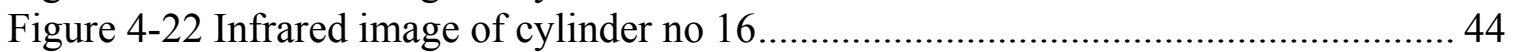

Figure 4-23 Infrared image of cylinder no 17............................................................ 44

Figure 4-24 Infrared image of water-filled debonds in (a) cylinder no 22 (1.4" x 1.4"

debond), (b) cylinder no 23 (2" x 2" debond), and (c) cylinder no 24 (3" x 3" debond) . 45

Figure 4-25 Infrared image of cylinder no 26 (3" x 3" water-filled debond on the top and

1.4 " x 1.4" water-filled debond on the bottom) ................................................................ 46

Figure 4-26 Raw GPR data of a defect-free cylinder wrapped with CFRP..................... 48

Figure 4-27 Raw GPR data of a defect-free cylinder wrapped with GFRP...................... 49

Figure 4-28 GPR data of a defect-free cylinder wrapped with CFRP after applying linear

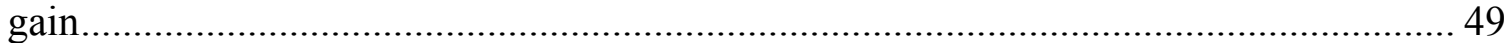

Figure 4-29 GPR data of a defect-free cylinder wrapped with GFRP after applying linear

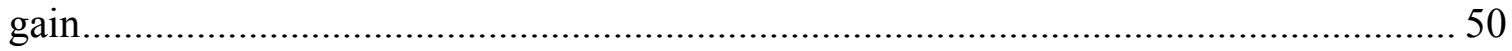

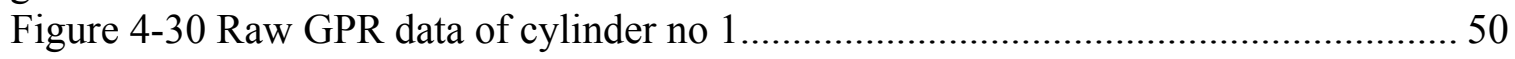

Figure 4-31 Raw GPR data of cylinder no 2...……………..................................... 51

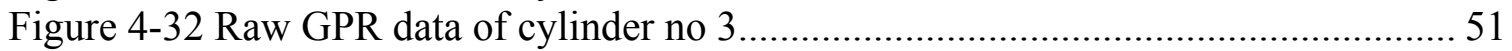

Figure 4-33 Processed GPR data of cylinder no 1 ....................................................... 52

Figure 4-34 Processed GPR data of cylinder no 2 ………......................................... 52

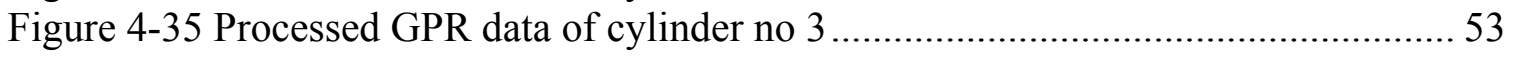

Figure 4-36 Raw GPR data of cylinder no 8............................................................ 54

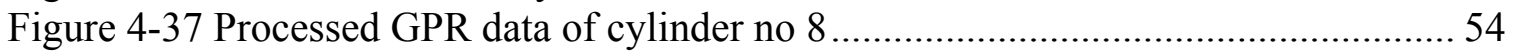

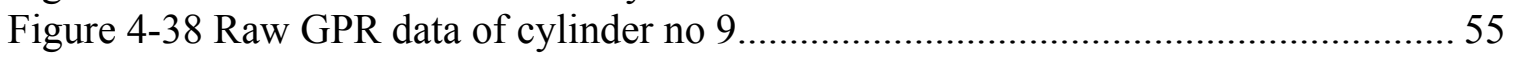

Figure 4-39 Processed GPR data of cylinder no 9...................................................... 55

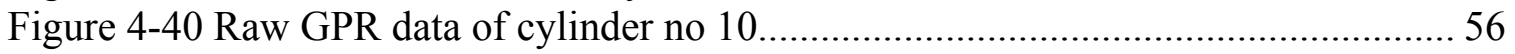

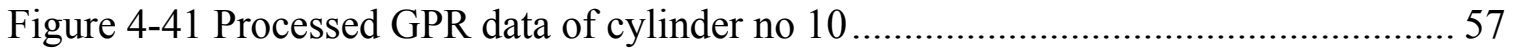

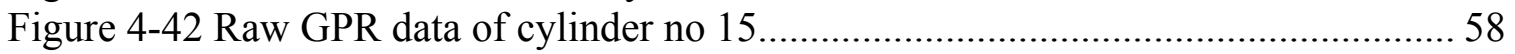

Figure 4-43 Raw GPR data of cylinder no 16.......................................................... 58

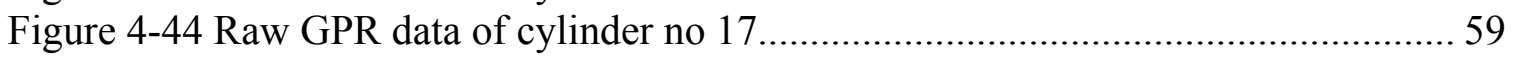

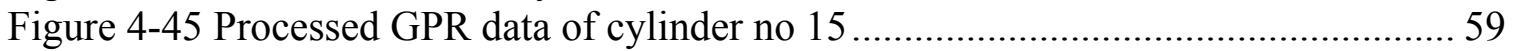

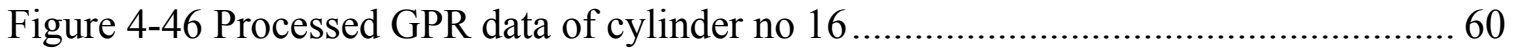

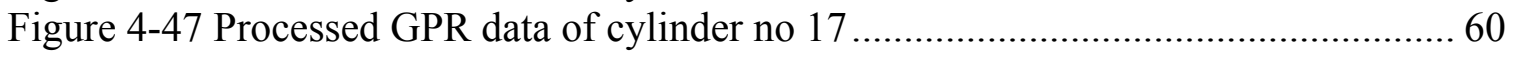

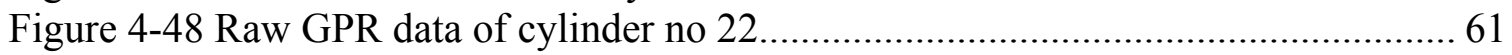

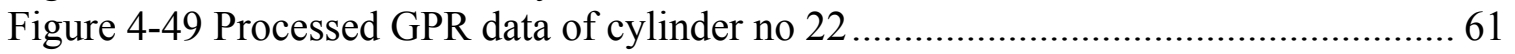

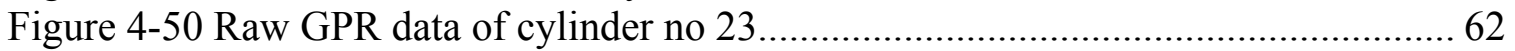

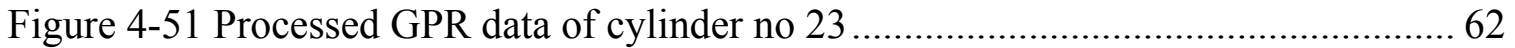

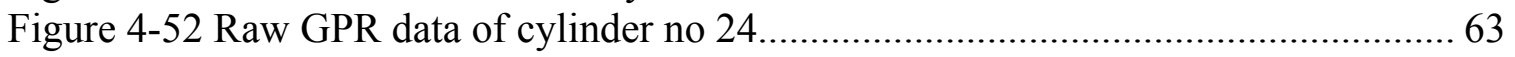

Figure 4-53 Processed GPR data of cylinder no 24 ..................................................... 63

Figure 4-54 Cylinder no 1 (3 minutes heating with $1500 \mathrm{~W}$ setting of the heater) ........... 65

Figure 4-55 Cylinder no 2 (3 minutes heating with $1500 \mathrm{~W}$ setting of the heater) ........... 65

Figure 4-56 Cylinder no 3 (5 minutes heating with $1500 \mathrm{~W}$ setting of the heater) ........... 66 
Figure 4-57 Cylinder no 4 (5 minutes heating with 750W setting of the heater) ............ 66

Figure 4-58 Cylinder no 5 (5 minutes heating with 750W setting of the heater) ............ 67

Figure 4-59 Cylinder no 6 (5 minutes heating with 750W setting of the heater) ............. 67

Figure 4-60 Cylinder no 7 (5 minutes heating with $750 \mathrm{~W}$ setting of the heater) ............. 68

Figure 4-61 Cylinder no 8 ( 5 minutes heating with $1500 \mathrm{~W}$ setting of the heater) ...........68

Figure 4-62 Cylinder no 9 (5 minutes heating with 1500W setting of the heater)...........69

Figure 4-63 Cylinder no 10 (5 minutes heating with $1500 \mathrm{~W}$ setting of the heater) ........ 69

Figure 4-64 Cylinder no 11 (5 minutes heating with $1500 \mathrm{~W}$ setting of the heater) ......... 70

Figure 4-65 Cylinder no 12 (5 minutes heating with $1500 \mathrm{~W}$ setting of the heater) ......... 70

Figure 4-66 Cylinder no 13 (5 minutes heating with $1500 \mathrm{~W}$ setting of the heater) ........ 71

Figure 4-67 Cylinder no 14 (3.5 minutes heating with 750W setting of the heater) ........ 71

Figure 4-68 Cylinder no 15 (3 minutes heating with $1500 \mathrm{~W}$ setting of the heater) ........ 72

Figure 4-69 Cylinder no 16 (3 minutes heating with $1500 \mathrm{~W}$ setting of the heater) ........ 72

Figure 4-70 Cylinder no 17 (5 minutes heating with $750 \mathrm{~W}$ setting of the heater) .......... 73

Figure 4-71 Cylinder no 18 (5 minutes heating with $750 \mathrm{~W}$ setting of the heater) .......... 73

Figure 4-72 Cylinder no 19 (5 minutes heating with $750 \mathrm{~W}$ setting of the heater) .......... 74

Figure 4-73 Cylinder no 20 (5 minutes heating with $750 \mathrm{~W}$ setting of the heater) ........... 74

Figure 4-74 Cylinder no 21 (5 minutes heating with $750 \mathrm{~W}$ setting of the heater) .......... 75

Figure 4-75 Cylinder no 22 (5 minutes heating with $1500 \mathrm{~W}$ setting of the heater) ........ 75

Figure 4-76 Cylinder no 23 (5 minutes heating with $1500 \mathrm{~W}$ setting of the heater) ........ 76

Figure 4-77 Cylinder no 24 (5 minutes heating with $1500 \mathrm{~W}$ setting of the heater) ........ 76

Figure 4-78 Cylinder no 25 (5 minutes heating with $1500 \mathrm{~W}$ setting of the heater) ......... 77

Figure 4-79 Cylinder no 26 (3.5 minutes heating with $750 \mathrm{~W}$ setting of the heater) ....... 77

Figure 4-80 Cylinder no 27 (3.5 minutes heating with $750 \mathrm{~W}$ setting of the heater) ....... 78

Figure 4-81Cylinder no 28 (3.5 minutes heating with $750 \mathrm{~W}$ setting of the heater) ........ 78

Figure 4-82 Cylinder no 1 ( 3 minutes heating with $1500 \mathrm{~W}$ setting of the heater) ........... 79

Figure 4-83 Cylinder no 2 (3 minutes heating with $1500 \mathrm{~W}$ setting of the heater) ........... 79

Figure 4-84 Cylinder no 3 (5 minutes heating with $1500 \mathrm{~W}$ setting of the heater) ...........8 80

Figure 4-85 Cylinder no 12 (5 minutes heating with $750 \mathrm{~W}$ setting of the heater) .......... 80

Figure 4-86 Cylinder no 8 (5 minutes heating with $1500 \mathrm{~W}$ setting of the heater) .......... 81

Figure 4-87 Cylinder no 9 (5 minutes heating with 1500W setting of the heater).......... 81

Figure 4-88 Cylinder no 10 (5 minutes heating with $1500 \mathrm{~W}$ setting of the heater) ........ 82

Figure 4-89 Cylinder no 15 (3 minutes heating with $1500 \mathrm{~W}$ setting of the heater) ........ 82

Figure 4-90 Cylinder no 16 (3 minutes heating with $1500 \mathrm{~W}$ setting of the heater) ........ 83

Figure 4-91 Cylinder no 17 (5 minutes heating with $750 \mathrm{~W}$ setting of the heater) ...........83

Figure 4-92 Cylinder no 22 (5 minutes heating with $1500 \mathrm{~W}$ setting of the heater) ........ 84

Figure 4-93 Cylinder no 23 (5 minutes heating with $1500 \mathrm{~W}$ setting of the heater) ........ 84

Figure 4-94 Cylinder no 24 (5 minutes heating with $1500 \mathrm{~W}$ setting of the heater) ........ 85

Figure 4-95 GFRP wrapped cylinders with air-filled debonds ................................... 92

Figure 4-96 GFRP wrapped cylinders with water-filled debonds ............................... 92

Figure 4-97 CFRP wrapped cylinders with air-filled debonds ................................... 93

Figure 4-98 CFRP wrapped cylinders with water-filled debonds ............................... 93

Figure 4-99 GFRP wrapped cylinders with air-filled debonds ................................... 94

Figure 4-100 GFRP wrapped cylinders with water-filled debonds .............................. 95

Figure 4-101 CFRP wrapped cylinders with air-filled debonds .................................. 95

Figure 4-102 CFRP wrapped cylinders with water-filled debonds ................................ 96 
Figure 4-103 Stress strain curves for concrete in triaxial compression (Mindness et al. 2003)

Figure 4-104 Confinement action (De Lorenzis et al. 2003) .......................................... 97

Figure 4-105 Failure mode of unwrapped concrete cylinder....................................... 102

Figure 4-106 Failure mode of concrete cylinders wrapped with CFRP Fabric .............. 103

Figure 4-107 Failure mode of concrete cylinders wrapped with GFRP Fabric .............. 103

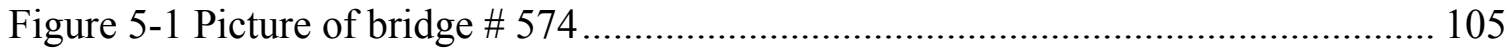

Figure 5-2 (a) Water underneath the bridge before pumping, and (b) picture after

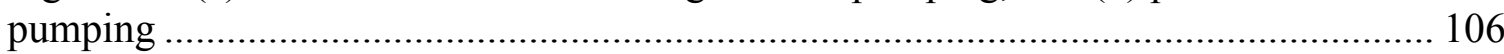

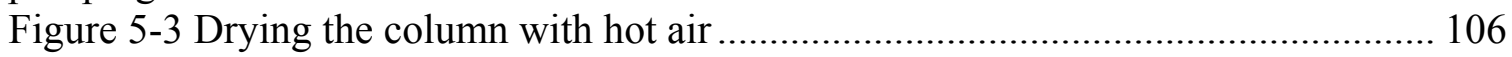

Figure 5-4 (a) Digital picture of first pile, and (b) infrared image .............................. 107

Figure 5-5 (a) Digital picture of second and third piles, and (b) infrared image........... 107

Figure 5-6 (a) Digital picture of fourth pile, and (b) infrared image ............................ 108

Figure 5-7 Infrared test setup in the field.............................................................. 109

Figure 5-8 (a) Digital picture of first pile, and (b) infrared image ............................. 110

Figure 5-9 (a) Digital picture of third pile, and (b) infrared image ............................. 110

Figure 5-10 (a) Digital picture of fourth pile, and (b) infrared image .......................... 111 


\section{LIST OF TABLES}

Table 2-1 Dielectric constants of common materials at $100 \mathrm{MHz}$ (GSSI 2003) ............. 15

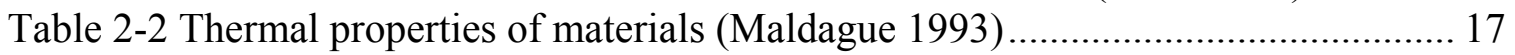

Table 3-1 Details of antennas manufactured by GSSI (GSSI 2004) .............................. 24

Table 4-1 Properties of carbon fiber tow sheet (Tonen Co., Japan, Manufacturer) ......... 32

Table 4-2 Properties of TYFO S Saturant Epoxy (Fyfe Co. LLC 2000).......................... 33

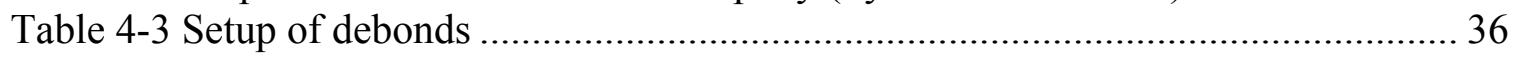

Table 4-4 Ultimate compressive strength of unwrapped cylinders ............................... 88

Table 4-5 Ultimate compressive strength of wrapped cylinders ................................ 88

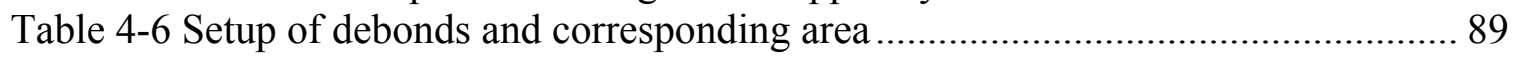

Table 4-7 Ultimate compressive strength of GFRP wrapped cylinders with air-filled debonds

Table 4-8 Ultimate compressive strength of GFRP wrapped cylinders with water-filled debonds

Table 4-9 Ultimate compressive strength of CFRP wrapped cylinders with air-filled debonds

Table 4-10 Ultimate compressive strength of CFRP wrapped cylinders with water-filled

debonds

Table 4-11 Regression relationships for various wrapped cylinders

Table 4-12 Comparison between experimental and analytical compressive strength of concrete cylinders wrapped with CFRP fabric 


\section{CHAPTER 1 \\ INTRODUCTION}

\subsection{BACKGROUND}

Although the history of composite materials application to civil infrastructure is only three decades old, they are now being widely used in myriad of applications in all types of engineering structures. As far as construction industry is concerned, composite materials have heralded a new trend of cost effective applications in the area of repair, rehabilitation, replacement and new construction of infrastructure. The use of composite materials in civil engineering infrastructure can be attributed to many advantages it enjoys over other conventional structural materials. The spectrum of key properties includes lightweight, excellent corrosion and fatigue resistance, high strength, and impact resistance, just to name a few.

A major application of composite materials in the reinforced concrete industry is for repairing and strengthening existing reinforced concrete beams and columns. This can be achieved by wrapping the beam or column with Fiber Reinforced Polymer (FRP) composite wraps. In addition to increasing the load carrying capacity, wrapping the structural component with FRP fabrics enhances its ductility which is very important, especially in seismic regions.

A proper bond between the FRP wrap and the underlying concrete surface is of primary importance for appropriate functioning of the FRP wrap, i.e., for effective transfer of load from concrete to the wrap through confining action. Discontinuity between the wrap and the concrete surface could be developed during wrapping of the FRP sheets and during the service life of the column due to various reasons, such as presence of moisture, vehicular loads etc. Such a discontinuity is commonly referred to as a debond. Hence, periodic field monitoring through nondestructive testing methods becomes imperative in order to inspect and assess the condition of the debonds and the FRP wrapped component as a whole. Early detection of deterioration makes the repair work less expensive and ensures continued structural integrity. 
This study focuses on the applicability of Infrared Thermography (IRT) and Ground Penetrating Radar (GPR) in detecting air-filled and water-filled debonds in concrete columns wrapped with Fiber Reinforced Polymer (FRP) fabrics. The usefulness as well as the limitations of IRT in detecting subsurface debonds in FRP composite bridge decks has been established in research previously conducted at the Constructed Facilities Center of West Virginia University (Vasudevan 2004). Although Infrared Thermography gave satisfactory results in locating air-filled discontinuities, water-filled debonds were hard to detect using this technique. Also, the infrared images did not show a prominent boundary of the debonds when wearing surface was laid over the top flange of the FRP bridge deck. In other words, the capability of IRT decreases as depth of location of the debond increases. On the other hand, GPR is more sensitive in detecting water-filled debonds than air-filled debonds. It has been shown that with certain limitations, GPR and IRT can complement each other to constitute a robust nondestructive evaluation system for assessment of FRP bridge decks (Hing 2006). Field testing results by Jackson et al. (2000) prove that integration of GPR with IRT can be an effective tool for tracking deterioration in FRP wrapped members.

\subsection{RESEARCH OBJECTIVES AND SCOPE}

The primary objectives of this research are: (a) to investigate the effectiveness of IRT and GPR for detecting subsurface debonds in FRP wrapped concrete columns, and (b) to study the effect of debonds on reduction in axial compressive strength of concrete columns. The specific sub-objectives are furnished below:

- To create air-filled and water-filled debonds of various lateral dimensions and investigate the use of IRT and GPR in locating these debonds in concrete columns (cylinders) wrapped with carbon fiber reinforced polymer fabric as well as Eglass fiber reinforced polymer fabric.

- To establish surface temperature versus time (after removal of heat source) curves and thermal difference versus time curves for different size debonds.

- To compare the advantages and disadvantages of IRT with GPR with respect to their ability to locate debonds in FRP wrapped concrete columns. 
- To establish a relationship between the decrease in axial compressive strength of concrete cylinders and the percentage area of debonds.

- To conduct field studies in order to assess the use of IRT for evaluating the performance of FRP wrapped columns in rehabilitated railroad bridges.

\subsection{FAILURE MODES IN UNWRAPPED AND WRAPPED CONCRETE CYLINDERS}

In case of uniaxial compression of plain (unwrapped) concrete cylinders, no cracks are developed until about 50 percent of failure stress. Cracks called shear bond cracks that already exist between the coarse aggregates and cement matrix are present at this stage. At higher stress levels, cracks are initiated within the matrix. The number and also the size of the cracks increases with increasing stress levels. These cracks and shear bond cracks eventually join up and develop a failure surface that is about $20^{\circ}$ to $30^{\circ}$ from the load direction (Figure 1-1).

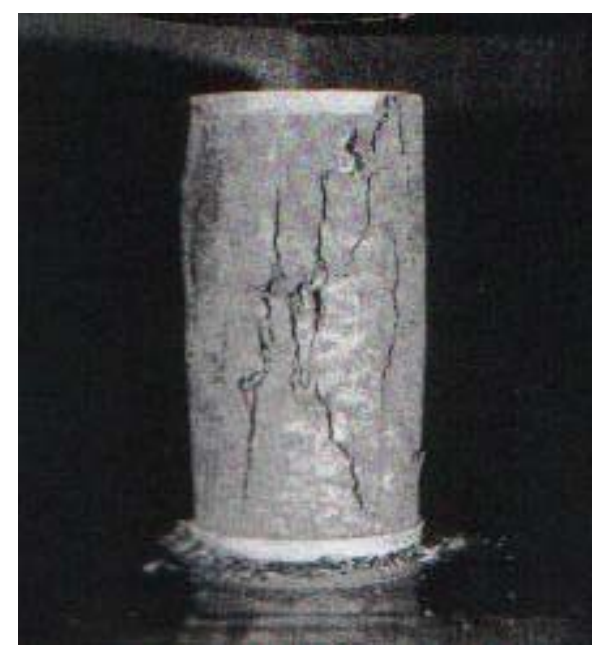

Figure 1-1 Failure of plain (unwrapped) concrete cylinder under compression (Mehta 1986)

In case of cylinders wrapped with fiber reinforced polymer wrap, failure modes depend on the type of wrap in use. According to a study by Buyukozturk et al. (2005), failure mode was brittle in case of cylinders wrapped with unidirectional E-glass fibers, as well as in case of unidirectional and angular $\left( \pm 45^{\circ}\right)$ fabric combination. Failure of the specimens was due to fiber fracture accompanied by crushing of the concrete core. In this case, the load deformation curves showed strain hardening after the axial stress reached a 
stress higher than the unconfined compressive strength. Cylinders with only bidirectional $\left(0^{\circ} / 90^{\circ}\right)$ fabric also gave rise to brittle failure probably due to low fiber strength. Figure 1-2Figure 1-2 to Figure 1-4Figure 1-4 show the brittle failure mode of cylinders.

Angular fabrics $\left( \pm 45^{\circ}\right)$ gave rise to a ductile failure state (Buyukozturk et al. 2005). This is also true for bidirectional and angular fabric combination. Fiber reorientation took place instead of fiber fracture that in turn facilitated the slippage of cracked concrete inside the jacket. Figure 1-5 to Figure 1-7 show ductile failure mode of cylinders.

The failure behavior of wrapped cylinders with embedded debonds has not been studied. The debonds can affect the load carrying capacity and possibly the failure modes. This study focuses on concrete cylinders with debonds and incorporates nondestructive tests for debond detection as well as destructive tests to assess compressive strength and failure modes.

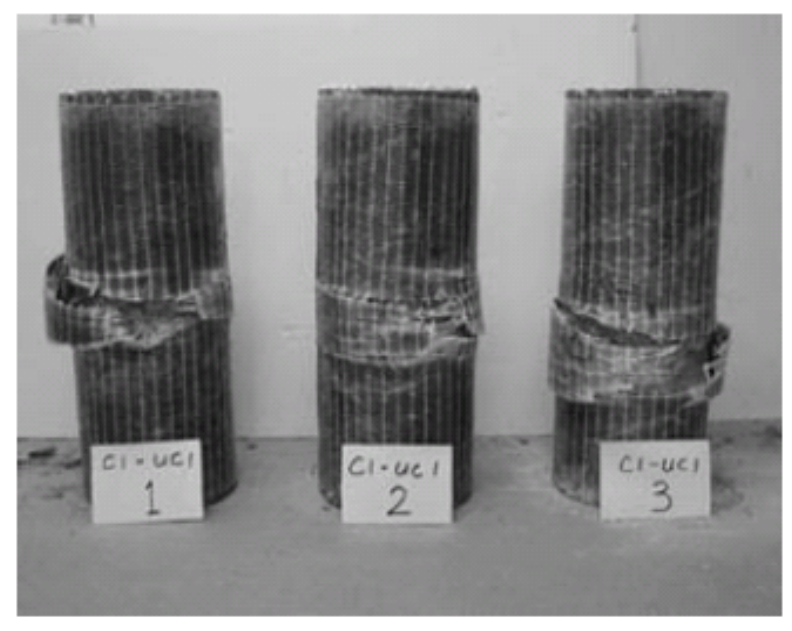

Figure 1-2 Brittle failure of cylinders wrapped with one layer of unidirectional fabric (Buyukozturk et al. 2005) 


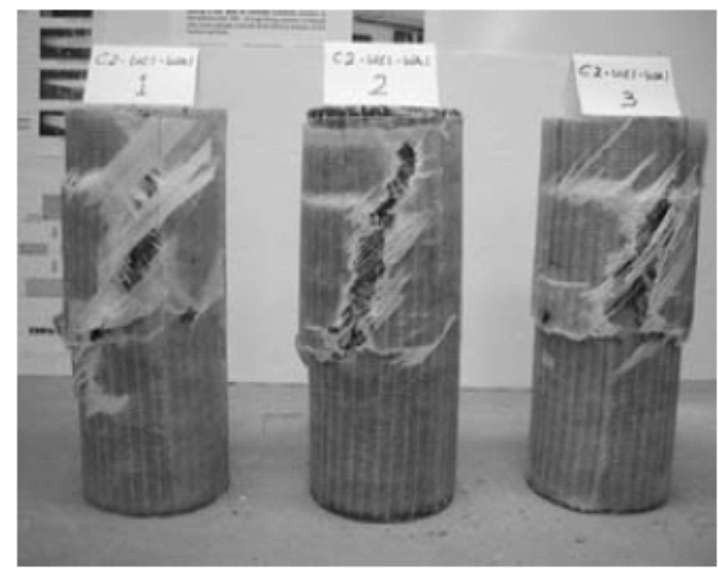

Figure 1-3 Brittle failure of cylinders wrapped with one inner layer of unidirectional fabric and one outer layer of angular $\left( \pm 45^{\circ}\right)$ fabric (Buyukozturk et al. 2005)

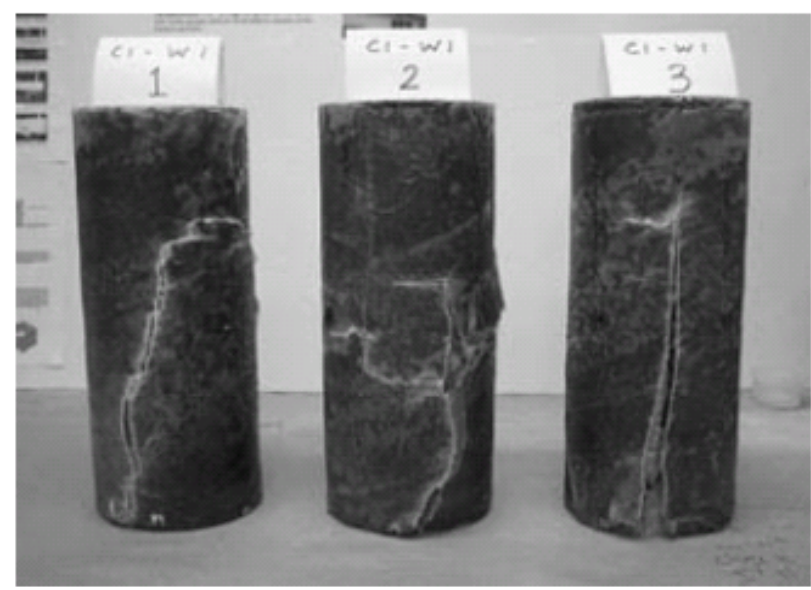

Figure 1-4 Brittle failure of cylinders wrapped with one layer of bidirectional $\left(0^{\circ} / 90^{\circ}\right)$ fabric (Buyukozturk et al. 2005) 


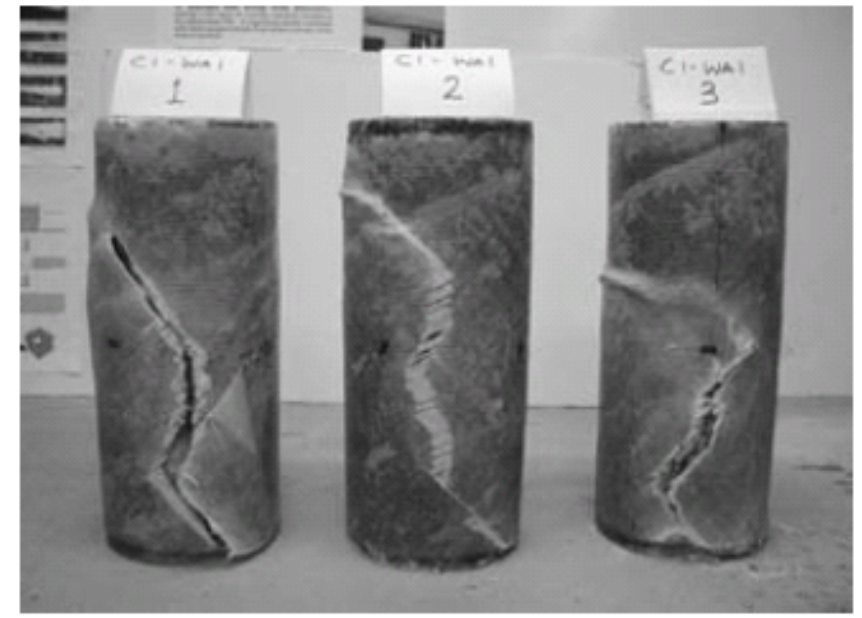

Figure 1-5 Ductile failure of cylinders wrapped with one layer of angular $\left( \pm 45^{\circ}\right)$ fabric (Buyukozturk et al. 2005)

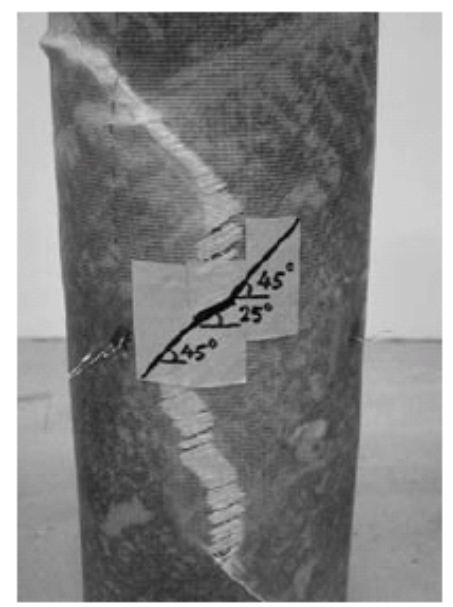

Figure 1-6 Fiber reorientation in angular $\left( \pm 45^{\circ}\right)$ fabrics (Buyukozturk et al. 2005)

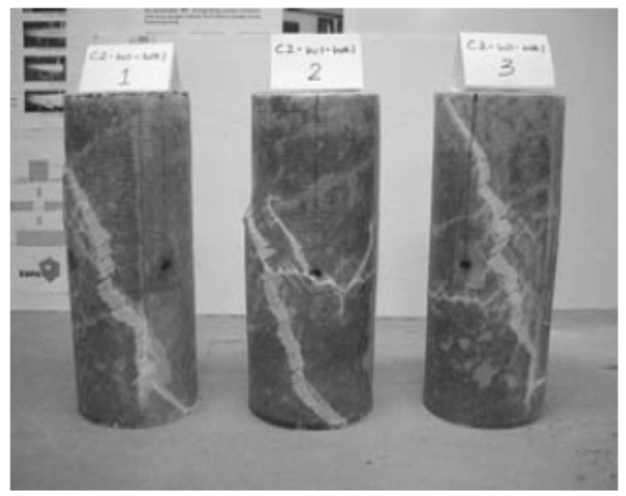

Figure 1-7 Ductile failure of cylinders wrapped with one inner layer of bidirectional $\left(0^{\circ} / 90^{\circ}\right)$ fabric and one outer layer of angular $\left( \pm 45^{\circ}\right)$ fabric (Buyukozturk et al. 2005) 


\subsection{ORGANIZATION}

This thesis is organized into six chapters. Chapter 1 is devoted to background as well as objectives and scope of the study. Chapter 2 presents the basics of Ground Penetrating Radar and Infrared Thermography, and advantages and disadvantages of both the techniques. This chapter also includes the literature review conducted as a part of this research. Chapter 3 describes various equipment that are used in this research. Chapter 4 presents the various laboratory tests that were conducted as well the corresponding results obtained from the tests. The procedure for making the laboratory samples, i.e., casting of the cylinders, preparation of the simulated debonds and the method of wrapping the cylinders are also furnished in detail in this chapter. Field tests conducted for the condition assessment of FRP wrapped timber piles on a railroad bridge and the corresponding results are discussed in Chapter 5. Chapter 6 contains the conclusions and recommendations of the study. This is followed by a listings of all the references cited in this research. 


\section{CHAPTER 2}

\section{BASICS OF GROUND PENETRATING RADAR AND INFRARED THERMOGRAPHY}

\subsection{OVERVIEW}

Ground Penetrating Radar (GPR) and Infrared Thermography (IRT) are noninvasive scanning techniques that can be used for mapping subsurface debonds in concrete bridges, pavements, and wooden components. This thesis investigates the use of GPR and IRT for detection of debonds in concrete columns wrapped with Carbon Fiber Reinforced Polymer (CFRP) fabric and Glass Fiber Reinforced Polymer (GFRP) fabric. This chapter gives a brief overview of the basic fundamentals of GPR and IRT and also their advantages and limitations over other NDE techniques.

\subsection{BASICS OF GPR}

There are two types of materials that exist in nature: conductors and insulators (Halabe et al. 1995). Electromagnetic (EM) waves are fully reflected by conductors and propagate through insulators or dielectrics. The propagation of EM waves depends on the electromagnetic properties of the material (Halabe et al. 1995). The complex dielectric permittivity of a medium can be defined as

$$
\varepsilon=\varepsilon^{\prime}+\mathrm{i} \varepsilon^{\prime \prime}
$$

where, $\varepsilon=$ Complex dielectric permittivity, $\varepsilon^{\prime}=$ Real part, also known as dielectric constant, $\varepsilon^{\prime \prime}=$ Imaginary part, also known as loss factor (Halabe et al. 1993). Dielectric permittivity is the ability of a medium to resist the flow of electric charge. Dielectric permittivity is usually expressed as relative dielectric permittivity, which is the ratio of the actual dielectric permittivity of the material to the permittivity of vacuum. The velocity as well as the intensity of the reflected waves depends on complex dielectric permittivity. For concrete in a dry condition only the real part contributes to complex dielectric permittivity (Maierhofer 2003). Complex dielectric permittivity in turn depends on the electromagnetic properties of the solid particles, moisture content, salt content, pulse frequency etc (Maierhofer 2003). Whenever EM waves encounter an interface of two media having differing dielectric constants, part of the wave is reflected back to the 
receiving antenna. The amount of scattering depends upon the contrast in dielectric properties of the two media. The velocity of an EM wave in concrete is given by the following equation (Halabe et al. 1993):

$$
V=\frac{V_{0}}{\sqrt{\varepsilon^{\prime}}}
$$

where $\mathrm{V}_{\mathrm{o}}$ is the velocity of $\mathrm{EM}$ wave in vacuum $\left(=3 \times 10^{8} \mathrm{~m} / \mathrm{s}\right), \varepsilon^{\prime}$ is the dielectric constant of dry concrete and V is the velocity of EM wave in dry concrete. The value of $\varepsilon^{\prime}$ decreases with increase in frequency of EM wave.

GPR emits electromagnetic impulses of pulse duration $\sim 1 \mathrm{~ns}$ from the transmitter of the antenna into the structure or material under investigation. These pulses are reflected from interfaces of two media having different dielectric constants and received by the receiver of the antenna. These received pulses are then converted into voltage signals. A record showing the amplitude of the reflected pulses and their arrival times is called a radar waveform. Typical radar waveforms are shown in Figure 2-1 (single waveform) and Figure 2-2 (series of waveforms) respectively. A wiggle plot or waterfall plot is the display containing a series of recorded waveforms as the radar antenna moves along the surface that is monitored.

Recent radar applications use graphic display of the scanned data which essentially means the conversion of the received signals in the form of voltages into grey scale or color plots. Different values of voltage are assigned different shades. This kind of display allows easy data analysis since the debonds appear with different shades of grey scale or colors compared to surrounding defect-free areas (Agrawal 2005). Examples of such scans are given in Figure 2-3 and Figure 2-4 respectively. 


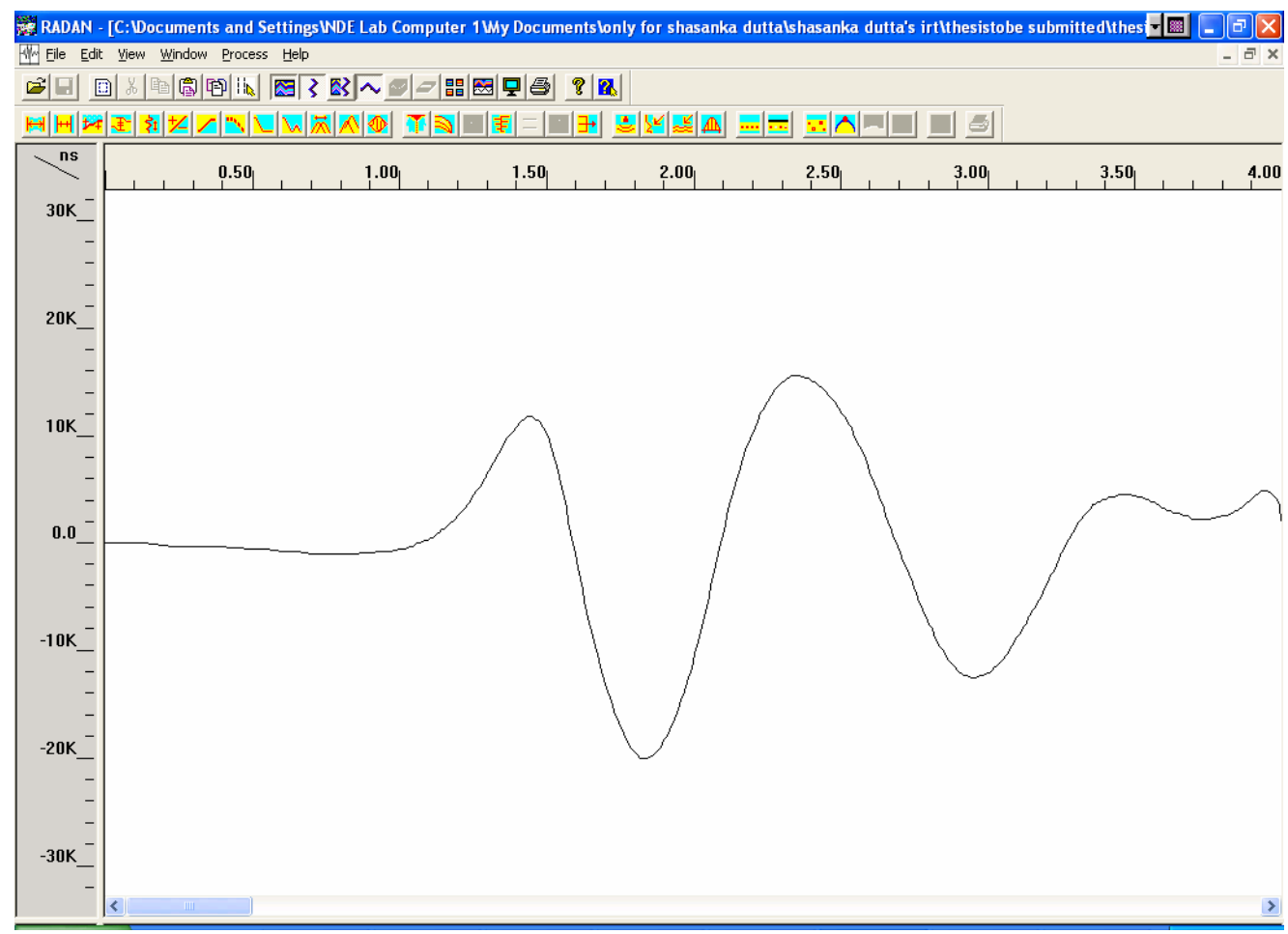

Figure 2-1 Single scan (extracted from sample of scans) with vertical axis showing the strength of the received signal in millivolts $(\mathrm{mV})$ and horizontal axis indicating the two way travel time within the material in nanoseconds (ns)

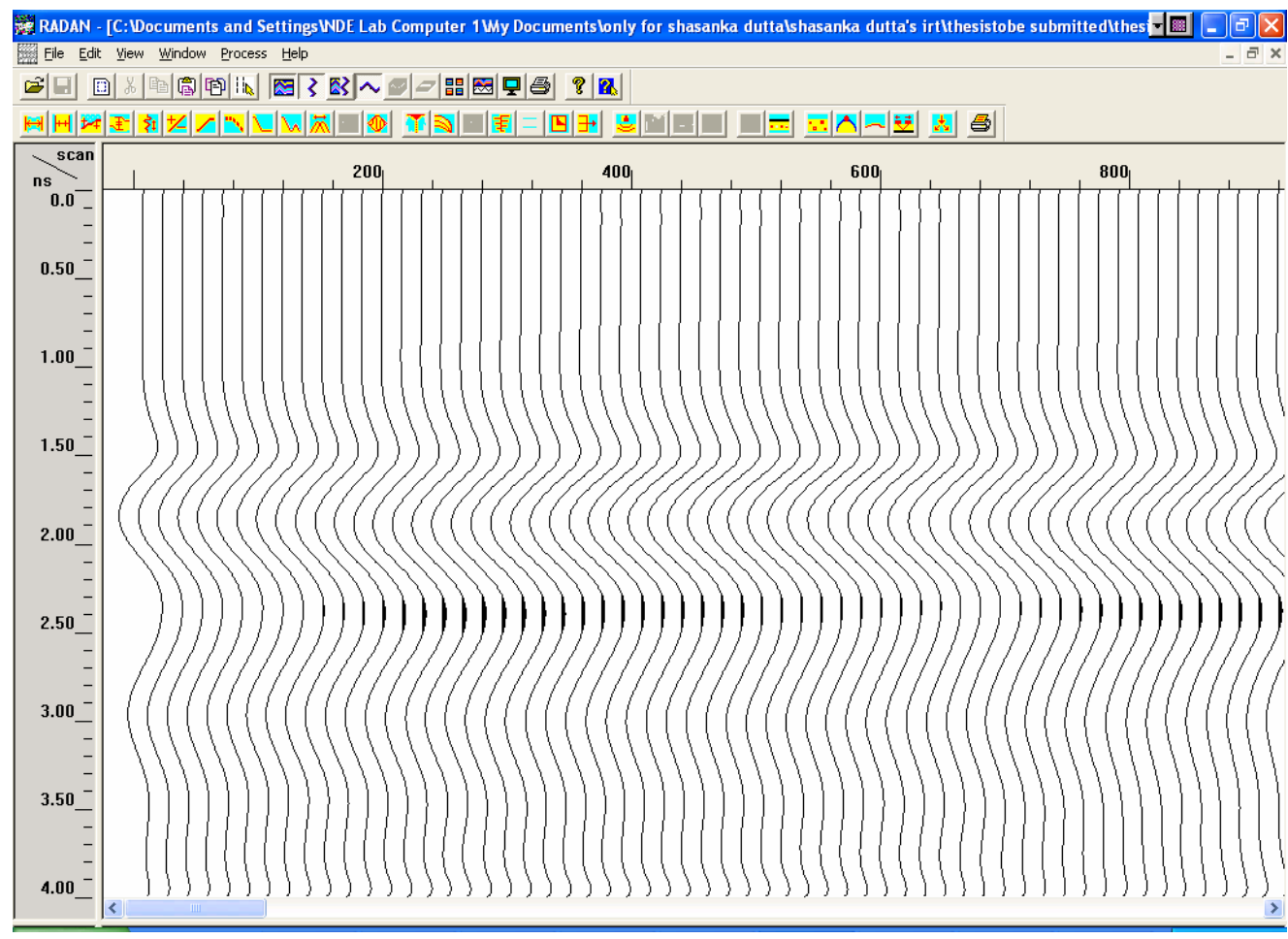

Figure 2-2 Wiggle plot 
RADAN - [C:Documents and SettingsWDE Lab Computer 1My Documentslonly for shasanka duttalshasanka dutta's irtlthesistobe submittedithesi

焉 File Édit View Window Process Help

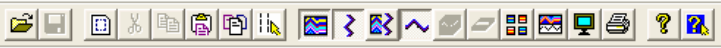

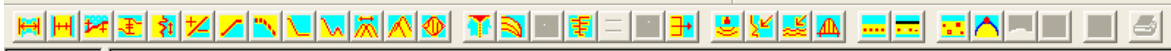

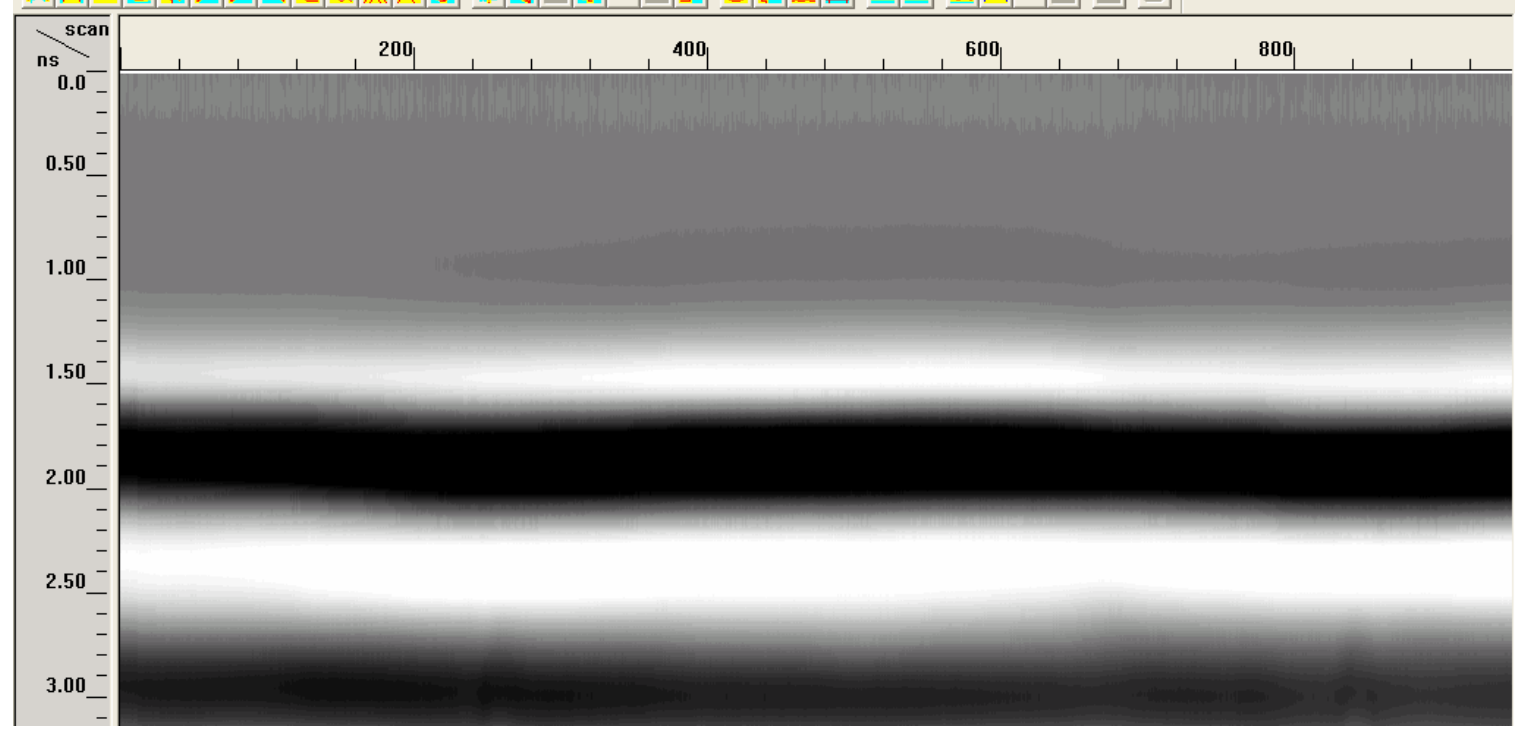

Figure 2-3 Grey scale scan

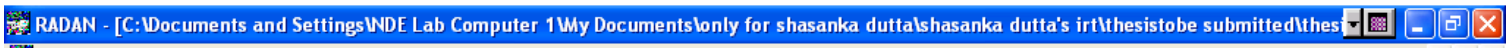
焉 File Edit View Window Process Help

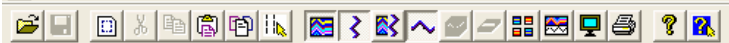

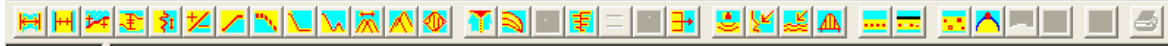

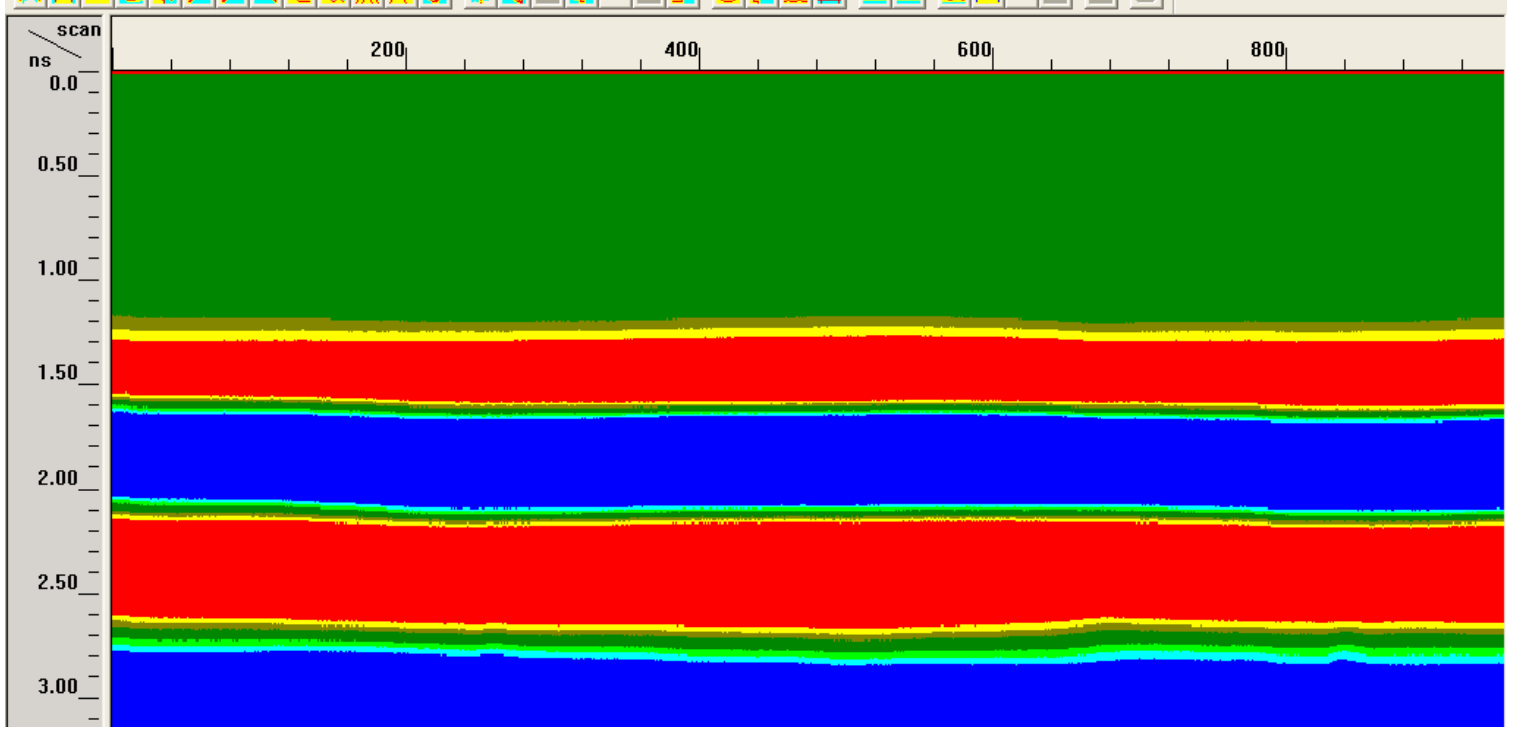

Figure 2-4 Color scan 


\subsubsection{Attenuation of Electromagnetic Waves}

An electromagnetic wave attenuates while propagating through a dielectric. For one dimensional wave propagation, the amplitude of the wave is given by (Halabe 1990):

$$
A(x, t)=A_{o} e^{-k_{I} x} e^{i\left(k_{R} x-\omega t\right)}
$$

where $A_{o}$ is the initial wave amplitude and $A(x, t)$ is the amplitude of the EM wave at a distance $x$ and time $t$. Here $k_{I}$ is the attenuation coefficient and is related to loss of EM wave energy. For concrete, attenuation coefficient is given by the following equation (Halabe et al. 1993):

$$
k_{I}=\frac{377 \sigma}{2 \sqrt{\varepsilon^{\prime}}}
$$

where $\sigma$ and $\varepsilon$ ' are the conductivity and dielectric constant of the medium respectively. So conductivity of the material largely influences the dissipation of EM wave energy. Conductivity $(\sigma)$ of a material is given by:

$$
\sigma=\omega \varepsilon_{o} \varepsilon^{\prime \prime}
$$

where, $\omega=$ Frequency of the EM wave

$$
\begin{aligned}
\varepsilon_{o} & =\text { Dielectric permittivity of vacuum } \\
& =8.854 \times 10^{-12} \text { farad } / \mathrm{m} \\
\varepsilon^{\prime \prime} & =\text { Imaginary part of relative dielectric permittivity }
\end{aligned}
$$

The value of $\varepsilon^{\prime \prime}$ increases with an increase in the amount of moisture content. So wave attenuation increases with the increase in moisture content. Among other factors affecting EM wave attenuation are salt content, frequency and temperature (Halabe et al. 1993). For EM waves traveling through concrete, the attenuated energy is given by the following equation (Clemena 1991):

$$
\begin{gathered}
A=12.863 \times 10^{-8} f \sqrt{\varepsilon^{\prime}}\left[\left(\sqrt{1+\tan ^{2} \delta}\right)-1\right]^{1 / 2} \\
\text { where, } f=\text { Wave frequency in } \mathrm{Hz}
\end{gathered}
$$




$$
\begin{aligned}
A & =\text { Wave attenuation in decibel } / \text { meter } \\
\varepsilon^{\prime} & =\text { Dielectric constant of concrete } \\
\tan \delta & =\text { Dissipation factor }=\frac{\varepsilon^{\prime \prime}}{\varepsilon^{\prime}}=1.8 \times 10^{10} \times \frac{\sigma}{f \varepsilon^{\prime}}
\end{aligned}
$$

\subsubsection{Reflection and Transmission of Radar Waves}

Since the entire principle of GPR is based on transmission of EM waves and detecting the part of the transmitted wave that are reflected back from debonds or interfaces within the medium, understanding the reflection and transmission of radar waves is of utmost importance. The amplitude reflection coefficient $R_{1,2}$ is defined as the ratio of reflected wave amplitude to the incident wave amplitude and is given by Equation 2.7 (Halabe et al. 1993):

$$
R_{1,2}=\frac{\sqrt{\varepsilon_{1}^{\prime}}-\sqrt{\varepsilon_{2}^{\prime}}}{\sqrt{\varepsilon_{1}^{\prime}}+\sqrt{\varepsilon_{2}^{\prime}}}
$$

where $\varepsilon_{1}^{\prime}$ and $\varepsilon_{2}^{\prime}$ are the relative dielectric constants of first and second media respectively. If $\varepsilon_{1}^{\prime}=\varepsilon^{\prime}{ }_{2}$ then no energy is reflected back to the receiving antenna indicating no debonds or interfaces. Another important point to be noted is that if $\varepsilon_{1}^{\prime}$ $<\varepsilon^{\prime}{ }_{2}$, then $R_{1,2}$ is negative which essentially means that reflected wave is reversed in phase. For metals, $\varepsilon^{\prime}$ may be assumed to be infinity. According to Equation 2.7, higher the contrast between the dielectric permittivity between the two media; sharper is the reflection we get from GPR.

The amplitude transmission coefficient, $T_{1,2}$ which is defined as the ratio of transmitted wave amplitude to the incident wave amplitude, is given by Equation 2.8 as (Halabe et al. 1993):

$$
T_{1,2}=\frac{2 \sqrt{\varepsilon_{1}^{\prime}}}{\sqrt{\varepsilon_{1}^{\prime}}+\sqrt{\varepsilon^{\prime}{ }_{2}}}
$$

where $\varepsilon_{1}^{\prime}$ and $\varepsilon_{2}^{\prime}$ are the relative dielectric constants of first and second media respectively. 
Reflection from a metal plate gives the amplitude of the transmitted radar pulse because for metals, dielectric constant is assumed to be infinity and hence metal reflects all of incident wave back to the receiving antenna. The reflection coefficient for air-FRP interface can be written as (Halabe et al. 1995):

$$
R=-R_{1,2}=\frac{\sqrt{\varepsilon_{a}^{\prime}}-1}{\sqrt{\varepsilon^{\prime}{ }_{a}}+1}=\frac{A}{A_{p}}
$$

where, $A=$ Amplitude of reflection from the FRP surface (i.e., air-FRP interface)

$$
\begin{aligned}
A_{p}= & \text { Amplitude of reflection from metal plate placed on the top of FRP } \\
& \text { wraps } \\
\varepsilon_{a}^{\prime}= & \text { Dielectric constant of FRP wrap }
\end{aligned}
$$

Hence,

$$
\varepsilon_{a}^{\prime}=\left[\frac{1+R}{1-R}\right]^{2}
$$

It should be noted that measurement of dielectric constant with this procedure is only possible with an air-launched antenna and not with a ground-coupled antenna. Table 2-1 gives dielectric constants of some common materials at $100 \mathrm{MHz}$. 
Table 2-1 Dielectric constants of common materials at $100 \mathrm{MHz}$ (GSSI 2003)

\begin{tabular}{|c|c|}
\hline Material & Dielectric Constant \\
\hline \hline Air & 1 \\
\hline Glacial Ice & 3.6 \\
\hline PVC & 3 \\
\hline Asphalt & $3-5$ \\
\hline Concrete & $4-11(5)$ \\
\hline Granite & $4-7$ \\
\hline Sandstone & 6 \\
\hline Shale & $5-15$ \\
\hline Limestone & $4-8$ \\
\hline Basalt & $8-9$ \\
\hline Water saturated sands $(20 \%$ & $19-24$ \\
\hline porosity) & $4-30$ \\
\hline Water & 81 \\
\hline
\end{tabular}

\subsubsection{Resolution and Polarization}

The effectiveness of GPR in evaluation of anomalies is attributed to resolution which can be classified as depth resolution and horizontal resolution (Maierhofer 2003). Depth resolution is a function of frequency bandwidth of the antenna used (Maierhofer 2003). However penetration depth decreases as antenna frequency increases (Maierhofer 2003). Horizontal resolution essentially is the horizontal distance at which two anomalies should be located in order to be differentiated. It depends on four factors namely depth of the medium, damping of EM waves, antenna aperture and frequency of the electromagnetic waves generated by the transmitter of the GPR system (Maierhofer 2003). Polarization of the antenna can also play an important role in detection of subsurface anomalies. Plane of Polarization is the direction in which electric field vector is directed (Maierhofer 2003). This is particularly useful while scanning for metallic bars. We get better reflection from a metallic bar if the electric field is aligned in the same direction as the bar (Maierhofer 2003).

\subsection{BASICS OF INFRARED THERMOGRAPHY}

Infrared Thermography is based on the principle that subsurface flaws or any other change in thermal properties affects the rate of heat flow which in turn causes 
surface temperature differentials. Measurement of this surface temperature differentials lead to the detection of the subsurface anomalies. Heat transfer from an object depends upon the thermal properties of the object. There are three modes of heat transfer namely conduction, convection and radiation. It's the radiation mode of heat transfer that the principle of Infrared Thermography is based upon. All objects radiate energy in the infrared zone of the electromagnetic spectrum above absolute zero temperature. Infrared scanning devices measures the infrared radiation emitted from the target object (Kaplan 1999). Post processing of the data enables the measured infrared radiation levels to be converted into corresponding temperatures which in turn are recorded in the form of thermograms (Starnes et al.2003). Thermograms can be easily interpreted to locate a subsurface debond.

The electromagnetic spectrum is showed in Figure 2-5. The infrared portion of the spectrum lies between from $0.75 \mu \mathrm{m}-100 \mu \mathrm{m}$. Radiative heat transfer takes place in the infrared spectrum although upper limit for practical measurement is $20 \mu \mathrm{m}$ (Kaplan 1999). Table 2-2 gives thermal properties of some common materials (Maldague 1993).

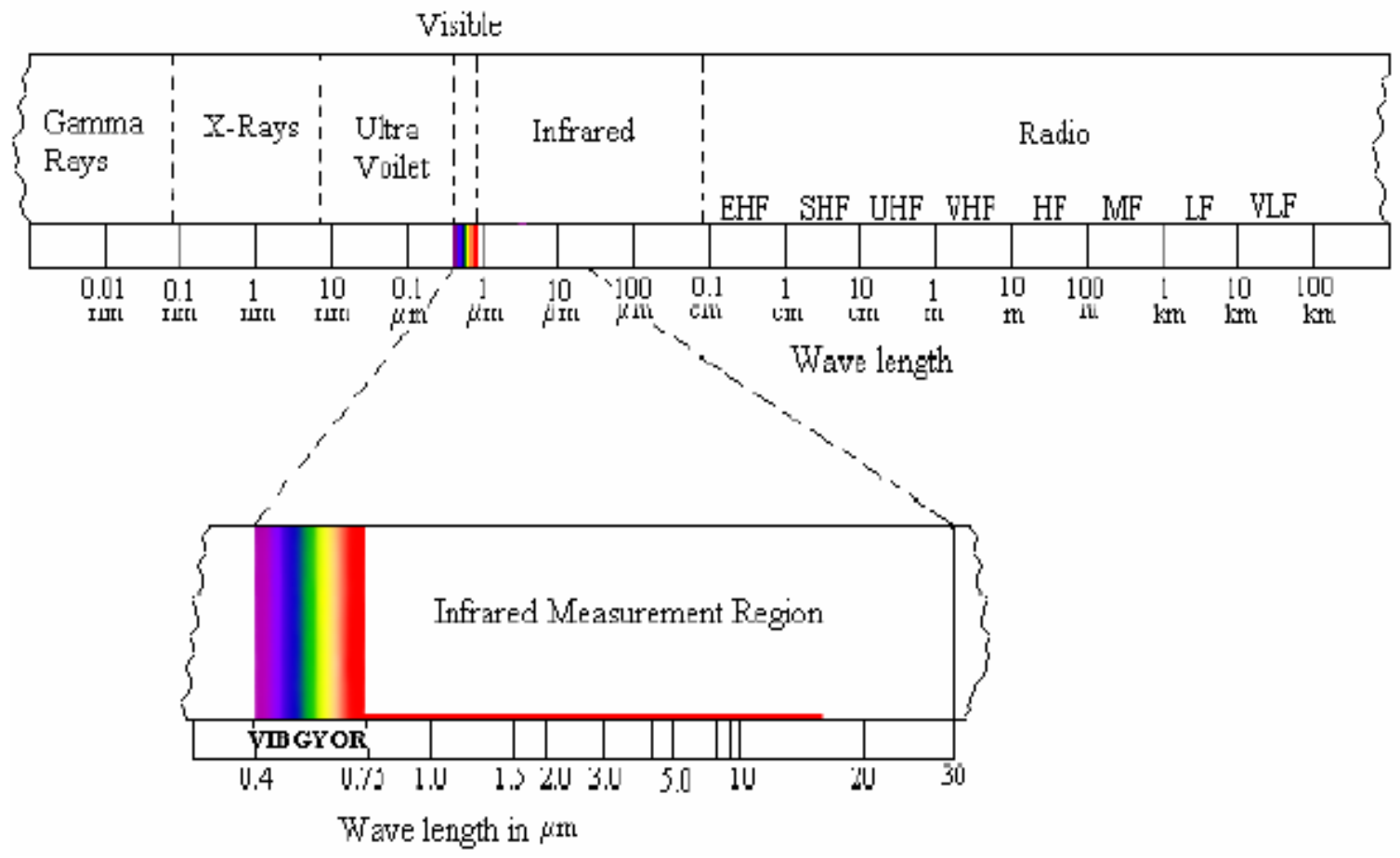

Figure 2-5 Infrared region in electromagnetic spectrum (Kaplan 1999) 
Table 2-2 Thermal properties of materials (Maldague 1993)

\begin{tabular}{|c|c|c|c|c|c|}
\hline Material & $\begin{array}{c}\text { Specific } \\
\text { Heat } \\
\mathbf{C} \\
\left(\mathrm{Jkg}^{-10} \mathrm{C}^{-1}\right)\end{array}$ & $\begin{array}{c}\text { Mass } \\
\text { Density } \\
\rho \\
\left(\mathrm{kg} \mathrm{m}^{-3}\right)\end{array}$ & $\begin{array}{c}\text { Heat } \\
\text { capacity } \\
\rho \mathbf{\rho} \\
\left(\mathbf{J ~ m}^{-30} \mathbf{C}^{-1}\right)\end{array}$ & 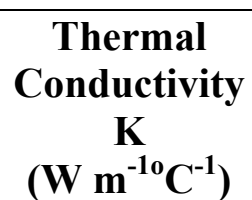 & $\begin{array}{c}\text { Thermal } \\
\text { Diffusivity } \\
\delta \\
\left(\mathrm{m}^{2} \mathrm{~s}^{-1}\right)\end{array}$ \\
\hline Air (as defect) & 700 & 1.2 & $0.0008 \times 10^{6}$ & 0.024 & $33 \times 10^{-6}$ \\
\hline Aluminium & 880 & 2700 & $2.4 \times 10^{6}$ & 230 & $95 \times 10^{-6}$ \\
\hline $\begin{array}{c}\text { Brass }(65 \% \mathrm{Cu} \\
\text { and } 35 \% \mathrm{Zn})\end{array}$ & 380 & 8400 & $3.2 \times 10^{6}$ & 130 & $32 \times 10^{-6}$ \\
\hline $\mathrm{CFRP}^{\mathrm{b}}$ (_I_fibers) & 1200 & 1600 & $1.9 \times 10^{6}$ & 0.8 & $0.42 \times 10^{-6}$ \\
\hline $\operatorname{CFRP}^{\mathrm{b}}(\|$ fibers $)$ & 1200 & 1600 & $1.9 \times 10^{6}$ & 7 & $3.7 \times 10^{-6}$ \\
\hline Concrete & 800 & 2400 & $1.9 \times 10^{6}$ & 1 & $0.53 \times 10^{-6}$ \\
\hline Copper & 380 & 8900 & $3.4 \times 10^{6}$ & 380 & $110 \times 10^{-6}$ \\
\hline Epoxy resin & 1700 & 1300 & $2.2 \times 10^{6}$ & 0.2 & $0.09 \times 10^{-6}$ \\
\hline Glass & 670 & 2600 & $1.7 \times 10^{6}$ & 0.7 & $0.41 \times 10^{-6}$ \\
\hline $\operatorname{GFRP}^{\mathrm{c}}\left(\_\right.$fibers $)$ & 1200 & 1900 & $2.3 \times 10^{6}$ & 0.3 & $0.13 \times 10^{-6}$ \\
\hline $\operatorname{GFRP}^{\mathrm{c}}(\|$ fibers $)$ & 1200 & 1900 & $2.3 \times 10^{6}$ & 0.38 & $0.17 \times 10^{-6}$ \\
\hline Lead & 130 & 11300 & $1.5 \times 10^{6}$ & 35 & $23 \times 10^{-6}$ \\
\hline Nickel & 440 & 8900 & $3.9 \times 10^{6}$ & 91 & $23 \times 10^{-6}$ \\
\hline Plexiglass $^{\mathrm{TM}}$ & - & 1200 & - & 0.2 & $0.25 \times 10^{-6}$ \\
\hline Porcelain & 1100 & 2300 & $2.5 \times 10^{6}$ & 1.1 & $0.43 \times 10^{-6}$ \\
\hline Steel (mild) & 440 & 7900 & $3.5 \times 10^{6}$ & 46 & $13 \times 10^{-6}$ \\
\hline Steel (stainless) & 440 & 7900 & $3.5 \times 10^{6}$ & 25 & $7.1 \times 10^{-6}$ \\
\hline Teflon $^{\mathrm{TM}}$ & - & - & - & 0.42 & $1.59 \times 10^{-6}$ \\
\hline Titanium & 470 & 4500 & $2.1 \times 10^{6}$ & 16 & $7.6 \times 10^{-6}$ \\
\hline Uranium & 120 & 18700 & $2.2 \times 10^{6}$ & 27 & $12 \times 10^{-6}$ \\
\hline Water & 4180 & 1000 & $4.2 \times 10^{6}$ & 0.6 & $0.14 \times 10^{-6}$ \\
\hline Zircaloy 2 & 280 & 6600 & $1.8 \times 10^{6}$ & 13 & $11 \times 10^{-6}$ \\
\hline
\end{tabular}

(Vavilov 1980, p 182; Reynolds and Wells 1984, p 43; Tretout 1987, p 49; Touloukian and Dewitt 1970)

${ }^{a}$ Defined as $\delta=\mathrm{K} / \rho \mathrm{C}$, where $\mathrm{K}$ is the thermal conductivity, $\rho$ is mass density, $\mathrm{C}$ is the specific heat, and $\rho \mathrm{C}$ is the heat capacity.

${ }^{\mathrm{b}}$ Carbon fiber reinforced polymer.

${ }^{\mathrm{c}}$ Glass fiber reinforced polymer.

The radiant behaviour of an object is governed by two equations namely Stefan Boltzmann law and Wien's displacement law. Stefan Boltzmann law is given by 
$W=\varepsilon \sigma T^{4}$

where, $W=$ Radiant intensity $\left(\frac{W}{m^{2}}\right)$

$\varepsilon=$ Emissivity of the object

$\sigma=$ Steafan-Boltzmann constant $\left(5.67 \times 10^{-8} \mathrm{Wm}^{-2} \mathrm{~K}^{-4}\right)$

$T=$ Absolute temperature $(K)$

Wien's displacement law is given by:

$\lambda_{\max }=\frac{b}{T}$

where, $b=$ Wien displacement constant $=2897 \frac{\mu m}{K}$

$\lambda_{\max }=$ Wavelength of maximum radiation intensity $(\mu m)$

Emissivity is the ratio of actual emission from the object to that from a hypothetical source called a "black body" at the same temperature. As an object cools down, it starts to emit wavelengths in the infrared zone of the electromagnetic spectrum (Kaplan 1999). This also follows from Wein's displacement law. At room temperature the radiation emitted are in the infrared zone (Starnes et al. 2003). Infrared sensors can detect those invisible wavelengths and enable us to determine surface temperature of an object (Kaplan 1999). Essentially, the sensors measure the infrared radiation emitted from an object and converts it to an equivalent temperature value in accordance with the Wein's law (Kaplan 1999). Figure 2-6 shows different blackbody curves at different temperatures. 


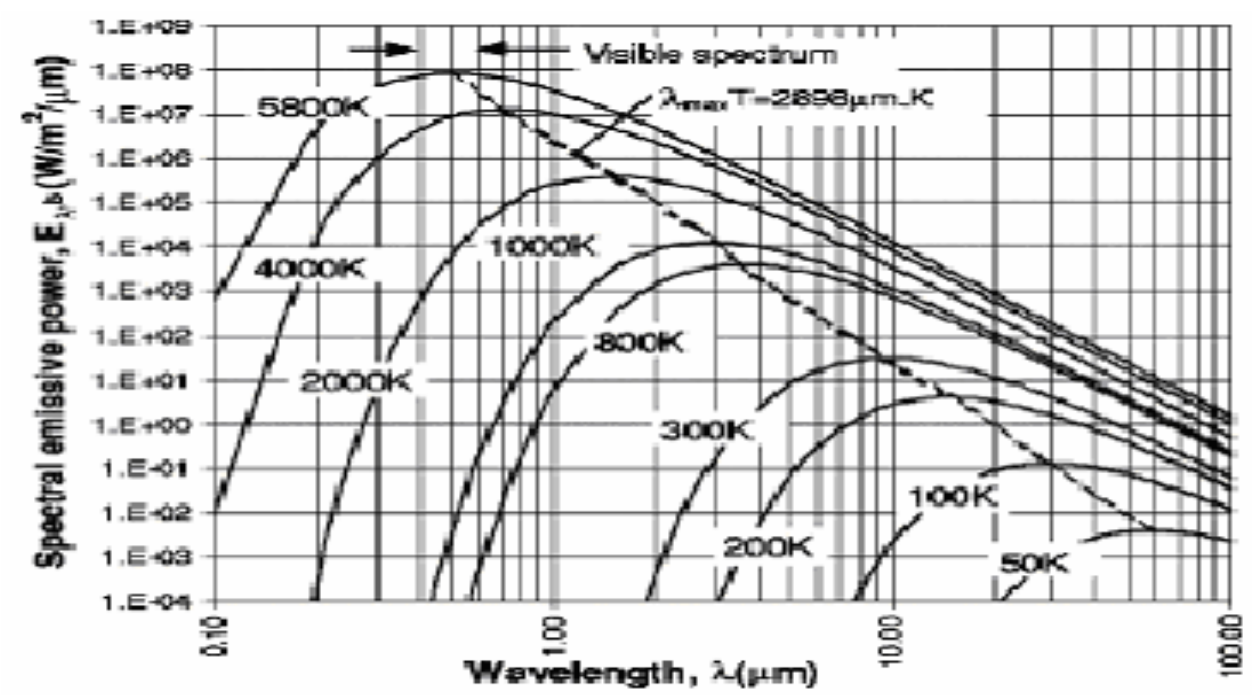

Figure 2-6 Blackbody curves at various temperatures (Kreith and Bohn 1993

\subsubsection{Active and Passive Thermography}

Infrared Thermography is used in two schemes, active and passive. In active Infrared Thermography, external heating source such as lamp, heater, heating blanket are used to drive heat across the object of interest (Maldague 2000). The thermal gradients developed at the surface are observed through the infrared camera. Uniform heating is of utmost importance in this case since thermal gradients produced by non uniform heating can be mistaken for debonds (Steele 2001). Solar radiation can also be used as a heating source. In passive approach, the natural temperature differences on the surface due to subsurface anomalies are observed (Maldague 2000). In passive thermography what is measured is the temperature difference with respect to the surroundings, often referred to as the 'hotspot'. A temperature difference of $1-2{ }^{\circ} \mathrm{C}$ is taken as suspicious whereas a difference of $4{ }^{\circ} \mathrm{C}$ confirms the presence of an anomaly (Maldague 2000). Sometimes cooling source can also be used to develop the thermal gradient. Examples of cooling sources include cold water, liquid nitrogen, liquid carbon dioxide etc. Nondestructive evaluation of civil engineering infrastructure often requires active thermography (Starnes et al. 2003).

\subsection{ADVANTAGES AND DISADVANTAGES OF GPR AND IRT}

Each NDE technique has its own advantages and disadvantages. Infrared Thermography is a non-contact technique meaning distant targets can be evaluated 
without actually accessing the object. No harmful radiations are emitted during the data collection process. Also, it is a fast technique and results can be analyzed with relative ease. Also, the measurements are highly influenced by environmental parameters such as wind, solar radiation, rain, adjacent trees, etc. Ground Penetrating Radar is being used for condition assessment of bridge decks and pavements. Ground Penetrating Radar, like Infrared Thermography, does not require any external sensors. Collected data can be analyzed on the site with the help of post processing software which is implemented in the data collection unit itself. GPR is very effective in detecting water-filled voids but its sensitivity decreases drastically for air-filled voids. However high moisture content also triggers an attenuation of the reflected wave and hence ideal time for conducting GPR surveys is when the surface of the bridge deck or the pavement is dry and moisture is entrapped in the subsurface voids, debonds or delaminations. So this condition puts a time constraint in GPR measurements. GPR data can also be influenced by environmental factors and spurious reflections from objects lying in the vicinity of the target object.

\subsection{LITERATURE REVIEW}

Jackson et al. (2000) demonstrated the use of GPR and Infrared Thermography to evaluate the FRP wrapped columns in Court Street Bridge over the Susquehanna River in Owego, New York. They showed that GPR could track defects at considerable depth. However for locating very shallow delaminations which includes FRP disbondment, low frequency antenna (such as $1 \mathrm{GHz}$ ) did not yield good results. They recommended higher frequency antenna (such as $2 \mathrm{GHz}$ ) for this purpose. Infrared Thermography was also excellent in monitoring FRP wrapped columns. Although IRT could detect disbondment, blisters, shallow defects and entrapped moisture between FRP wrap and concrete, the state of the art technique performed poorly when it came to locating deeper defects. Other studies (Steele 2001, Vasudevan 2004), which focused only on IRT, were successful in detecting debonds in GFRP wrapped timber columns in the field. 


\section{CHAPTER 3 \\ EQUIPMENT AND EXPERIMENTAL SETUP}

\subsection{GPR SYSTEM}

The GPR system used for our research is SIRveyor SIR-20, manufactured by Geophysical Survey System, Inc. (GSSI). The GPR equipments utilized in the laboratory for non destructive evaluation of concrete cylinders consist of a data acquisition system (DAQ), one antenna, a portable antenna deployment frame and a rotating table. The control units as well as the storage and display devices are incorporated in the data acquisition system. The transmitter and receiver are both incorporated in the same antenna. Figure 3-1 shows a typical GPR scanning setup used in the laboratory.

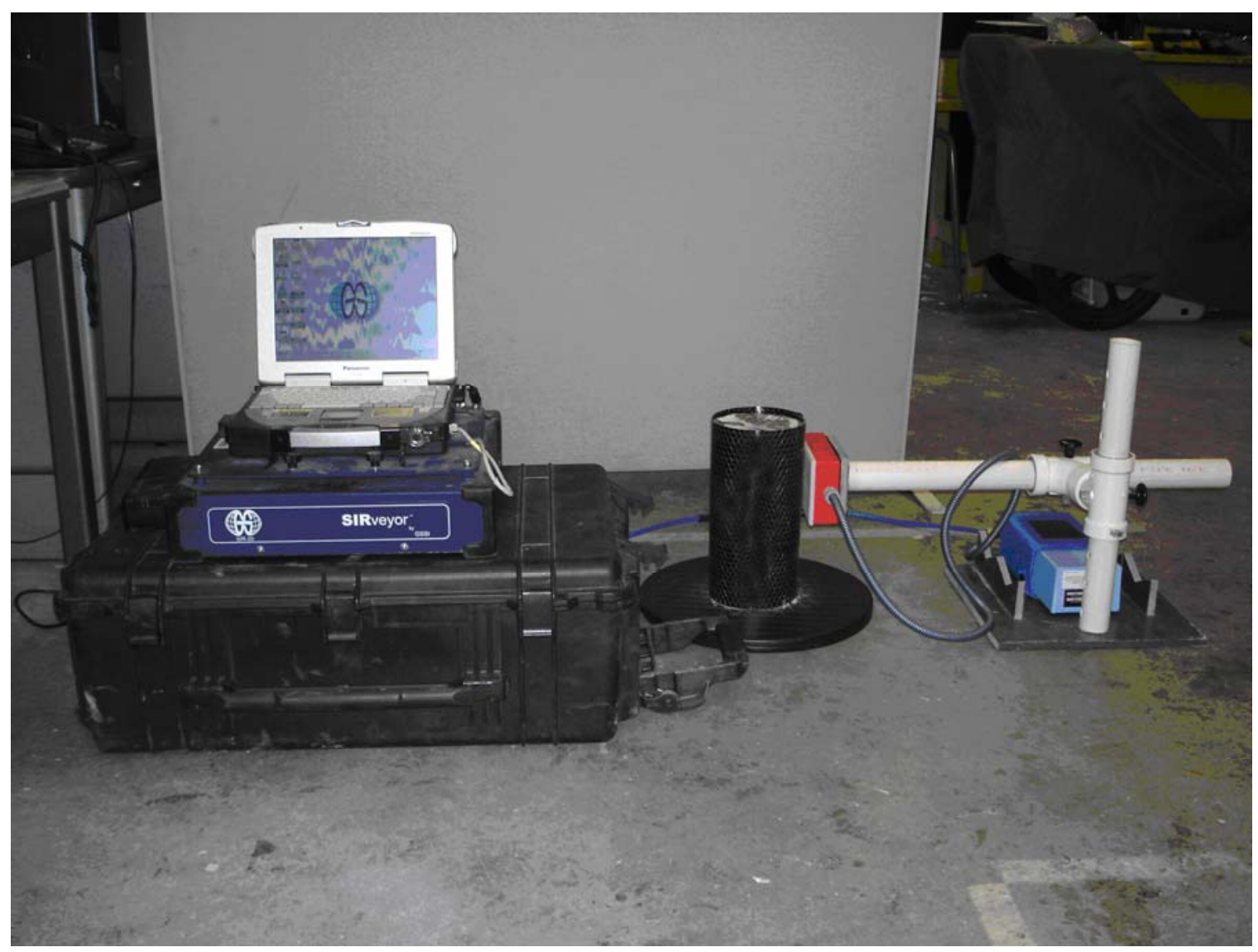

Figure 3-1 GPR scanning setup for laboratory testing of FRP wrapped cylinders 


\subsubsection{Data Acquisition System}

The SIRveyor SIR-20 consists of a robust two channel data collection unit controlled by a Windows based portable laptop computer with GSSI's Windows-based RADAN post-processing software (GSSI 2006). The system works in conjunction with standard GSSI antennas for a myriad of applications. Figure 3-2 shows the data acquisition system. Some of the advantages that SIR-20 offers are:

- Multichannel data collection.

- GPS compatibility.

- Allows 3D imaging.

- Can be used with all antennas manufactured by GSSI.

- Allows data collection and post processing instantly in the same unit (GSSI 2006).

The 3D format data collection is currently available only for planar objects and not for objects with circular cross-section such as cylinders. Post processing software RADAN is very much user friendly and allows quick interpretation of the collected data. Some of the typical applications of SIR-20 are evaluation of bridge decks, inspection of roads, utility detection and concrete evaluation (GSSI 2006).
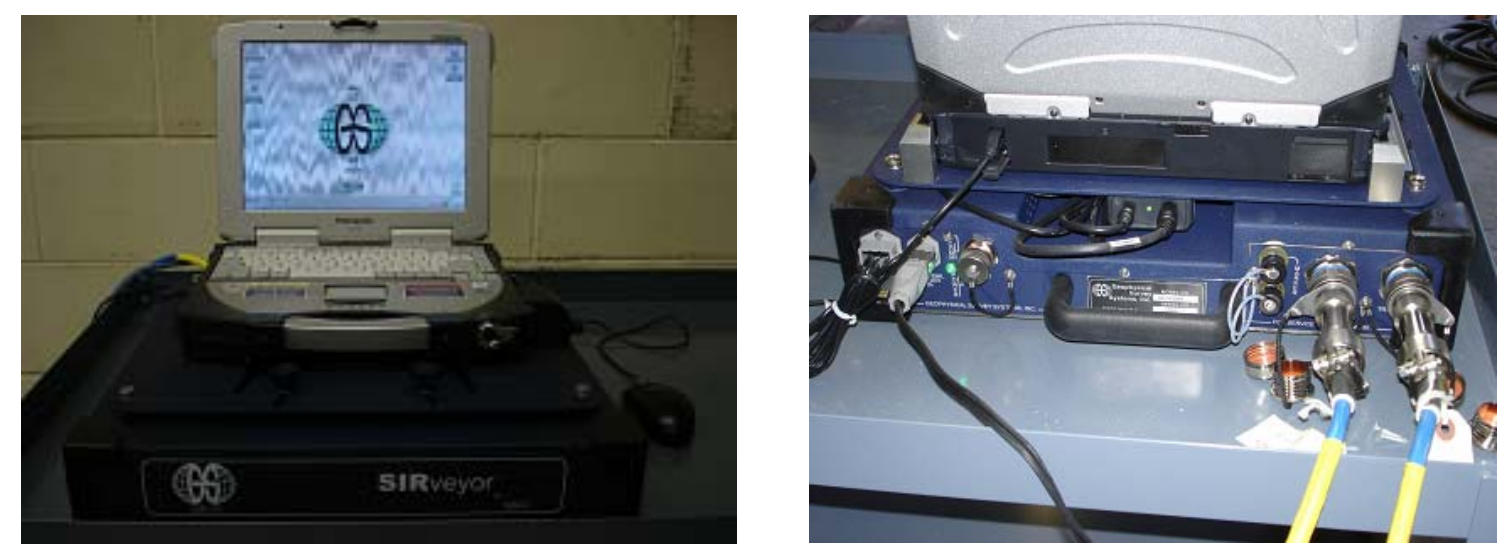

Figure 3-2 Data acquisition system (laptop computer and main frame)

\subsubsection{Antenna}

GPR antennas can be broadly classified into three groups namely ground coupled, air launched, and borehole antennas. Table 3-1 provides the detail of all the antennas 
manufactured by GSSI. Both transmitter and receiver are housed in the same antenna implying that they are mono-static. However when one antenna is triggered by pulses from the SIR system and sends electromagnetic energy and the other one receives the reflected signal they are said to work in bi-static mode. The central frequency of an antenna is the median frequency it transmits (GSSI 2002a). The antenna actually sends out electromagnetic energy at a frequency range 1.5-2 times its central value (GSSI 2002a). The central frequency is important because it determines the depth of penetration and size of the objects visible (GSSI 2002a). Also in case of ground coupled antennas, dielectric properties of the medium to which the near field of the antenna is in contact also govern the radiated frequency of the EM waves (Maierhofer 2003). Penetration depth for ground coupled antennas are more than air launched ones. This can be attributed to the reasons that ground coupled antennas are coupled to the material surface and that most ground coupled antennas have lower frequencies. On the other hand air launched antennas provide better depth resolution because depth resolution depends upon frequency bandwidth of the antenna (Maierhofer 2003). Horizontal resolution depends upon factors like depth of the material to be evaluated, damping of the EM waves, antenna aperture and the frequency (Maierhofer 2003). For this research, a GSSI Model 5100 antenna (with a central frequency of $1500 \mathrm{MHz}$ ) was used (Figure 3-3). This antenna was chosen because of the following reasons:

- The plan size of the antenna was about 4"' $\mathrm{x}$ 7', (101.6 mm x $177.8 \mathrm{~mm})$. This size was small enough so that maneuvering the antenna around the surface of the cylinder was easy.

- This antenna could provide penetration depths of up to $0.5 \mathrm{~m}$ which is enough for our application (GSSI 2004).

- This is the highest frequency in the ground coupled antenna category that is commercially available. Higher the frequency, lower the wavelength and hence better resolution. 
Table 3-1 Details of antennas manufactured by GSSI (GSSI 2004)

\begin{tabular}{|c|c|c|c|}
\hline Model & $\begin{array}{c}\text { Center } \\
\text { Frequency }\end{array}$ & $\begin{array}{c}\text { Depth of } \\
\text { Penetration }\end{array}$ & Typical Applications \\
\hline \multicolumn{4}{|c|}{ Ground Coupled Antennas } \\
\hline 5100 & $1500 \mathrm{MHz}$ & $0.5 \mathrm{~m}$ & Concrete Evaluation \\
\hline $3101 \mathrm{D}$ & $900 \mathrm{MHz}$ & $1 \mathrm{~m}$ & Concrete Evaluation, Void Detection \\
\hline 5103 & $400 \mathrm{MHz}$ & $4 \mathrm{~m}$ & $\begin{array}{l}\text { Utility, Engineering, Environmental, Void } \\
\text { Detection }\end{array}$ \\
\hline 5104 & $270 \mathrm{MHz}$ & $6 \mathrm{~m}$ & Utility, Engineering, Geotechnical \\
\hline 5106 & $200 \mathrm{MHz}$ & $7 \mathrm{~m}$ & Geotechnical, Engineering, Environmental \\
\hline 3207 & $100 \mathrm{MHz}$ & $20 \mathrm{~m}$ & Geotechnical, Environmental, Mining \\
\hline $3200 \mathrm{MLF}$ & $\begin{array}{l}\text { MHz }-80 \\
\mathrm{MHz}\end{array}$ & $25-35 \mathrm{~m}$ & Geotechnical \\
\hline \multicolumn{4}{|c|}{ Air-Launched Antennas } \\
\hline 4105 Horn & $2.2 \mathrm{GHz}$ & $\begin{array}{l}\text { Up to } 0.75 \mathrm{~m} \\
\text { depending } \\
\text { on medium }\end{array}$ & $\begin{array}{c}\text { Pavement Thickness and Road Condition } \\
\text { Assessment }\end{array}$ \\
\hline 4108 Horn & $1000 \mathrm{MHz}$ & $1 \mathrm{~m}$ & Highway and Bridge Deck Evaluations \\
\hline
\end{tabular}

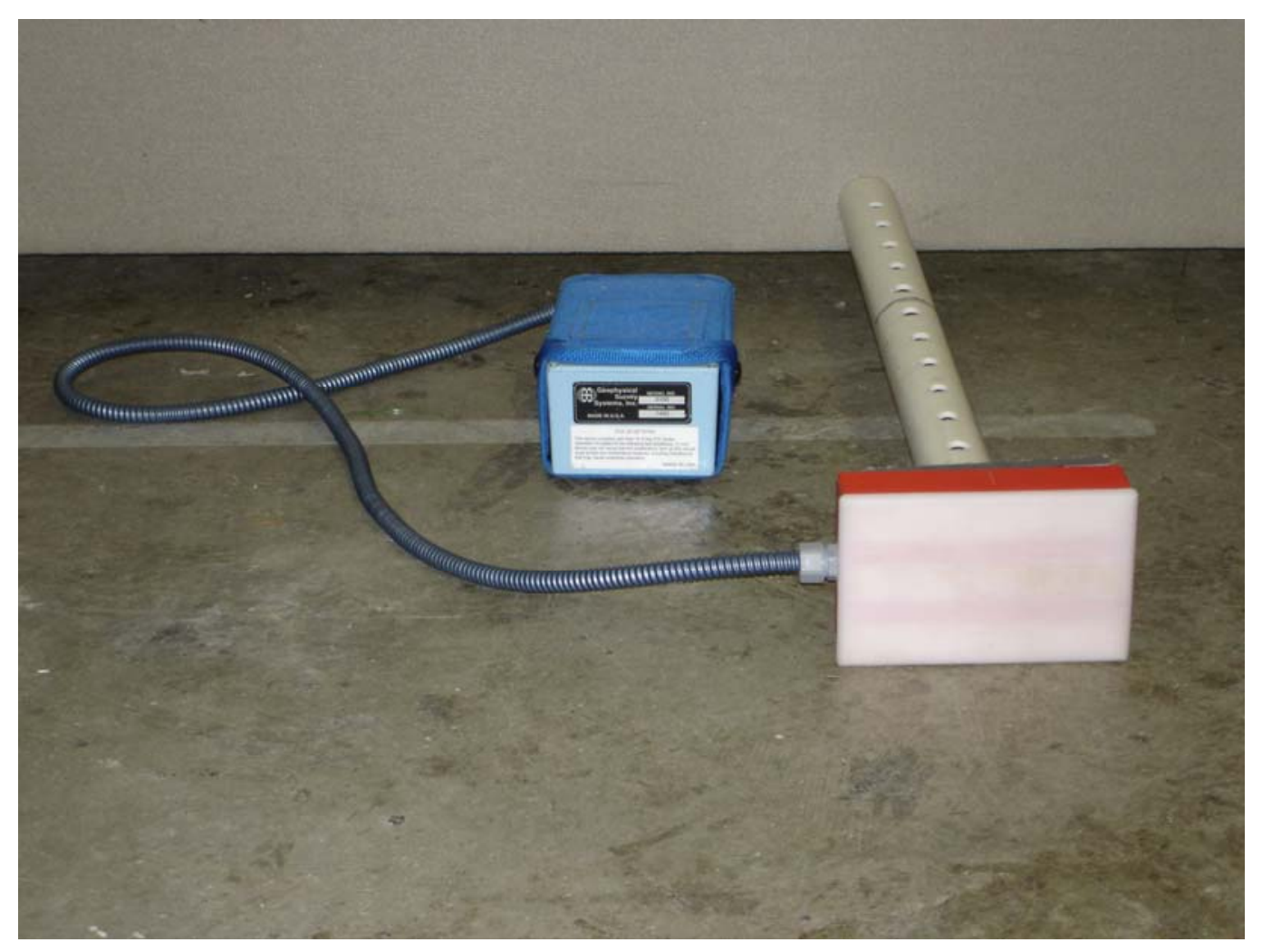

Figure 3-3 Ground coupled $1500 \mathrm{MHz}$ antenna 


\subsubsection{Antenna Deployment Frame and Rotating Table}

The antenna deployment frame and rotating table is shown in Figure 3-4. The frame was specially designed using polyvinyl chloride (PVC) pipes and FRP plate to avoid the interference of metal with EM wave energy. The cylinder was placed exactly at the center of the rotating table. The antenna was placed touching the surface of the wrapped cylinder. The rotating table was then rotated while the antenna collected GPR data in the free run mode. In the free run mode, the antenna is always collecting data, even when stationary unless the deadman switch (Stop button) in the acquisition software is clicked. The other ways to collect data are using the survey wheel mode and the point mode. Survey wheel mode is important in cases where the horizontal distance information is important, such as finding anomalies in a long field column or a bridge deck with respect to a fixed reference point. In this research, since the objects that were scanned (6" x 12" cylinders) were small in size (comparable to the antenna size), data collection in the free run mode using the rotating table assembly in Figure 3-4 was convenient.

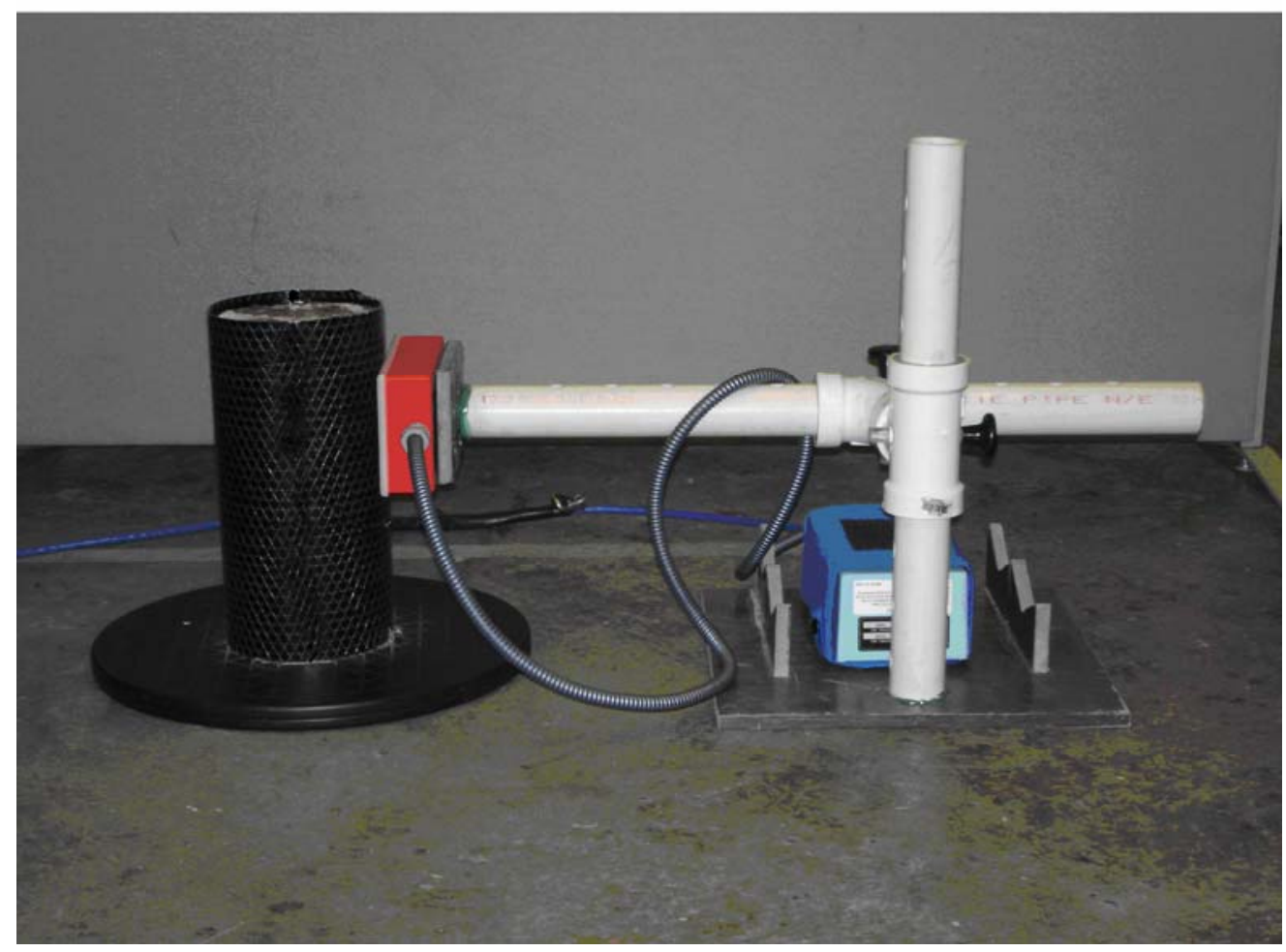

Figure 3-4 Antenna deployment frame and rotating table 


\subsection{INFRARED THERMOGRAPHY}

\subsubsection{Infrared Camera}

The digital infrared camera that is used in the experiments is ThermaCAM ${ }^{\mathrm{TM}} \mathrm{S} 60$ by FLIR Systems. Figure 3-5 shows the digital picture of the Infrared camera.

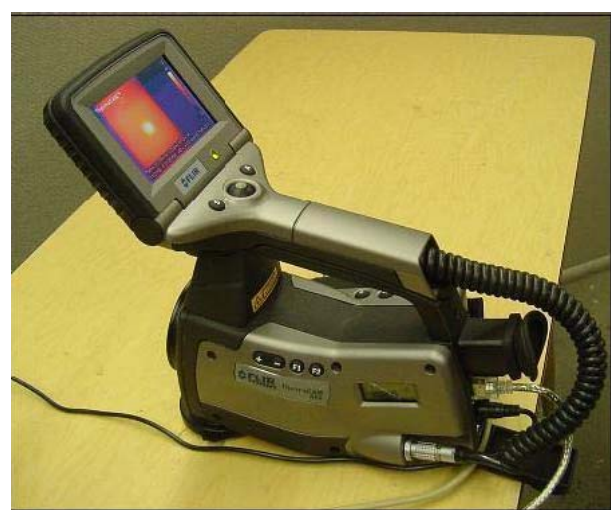

Figure 3-5 ThermaCAM ${ }^{\mathrm{TM}} \mathrm{S60}$ digital infrared camera

The camera is a lightweight one with a built in $24^{\circ}$ lens. It can detect infrared radiation in the spectral range of 7.5 to 13 microns. The different temperature ranges that the camera offers are 0 to $+500{ }^{\circ} \mathrm{C}\left(+32\right.$ to $\left.+932{ }^{\circ} \mathrm{F}\right),-40$ to $+120{ }^{\circ} \mathrm{C}\left(-40\right.$ to $\left.+248{ }^{\circ} \mathrm{F}\right)$ and +350 to $1500{ }^{\circ} \mathrm{C}\left(+662\right.$ to $+2732{ }^{\circ} \mathrm{F}$ ). Thermal sensitivity of the device at $30{ }^{\circ} \mathrm{C}$ is as low as $0.08{ }^{\circ} \mathrm{C}$. The imaging performance for the camera has a spatial resolution of $1.3 \mathrm{mrad}$ and the infrared image capture rate can go as high as 60 frames per second. It is possible to capture and store images on a removable flash card. The camera also features burst recording functionality that allows the user to record sequences of events into the internal RAM memory. The images that the camera produces can be analyzed either in the field by using the real-time measurement markers built into the camera software, or in a PC using FLIR Systems software (FLIR Systems 2002a). The software ThermaCAM ${ }^{\mathrm{TM}}$ Researcher 2002, which is used along with the camera, deals with the live IR images arriving through the camera interface. It can also receive IR images from other media, such as PC card hard disk from the camera. The analysis of the images can be made with the various analysis tools like isotherm, spotmeter, area and line. The temperature corresponding to any point can be obtained by using the spot temperature measurement option offered by the software. In other words, we can obtain detailed information at 
every pixel. Since the camera captures fully radiometric digital images, a reference image can be subtracted from the full image sequence to achieve better results in terms of detectability of defects and to conduct a quantitative analysis (FLIR Systems 2002b).

\subsubsection{Shop Heater}

The shop heater shown in Figure 3-6 can be used to heat the specimens placed in any position. This heater can also be operated in two power settings, 750 and 1500 Watts.

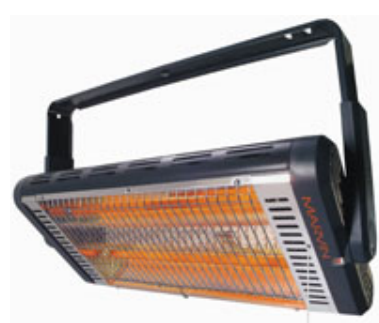

Figure 3-6 Shop heater

The plan size of the heater is 24 " $\mathrm{x} 12$ " $(0.6096 \mathrm{~m} \times 0.3048 \mathrm{~m})$ and its thickness is 3 " $(0.0762 \mathrm{~m})$. The safety features include automatic tip-over and overheat shut off. One of the disadvantages of this heater is that it does not have an in-built fan.

The basic Infrared Thermography setup for laboratory testing of wrapped cylinders is shown in Figure 3-7.

\subsection{COMPRESSION-TESTING}

\subsubsection{Universal Compression-Testing Machine}

The universal compression-testing machine used in this study to measure the failure load of the concrete specimen had two load indicator dials. One has a maximum capacity of 60 kips while the second one can read loading up to 350 kips. For this research, the higher scale was used since a higher load carrying capacity was anticipated with the cylinders being wrapped with 3 layers of FRP fabrics. Figure 3-8 shows the universal compression-testing machine. 


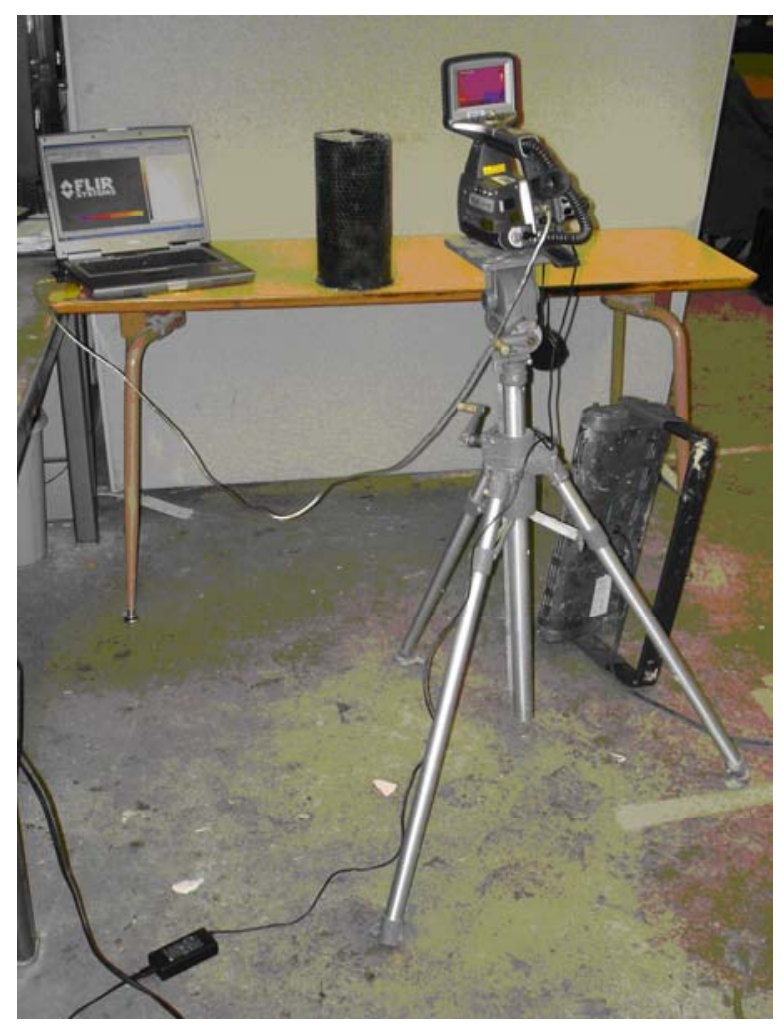

Figure 3-7 Laboratory setup for infrared testing of wrapped cylinders

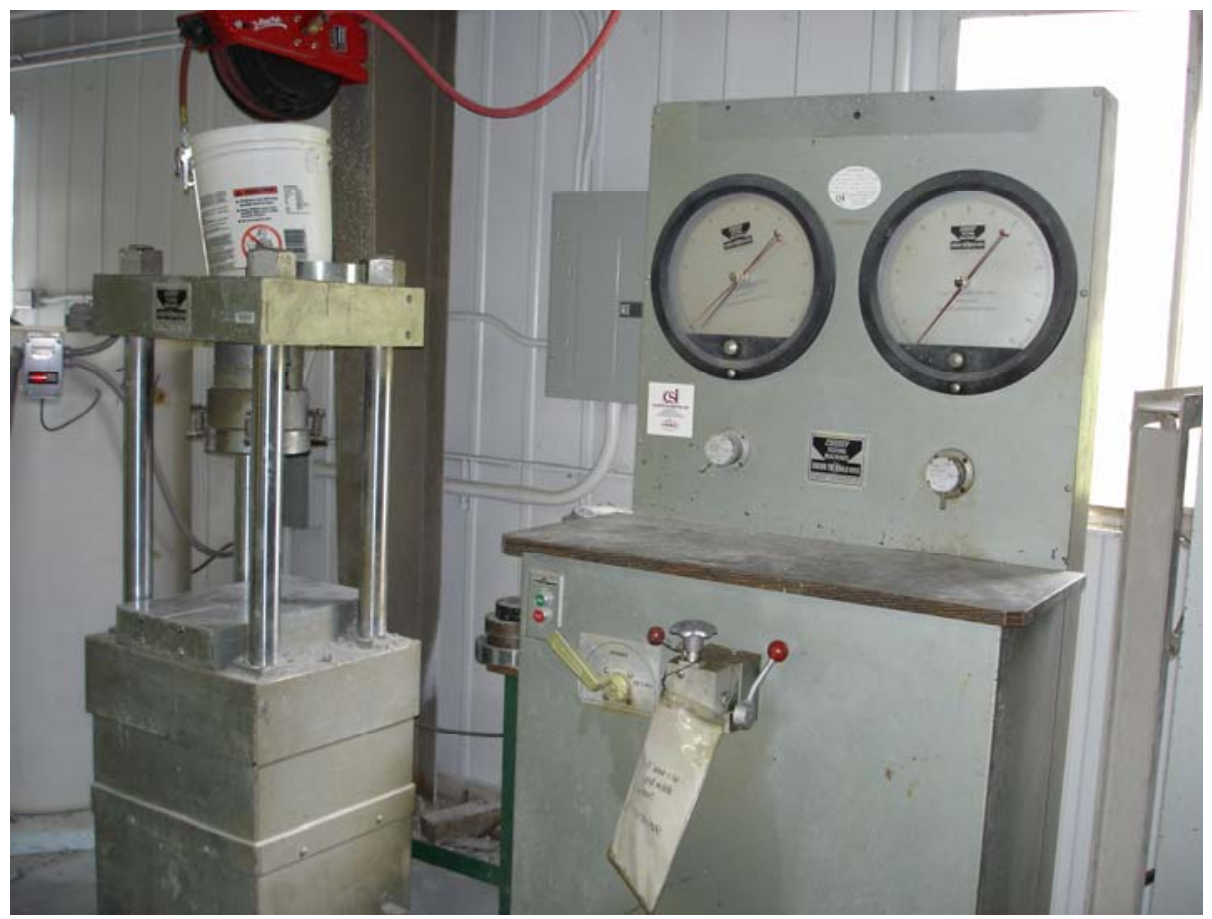

Figure 3-8 Universal compression testing machine 


\section{CHAPTER 4}

\section{LABORATORY EXPERIMENTS, ANALYSIS AND RESULTS}

Fiber reinforced polymer wraps have been used extensively for providing confinement and thereby increasing the load carrying capacity of tension carrying members and columns (Godinez-Azcuaga et al. 2004). Fiber reinforced polymer wraps are also being used to repair, retrofit and rehabilitate infrastructure. They play a significant role in increasing the earthquake resistance of concrete structures by increasing the energy absorption capacity (Toutanji 1999). However, for all the aforementioned goals to be achieved, a proper bonding between the FRP wraps and the underlying material is of utmost importance. Constant monitoring and evaluation of these composite components becomes essential to ensure continued structural integrity. This chapter discusses the laboratory experiments conducted in order to establish the applicability of GPR and digital Infrared Thermography in inspecting concrete columns wrapped with FRP. The chapter also focuses on the effect of subsurface debonds on the axial compressive strength of concrete cylinders. Details of the conducted tests along with the analysis and results are presented in this chapter.

\subsection{PREPARATION OF THE SPECIMENS}

This section discusses the preparation of the wrapped concrete cylinders with simulated subsurface debonds that were used for the experimental testing.

\subsubsection{Casting of Concrete Cylinders}

Thirty nine concrete cylinders were caste for this research. While casting, demolding agent was applied inside the surface of the molds. The size of the cylinders was 6" x 12" (152.4 mm x $304.8 \mathrm{~mm})$, which is a standard cylinder size specified by ASTM/ACI. Concrete used to cast the cylinders was provided by Hoy Redi-Mix, Morgantown. This concrete was designed to have a compressive strength of $4000 \mathrm{psi}$. Cylinders were cast at Hoy Redi-Mix plant in accordance with the ASTM standards and were left there to set in the mold for initial 48 hours. Cylinders were covered with plastic sheet in order to prevent moisture loss during initial curing. After two days, the cylinders were transported to the NDE laboratory, taken out from the molds and cured under 
ambient conditions $\left(\sim 70^{\circ} \mathrm{F}\right)$ by submerging in water tanks for 28 days. After 28 days of curing, the cylinders were taken out and allowed to dry for 7 days. Then 5 cylinders were crushed using a 350 kips capacity universal compression testing machine in order to measure the average compressive strength of the cylinders. It should be noted that all the cylinders used in this study were plain concrete cylinders without any internal reinforcement. Some of the cylinders were later wrapped with FRP fabrics prior to testing.

\subsubsection{Making of Debonds}

Various subsurface debonds were created between the FRP wraps and the underlying concrete cylinders to simulate debonded specimens. Debond refers to a defect that is present between the composite wrap and the underlying concrete surface. The cylinders with the debonds were nondestructively evaluated using GPR and Infrared Thermography and subsequently crushed to investigate the effect of debonds on axial compressive strength. Two types of debonds namely air-filled debond and water-filled debond were used in this study. Debonds were made into three plan sizes: 3" x 3" (76.2 $\mathrm{mm}$ x $76.2 \mathrm{~mm}), 2$ " x 2" (50.8 mm x $50.8 \mathrm{~mm})$ and 1.4" x 1.4" (35.56 mm x 35.56 $\mathrm{mm})$. Thickness of all debonds were $1 / 10$ " (2.54 mm).

Air-filled debonds were made by cutting small stripes of plastic sheets and gluing them along the boundary as spacers. The spacers were then glued in between two plastic sheets of the same size so that an air pocket of desired thickness was enclosed between the two sheets. Curved plastic containers were used in this case so that the debonds would fit snuggly on the surface of the curved concrete cylinders. Water-filled debonds were made by filling water in custom made polyethylene pouches. As custom made pouch of size 1.4" x 1.4" (35.56 mm x $35.56 \mathrm{~mm})$ could not be procured, water-filled debond of that size was made from 3" x 3" size with the help of an impulse sealer. Although care was taken to fill the pouches with the amount of water that made them 1/10" $(2.54 \mathrm{~mm})$

thick, some air bubbles were trapped inside which could not be avoided. Figure 4-1 and Figure 4-2 show the air-filled debonds and the water-filled debonds, respectively. 


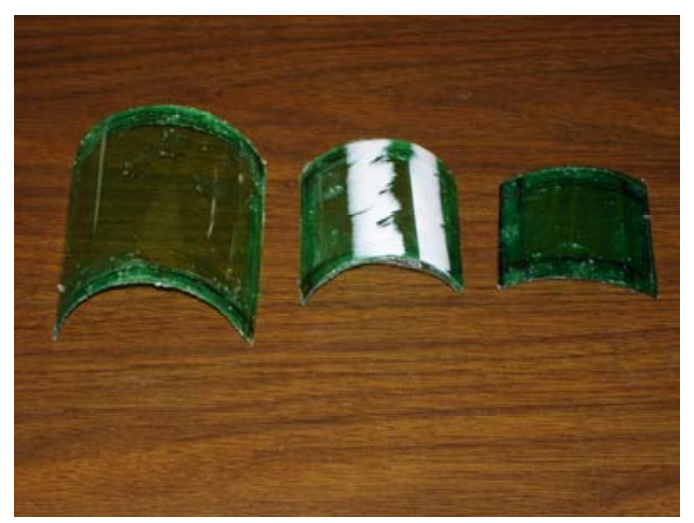

Figure 4-1 Air-filled debonds

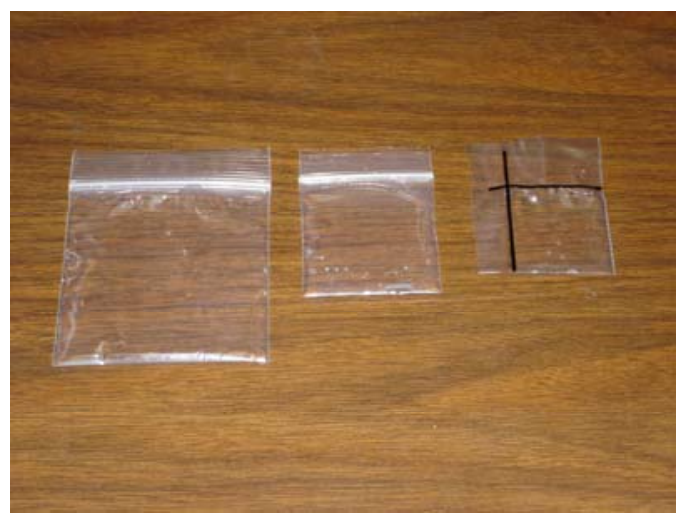

Figure 4-2 Water-filled debonds

\subsubsection{Wrapping of Cylinders}

The surfaces of the cured concrete cylinders were cleaned with a brush so as to obtain a clean, dry surface. The fiber reinforced fabrics used to wrap the cylinders were of two types: carbon FRP and glass FRP. Carbon fiber tow sheet that was used in this research (Figure 4-3) was manufactured by Tonen Corporation, Japan. The sheet was made of unidirectional fibers $\left(0^{\circ}\right)$ and the fibers were resistant to moisture, bases and weak acids (Rajappa 2004). Table 4-1 contains the properties of the carbon fiber tow sheet as given by the manufacturer. The glass FRP fabric (Figure 4-4) was obtained from Bedford Plastics, Pennsylvania 


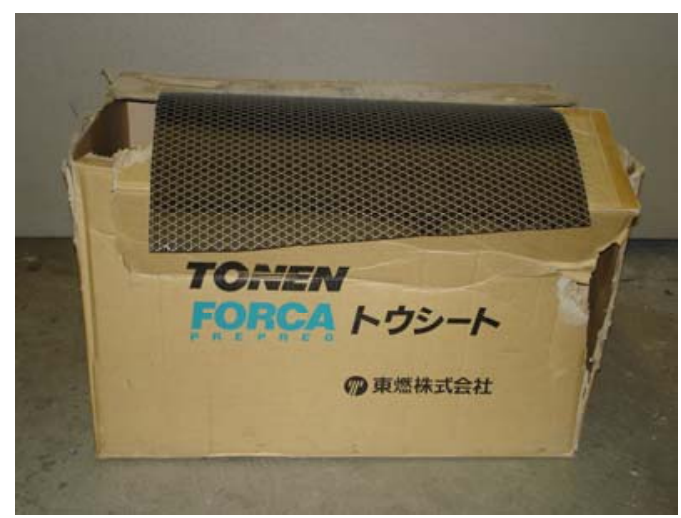

Figure 4-3 Carbon fiber tow sheet

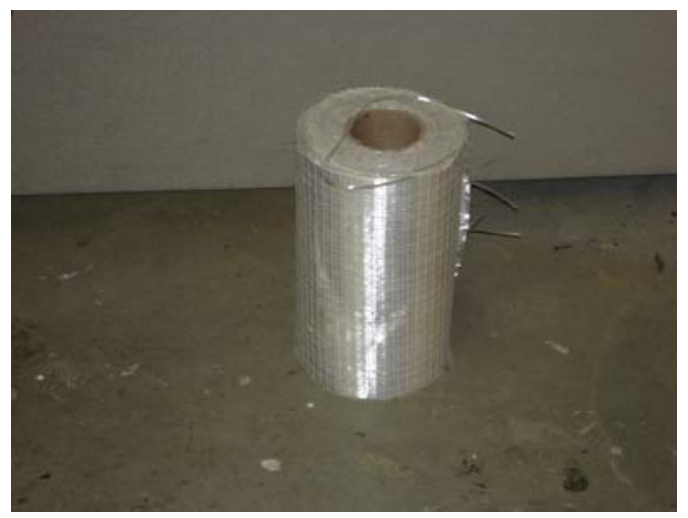

Figure 4-4 Glass FRP fabric

Table 4-1 Properties of carbon fiber tow sheet (Tonen Co., Japan, Manufacturer)

\begin{tabular}{|c|c|}
\hline Design Thickness Based on Single Uncoated Fabric & 0.004 " $(0.1 \mathrm{~mm})$ \\
\hline Tensile Strength & $22 \mathrm{kip} / \mathrm{inch}(382 \mathrm{~N} / \mathrm{mm})$ \\
\hline Tensile Modulus & $33 \mathrm{Msi}\left(23.03 \times 10^{4} \mathrm{~N} / \mathrm{mm}^{2}\right)$ \\
\hline Ultimate Strain & $1.5 \%$ or .015 \\
\hline Density & $0.056 \mathrm{bs} / \mathrm{in}^{3}$ \\
\hline Shear Modulus & $7687 \mathrm{Ksi}$ \\
\hline Poisson's Ratio & 0.28 \\
\hline
\end{tabular}

In case of the Glass FRP fabric, the orientation of fibers was $0^{\circ} / 90^{\circ}$. An epoxy resin known as Tyfo S Saturant Epoxy manufactured by Fyfe Co. LLC was used as the matrix to bind the FRP wraps (both glass and carbon wraps) to the concrete surface. The adhesive had two parts: Part A (resin) and Part B (Hardener) (Figure 4-5). 


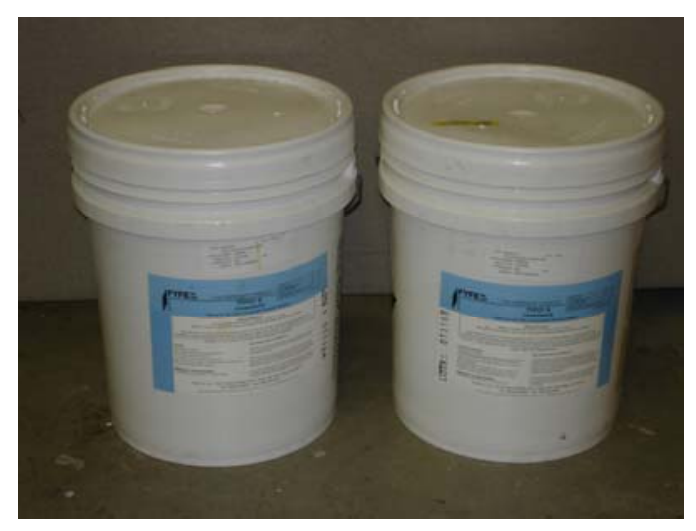

Figure 4-5 Tyfo S Saturant Epoxy (Type A and Type B)

The mix ratio for the two parts was 100 parts of component A to 42 parts of component B by volume. Properties of the TYFO S Saturant Epoxy supplied by the manufacturer are furnished in Table 4-2.

Table 4-2 Properties of TYFO S Saturant Epoxy (Fyfe Co. LLC 2000)

\begin{tabular}{|c|c|}
\hline Tensile Strength & $10500 \mathrm{psi}$ \\
\hline Tensile Modulus & $461000 \mathrm{psi}$ \\
\hline Elongation percent & $5 \%$ \\
\hline Flexural Strength & $17900 \mathrm{psi}$ \\
\hline Flexural Modulus & $452000 \mathrm{psi}$ \\
\hline Curing time & 72 hours at $60^{\circ} \mathrm{C}$ \\
\hline
\end{tabular}

The wrapping procedure is explained below and is shown from Figure 4-6 to Figure 4-10.

- The FRP sheets were cut to cover the circumference of the cylinder with an extra overlap length of $\sim 3$ ',

- The epoxy component A and component B were mixed in the given ratio with a low speed mixer at 400-600 rpm until the components were mixed thoroughly.

- Epoxy was applied on both sides of the FRP wraps and also to the concrete surface with a brush. Extra epoxy was stroked off with a plastic trowel.

- FRP fabrics were wrapped around the cylinder and were gently pressed with a plastic trowel in order to remove any unwanted air bubbles.

- The cylinders were left to cure at room temperature for five days. 


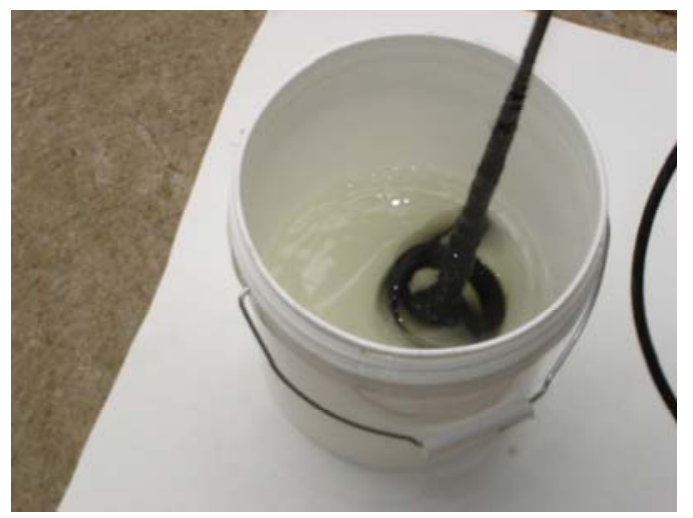

Figure 4-6 Mixing the two parts of the resin with a low speed mixer

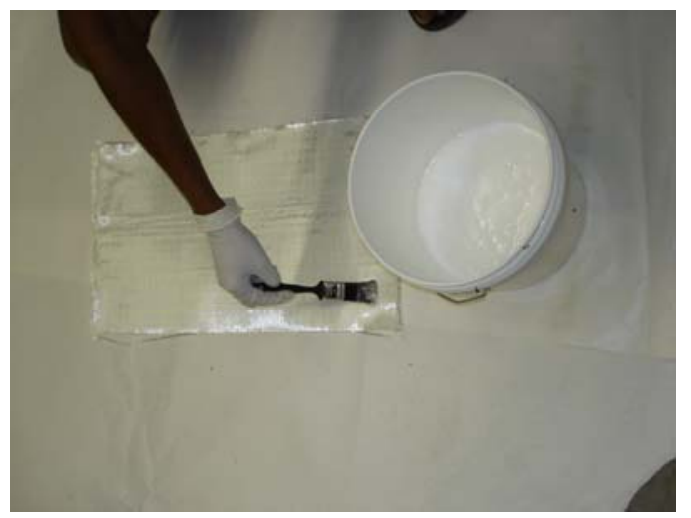

Figure 4-7 Applying the mixed resin on FRP sheets

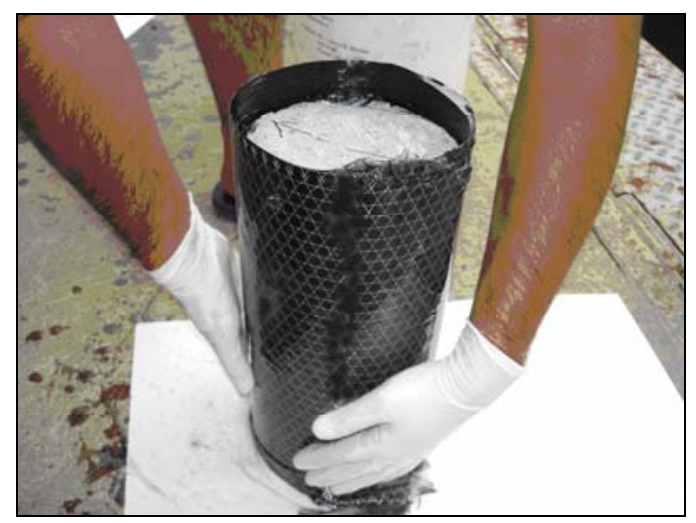

Figure 4-8 Wrapping the cylinders with FRP sheets 


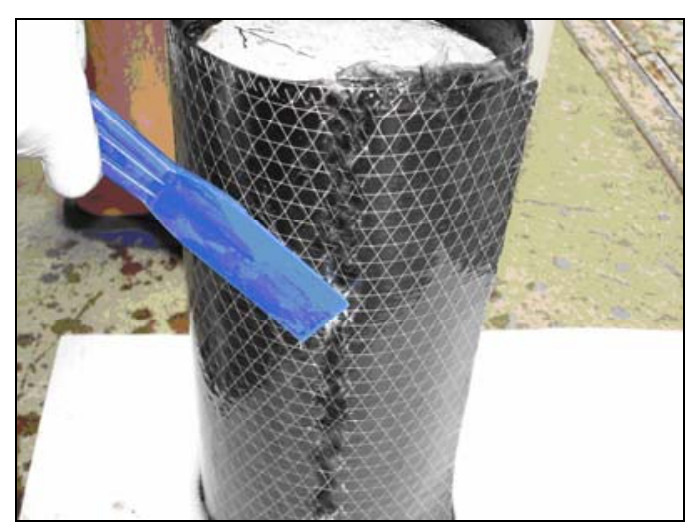

Figure 4-9 Removing air bubbles

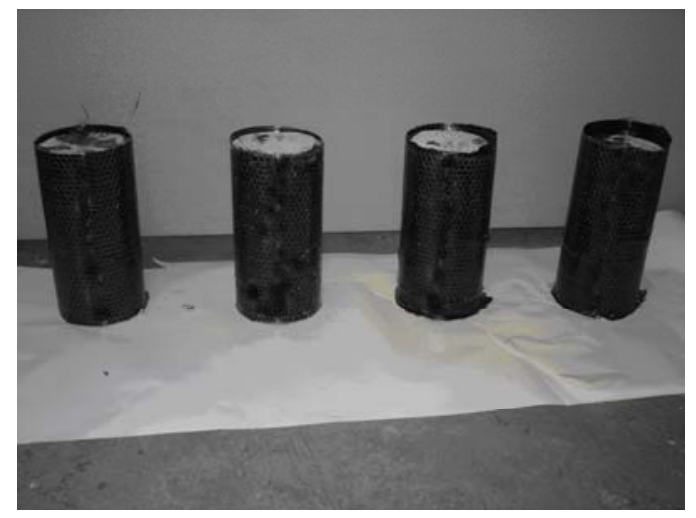

Figure 4-10 Curing the FRP wrapped cylinders

A total of 39 concrete cylinders were cast and 5 of them were tested for compressive strength. Out of the remaining 34 cylinders, 28 were wrapped with FRP wraps with debond inserted between the FRP wrap and concrete surface and 6 were wrapped with FRP wraps without debonds. These 6 cylinders were used as control specimens to relate area of debond to the reduction in compressive strength. All the cylinders were wrapped with 3 layers of CFRP and GFRP fabric. Table 4-3 lists the setup of debonds in the 28 cylinders that were numbered from 1 to 28 . The cylinders are referred using this numbering system here onwards. The debonds were inserted in diametrically opposite location maintaining diametrical symmetry. 
Table 4-3 Setup of debonds

\begin{tabular}{|c|c|}
\hline $\begin{array}{c}\text { Column } \\
\text { No }\end{array}$ & Setup of debonds \\
\hline \multicolumn{2}{|r|}{ Wrapped With GFRP } \\
\hline 1 & one 1.4" x 1.4" air-filled debond on each side \\
\hline 2 & one $2 "$ × 2" air-filled debond on each side \\
\hline 3 & one 3 " x 3" air-filled debond on each side \\
\hline 4 & one 2" x 2" and one 1.4"x 1.4" air-filled debond on each side \\
\hline 5 & one 3" x 3" and one 1.4"x 1.4" air-filled debond on each side \\
\hline 6 & one $3 "$ x $3 "$ and one $2 " x$ 2" air-filled debond on each side \\
\hline 7 & $\begin{array}{c}\text { one 3" x 3", one 2"x 2", and one 1.4" x 1.4" air-filled debond on } \\
\text { each side }\end{array}$ \\
\hline 8 & one $1.4 "$ x $1.4 "$ water-filled debond on each side \\
\hline 9 & one $2 " \mathrm{x} 2$ " water-filled debond on each side \\
\hline 10 & one 3" x 3" water-filled debond on either side \\
\hline 11 & one 2" x 2" and one 1.4"x 1.4" water-filled debond on each side \\
\hline 12 & one 3" x 3" and one 1.4"x 1.4" water-filled debond on each side \\
\hline 13 & one 3" x 3" and one 2"x 2" water-filled debond on each side \\
\hline 14 & $\begin{array}{c}\text { one 3" x 3", one 2"x 2" and one 1.4" x 1.4" water-filled debond } \\
\text { on each side }\end{array}$ \\
\hline \multicolumn{2}{|r|}{ Wrapped With CFRP } \\
\hline 15 & one 1.4" x 1.4" air-filled debond on each side \\
\hline 16 & one $2 " \times 2$ " air-filled debond on each side \\
\hline 17 & one $3 "$ " 3 " air-filled debond on each side \\
\hline 18 & one 2" x 2" and one 1.4"x 1.4" air-filled debond on each side \\
\hline 19 & one 3" x 3" and one 1.4"x 1.4" air-filled debond on each side \\
\hline 20 & one 3" x 3" and one 2"x 2" air-filled debond on each side \\
\hline 21 & $\begin{array}{c}\text { one 3" x 3", one 2"x 2", and one 1.4" x 1.4" air-filled debond on } \\
\text { each side }\end{array}$ \\
\hline 22 & one $1.4 "$ x 1.4 " water-filled debond on each side \\
\hline 23 & one $2 "$ x 2" water-filled debond on each side \\
\hline 24 & one 3" x 3" water-filled debond on either side \\
\hline 25 & one 2 " $x 2$ " and one $1.4 " \mathrm{x} 1.4$ " water-filled debond on each side \\
\hline 26 & one 3" x 3" and one 1.4"x 1.4" water-filled debond on each side \\
\hline 27 & one 3" x 3" and one 2"x 2" water-filled debond on each side \\
\hline 28 & $\begin{array}{l}\text { one 3" x 3", one 2"x 2" and one 1.4" x 1.4" water-filled debond } \\
\text { on each side }\end{array}$ \\
\hline
\end{tabular}

\subsection{DETECTION OF DEBONDS BY IRT}

The following sections describe the laboratory results for detecting debonds using Infrared Thermography. The experimental setup for the laboratory experiments using 
Infrared Thermography is already discussed in the previous chapter. In all the experiments, a shop heater described in the previous chapter was used to heat the specimen. The distance of the specimens from the infrared camera during the experiments was 3 feet. All data were processed with the help of ThermaCAM $^{\mathrm{TM}}$ Researcher 2002 software.

\subsubsection{Detection of Debonds in Cylinders Wrapped with GFRP}

\subsubsection{Detection of 1.4'" x 1.4', Air-Filled Debond}

The photographic view of one side of the cylinder no 1 showing the location of the 1.4" x 1.4" debond is shown in Figure 4-11. After placing the debond, the cylinder was wrapped with three layers of GFRP fabric.

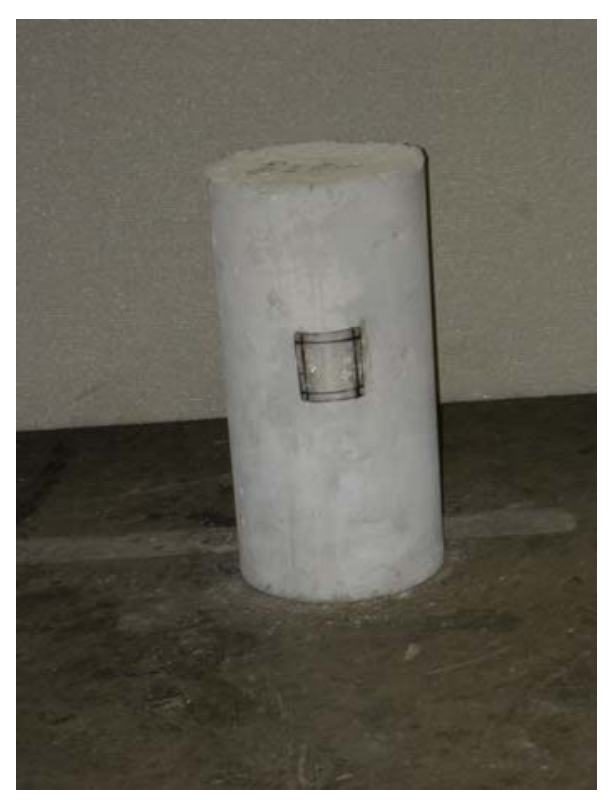

Figure 4-11 Cylinder no 1 with 1.4"' x 1.4"' air-filled debond at the center

The infrared image taken after heating the debonded side clearly shows the 1.4" $\mathrm{x}$ 1.4" air-filled debond as a region of higher temperature (white area in the infrared image) with respect to the surrounding defect-free regions (Figure 4-12). This is expected as air has a substantially lower thermal conductivity value compared to GFRP (see values in Table 2-2) and hence an air-filled debond acts as a thermal insulator. Since the heat can not conduct efficiently through the air-filled debond, the thermal energy gets trapped in the FRP layers above the debond which leads to higher surface temperature above the 
debonded area compared to the sound areas. The color scale showing the temperature profile over the surface of the cylinder is also shown in Figure 4-12.

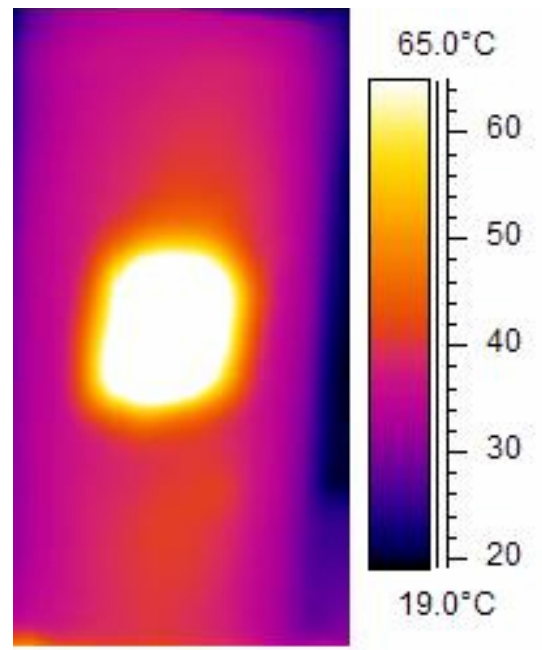

Figure 4-12 Infrared image of cylinder no 1 showing the air-filled debond

\subsubsection{Detection of 2"' x 2"' Air-Filled Debond}

Figure 4-13 shows the digital picture of cylinder no 2 showing the debond location.

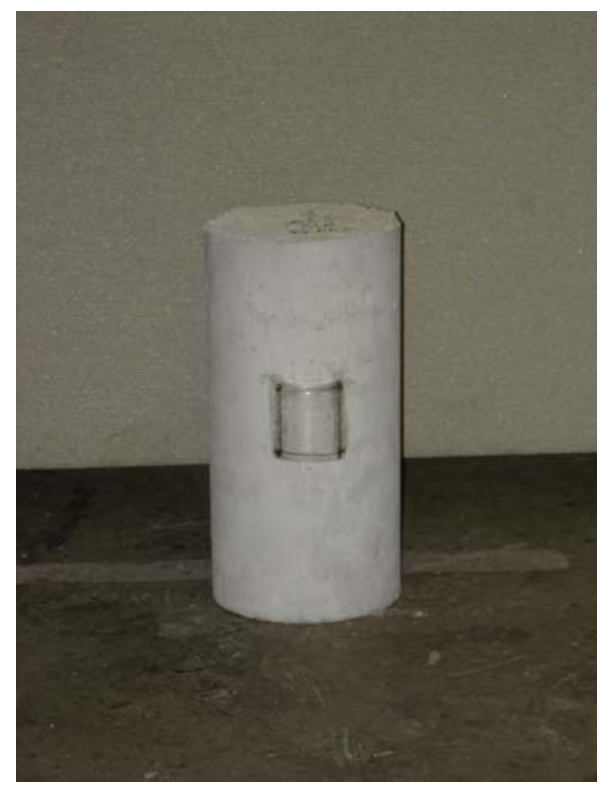

Figure 4-13 Cylinder no 2 with 2" x 2" air-filled debond at the center 
In this case also, the 2" x 2" air-filled debond was identified with ease. The corresponding infrared image with the color scale is shown in Figure 4-14, and it clearly reveals the debond.

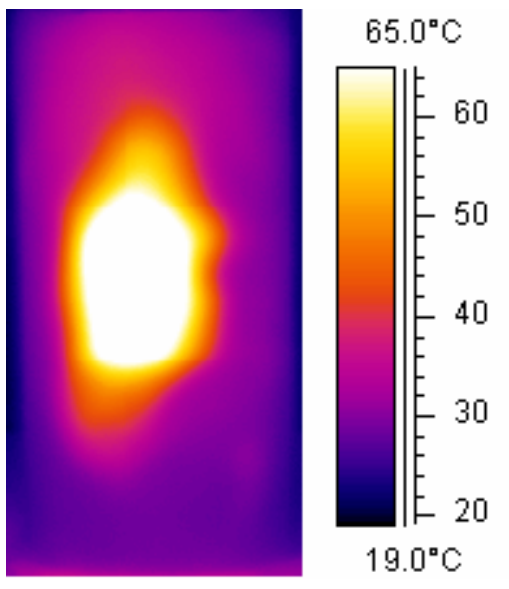

Figure 4-14 Infrared image of cylinder no 2

\subsubsection{Detection of 3"' $x$ 3"' Air-Filled Debond}

Figure 4-15 presents the digital picture of one side of cylinder no 3 with 3" x 3 "' air-filled debond.

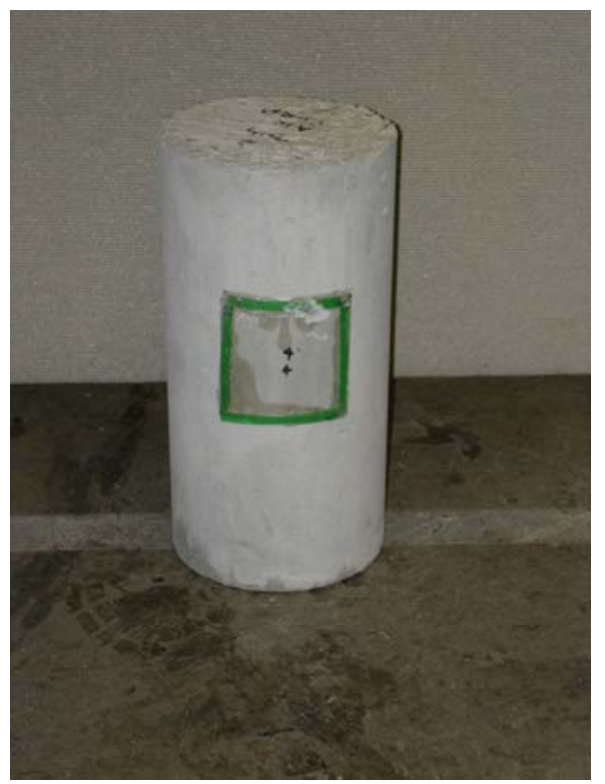

Figure 4-15 Cylinder no 3 with 3" $x$ 3"' air-filled debond at the center 
The infrared image (Figure 4-16) clearly shows the debond. In this case, the boundary of the square is not revealed because of the additional air gaps formed outside the edges of the air-filled debond during wrapping.

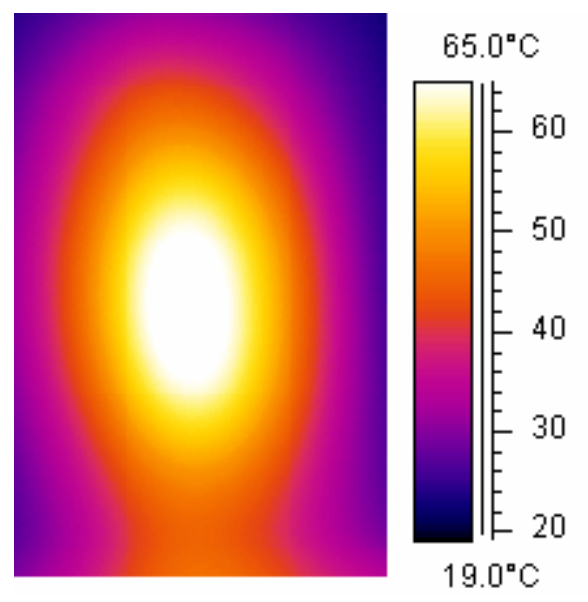

Figure 4-16 Infrared image of cylinder no 3

\subsubsection{Detection of Water-Filled Debonds}

Water-filled debonds of any of the sizes i.e., 1.4" x 1.4", 2" x 2" and 3" x 3" could not be detected by Infrared Thermography technique. Digital pictures of cylinder no 8, 9 and 10 showing the locations of the water-filled debonds of sizes 1.4" x 1.4", 2", x 2" and 3" x 3"' are shown in Figure 4-17, Figure 4-18 and Figure 4-19 respectively.

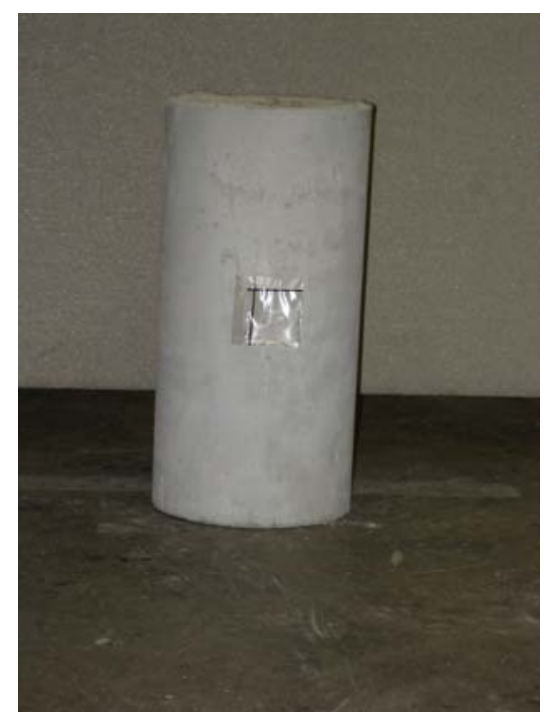

Figure 4-17 Cylinder no 8 with 1.4" $x$ 1.4" water-filled debond at the center 


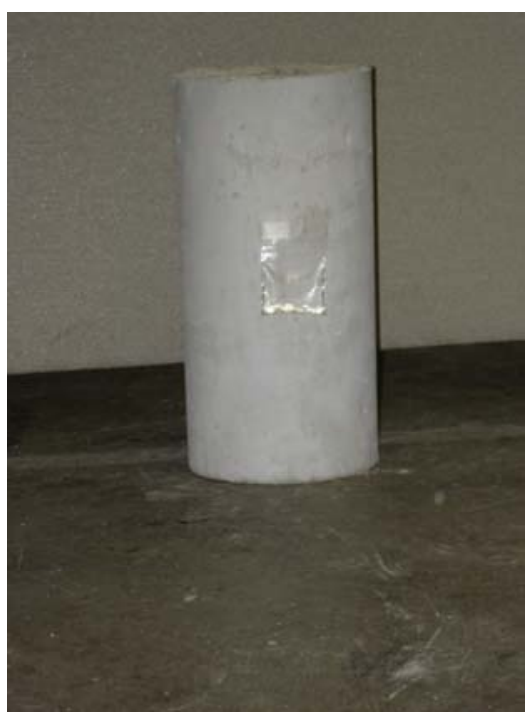

Figure 4-18 Cylinder no 9 with 2"' $x$ 2"' water-filled debond at the center

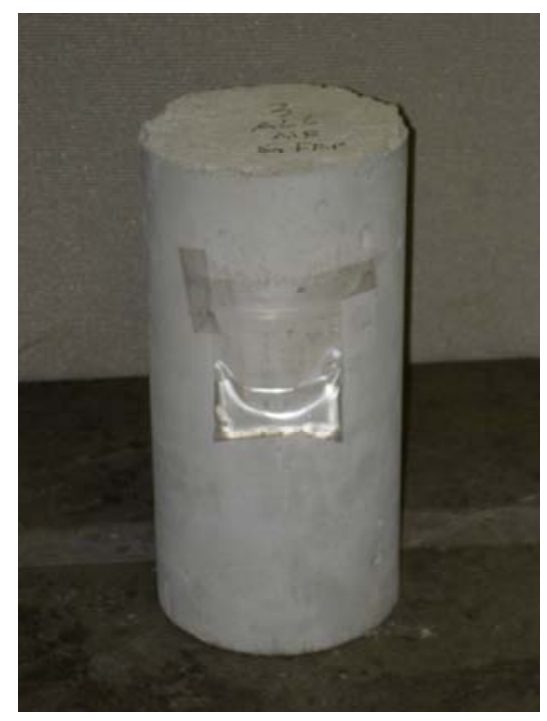

Figure 4-19 Cylinder no 10 with 3" $x$ 3" water-filled debond at the center

As mentioned earlier, each cylinder had identical debonds placed in diametrically opposite locations to maintain symmetry. The cylinders with water-filled debonds were heated for a longer duration ( $\sim 5$ minutes) because of the fact that water has a high specific heat thus requiring a longer duration for the water to get heated up. According to the principle of conductive heat transfer, a water-filled debond which has a high thermal conductivity compared to GFRP fabrics (see values in Table 2-2) should show up as a cold spot or in other words, surface temperature of the region above the water-filled debond should be lower compared to the surface temperature of the region above the 
defect-free areas. This is attributed to the fact that water has a higher thermal conductivity value compared to GFRP and hence conducts heat at a faster rate than the defect-free area. However, in our test, the water-filled debonds showed up as hot spots giving the indication of an air gap. This was again because of high specific value of water which meant that water stored a significant amount of heat after prolonged heating thus giving a false impression by appearing as an air-filled debond. Figure 4-20 shows the infrared images of the cylinders where the water-filled debonds appear as "hot spots" with no clear boundary of the water-

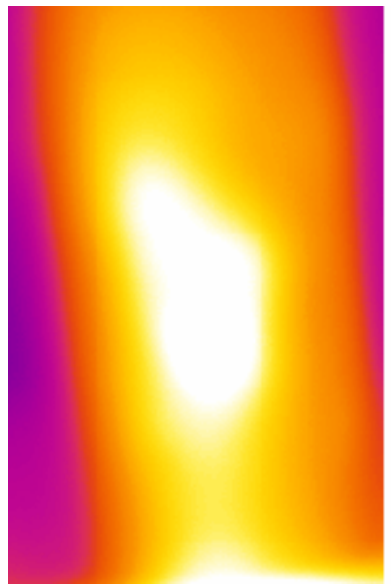

(a)

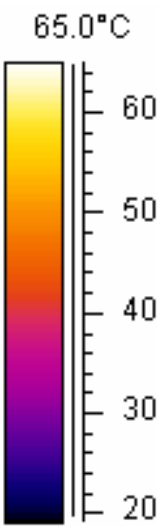

$19.0^{\circ} \mathrm{C}$
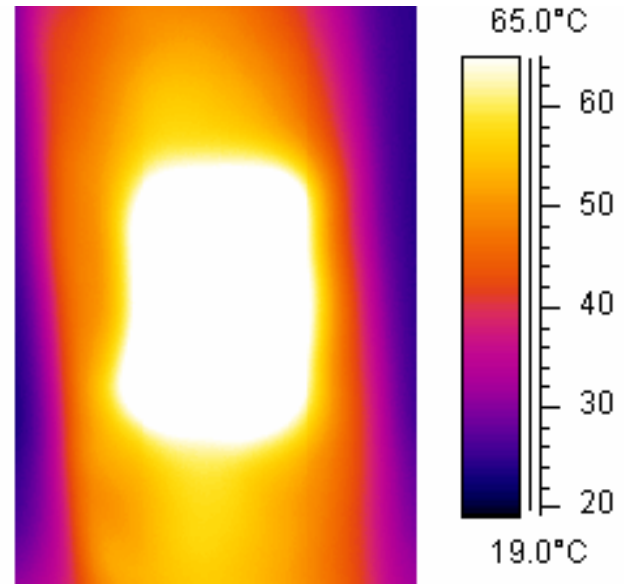

(b)
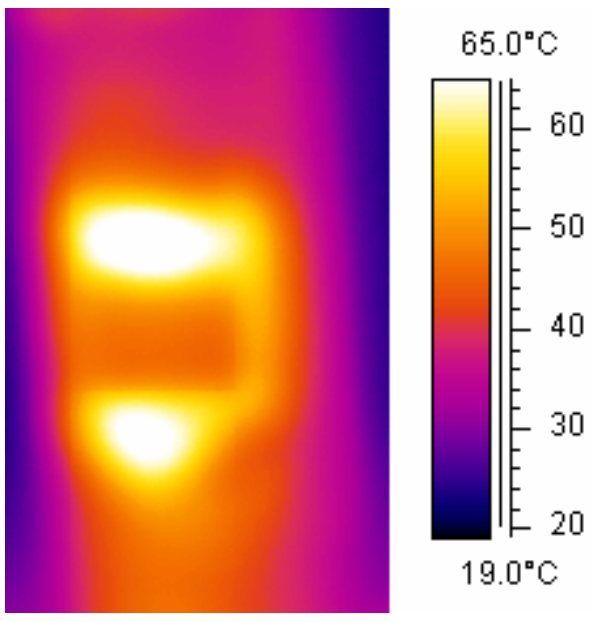

(c)

Figure 4-20 Infrared image of water-filled debonds in (a) cylinder no 8 (1.4" x 1.4" debond), (b) cylinder no 9 (2" x 2" debond), and (c) cylinder no 10 ( 3 " x 3" debond) 
filled debonds being defined in any of the images. The debond appears quite large in Figure 4-20(b) due to air gaps around the edges which were created while wrapping over the debonds. The bright regions at the top and bottom of the debond in Figure 4.20(c) also indicate the presence of air gaps around the debond. However, the actual debond in Figure 4-20(c) shows a smaller temperature difference compared to the smaller debonds in Figures 4-20(a) and 4-20(b). This could be because of the larger water body with higher capacity to absorb heat with only a small temperature change. This debond was later tested using GPR (section 4.3) which confirmed the presence of water in the debond.

\subsubsection{Detection of Debonds in Cylinders Wrapped with CFRP}

\subsubsection{Detection of 1.4' $x$ 1.4', Air-Filled Debond}

Air-filled debond of size 1.4" x 1.4" inserted between the CFRP wrap and concrete surface could be easily identified as a bright square region (area with higher surface temperature compared to surrounding area). Figure 4-21 gives the infrared image of the cylinder no 15 obtained after the application of heat.

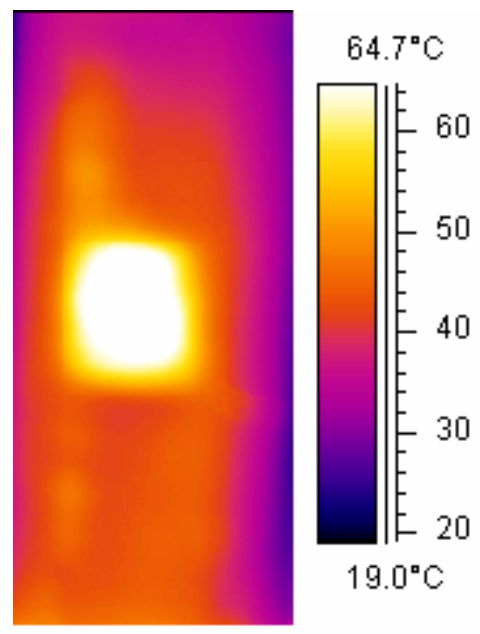

Figure 4-21 Infrared image of cylinder no 15

\subsubsection{Detection of 2"' x 2"' Air-Filled Debond}

Figure 4-22 represents the infrared image of one side of cylinder no 16 with a 2" x 2" air-filled debond. While the infrared image shows the debond very prominently, the debond appears to be longer in the vertical direction. This is due to the air pockets around the debond created during the wrapping process.. 


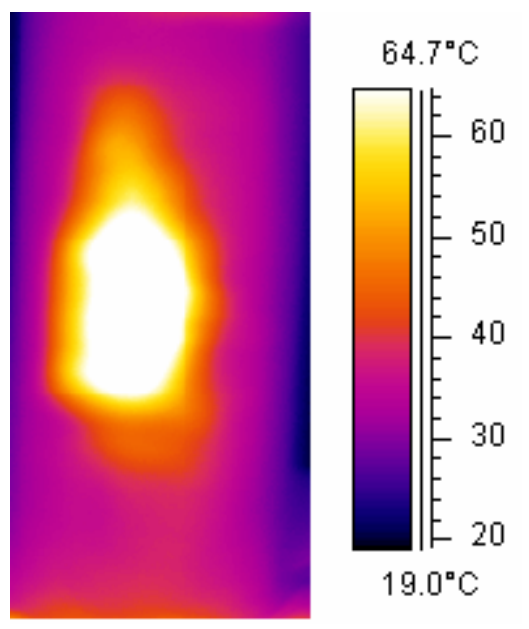

Figure 4-22 Infrared image of cylinder no 16

\subsubsection{Detection of 3' $x$ 3'" Air-Filled Debond}

Figure 4-23 gives the infrared image of the cylinder no 17 in which the boundary of the 3" x 3"' air-filled debond cannot be seen prominently. The debond appears to be elongated vertically because of air pockets above and below the debond. Those air pockets are also appearing as areas of higher temperature in the infrared image.

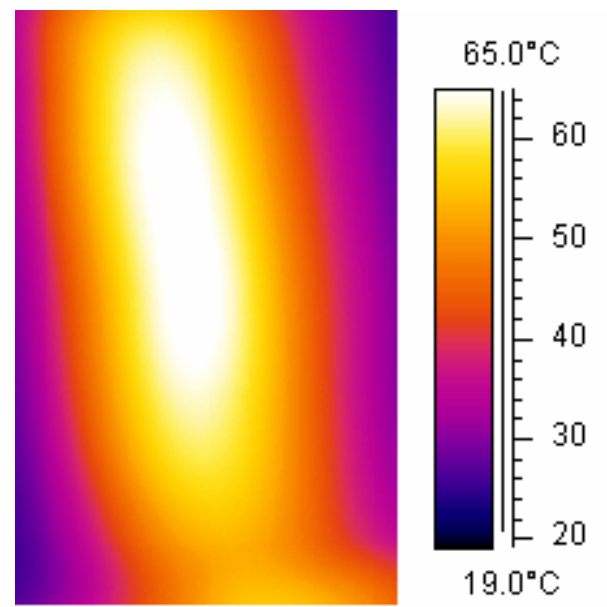

Figure 4-23 Infrared image of cylinder no 17

\subsubsection{Detection of Water-Filled Debonds}

Water-filled debonds were also detected as "hot spots" by the Infrared Thermography technique. After the heating of few minutes, the water-filled debonds 
showed up as regions of higher temperature. This phenomenon was explained above and has more to do with water's high specific heat rather than its thermal conductivity.

Infrared images of cylinder no 22, 23, 24 are shown from Figure 4-24(a) to 424(c) where the water-filled debonds appear as 'hot spots'. Also, in these CFRP wrapped cylinders, the observed "hot spot" is larger for the larger debond.

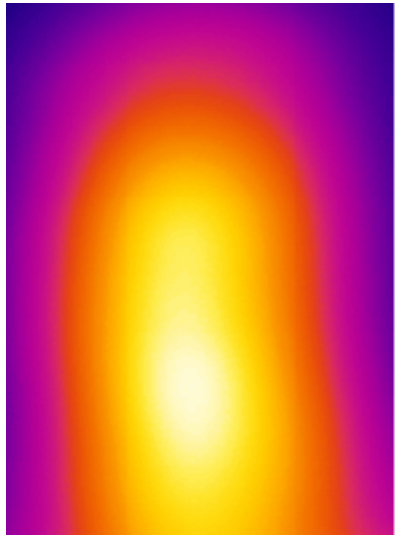

(a)
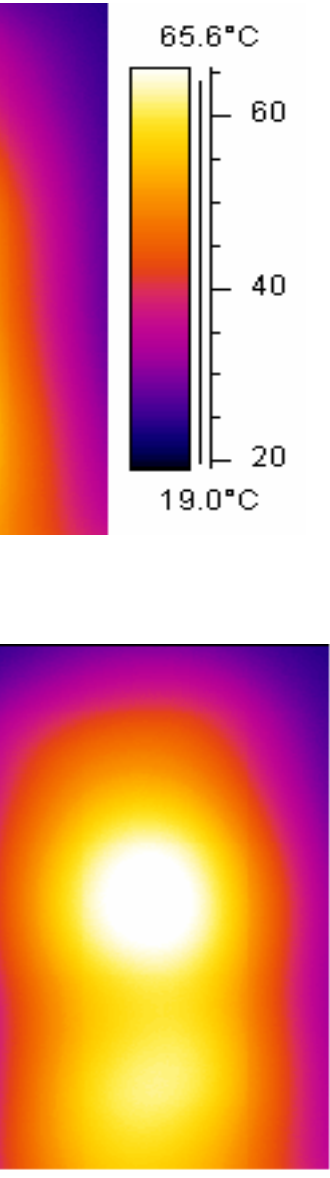

(c)

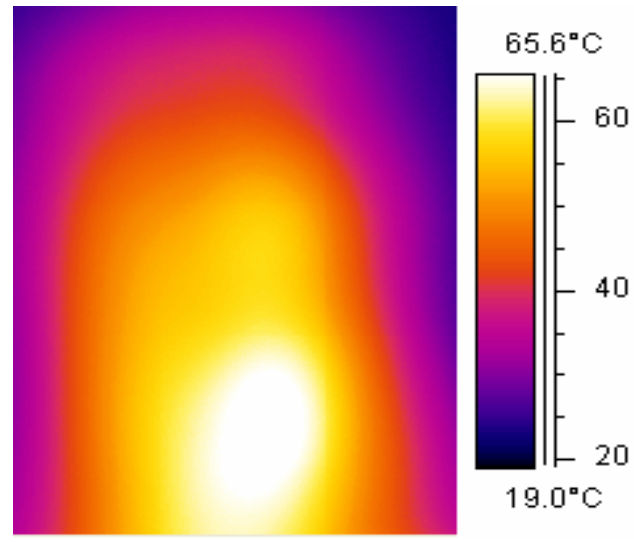

(b)

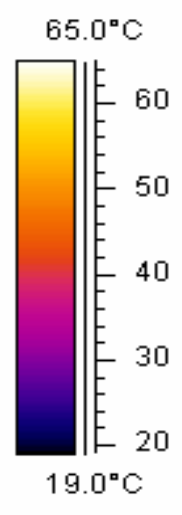

Figure 4-24 Infrared image of water-filled debonds in (a) cylinder no 22 (1.4" x 1.4" debond), (b) cylinder no 23 (2" x 2" debond), and (c) cylinder no 24 (3" x 3" debond)

\subsubsection{Effect of Input of Lower Heat Energy}

So far the cylinders containing water-filled debonds were being heated for 5 minutes. This was because of high specific heat value of water resulting in longer time for water to get heated. In the process, water-filled debonds were getting revealed as 'hot spots'. Cylinder no 26 was heated for 3.5 minutes and with 750 Watts power setting of 
the shop heater to observe the behavior of water-filled debonds under less heating. In this case also, surface temperatures above the water-filled debonds were higher than the surface temperature of the region above the sound area giving the impression of an air pocket. Figure 4-25 shows the infrared image of one side of cylinder no 26 during the cooling phase.
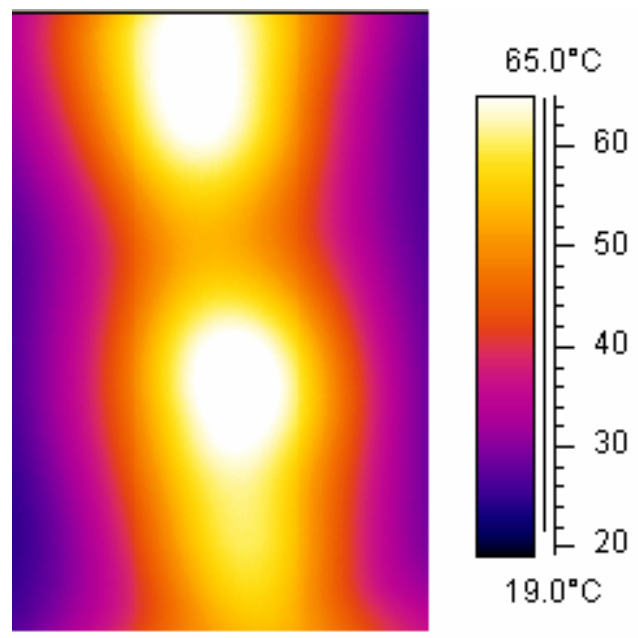

Figure 4-25 Infrared image of cylinder no 26 (3" x 3" water-filled debond on the top and 1.4" $x$ 1.4" water-filled debond on the bottom)

\subsubsection{Conclusions}

Digital Infrared Thermography has successfully detected the presence of air-filled debonds of sizes 3" x 3", 2" x 2" and 1.4" x 1.4" in concrete columns wrapped with CFRP and GFRP. The boundary of the 3" x 3" air-filled debond was not clearly seen because of the air pockets that were formed above and below the air-filled debond. Also, water-filled debonds appeared as air debonds or 'hot spots'. This is due to the fact that the thickness of the FRP wraps were very small and hence even a small amount of heat that was applied was quickly absorbed by water-filled debonds, resulting in hot spots above the debond.

\subsection{DETECTION OF DEBONDS BY GPR}

The objective of this portion of the research was to evaluate the sensitivity of Ground Penetrating Radar in detecting subsurface debonds. In this study, the FRP wrapped cylinders with simulated debonds inserted between the FRP fabric and the 
concrete surface were scanned using GSSI's SIR-20 unit along with the $1.5 \mathrm{GHz}$ groundcoupled antenna. The acquired data was processed with the help of RADAN 5.0 post processing software provided by GSSI (2003).

The data range for this study was set to 4 nanoseconds for CFRP wrapped cylinders and 3 nanoseconds in case of GFRP wrapped cylinders. Also, the data collection parameter was set to collect 512 points for each signal trace. This enabled a faster rate of data collection while ensuring high resolution at the regions where clarity of acquired data was required. The values of the ranges that were set were based on the values of dielectric constants for both types of wraps. The dielectric constants for the wraps were computed using the procedure that was described in Chapter 2 using Equations 2.9 and 2.10. The information on dielectric constant is important because SIR20 system needs user to input the dielectric constant value of the first medium that the GPR antenna will encounter. Dielectric constant for GFRP was found to be low $(\sim 6)$ and that for CFRP was computed to be higher $(\sim 30)$. These values were obtained using the 1.5 GHz ground-coupled antenna and were also verified using a $2.0 \mathrm{GHz}$ air-launched antenna. Of the many post processing features that are offered by RADAN 5.0 software, the Linear Range Gain feature was used for post processing of the acquired data. Radar signals undergo attenuation as it travels deeper into a material. As a result, amplitude of the reflected waves decreases with depth. For this reason, the signal amplitude has to be artificially "amplified" so that reflections become clearly visible in the radar san displays. RADAN 5.0 software offers three range gain options to the user: Automatic Gain, Linear Gain and Exponential Gain. In our research, Linear Gain was applied to all the GPR data as it resulted in significant gain for deeper echoes. The antenna transmits energy at a frequency bandwidth that is roughly equivalent to 1.5 to 2 times the center frequency. One more striking post processing option that RADAN 5.0 offers to the user is the FIR filter. FIR filter contains features like Background Removal (Horizontal High Pass filter), Vertical High Pass filter and Vertical Low Pass filter that are used to remove noise from the radar data. A high pass filter allows only those signals whose frequencies are higher than the threshold frequency to which it is set. On the other hand, a low pass filter allows signals having frequency lower than its threshold frequency. However in our study, FIR filter was not used because filtering removed the desirable features from raw data. Only 
the range and display gains were used. Figure 4-26 and Figure 4-27 show the raw GPR data of defect-free CFRP wrapped cylinder and defect-free GFRP wrapped cylinder respectively. Figure 4-28 and Figure 4-29 represent the GPR data of the defect-free CFRP wrapped cylinder and defect-free GFRP wrapped cylinder respectively after applying linear range gain to the raw data. All these GPR data appear to be void of any abnormal features as expected. The gained data shows the surface reflection more prominently.

\subsubsection{Detection of Debonds in Cylinders Wrapped with GFRP}

\subsubsection{Detection of Air-Filled Debonds}

Ground Penetrating Radar did not prove to be effective in locating air-filled debonds in GFRP wrapped cylinders. This is attributed to the fact that dielectric constant of air $(=1)$ is very close to that of GFRP $(\sim 6)$. Hence amplitudes of reflected EM waves from air-filled debonds are not very high. Even after applying linear gain to the data, none of the air-filled debonds were visible. Figure 4-30 to Figure 4-32 show the raw GPR data of GFRP wrapped cylinders containing 1.4" x 1.4', 2"' x 2" and 3" x 3" air debonds, respectively. Even from the processed GPR data (Figure 4-33 to Figure 4-35), none of the air debonds could be identified with certainty.

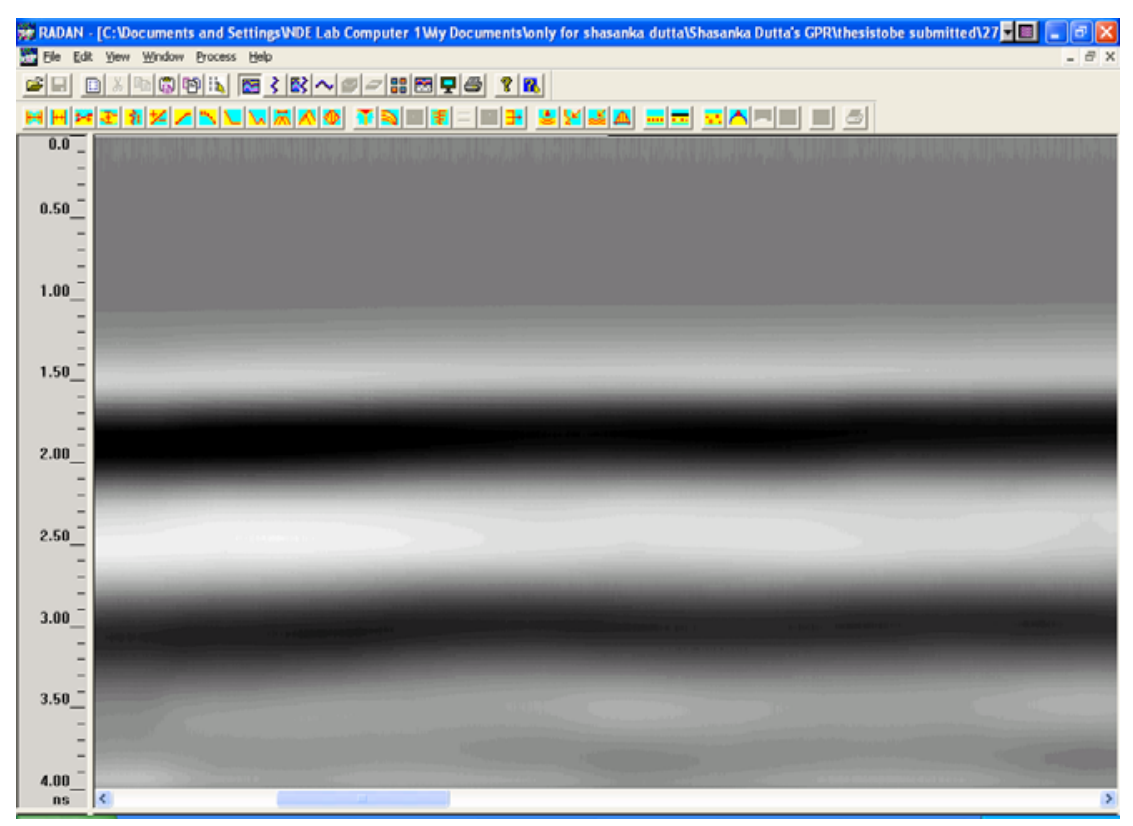

Figure 4-26 Raw GPR data of a defect-free cylinder wrapped with CFRP 


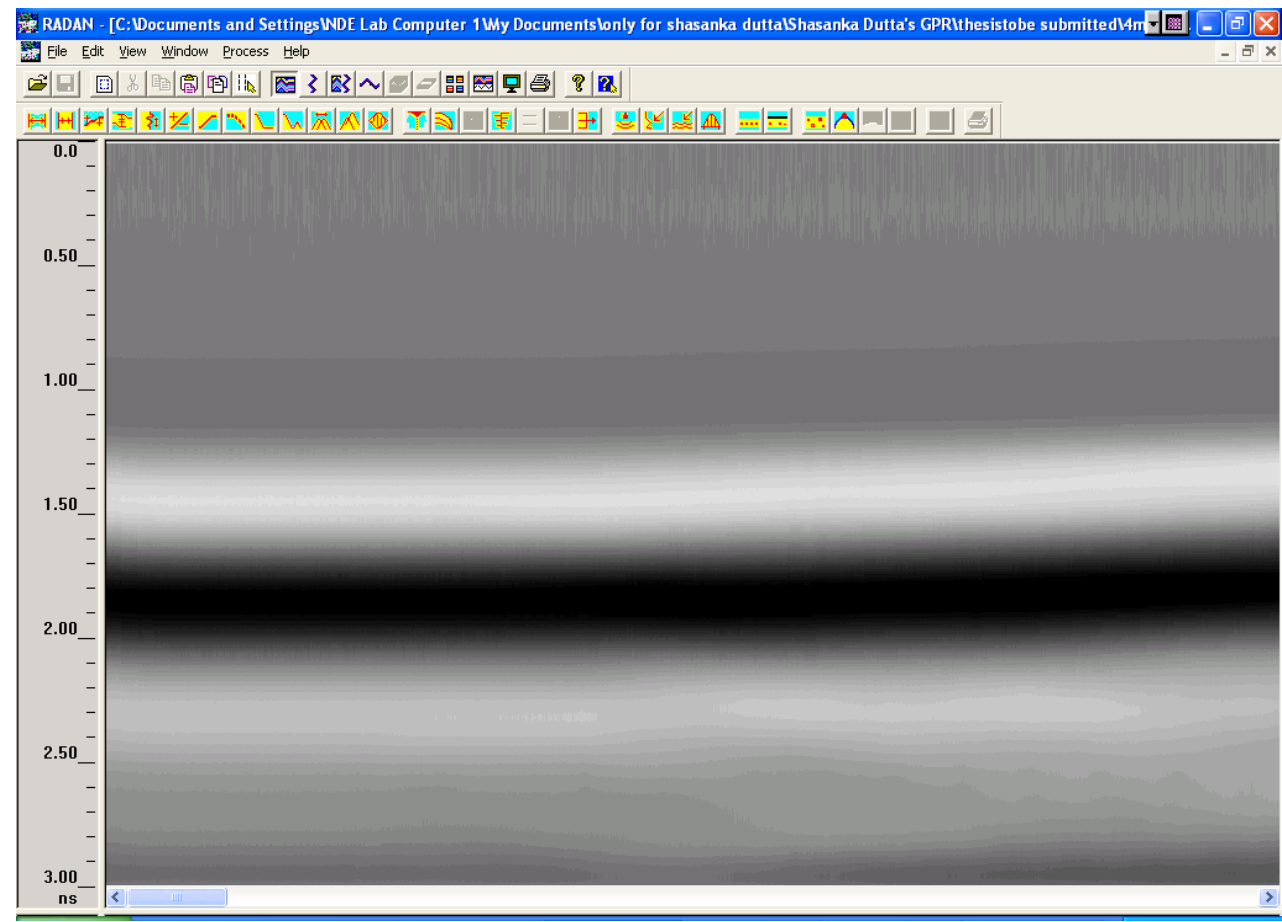

Figure 4-27 Raw GPR data of a defect-free cylinder wrapped with GFRP

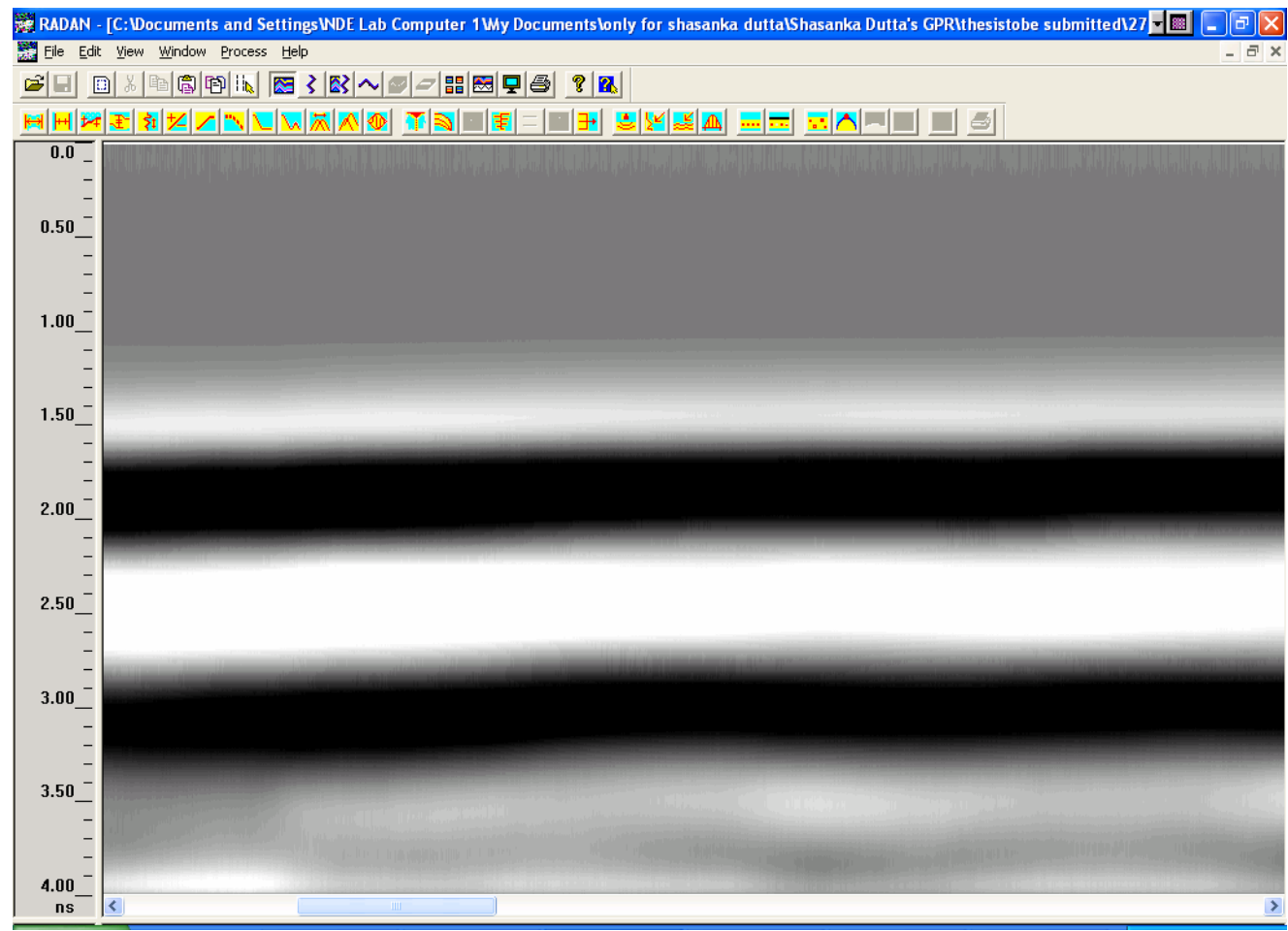

Figure 4-28 GPR data of a defect-free cylinder wrapped with CFRP after applying linear gain 


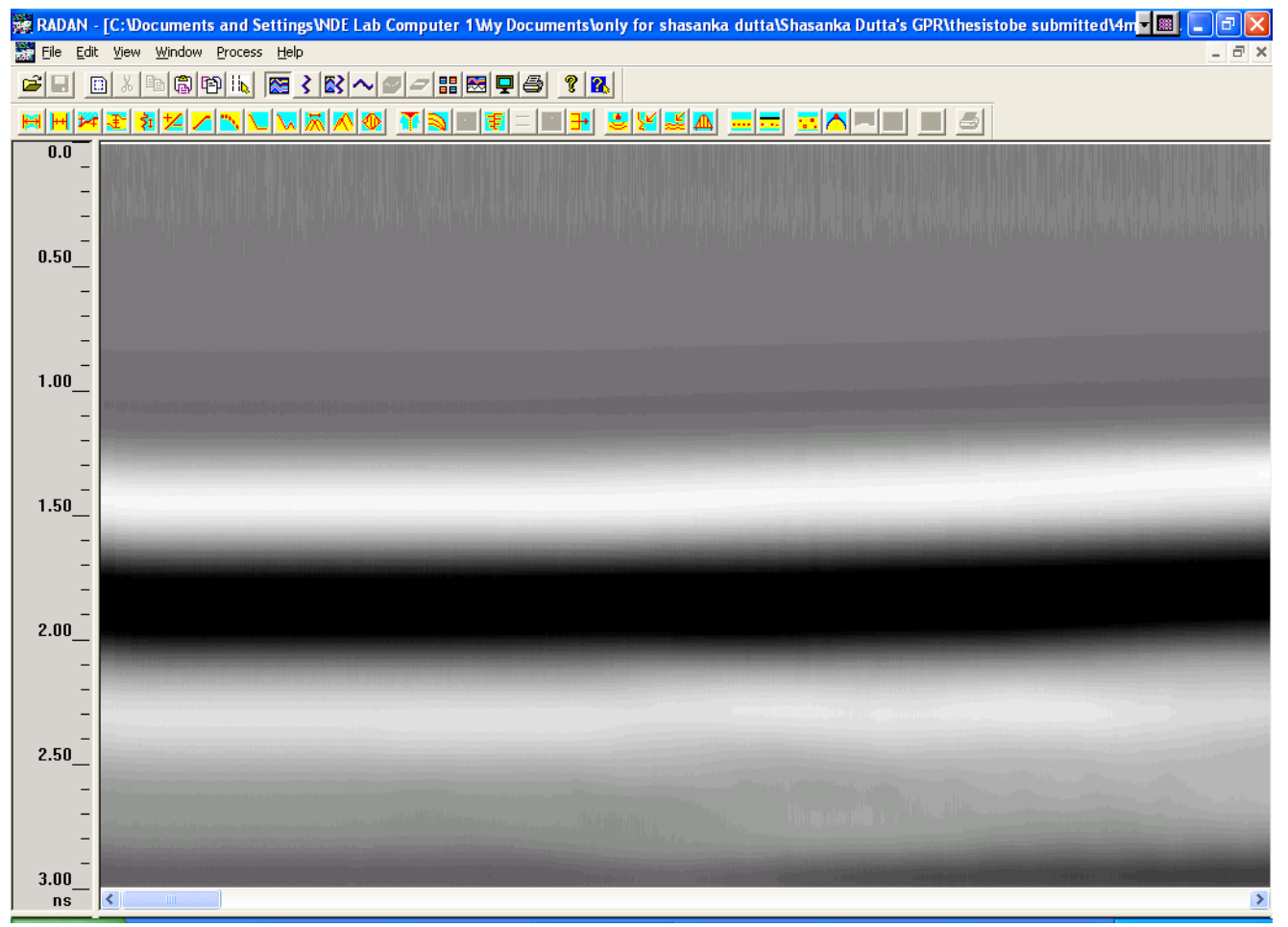

Figure 4-29 GPR data of a defect-free cylinder wrapped with GFRP after applying linear gain

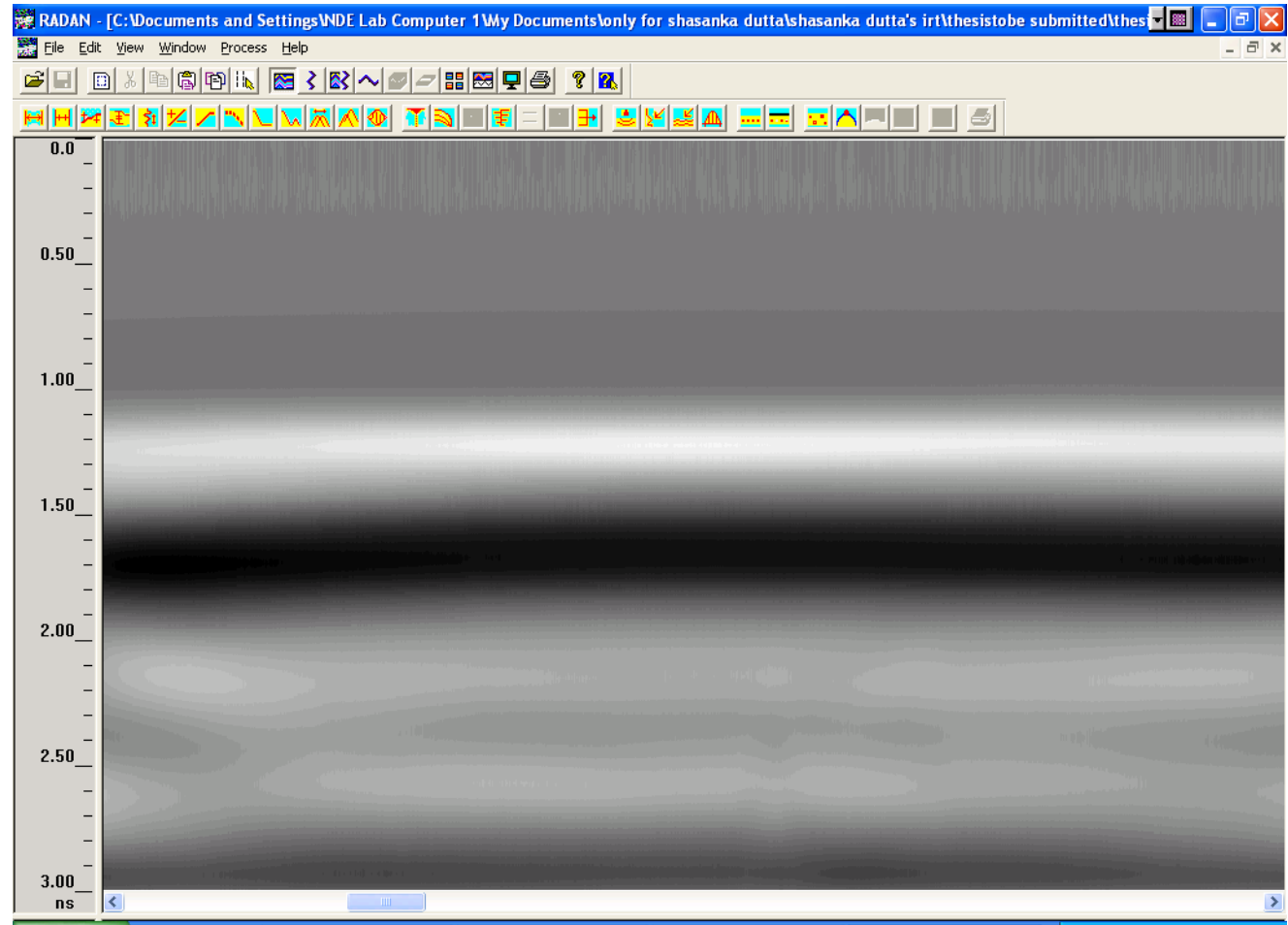

Figure 4-30 Raw GPR data of cylinder no 1 


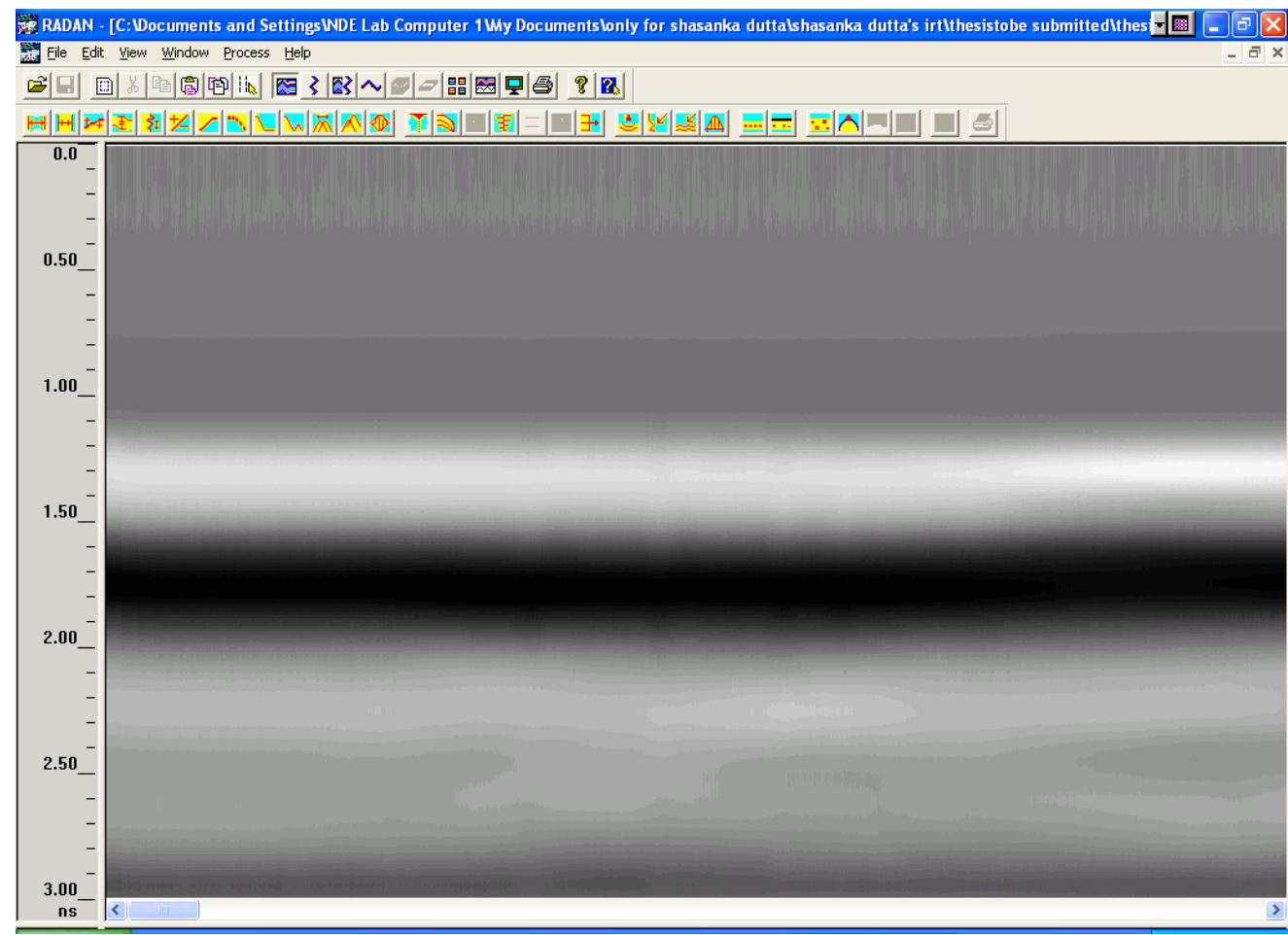

Figure 4-31 Raw GPR data of cylinder no 2

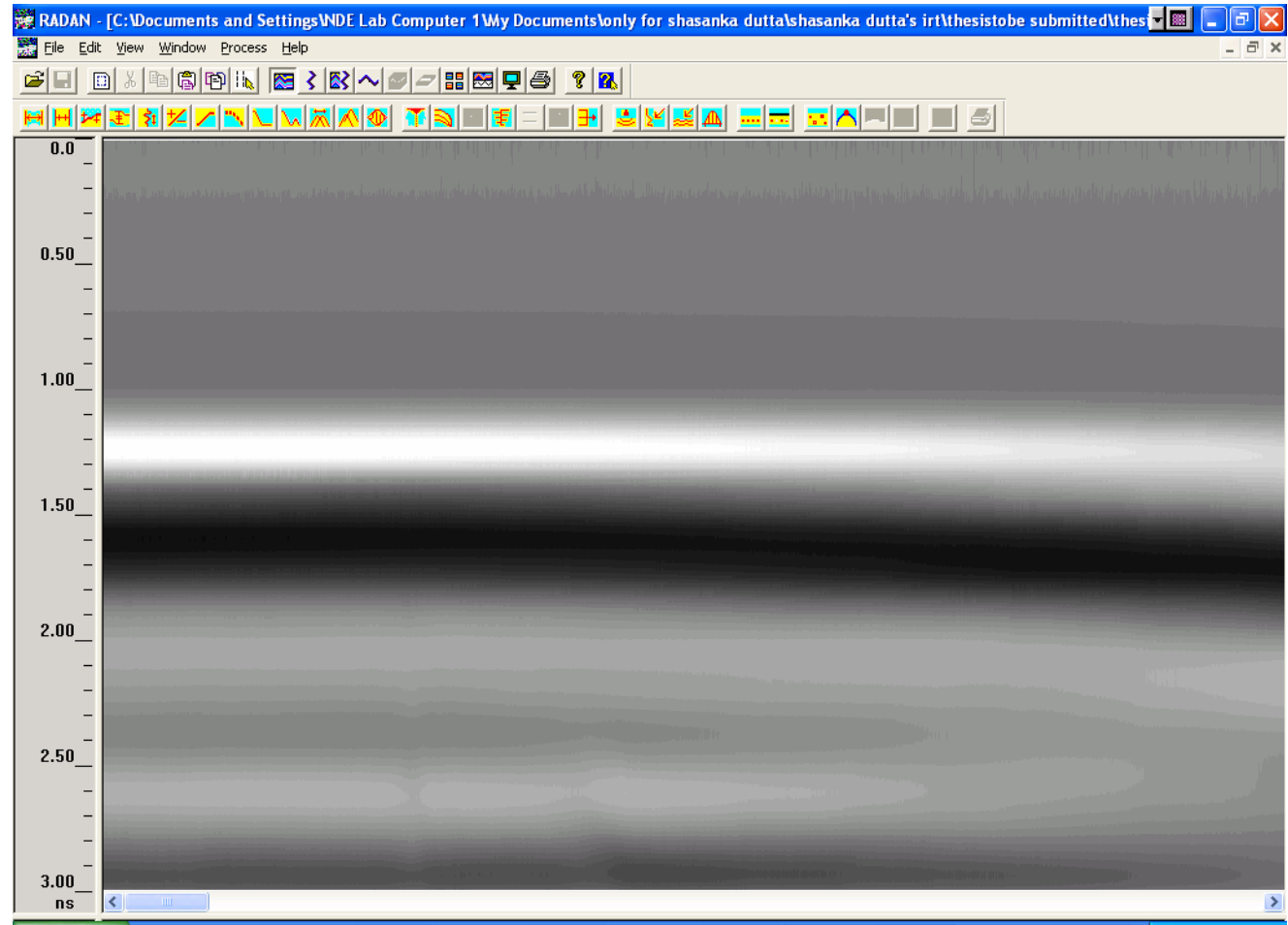

Figure 4-32 Raw GPR data of cylinder no 3 


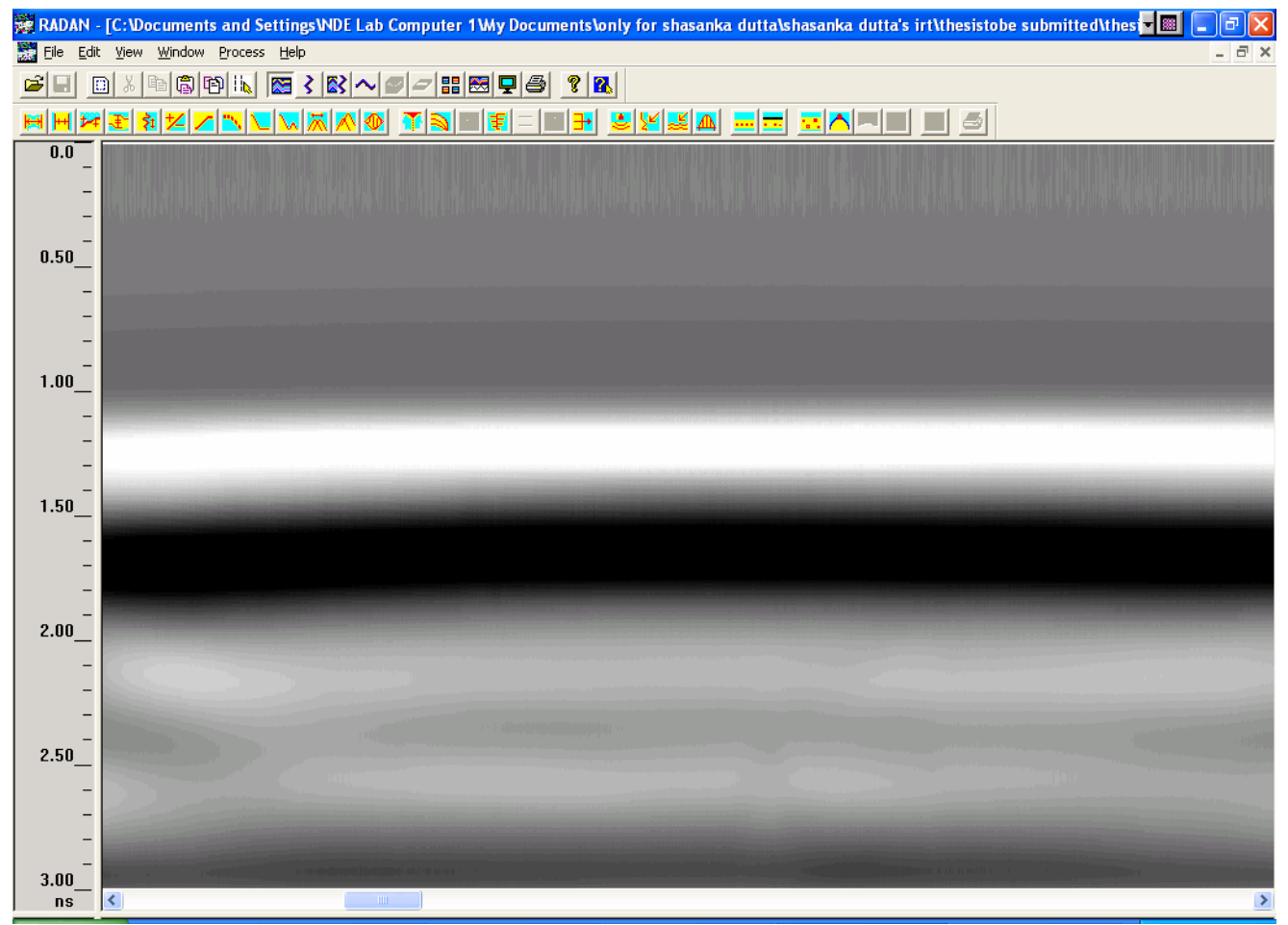

Figure 4-33 Processed GPR data of cylinder no 1

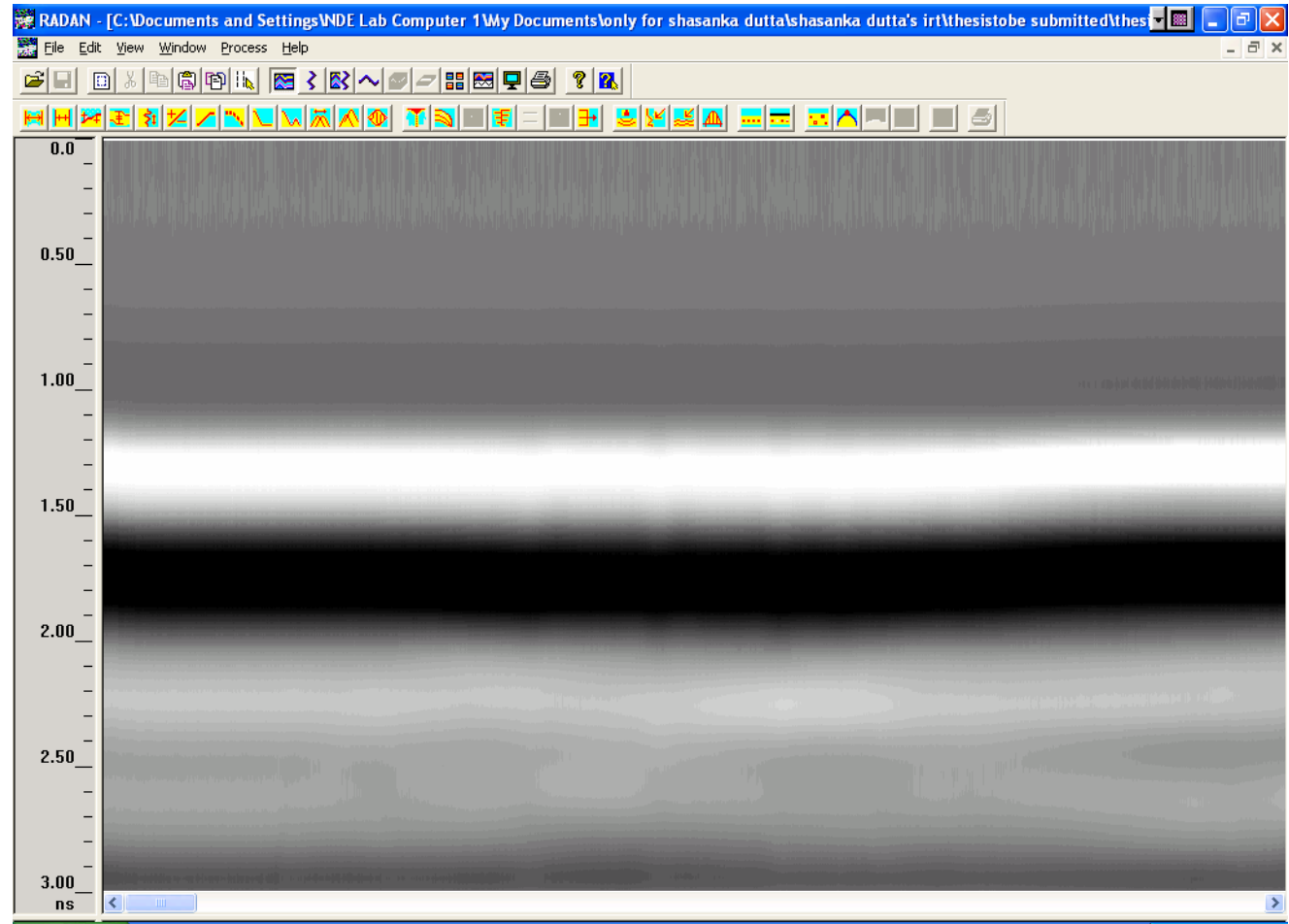

Figure 4-34 Processed GPR data of cylinder no 2 


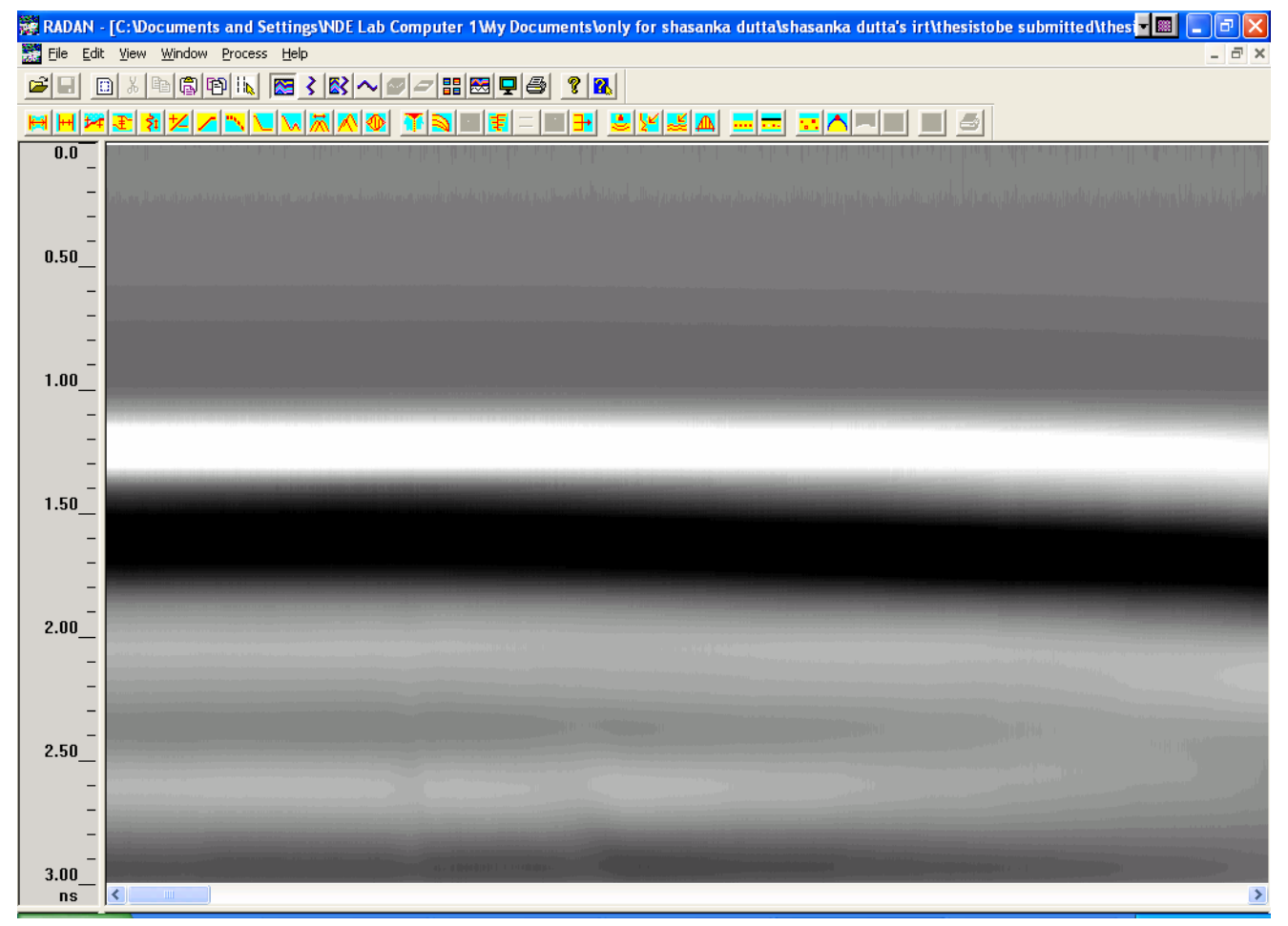

Figure 4-35 Processed GPR data of cylinder no 3

\subsubsection{Detection of 1.4" $x$ 1.4" Water-Filled Debond}

1.4 ' $x 1.4$ " water-filled debond could be located with the help of GPR. However, raw data (Figure 4-36) had to be processed in order to detect the debond with absolute certainty. Figure 4-37 shows the processed GPR data. Locating water-filled debond is easy compared to air-filled debond because of the large contrast between the dielectric permittivity value of water $(\sim 80)$ and GFRP wrap $(\sim 6)$ which results in high amplitude of the EM wave reflected from the GFRP-water interface. 


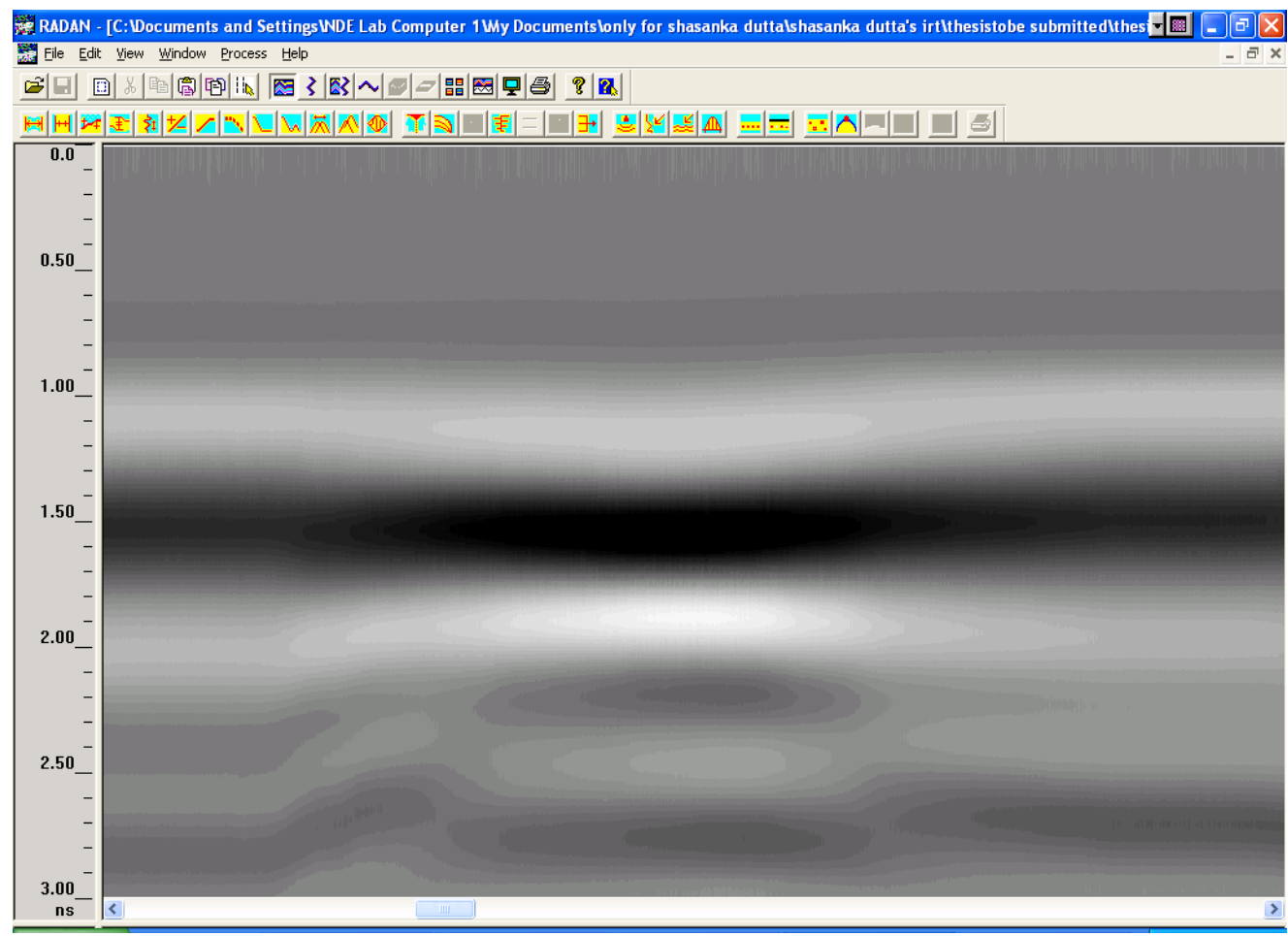

Figure 4-36 Raw GPR data of cylinder no 8

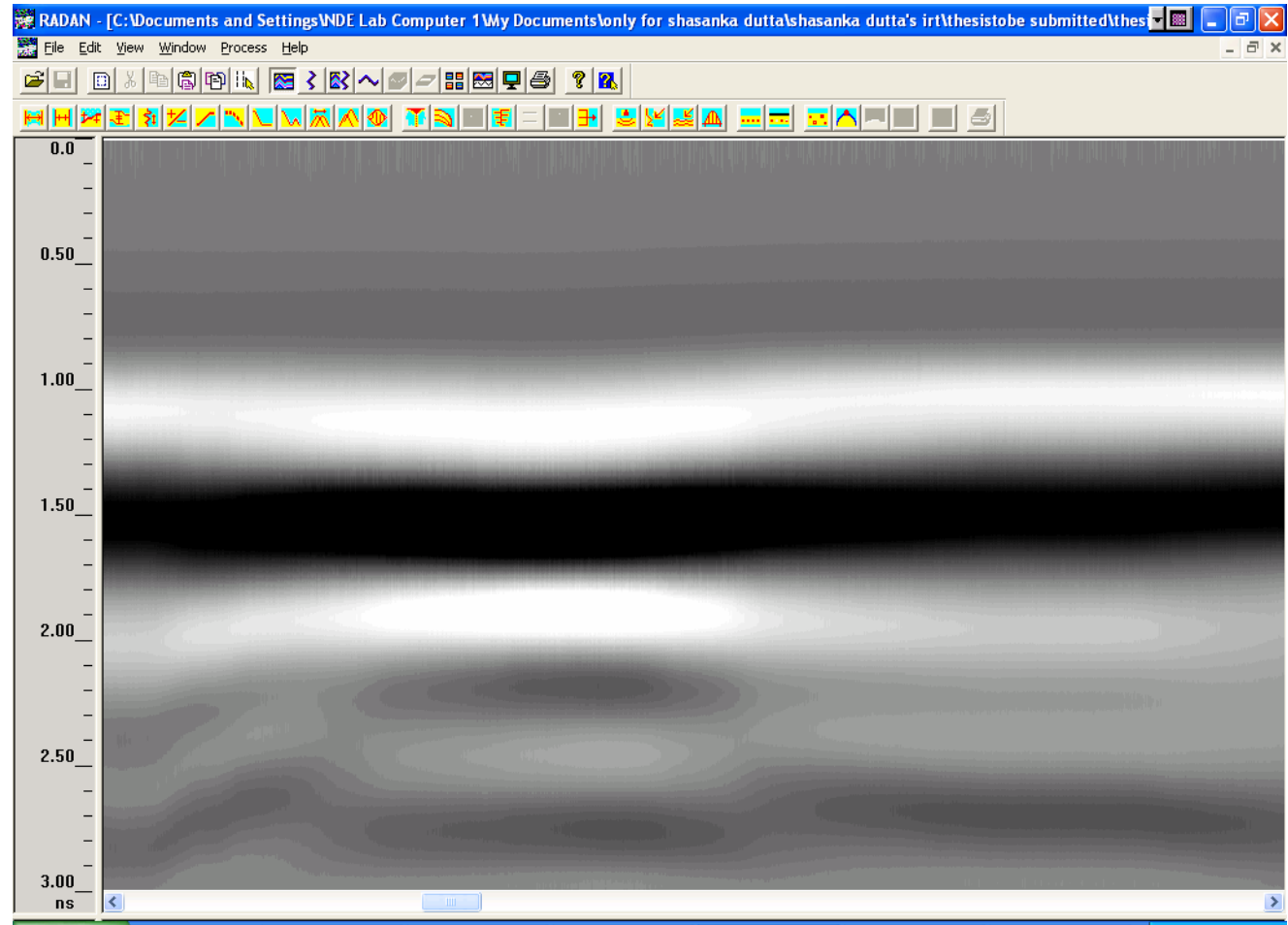

Figure 4-37 Processed GPR data of cylinder no 8 


\subsubsection{Detection of 2" $x 2$ "' Water-Filled Debond}

2" x 2" water-filled debond could be detected even from the raw data (Figure 4-38). The raw data was also processed and is shown in Figure 4-39 where the 2" x 2'" water-filled debond can be clearly detected.

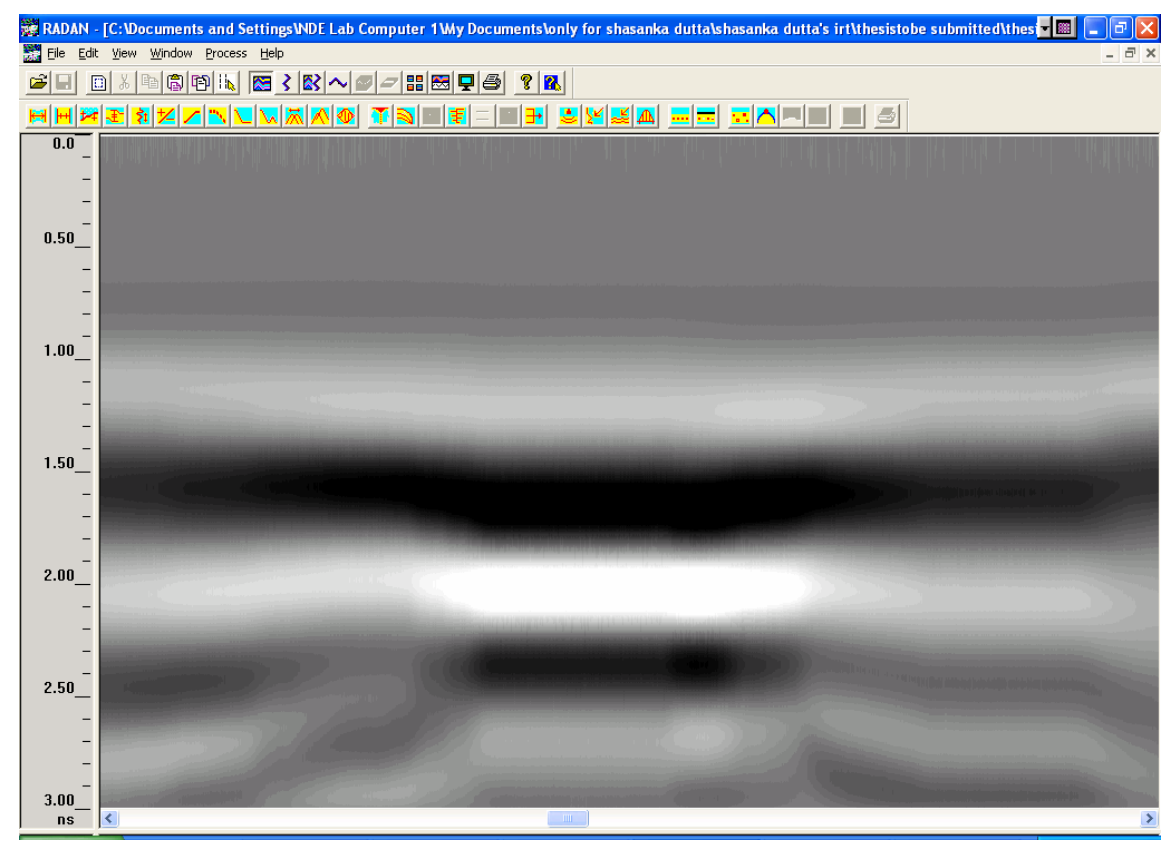

Figure 4-38 Raw GPR data of cylinder no 9

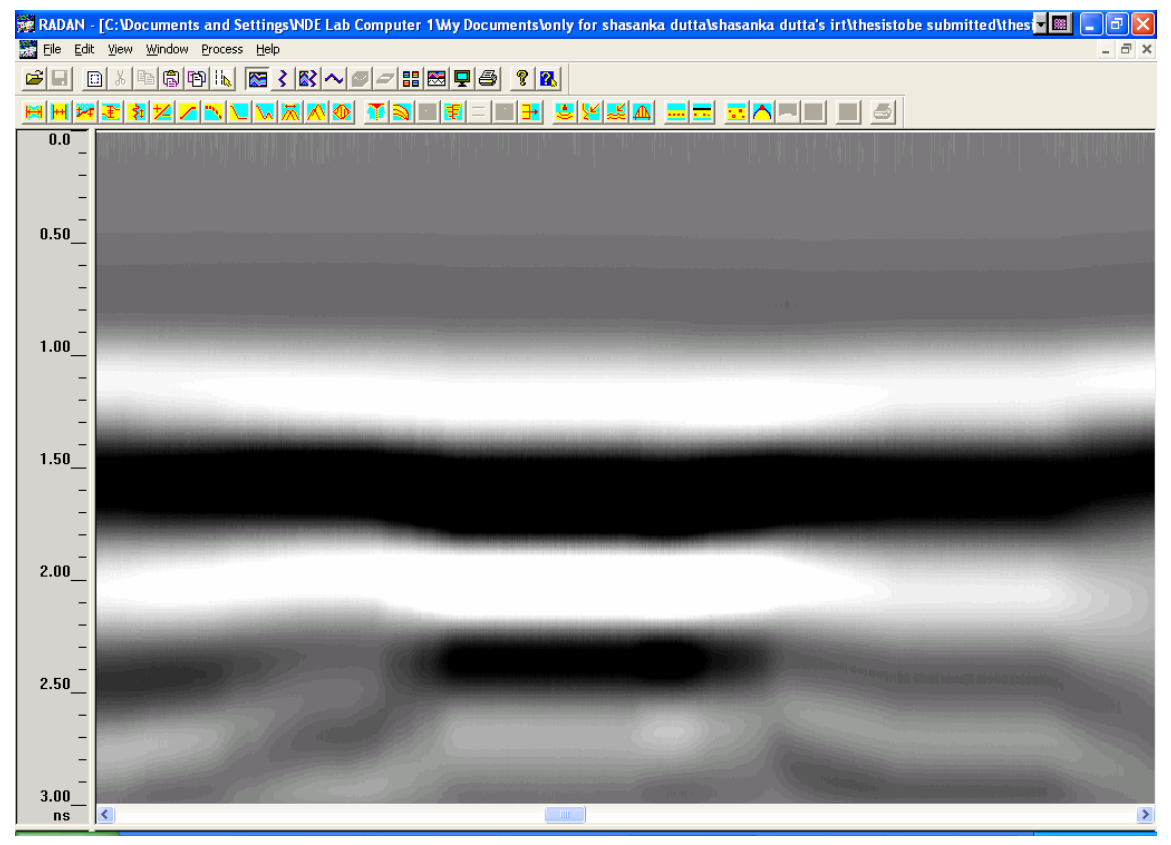

Figure 4-39 Processed GPR data of cylinder no 9 


\subsubsection{Detection of 3" x 3"' Water-Filled Debond}

As in the case of 2" $\times 2$ "' water-filled debond, the 3" x 3"' water-filled debond was also located clearly from the raw GPR data (Figure 4-40) and from the processed data (Figure 4-41). However, 3"' x 3"' water-filled debond was seen to be creating a "downward wave" as opposed to the characteristic "upward wave" of the water-filled debonds in flat objects. This "downward wave" may be attributed to the fact that the scanned surface is curved in nature and also because the EM waves are slower while traveling through the water-filled debond. This "downward wave" feature was not visible in case of the other two (smaller) debond sizes. This may be due to their less pronounced effect on the radar signals because of their smaller sizes.

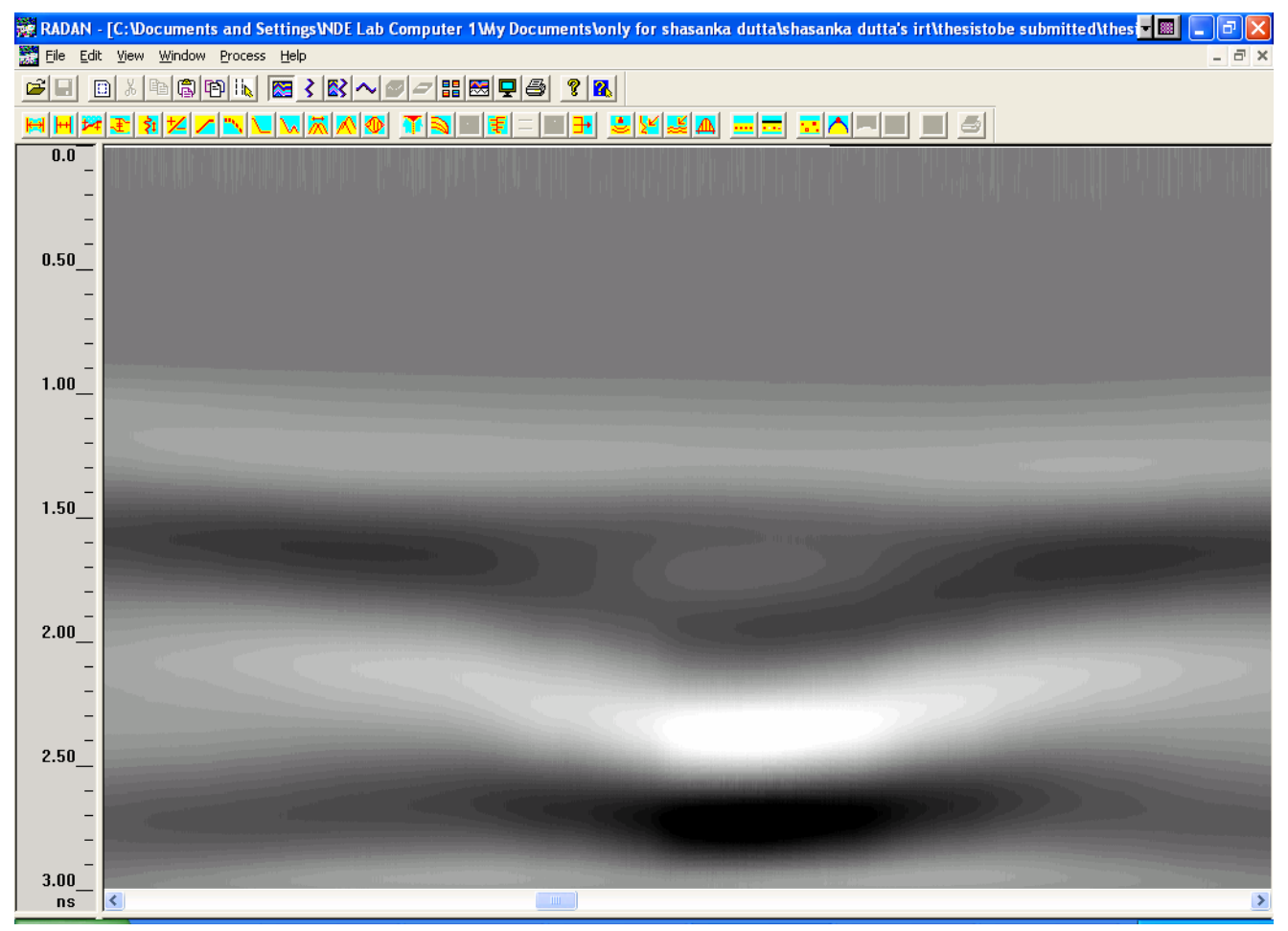

Figure 4-40 Raw GPR data of cylinder no 10 


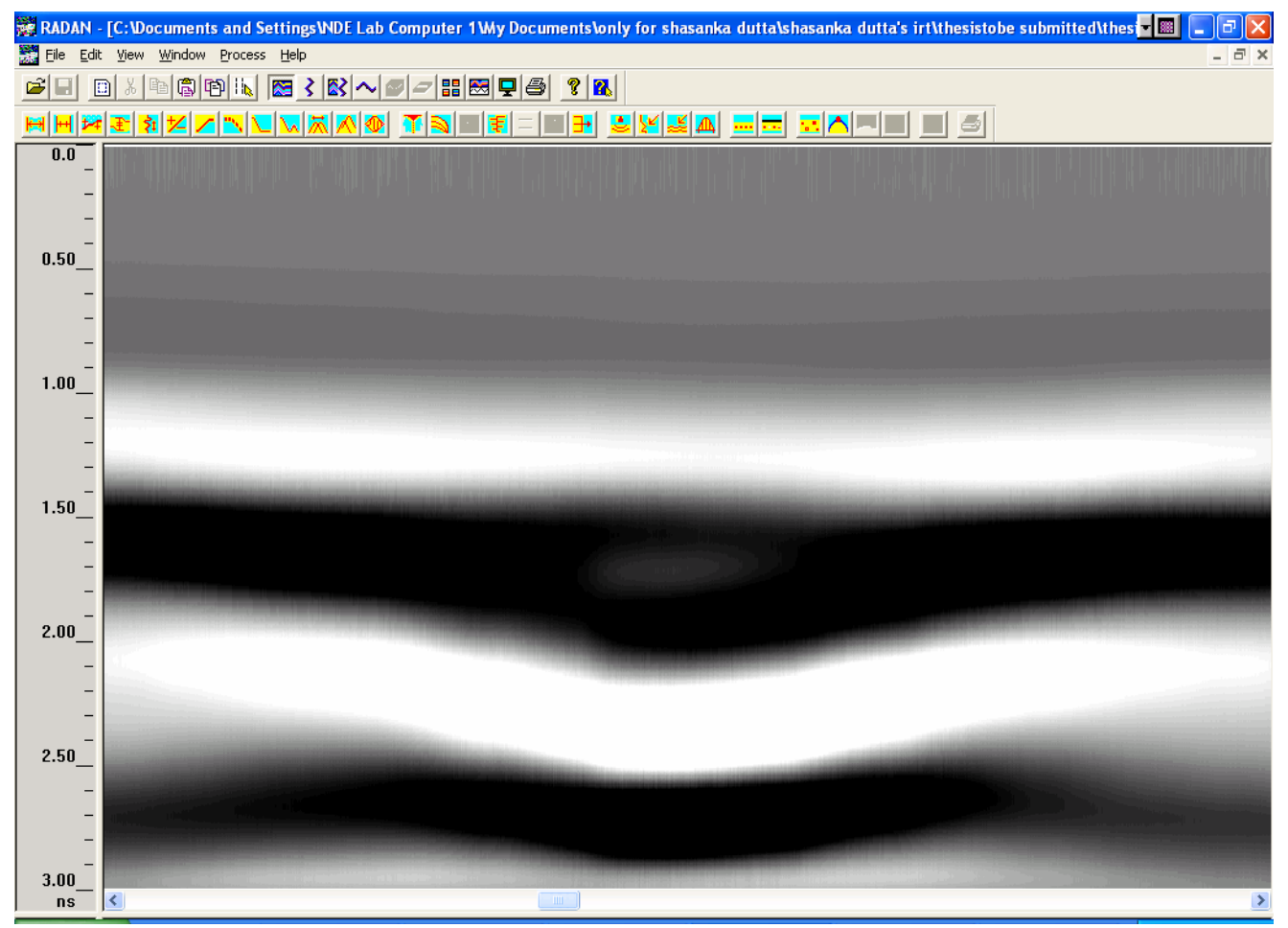

Figure 4-41 Processed GPR data of cylinder no 10

\subsubsection{Detection of Debonds in Cylinders Wrapped with CFRP}

\subsubsection{Detection of Air-Filled Debonds}

Unlike GFRP wrapped cylinders, dielectric contrast between the CFRP $\left(\varepsilon^{\prime} \sim 30\right)$ and air $\left(\varepsilon^{\prime} \sim 1\right)$ was significant. However, air-filled debonds could still not be detected by GPR in concrete cylinders wrapped with CFRP fabrics. Hence the reason for which GPR was unable to pin point the air-filled debonds could be the destructive superposition of signals from the CFRP-air interface and the air-concrete interface. This is because the debonds were glued to the concrete surface and hence the distance between the two interfaces (i.e., the debond thickness) was very minimal ( 0.1"). Figure 4-42 to Figure 4-44 show the raw GPR data from the cylinders with 1.4'” x 1.4', 2', x 2' and 3' $\mathrm{x}$ 3"'air-filled debonds, respectively. None of these scans show any debonds. Also, the processed GPR data (Figure 4-45 to Figure 4-47) do not reveal any of the air-filled debonds could be located. 


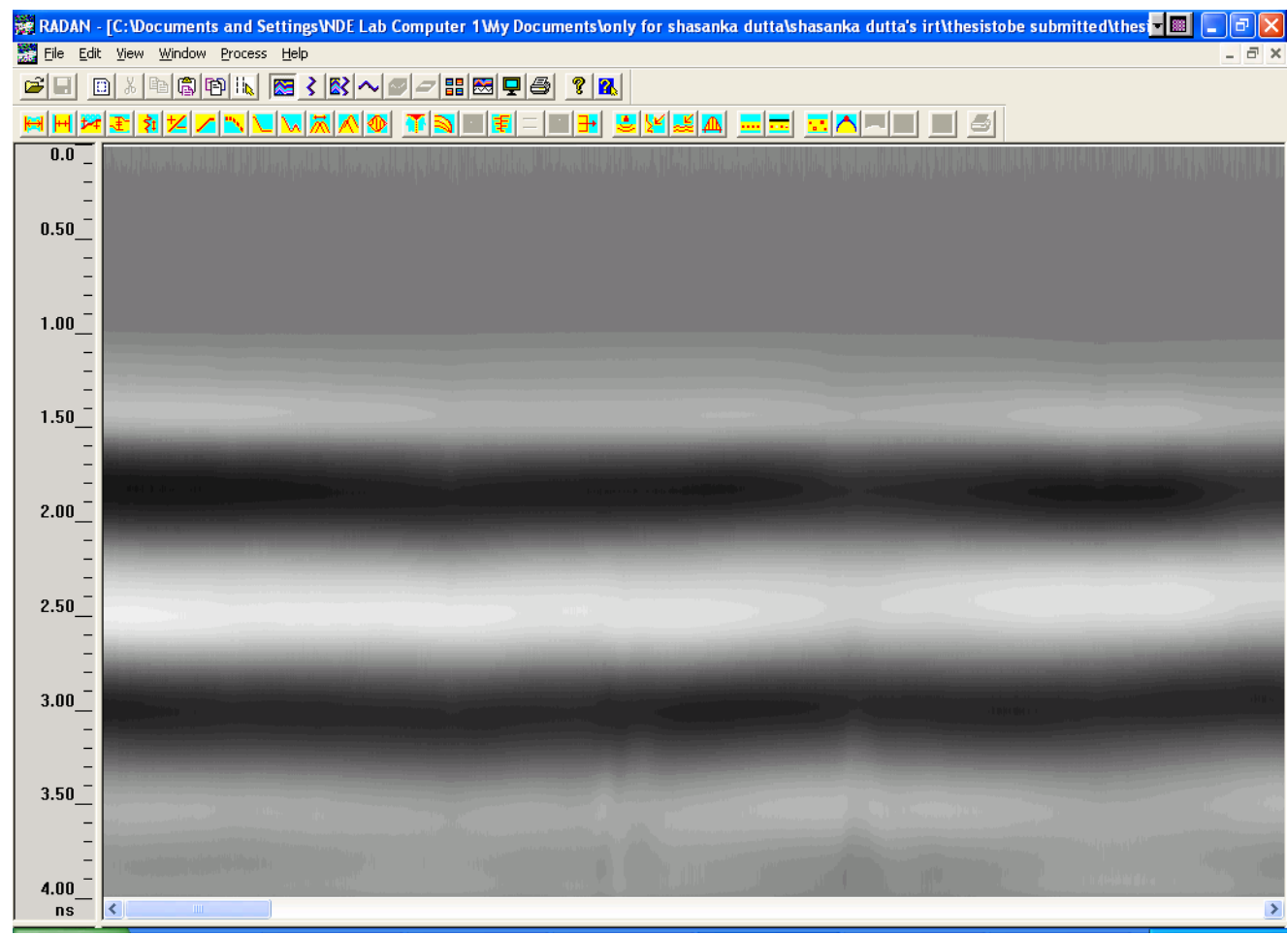

Figure 4-42 Raw GPR data of cylinder no 15

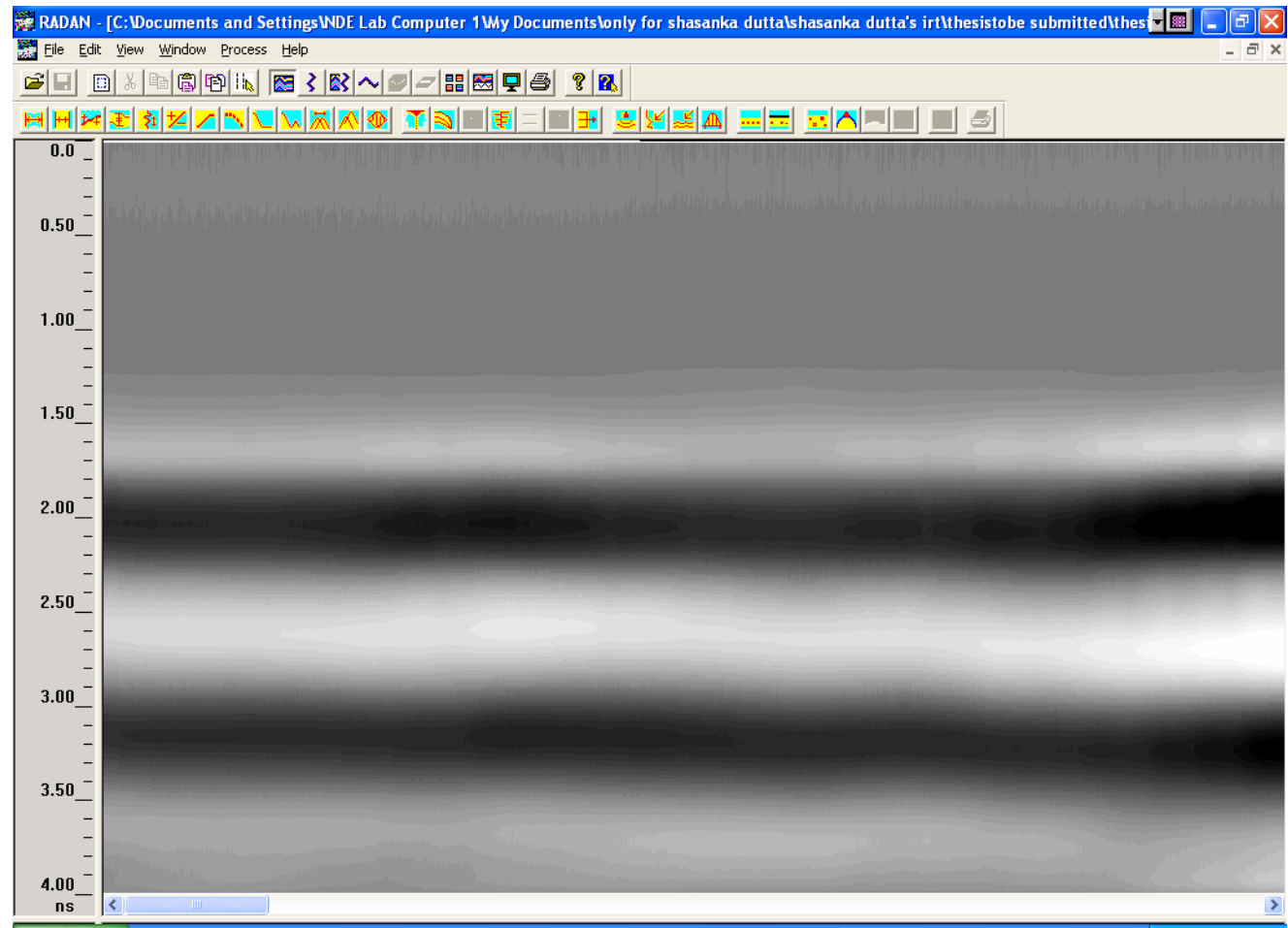

Figure 4-43 Raw GPR data of cylinder no 16 


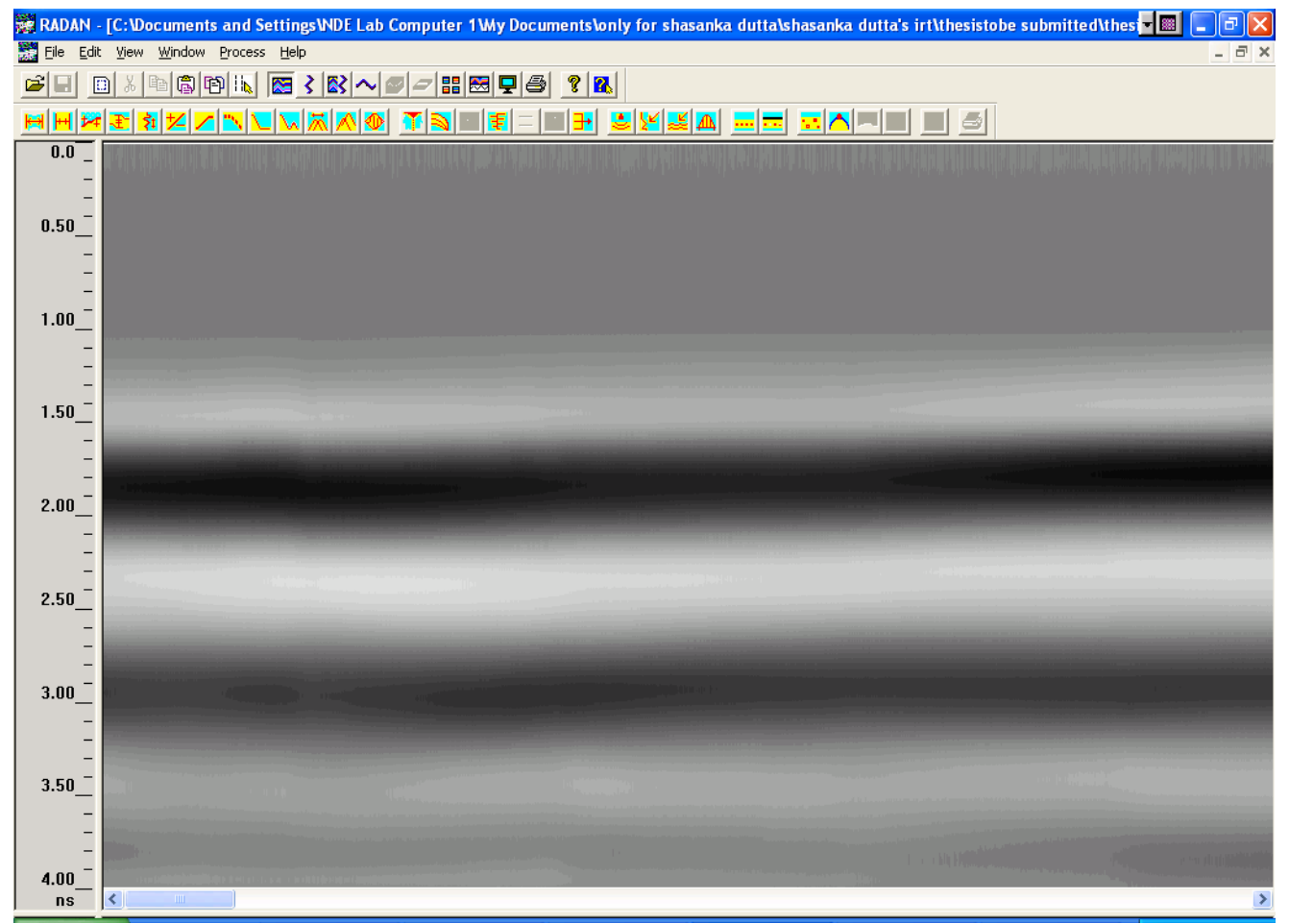

Figure 4-44 Raw GPR data of cylinder no 17

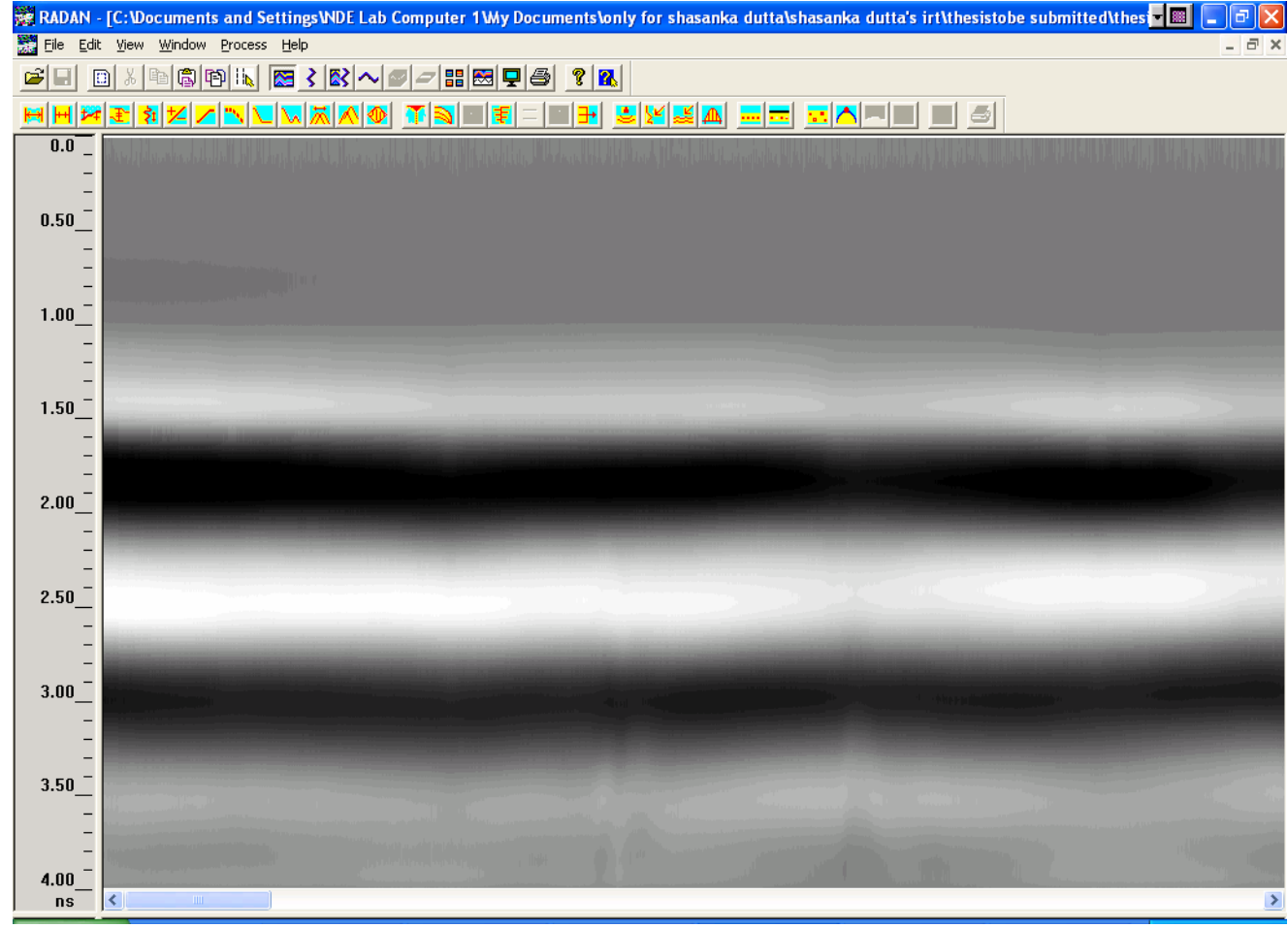

Figure 4-45 Processed GPR data of cylinder no 15 


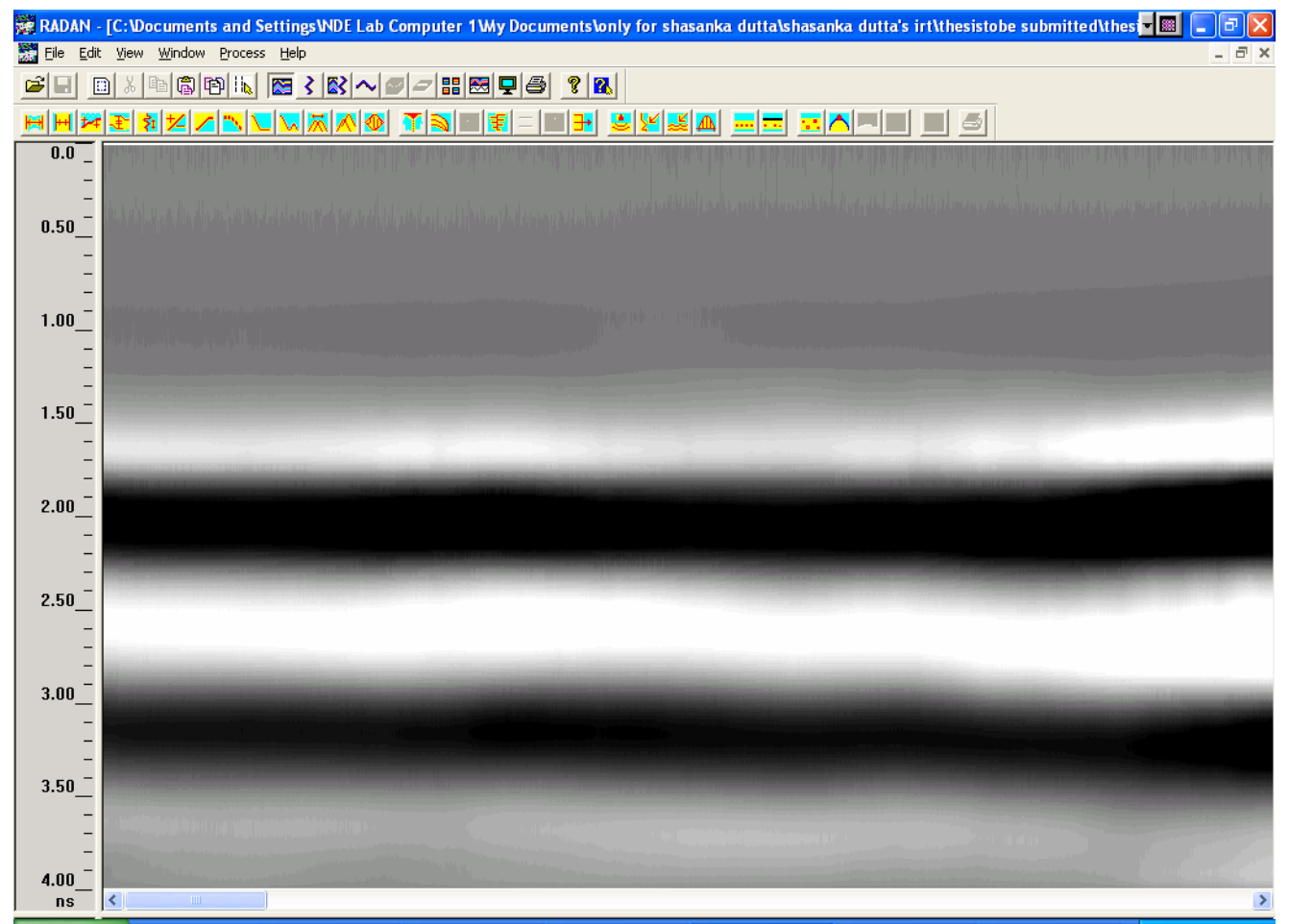

Figure 4-46 Processed GPR data of cylinder no 16

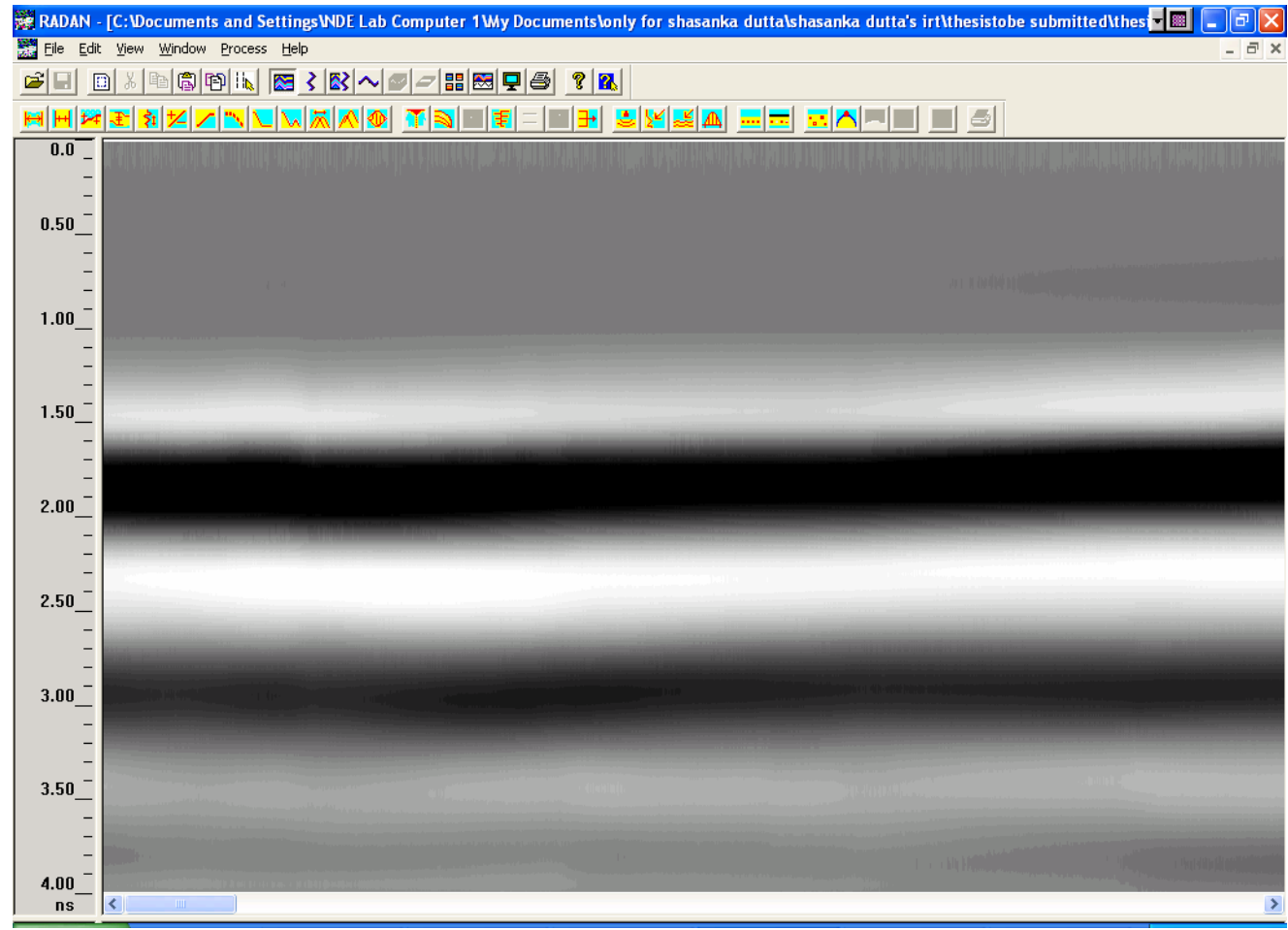

Figure 4-47 Processed GPR data of cylinder no 17 


\subsubsection{Detection of 1.4"' $x$ 1.4"' Water-Filled Debond}

GPR was able to detect 1.4" x 1.4" water-filled debond with precision. Figure 4-48 and Figure 4-49 show the raw data and processed data respectively. However, in this case the raw data showed the debond much more clearly compared to the processed data.

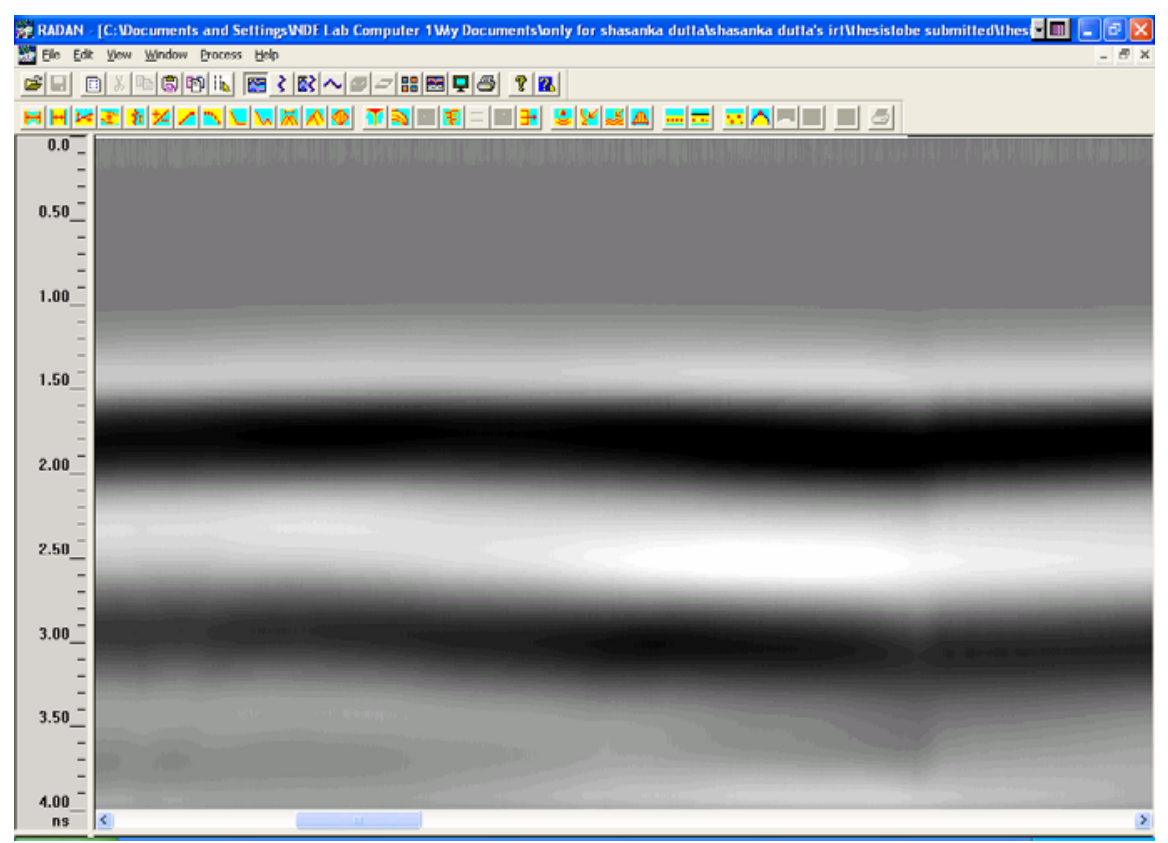

Figure 4-48 Raw GPR data of cylinder no 22

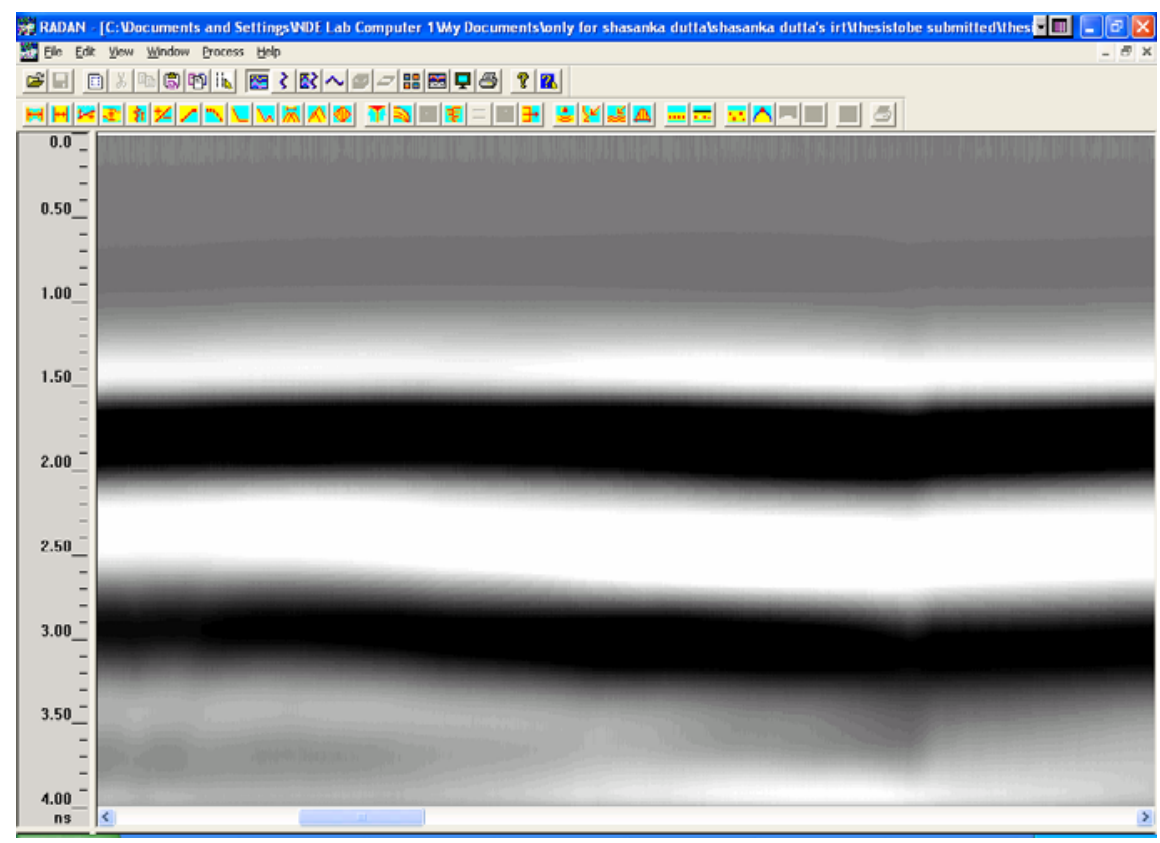

Figure 4-49 Processed GPR data of cylinder no 22 


\subsubsection{Detection of 2" $\times 2$ "' Water-Filled Debond}

Figure 4-50 and Figure 4-51 show the raw data and the processed data for 2' $\mathrm{x}$ 2" water-filled debond. In this case, the water-filled debond can be conclusively identified from the processed data rather than the raw data.

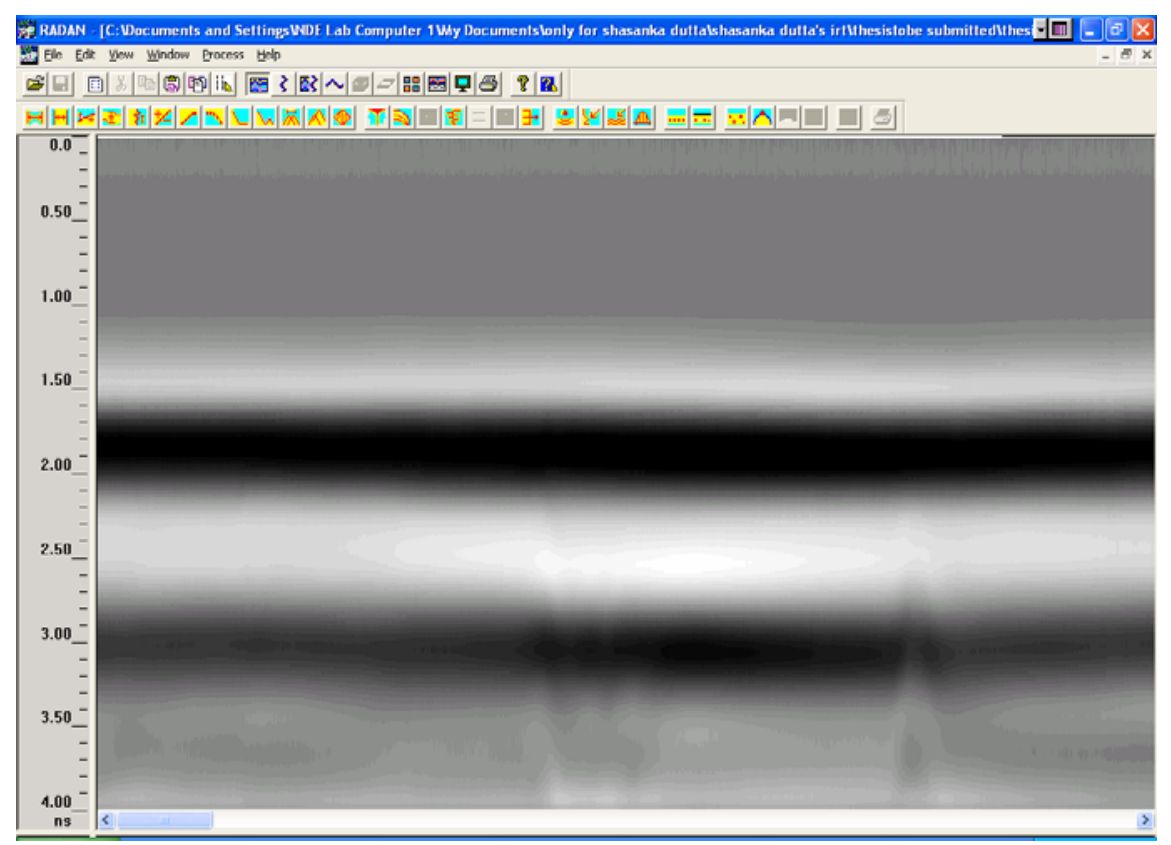

Figure 4-50 Raw GPR data of cylinder no 23

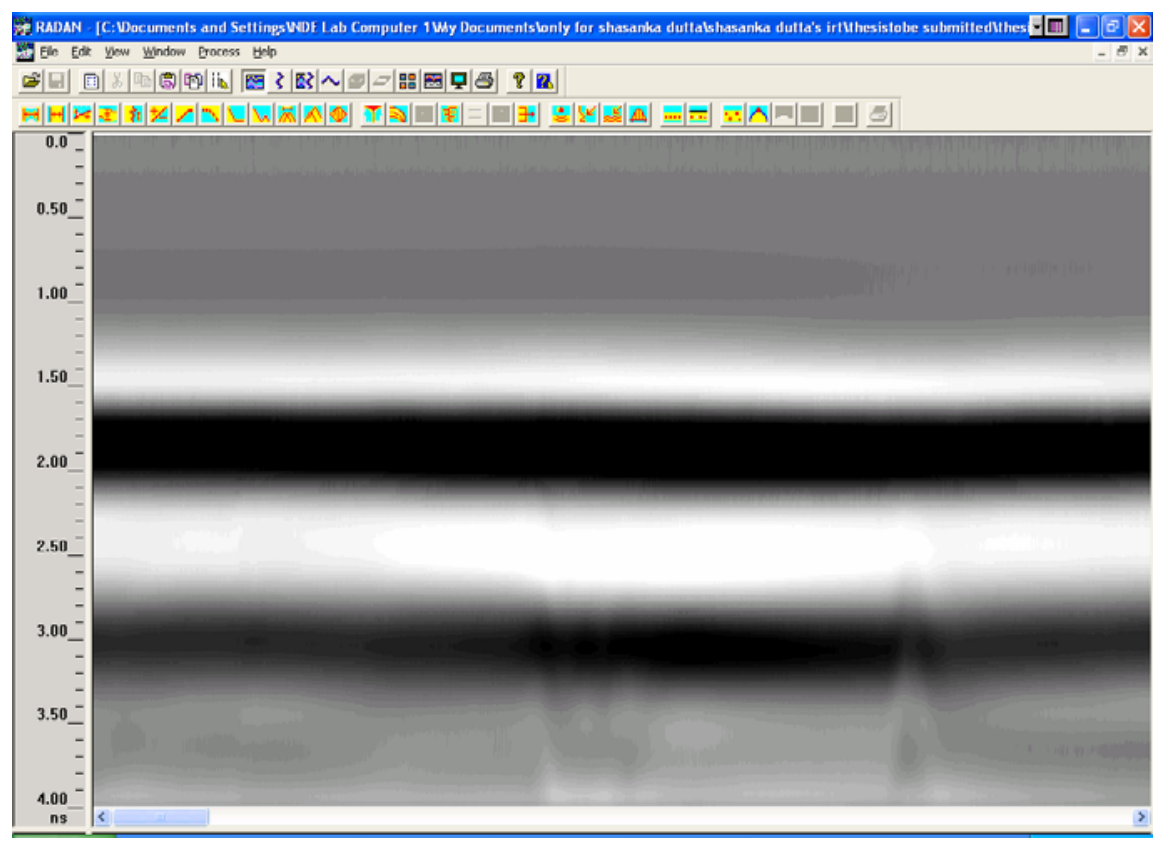

Figure 4-51 Processed GPR data of cylinder no 23 


\subsubsection{Detection of 3" $\times 3$ 3" Water-Filled Debond}

GPR was able to locate the 3" $\mathrm{x}$ 3" water-filled debond in CFRP wrapped concrete cylinders (Figure 4-52 and Figure 4-53). However in this case, the "downward wave" feature of the 3" $\mathrm{x}$ 3" water-filled debond (observed earlier in case of GFRP wrapped cylinder) was not visible.

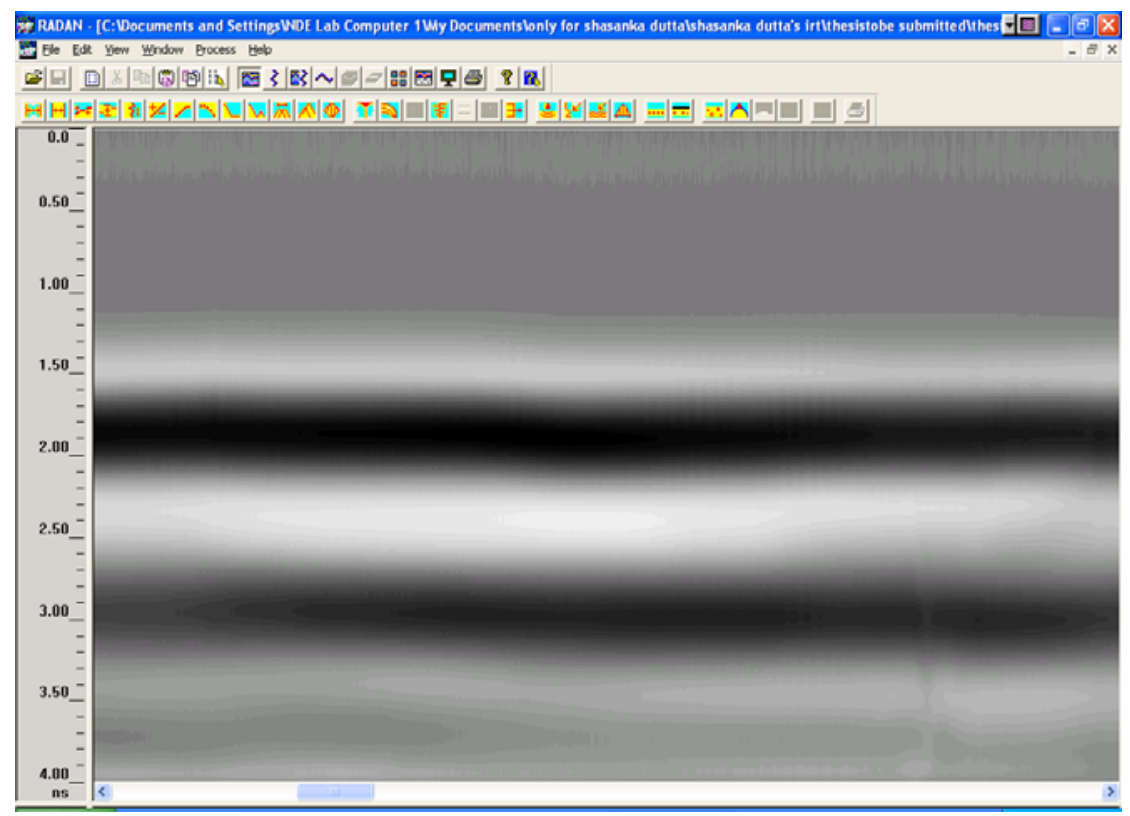

Figure 4-52 Raw GPR data of cylinder no 24

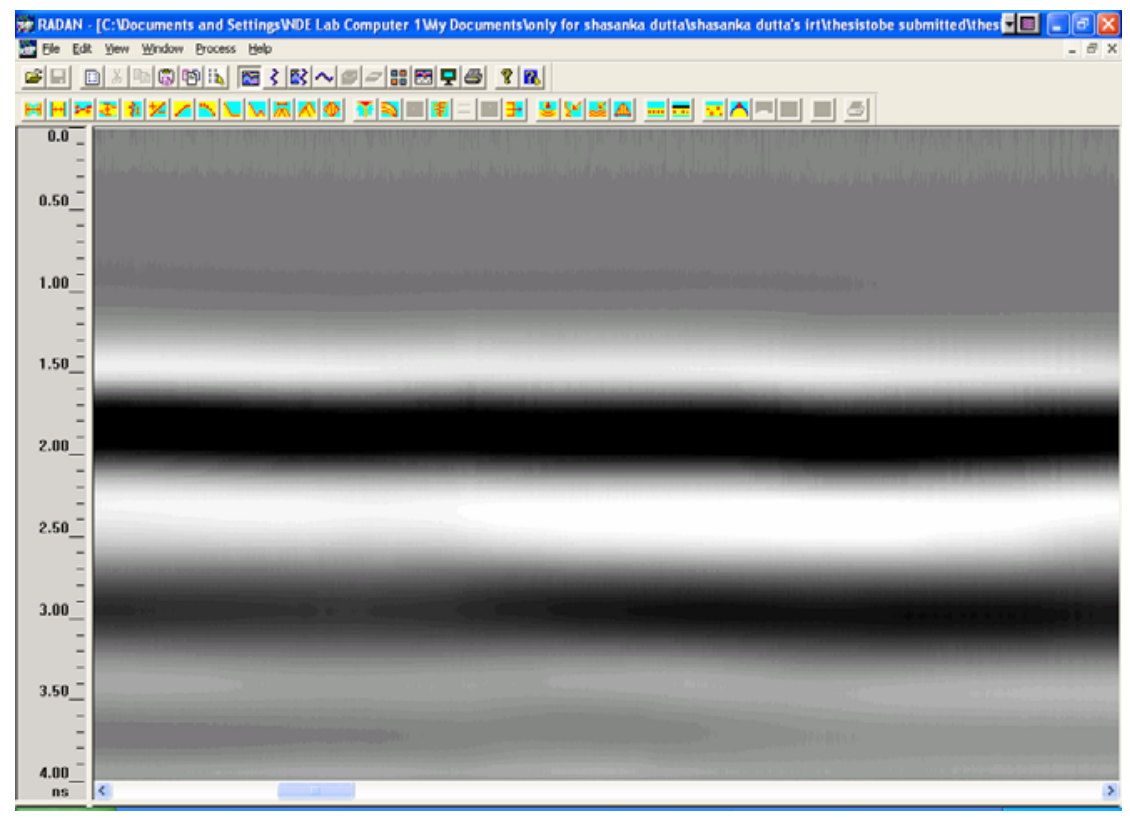

Figure 4-53 Processed GPR data of cylinder no 24 


\subsubsection{Conclusions}

Ground Penetrating Radar proved to be an excellent tool for finding subsurface water-filled debonds of plan sizes 3' $x$ 3', 2', x 2'" and 1.4' x 1.4' in FRP wrapped cylinders. However it was unable to pick up air-filled debonds. The degree of clarity of water-filled debonds in GPR data was much more in case of GFRP wrapped concrete cylinders compared to CFRP wrapped cylinders. This can be attributed to the fact that the dielectric contrast between GFRP and water is significantly higher than the dielectric contrast between CFRP and water.

\subsection{SURFACE TEMPERATURE CURVES AND THEIR ANALYSIS}

The main thermal response parameters that are of interest in nondestructive testing using infrared thermography technique are thermal difference and maximum surface temperature (Starnes et al. 2003). Thermal difference is defined as

$$
\Delta T=T_{\text {defect }}-T_{\text {background }}
$$

Where, $T_{\text {defect }}$ is the surface temperature above the debond and $T_{\text {background }}$ is the surface temperature above the defect-free area (Starnes et al. 2003). In this study, surface temperatures above the debonds and also above the defect-free areas were recorded after every 5 second interval. In this section, two sets of curves are presented.

- Curves representing the variation of surface temperature of defective and defectfree areas with time.

- Curves representing the variation of thermal difference with time.

Maximum thermal difference, $\Delta T_{\max }$ and time to reach it are also important parameters that are worth observing (Starnes et al. 2003). Surface temperature versus time curves are presented here for all the 28 FRP wrapped cylinders according to the number scheme of the cylinders that was stated earlier in Table 4-3. Curves for "thermal difference" versus time were produced only for those cylinders where the edge effect was minimum, i.e., cylinders having only two debonds (one on each side). This was done to eliminate the influence of unwanted air gaps between successive defects and at the edges in the analysis of the thermal difference results. 


\subsubsection{Surface Temperature versus Time Curves for GFRP Wrapped Cylinders}

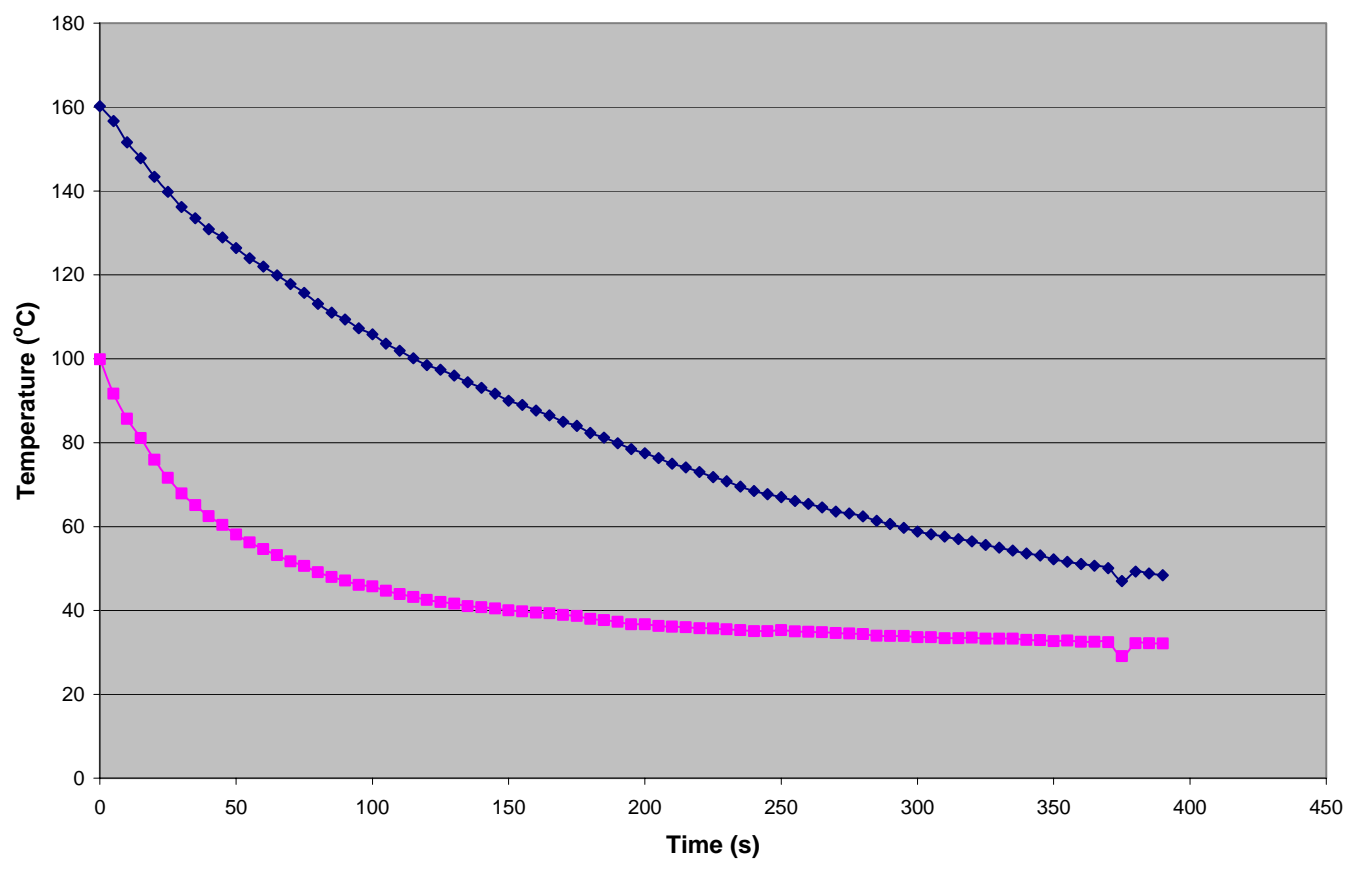

$\multimap-1.4 "$ x 1.4" Air-Filled Debond $\rightarrow-$ Defect-Free

Figure 4-54 Cylinder no 1 ( 3 minutes heating with $1500 \mathrm{~W}$ setting of the heater)

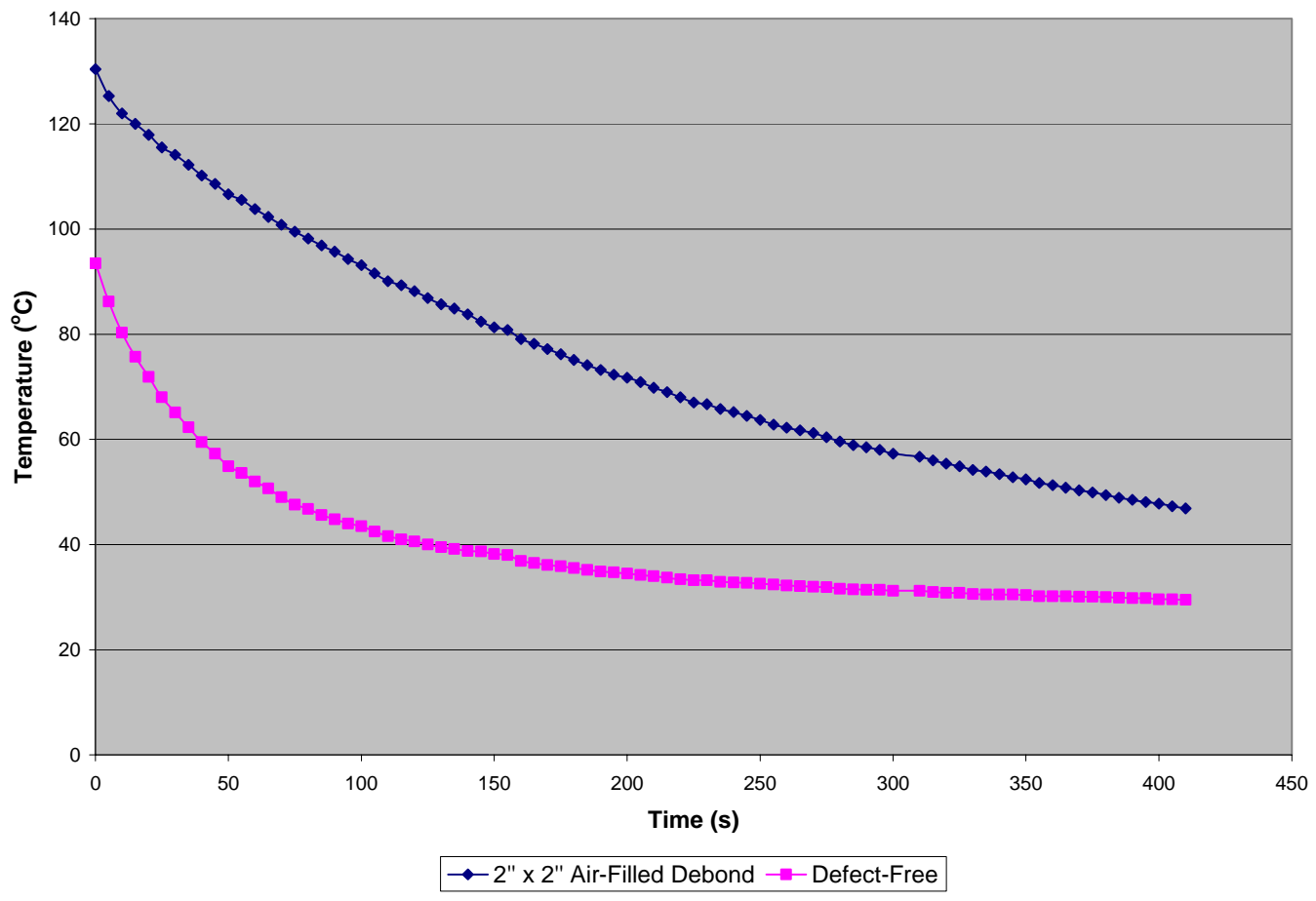

Figure 4-55 Cylinder no 2 ( 3 minutes heating with $1500 \mathrm{~W}$ setting of the heater) 


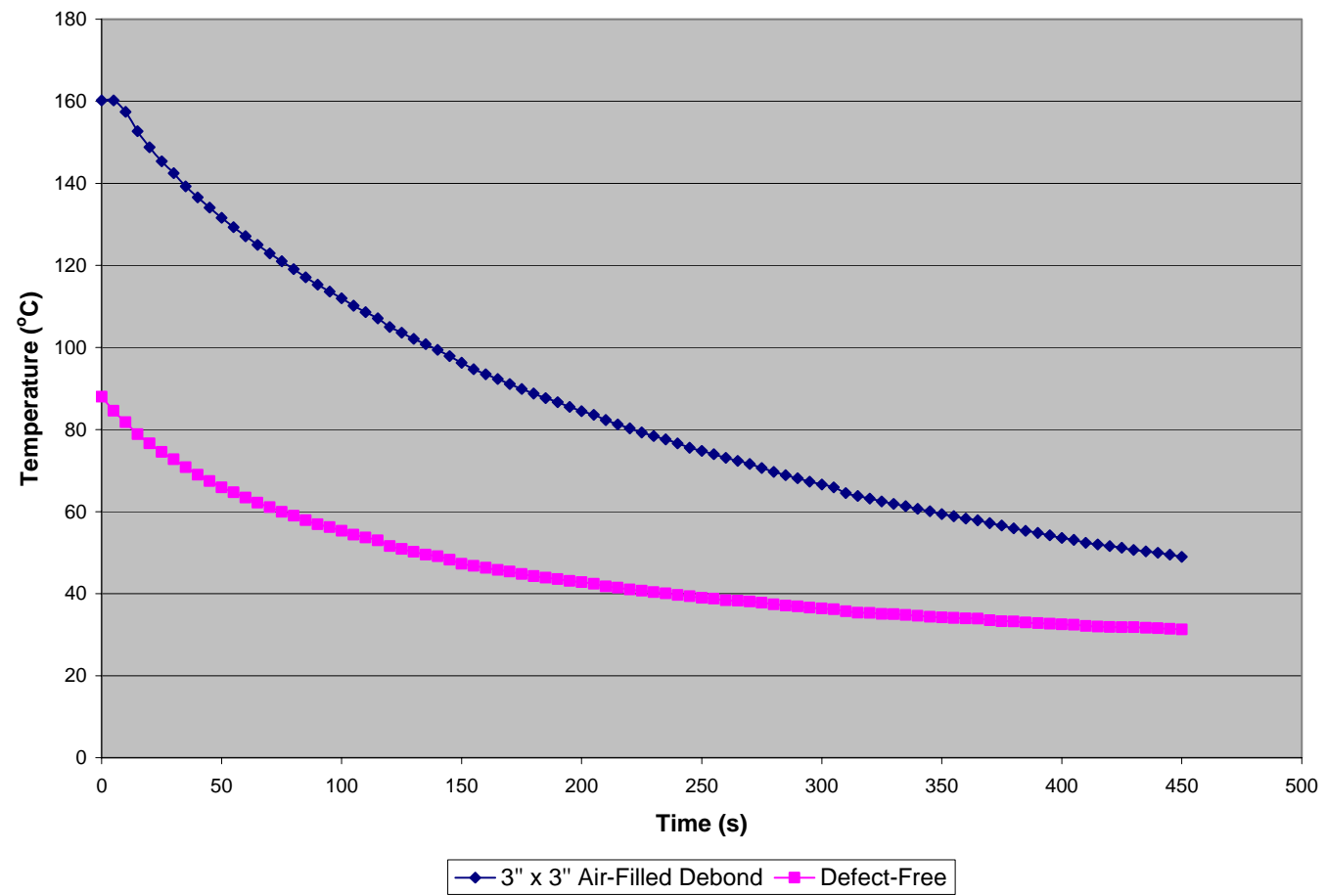

Figure 4-56 Cylinder no 3 (5 minutes heating with $1500 \mathrm{~W}$ setting of the heater)

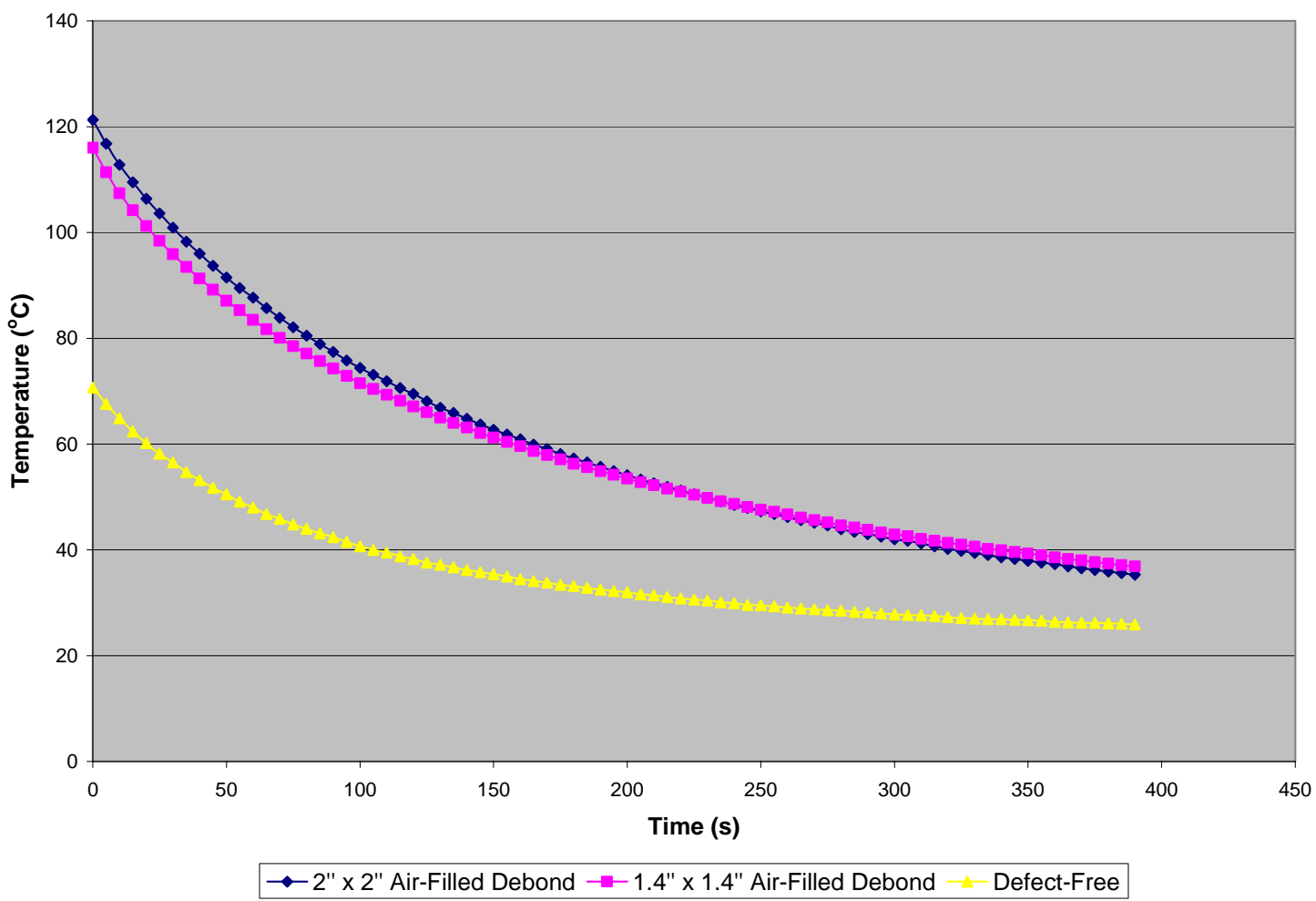

Figure 4-57 Cylinder no 4 (5 minutes heating with $750 \mathrm{~W}$ setting of the heater) 


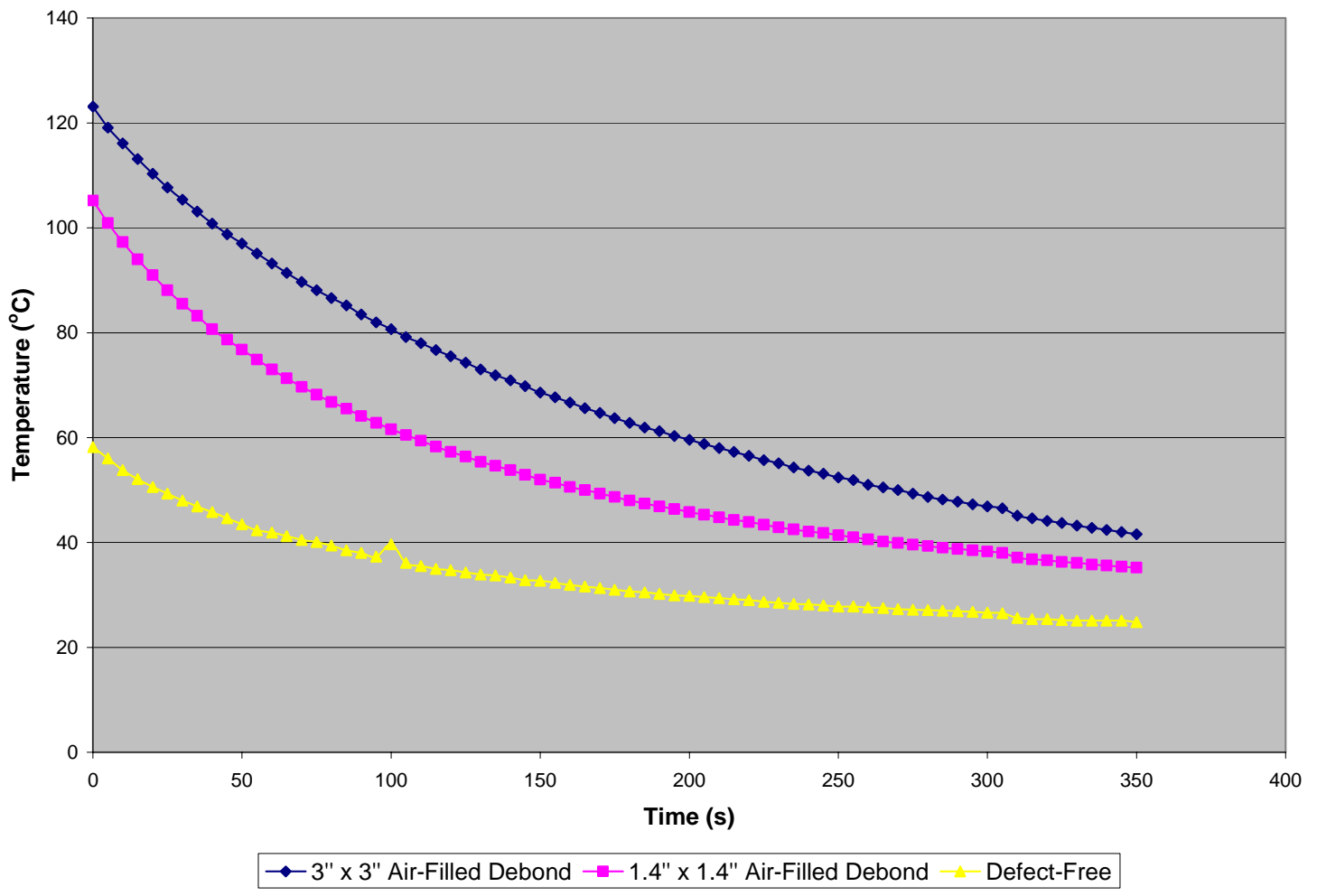

Figure 4-58 Cylinder no 5 (5 minutes heating with $750 \mathrm{~W}$ setting of the heater)

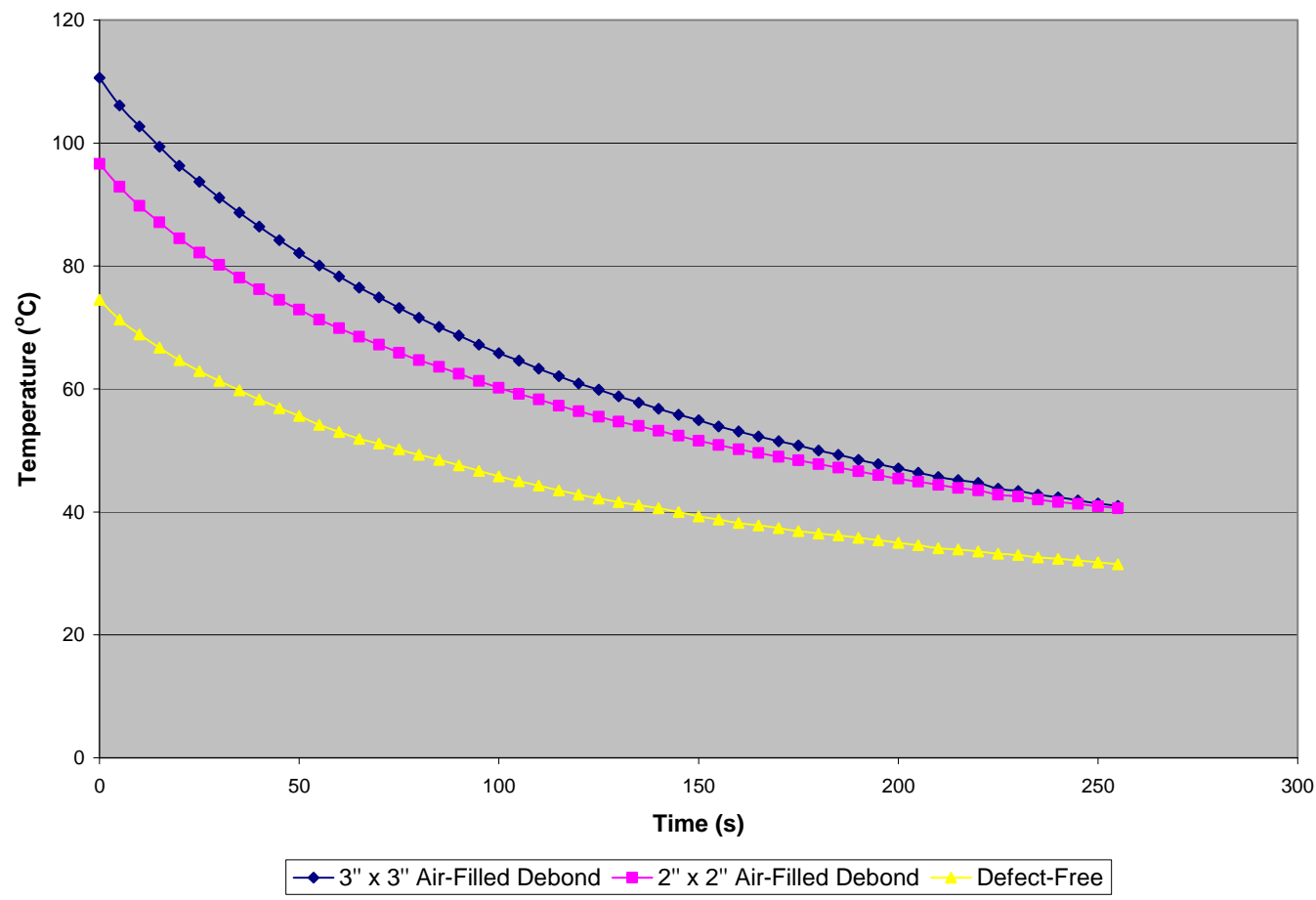

Figure 4-59 Cylinder no 6 (5 minutes heating with 750W setting of the heater) 


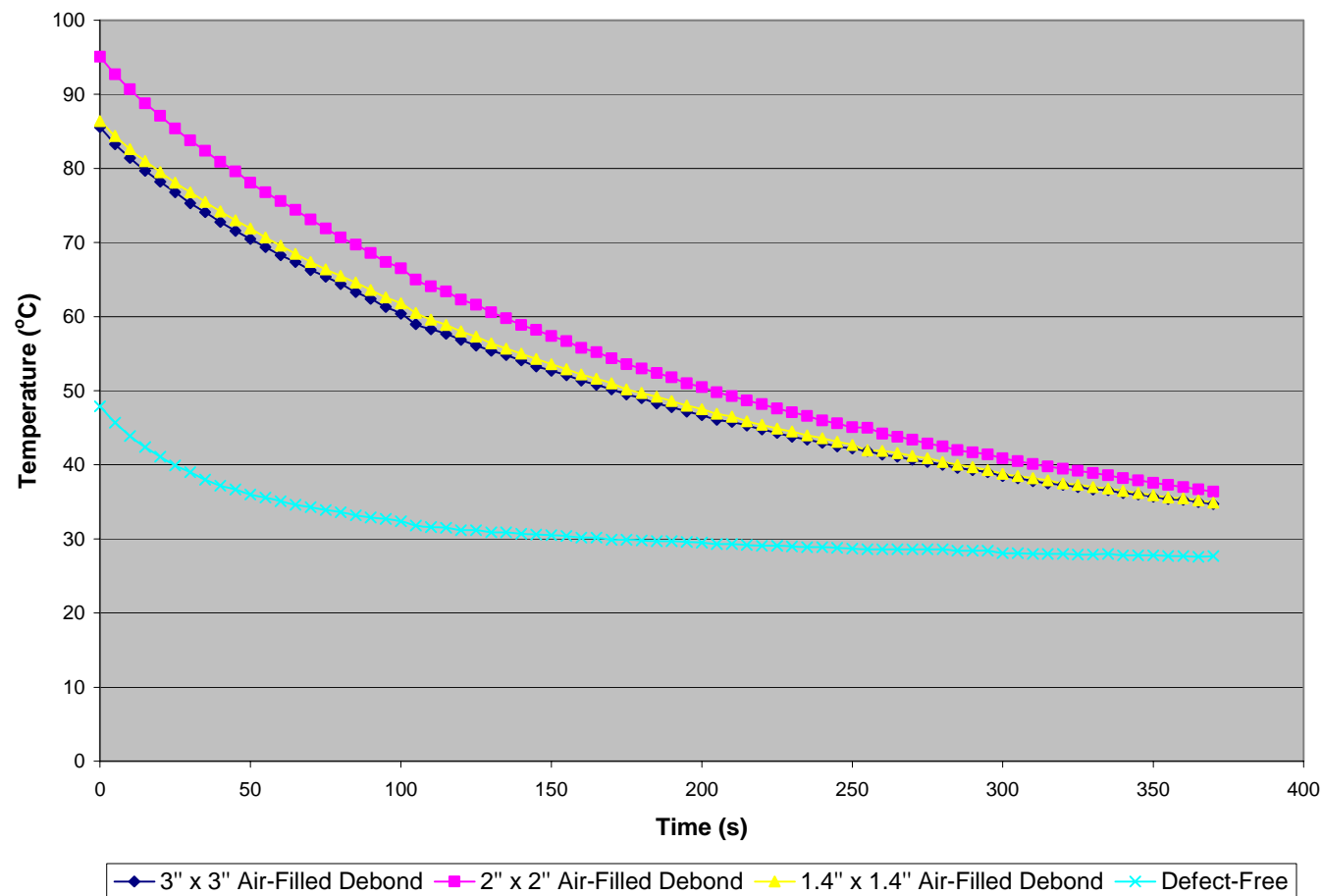

Figure 4-60 Cylinder no 7 (5 minutes heating with $750 \mathrm{~W}$ setting of the heater)

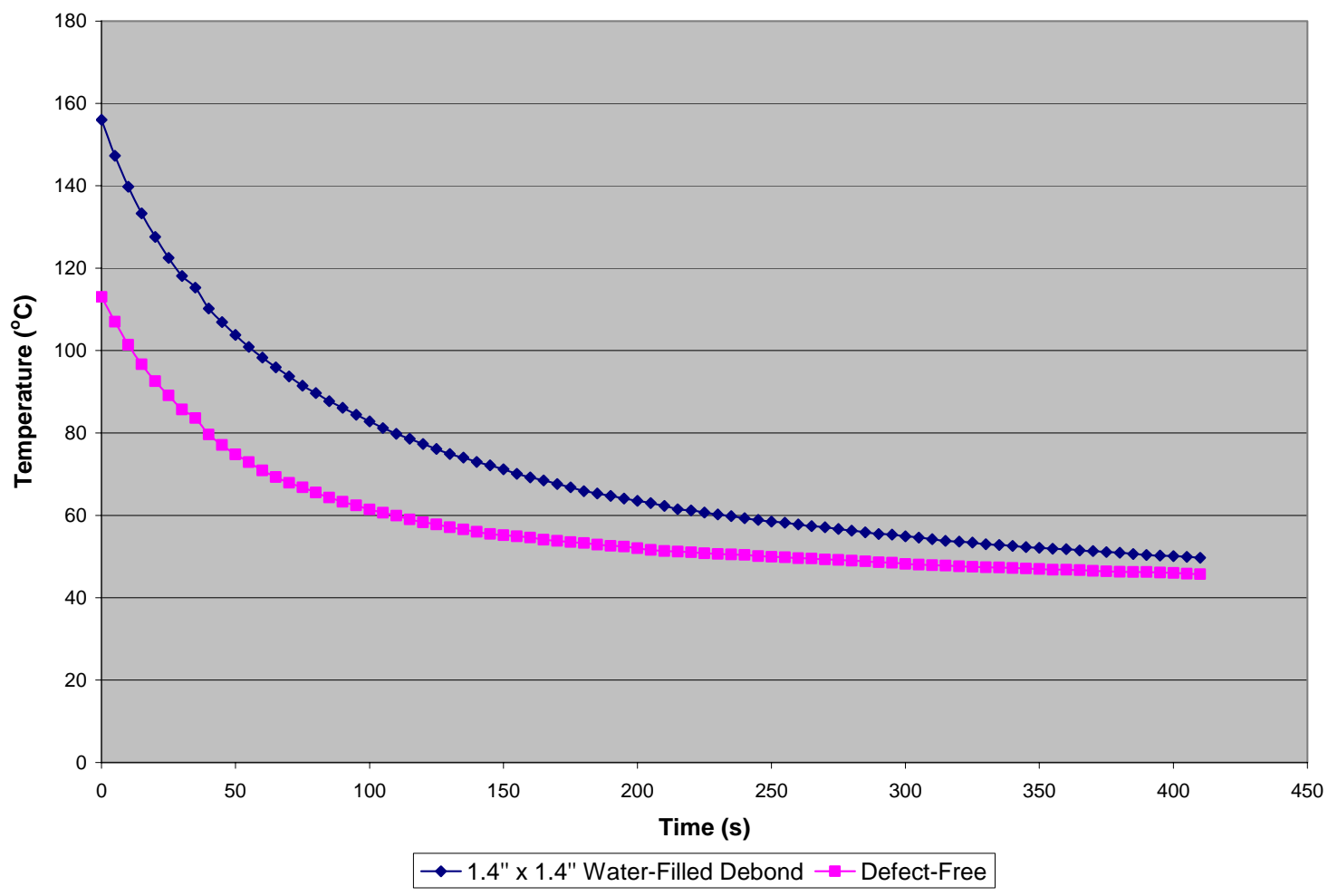

Figure 4-61 Cylinder no 8 ( 5 minutes heating with $1500 \mathrm{~W}$ setting of the heater) 


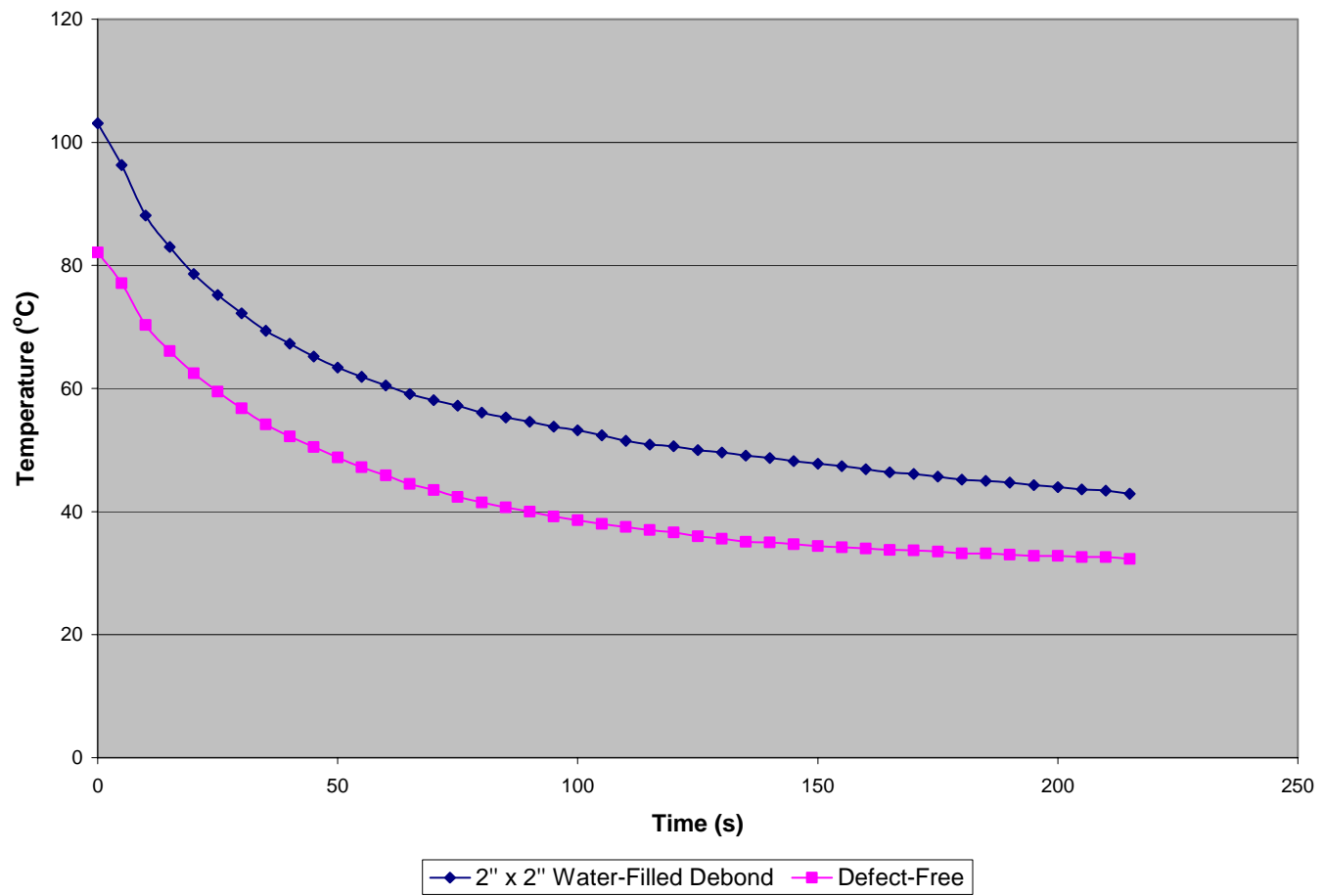

Figure 4-62 Cylinder no 9 (5 minutes heating with $1500 \mathrm{~W}$ setting of the heater)

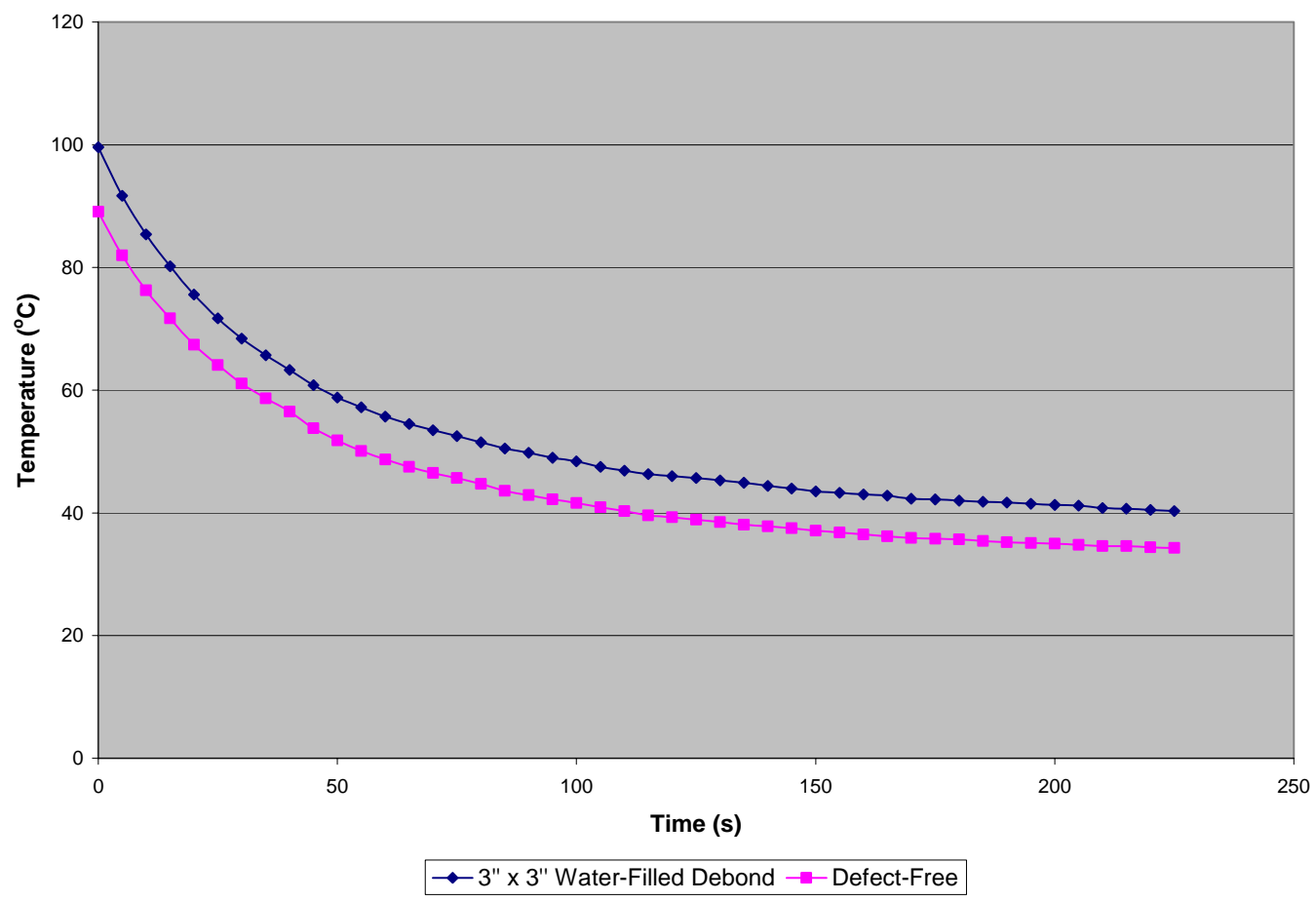

Figure 4-63 Cylinder no 10 (5 minutes heating with $1500 \mathrm{~W}$ setting of the heater) 


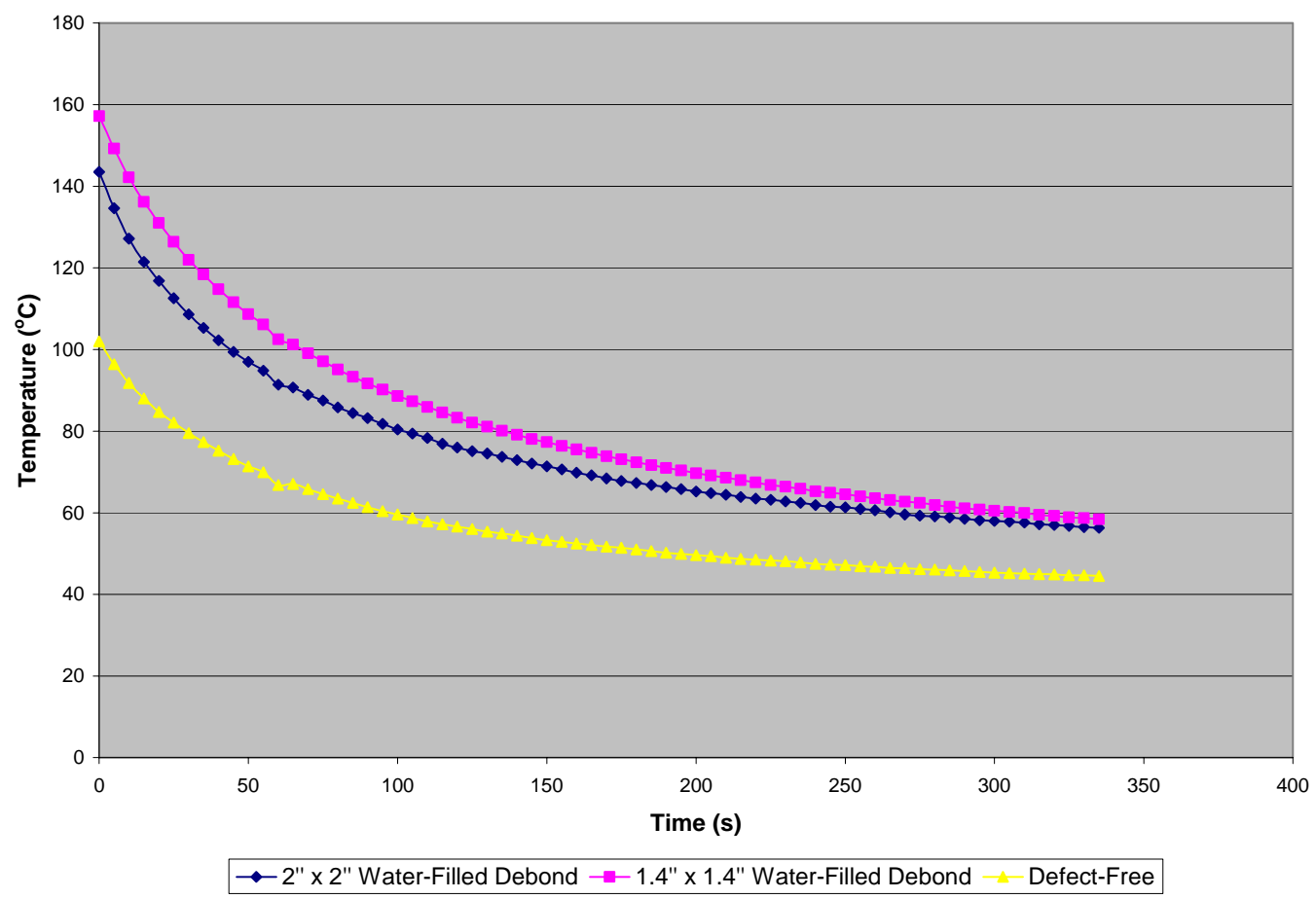

Figure 4-64 Cylinder no 11 (5 minutes heating with $1500 \mathrm{~W}$ setting of the heater)

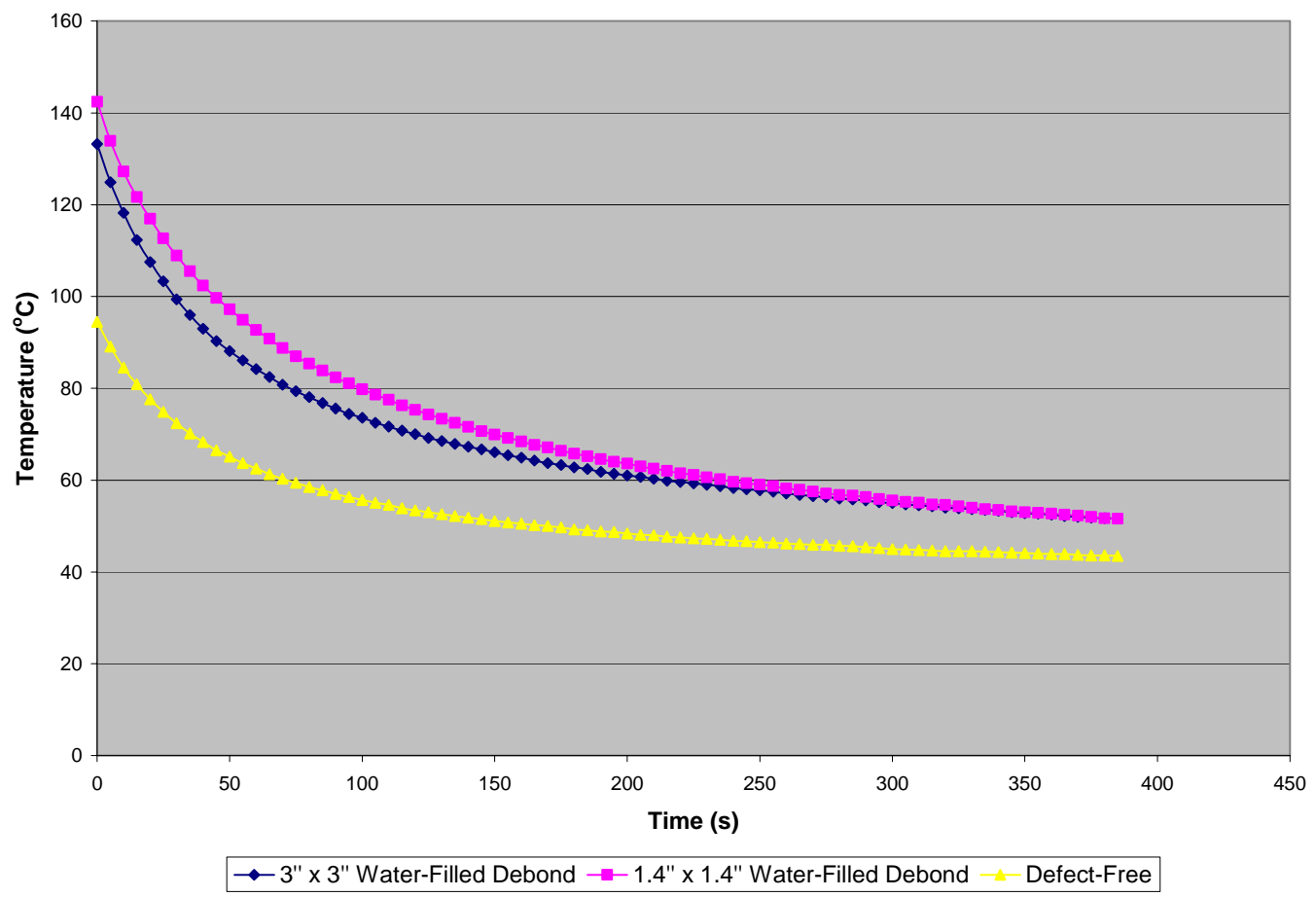

Figure 4-65 Cylinder no 12 (5 minutes heating with $1500 \mathrm{~W}$ setting of the heater) 


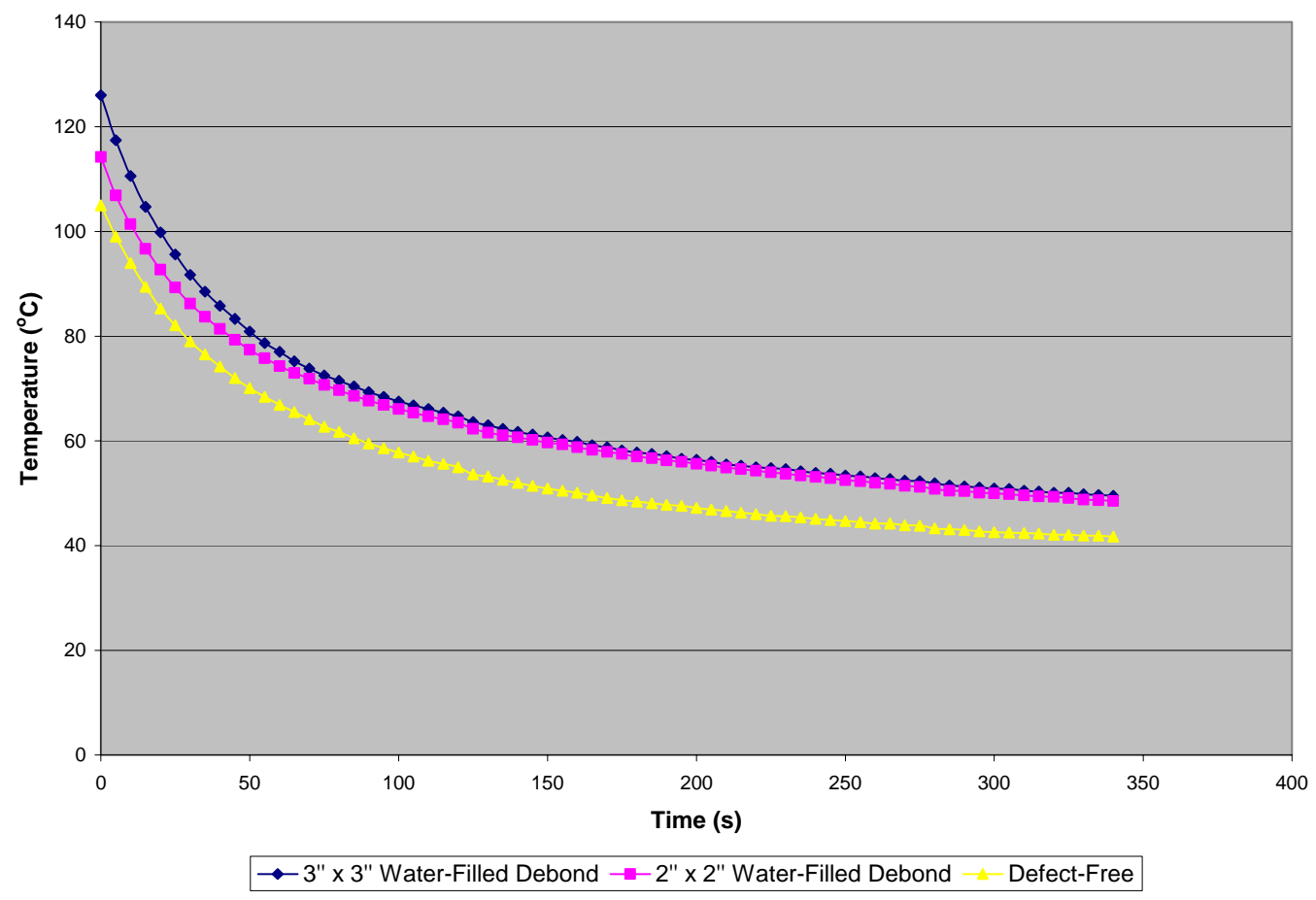

Figure 4-66 Cylinder no 13 (5 minutes heating with $1500 \mathrm{~W}$ setting of the heater)

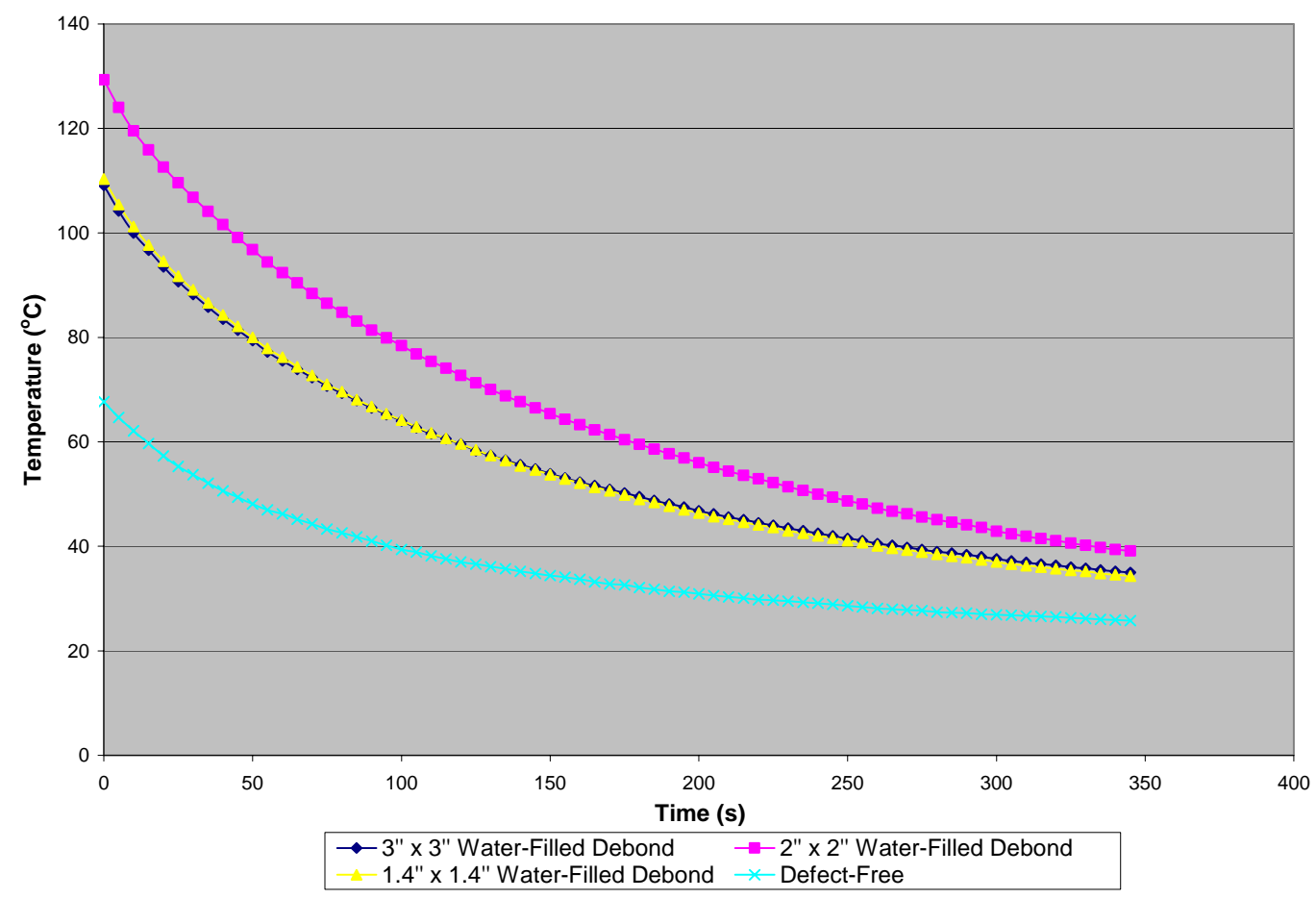

Figure 4-67 Cylinder no 14 (3.5 minutes heating with $750 \mathrm{~W}$ setting of the heater) 


\subsubsection{Surface Temperature versus Time Curves for CFRP Wrapped Cylinders}

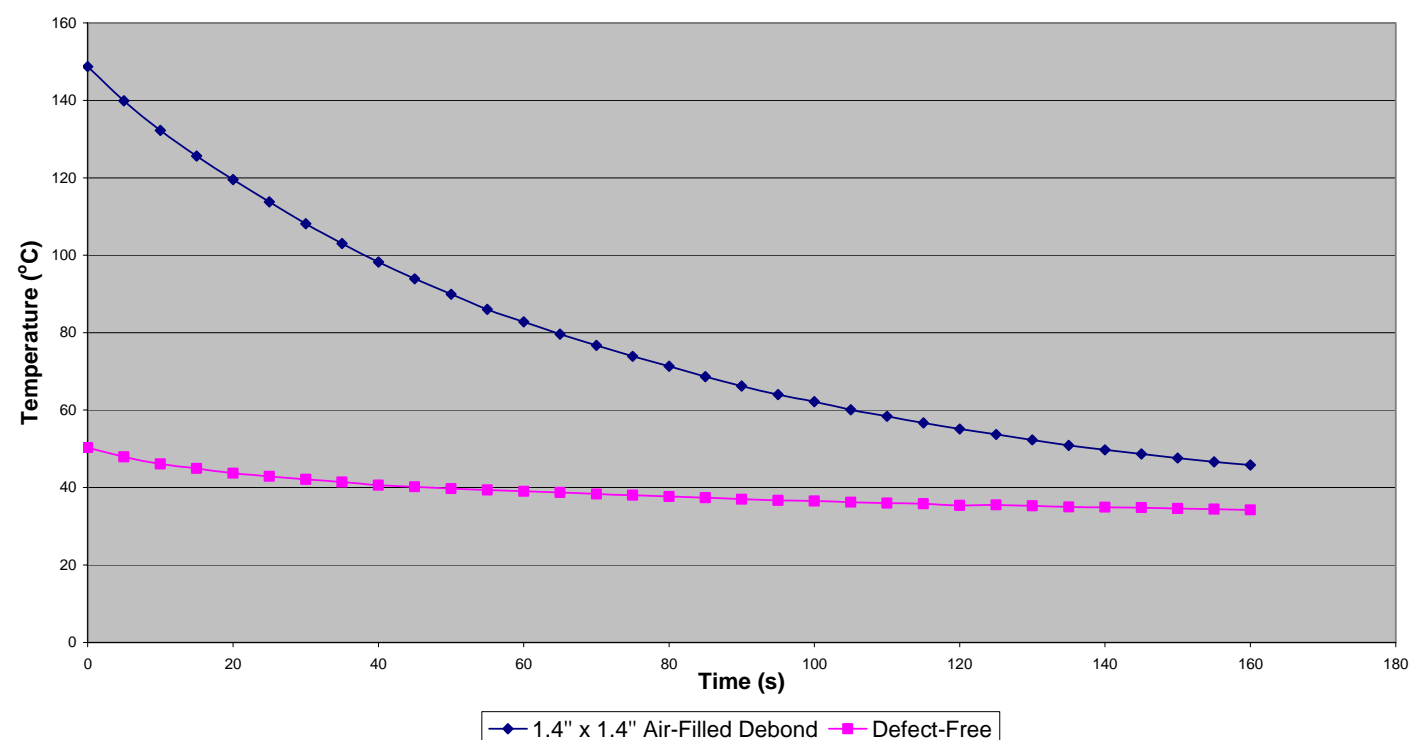

Figure 4-68 Cylinder no 15 ( 3 minutes heating with $1500 \mathrm{~W}$ setting of the heater)

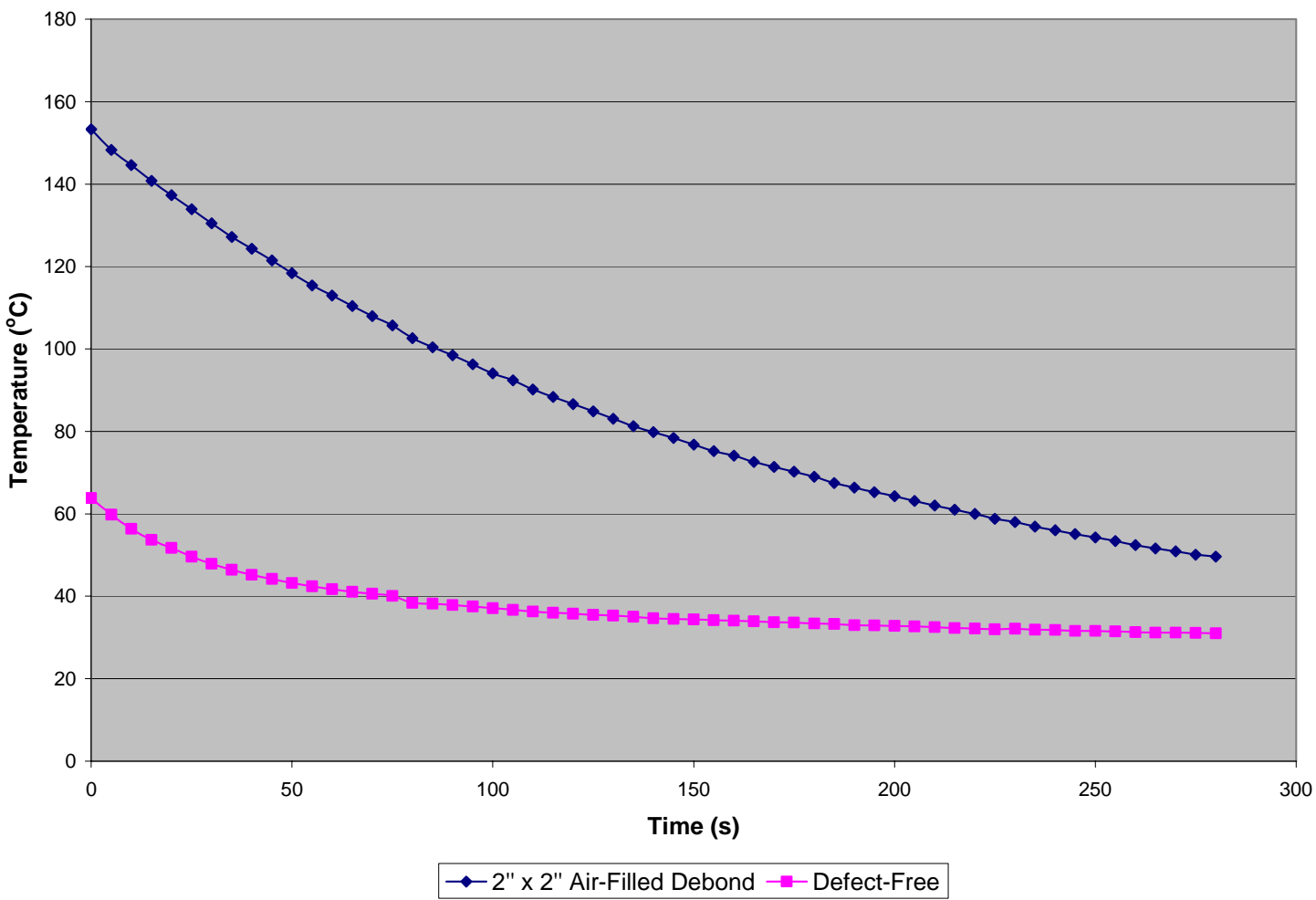

Figure 4-69 Cylinder no 16 (3 minutes heating with $1500 \mathrm{~W}$ setting of the heater) 


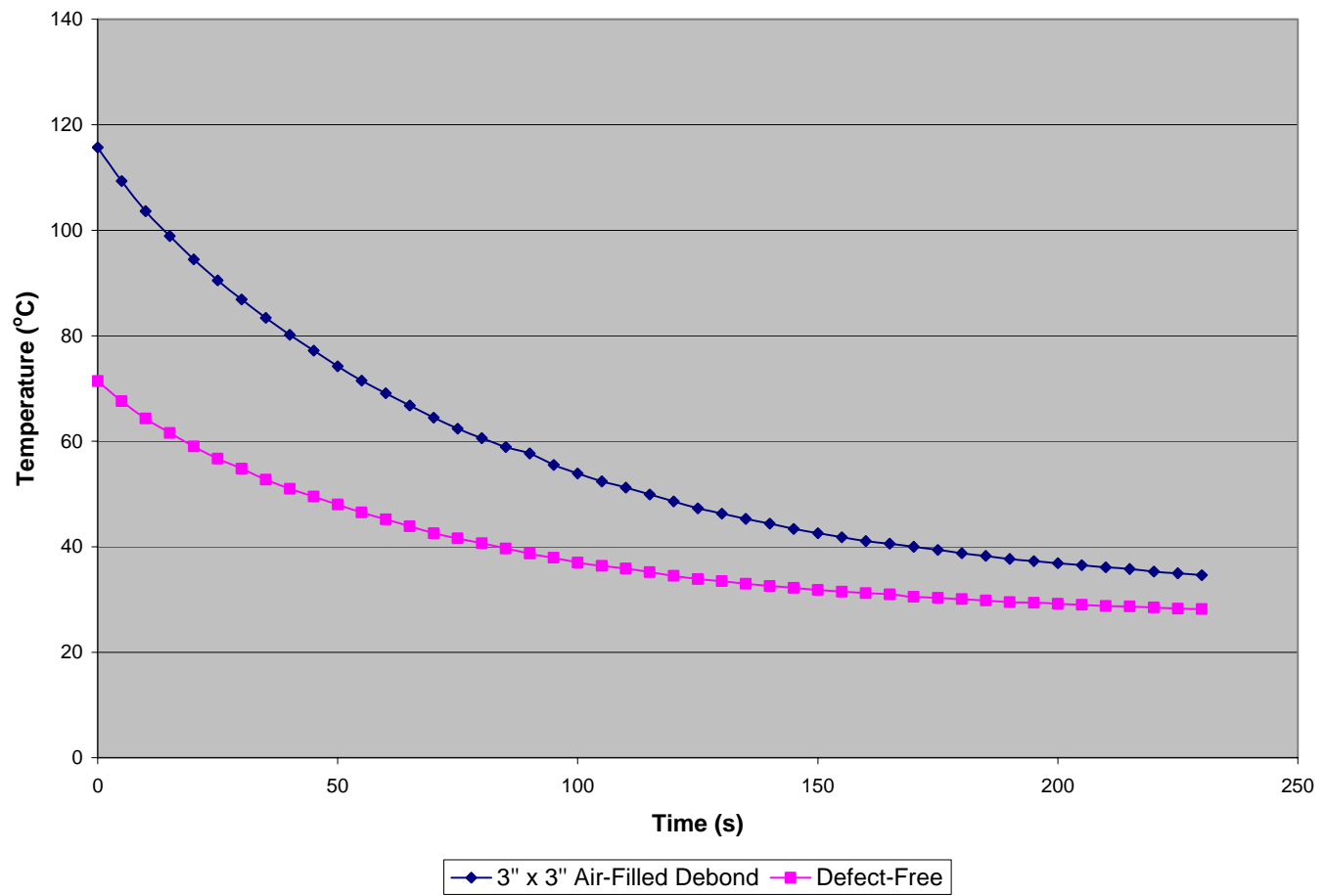

Figure 4-70 Cylinder no 17 (5 minutes heating with $750 \mathrm{~W}$ setting of the heater)

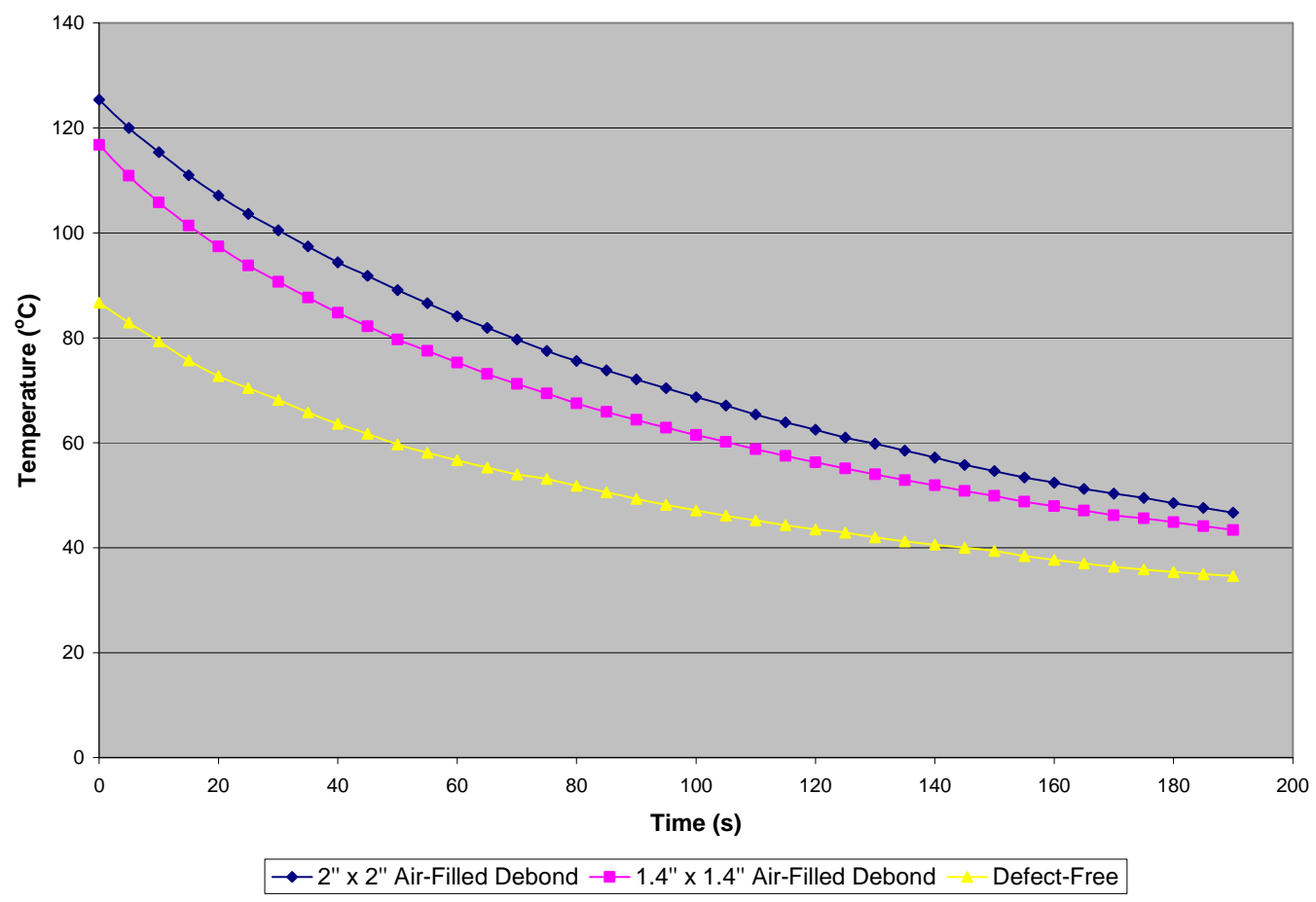

Figure 4-71 Cylinder no 18 ( 5 minutes heating with $750 \mathrm{~W}$ setting of the heater) 


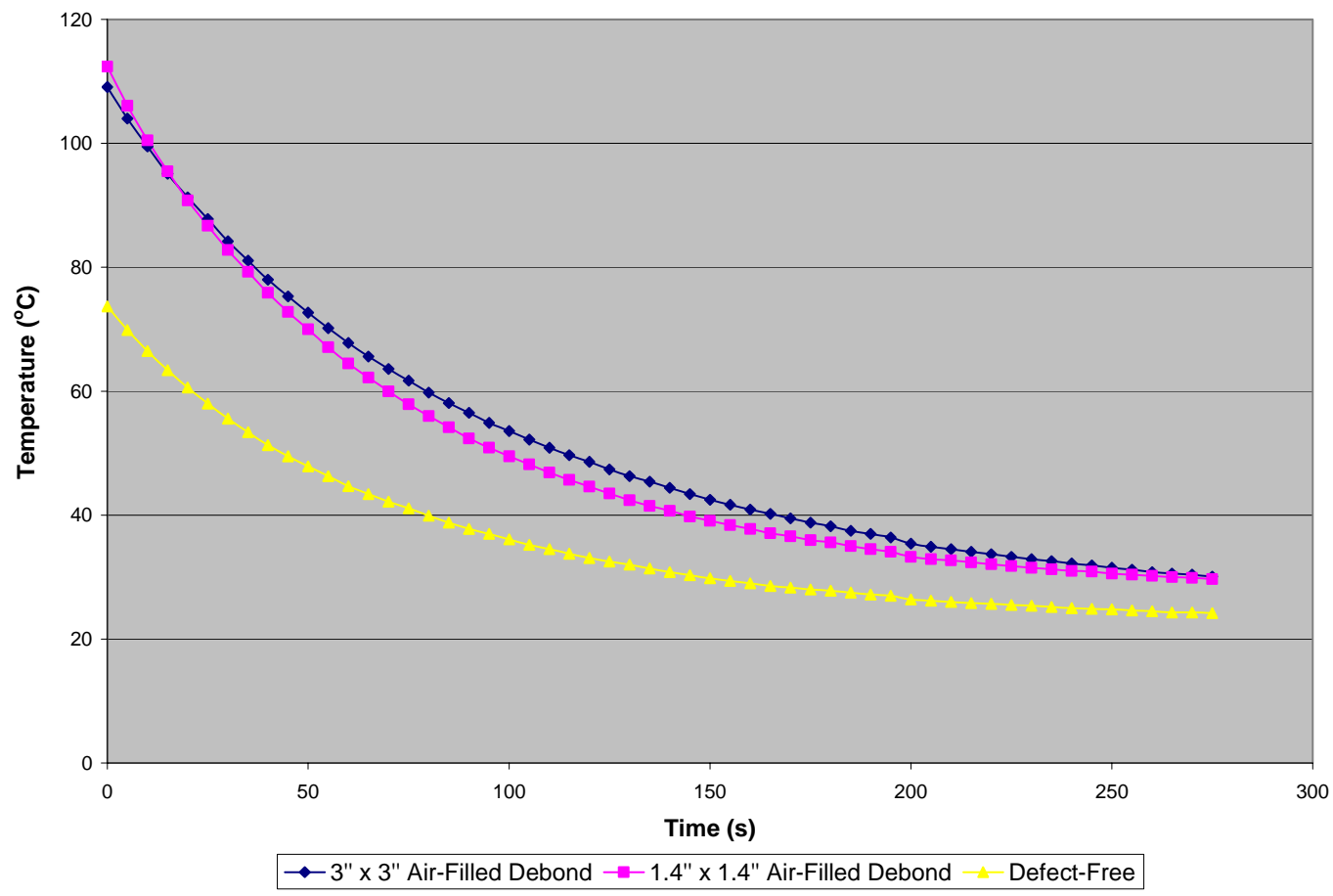

Figure 4-72 Cylinder no 19 ( 5 minutes heating with $750 \mathrm{~W}$ setting of the heater)

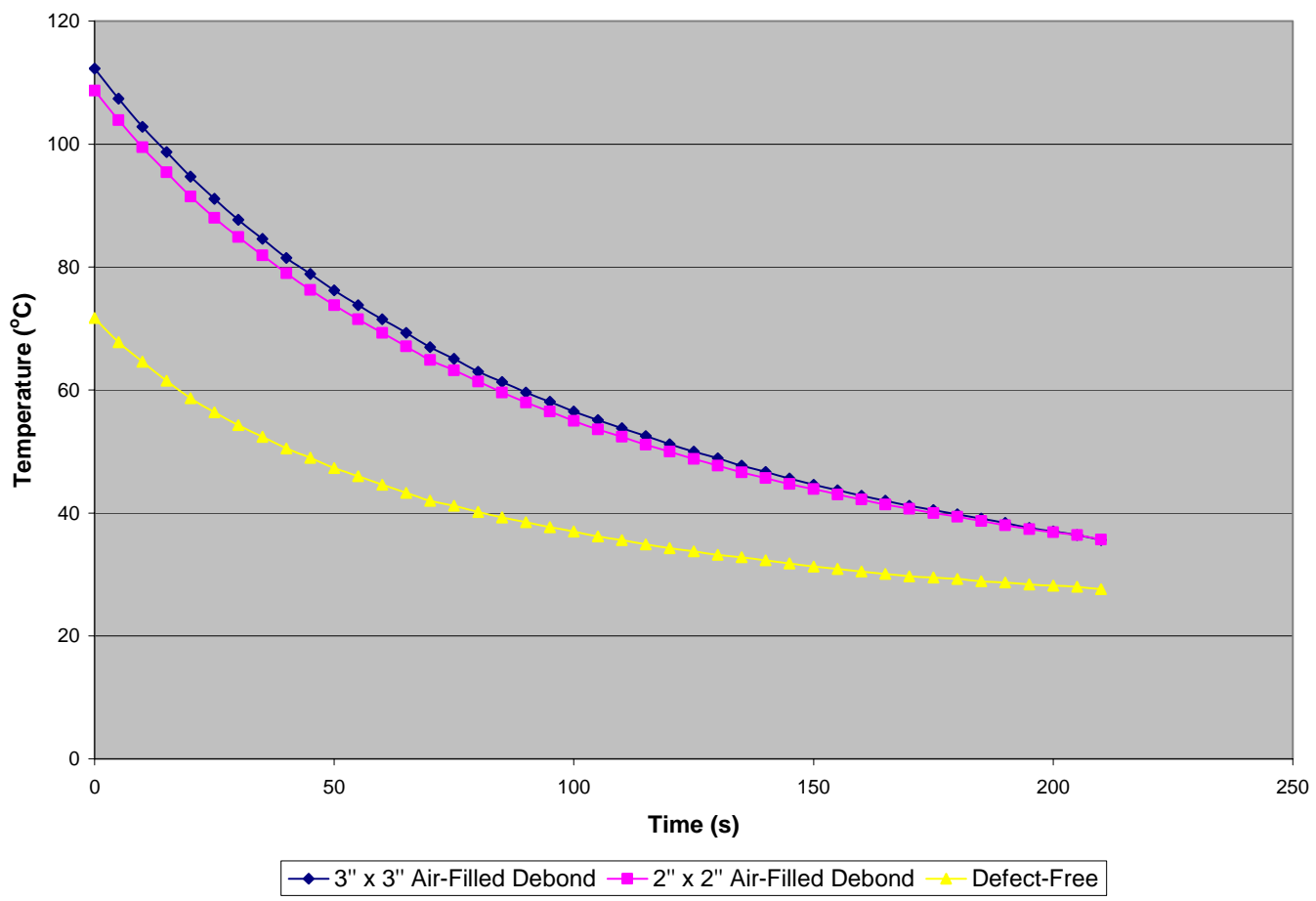

Figure 4-73 Cylinder no 20 (5 minutes heating with $750 \mathrm{~W}$ setting of the heater) 


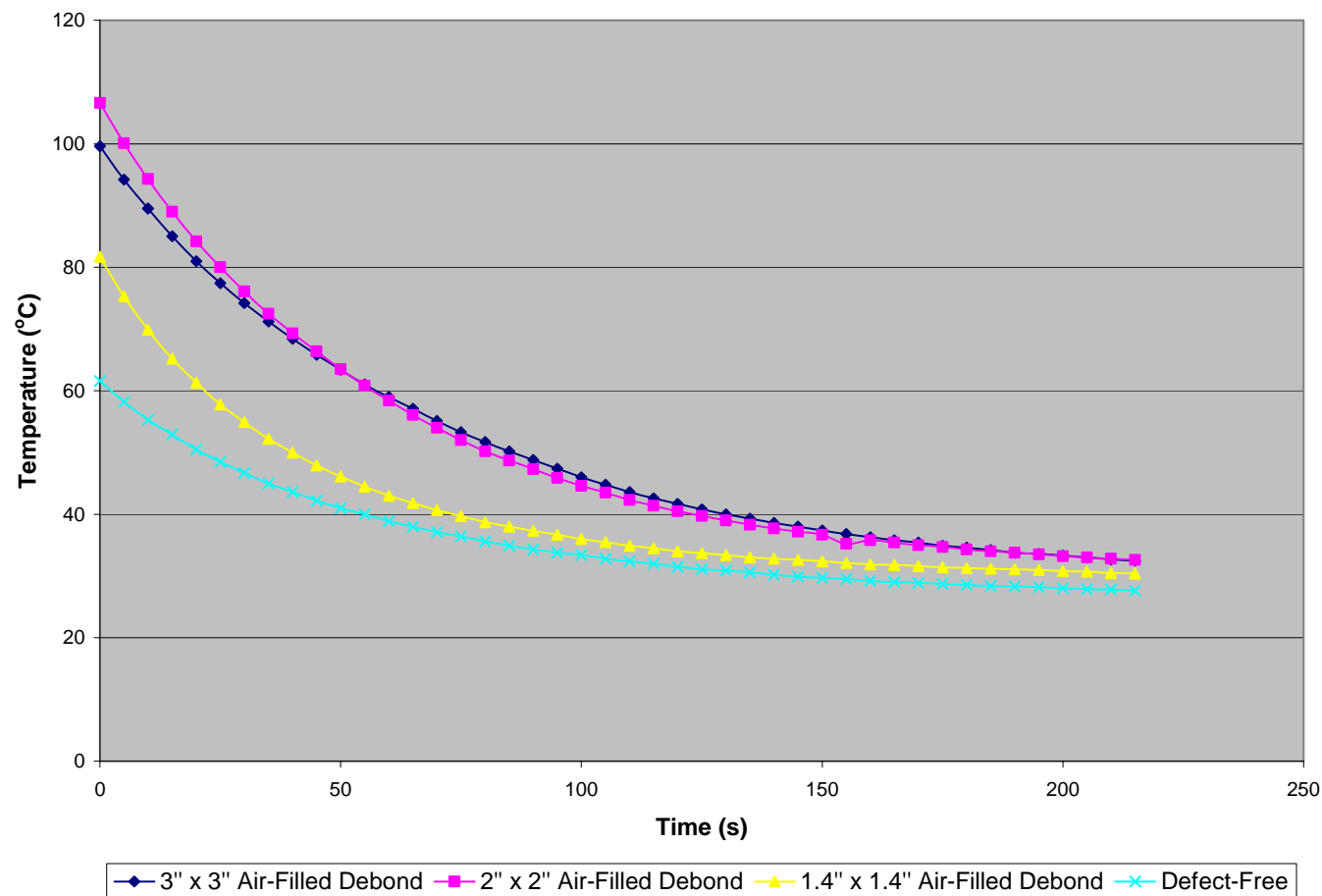

Figure 4-74 Cylinder no 21 ( 5 minutes heating with $750 \mathrm{~W}$ setting of the heater)

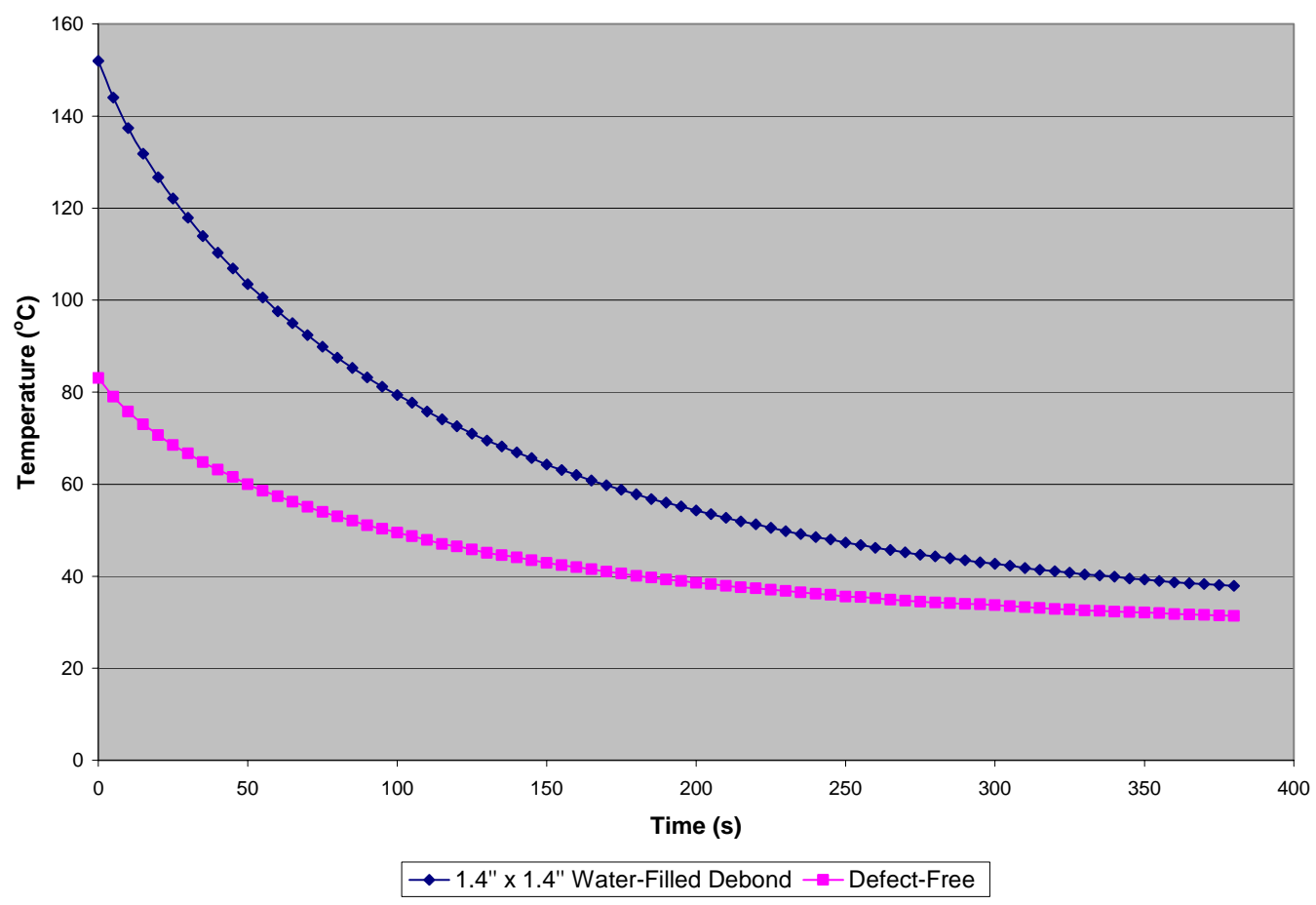

Figure 4-75 Cylinder no 22 (5 minutes heating with $1500 \mathrm{~W}$ setting of the heater) 


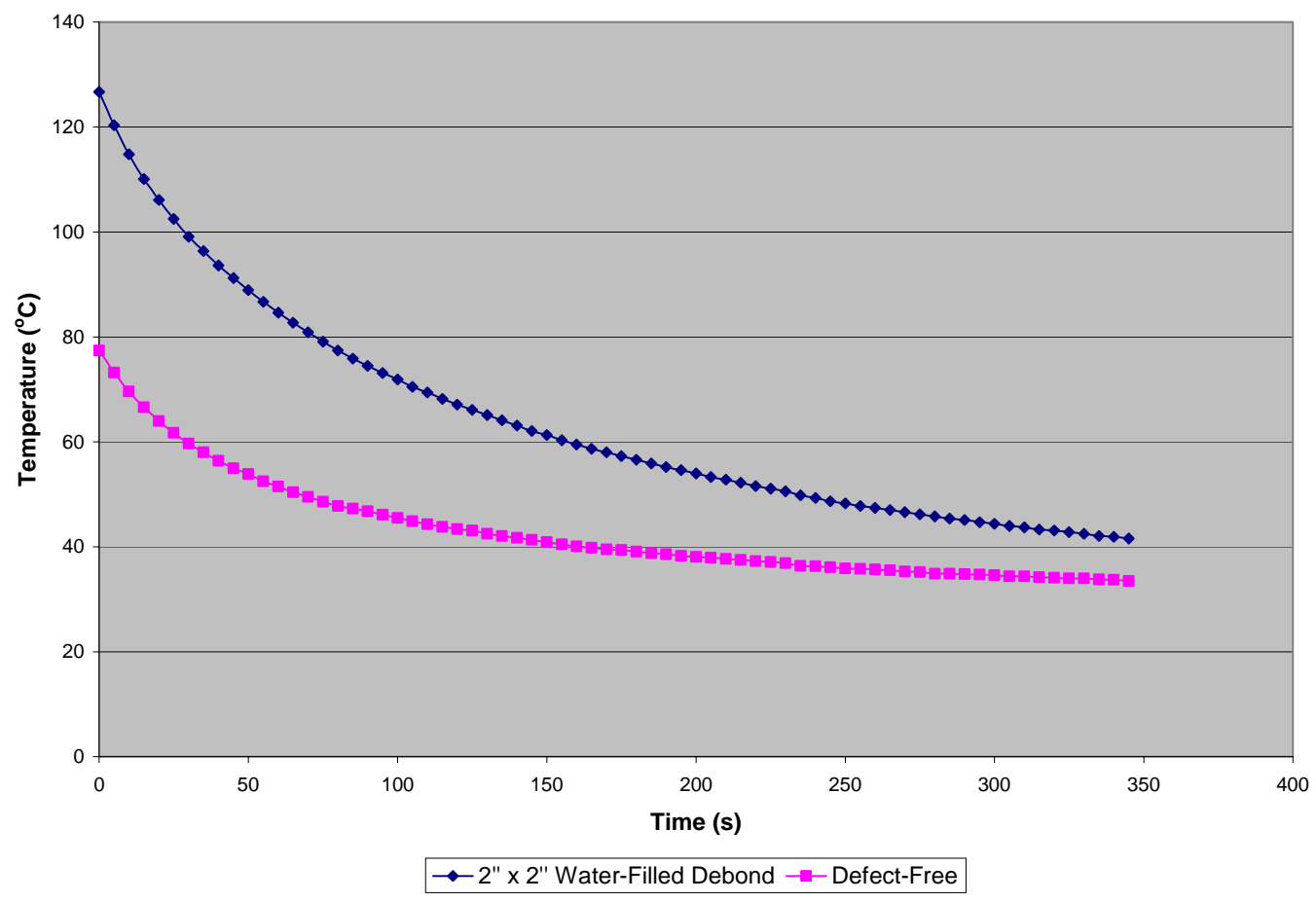

Figure 4-76 Cylinder no 23 (5 minutes heating with $1500 \mathrm{~W}$ setting of the heater)

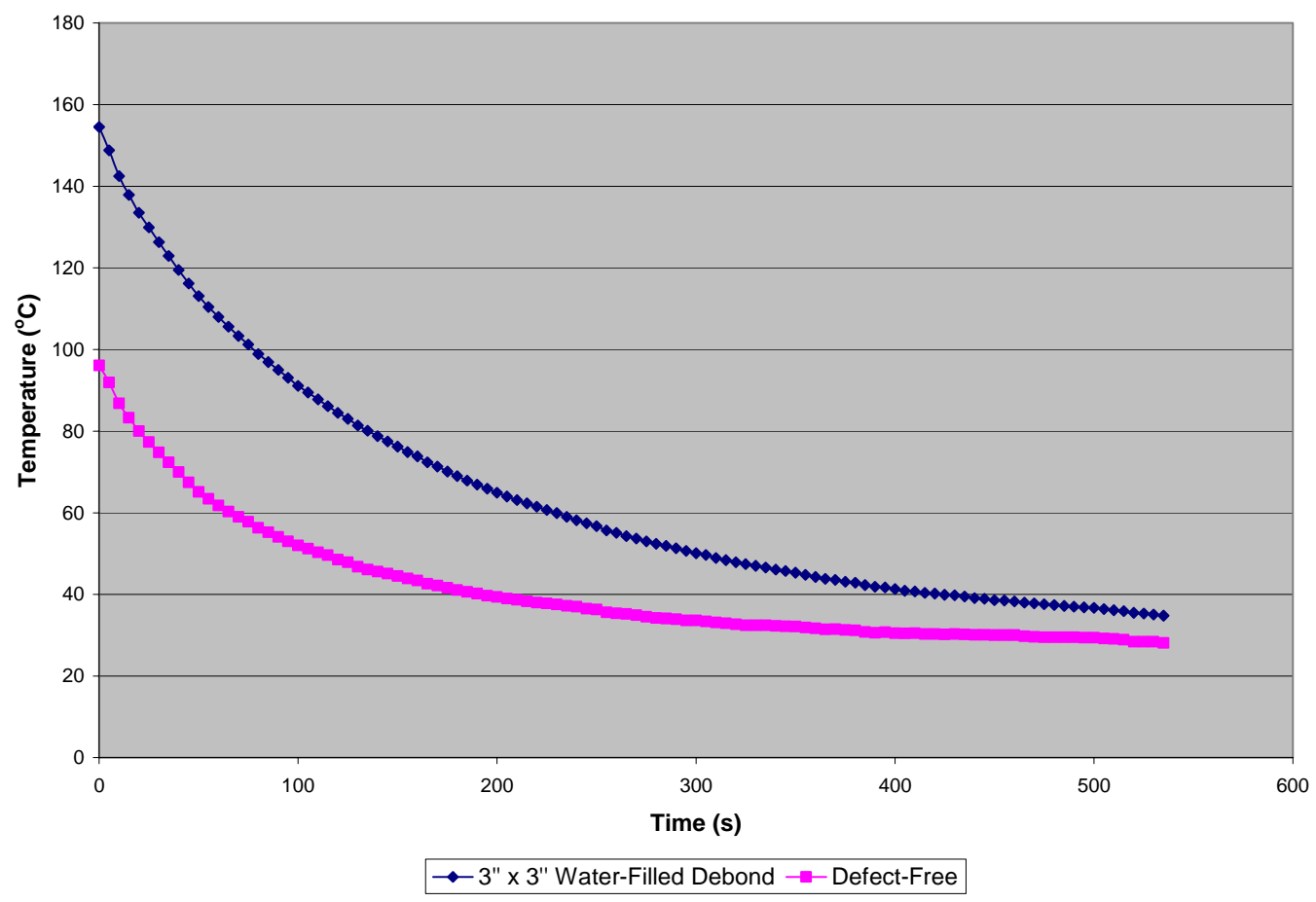

Figure 4-77 Cylinder no 24 (5 minutes heating with $1500 \mathrm{~W}$ setting of the heater) 


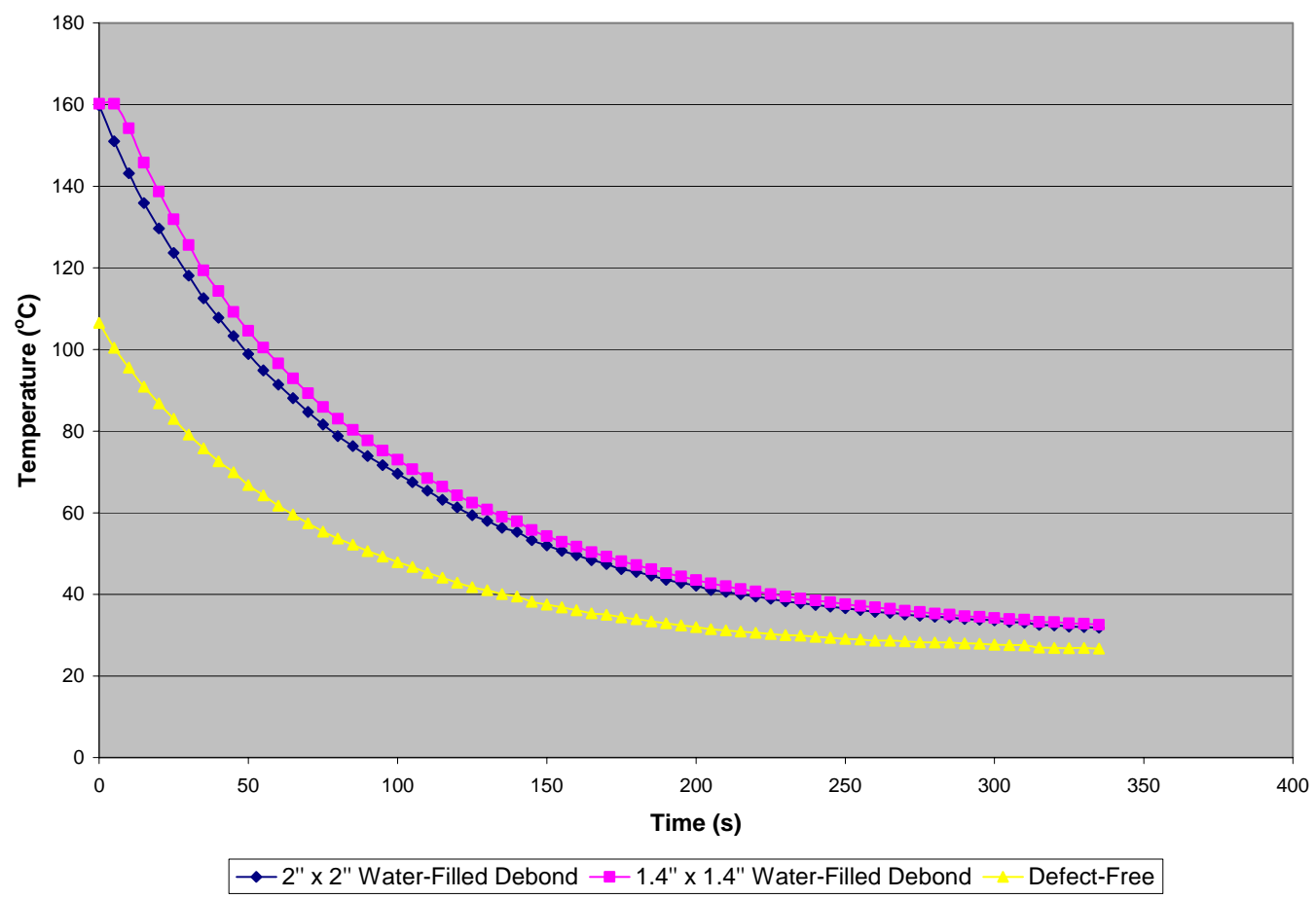

Figure 4-78 Cylinder no 25 (5 minutes heating with $1500 \mathrm{~W}$ setting of the heater)

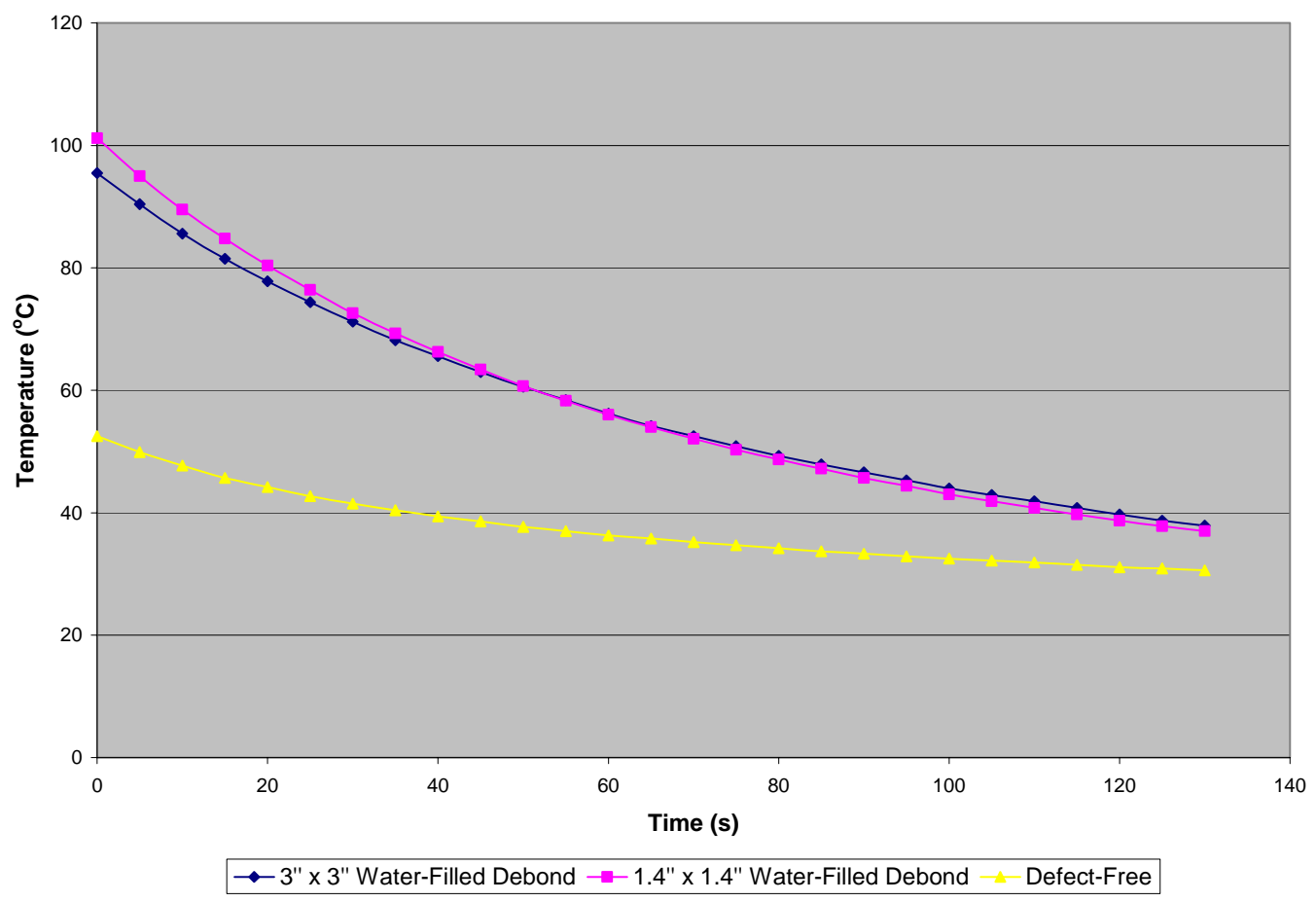

Figure 4-79 Cylinder no 26 ( 3.5 minutes heating with $750 \mathrm{~W}$ setting of the heater) 


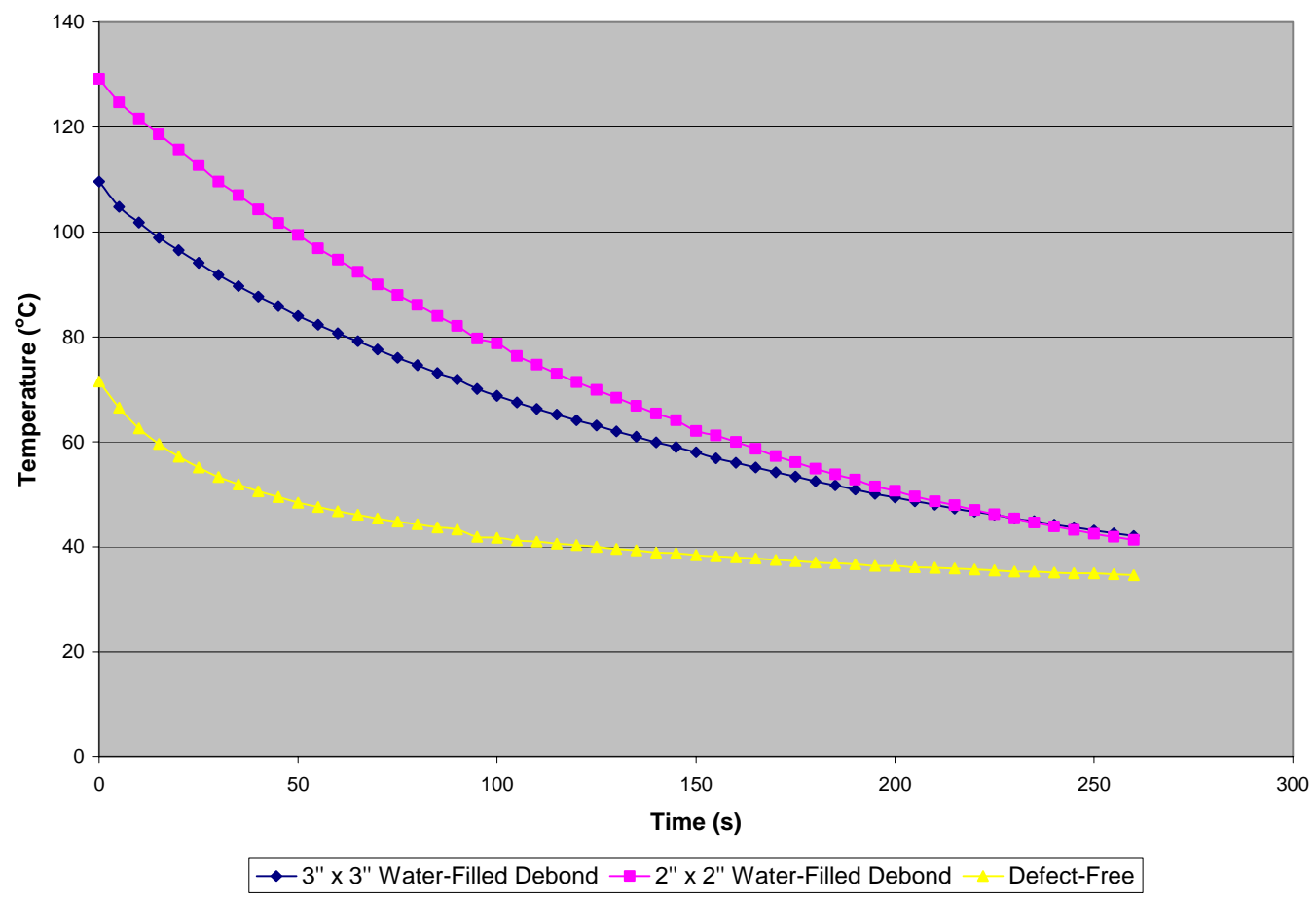

Figure 4-80 Cylinder no 27 (3.5 minutes heating with $750 \mathrm{~W}$ setting of the heater)

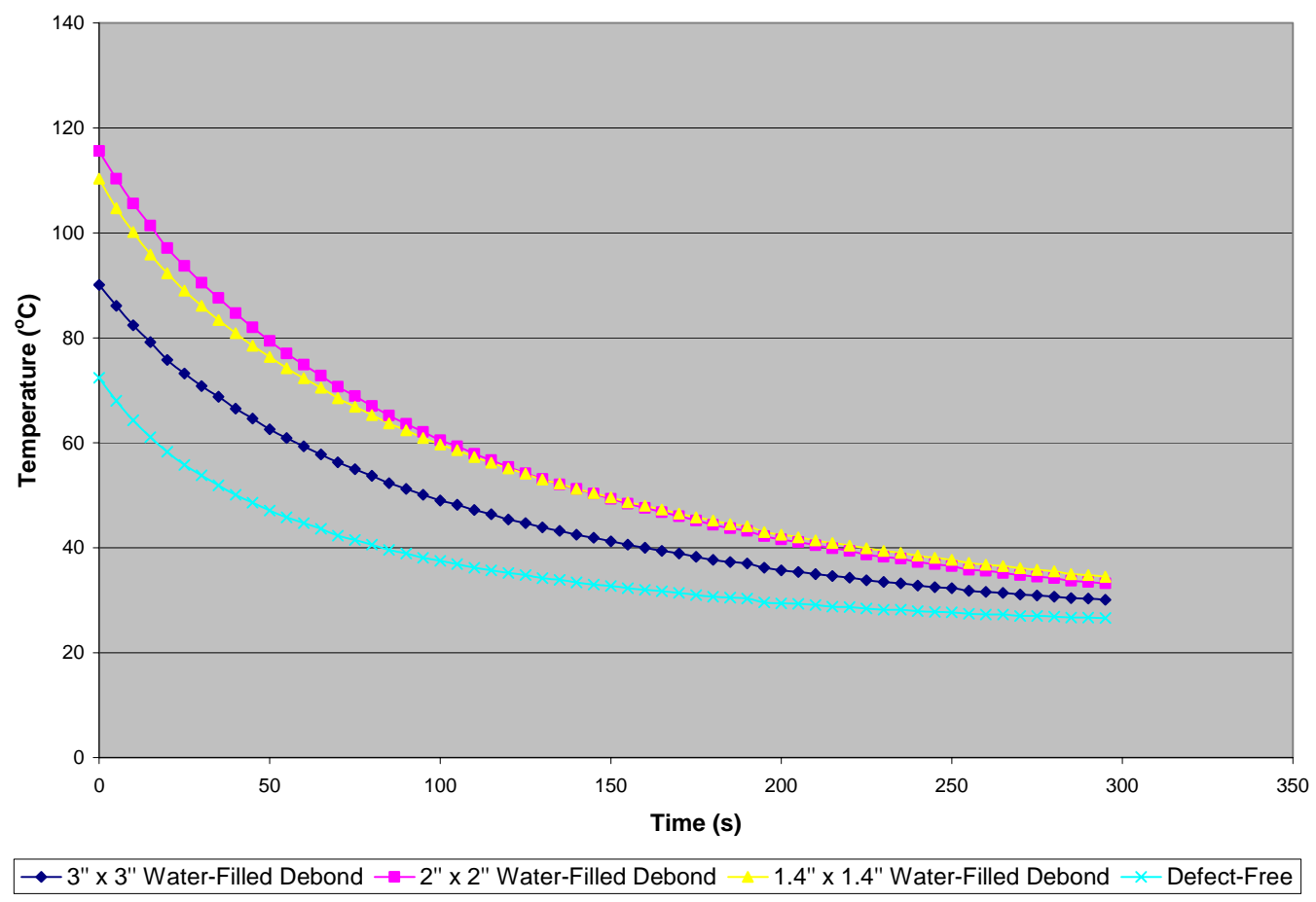

Figure 4-81Cylinder no 28 (3.5 minutes heating with $750 \mathrm{~W}$ setting of the heater) 


\subsubsection{Thermal Difference versus Time Curves for GFRP Wrapped Cylinders}

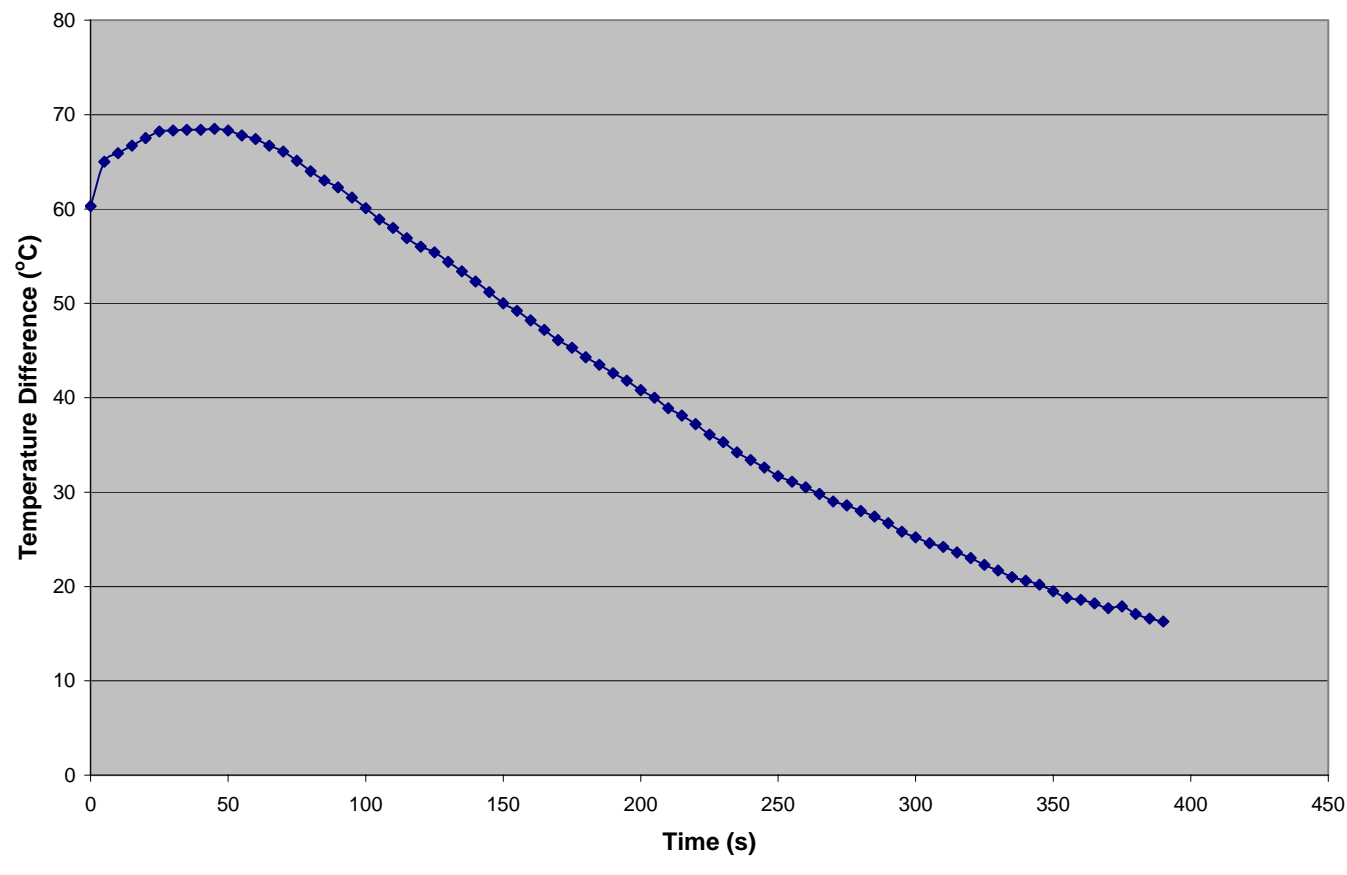

$\bullet-1.4 "$ x 1.4" Air -Filled Debond minus Defect-Free

Figure 4-82 Cylinder no 1 ( 3 minutes heating with $1500 \mathrm{~W}$ setting of the heater)

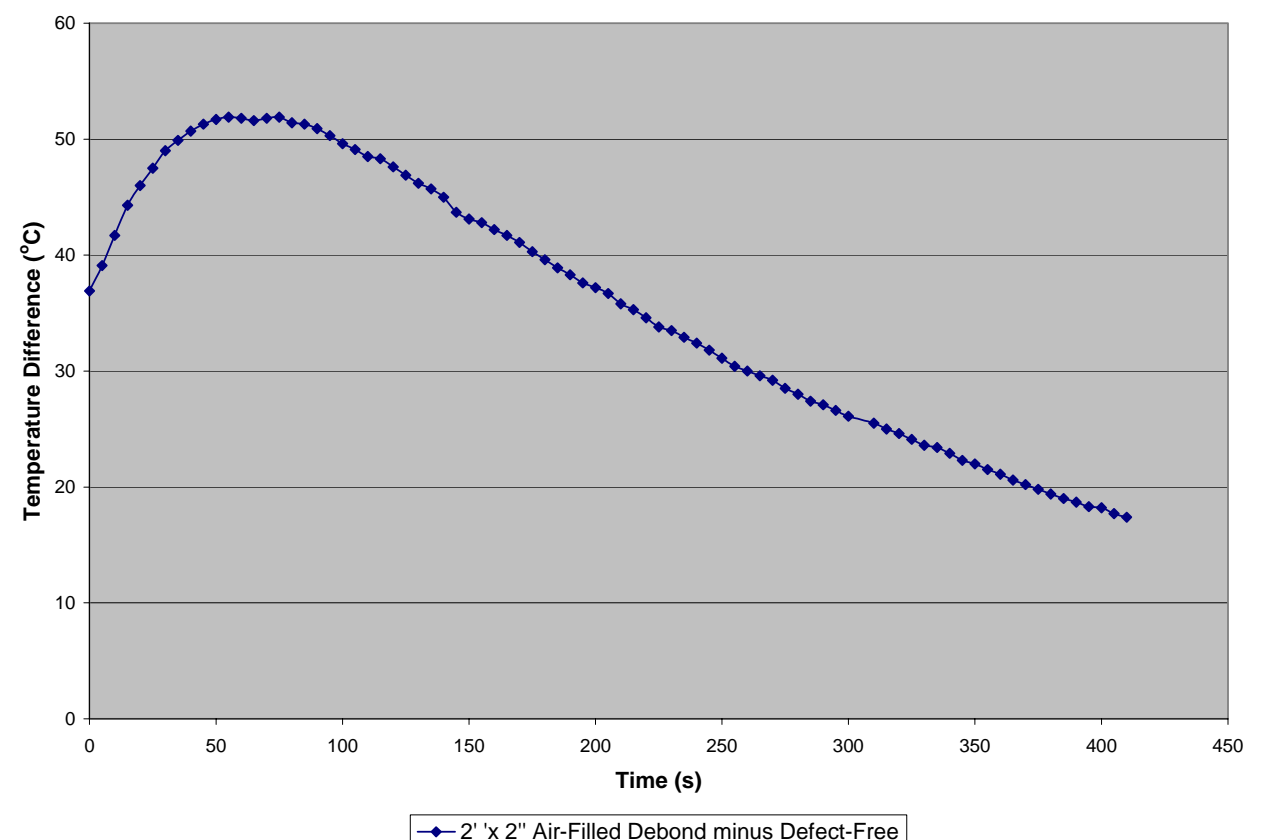

Figure 4-83 Cylinder no 2 ( 3 minutes heating with $1500 \mathrm{~W}$ setting of the heater) 


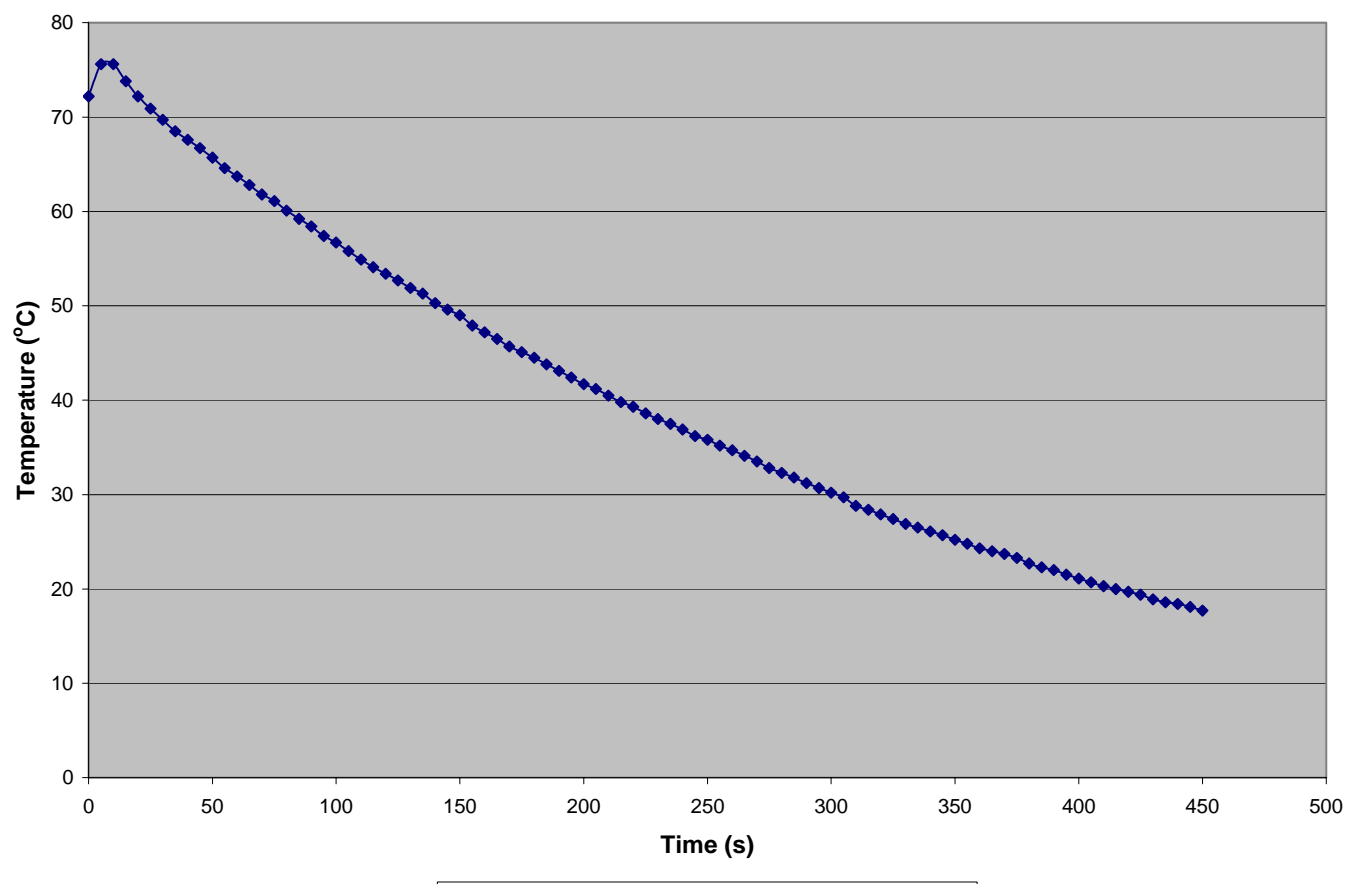

3" x 3" Air-Filled Debond minus Defect-Free

Figure 4-84 Cylinder no 3 ( 5 minutes heating with $1500 \mathrm{~W}$ setting of the heater)

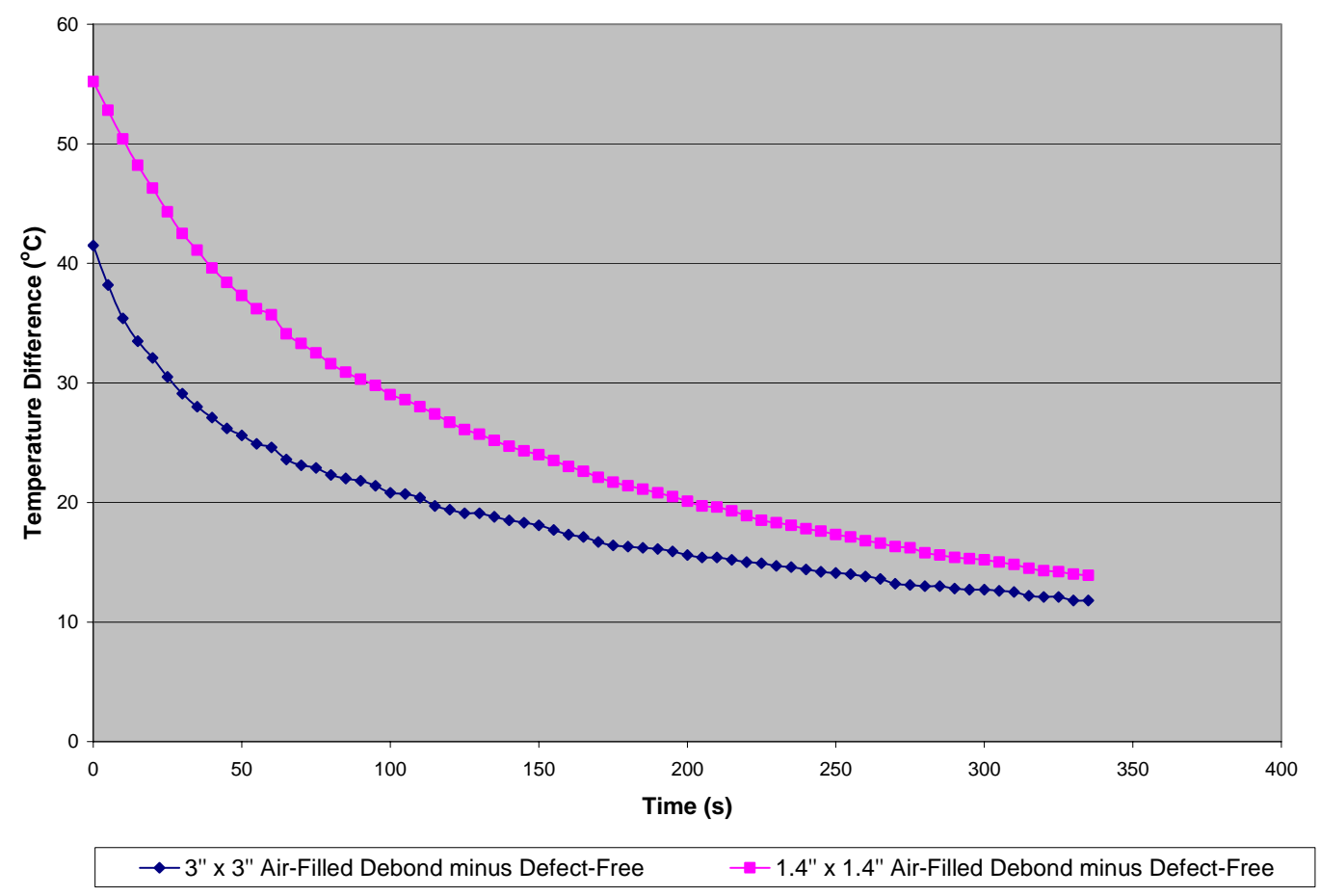

Figure 4-85 Cylinder no 12 (5 minutes heating with $750 \mathrm{~W}$ setting of the heater) 


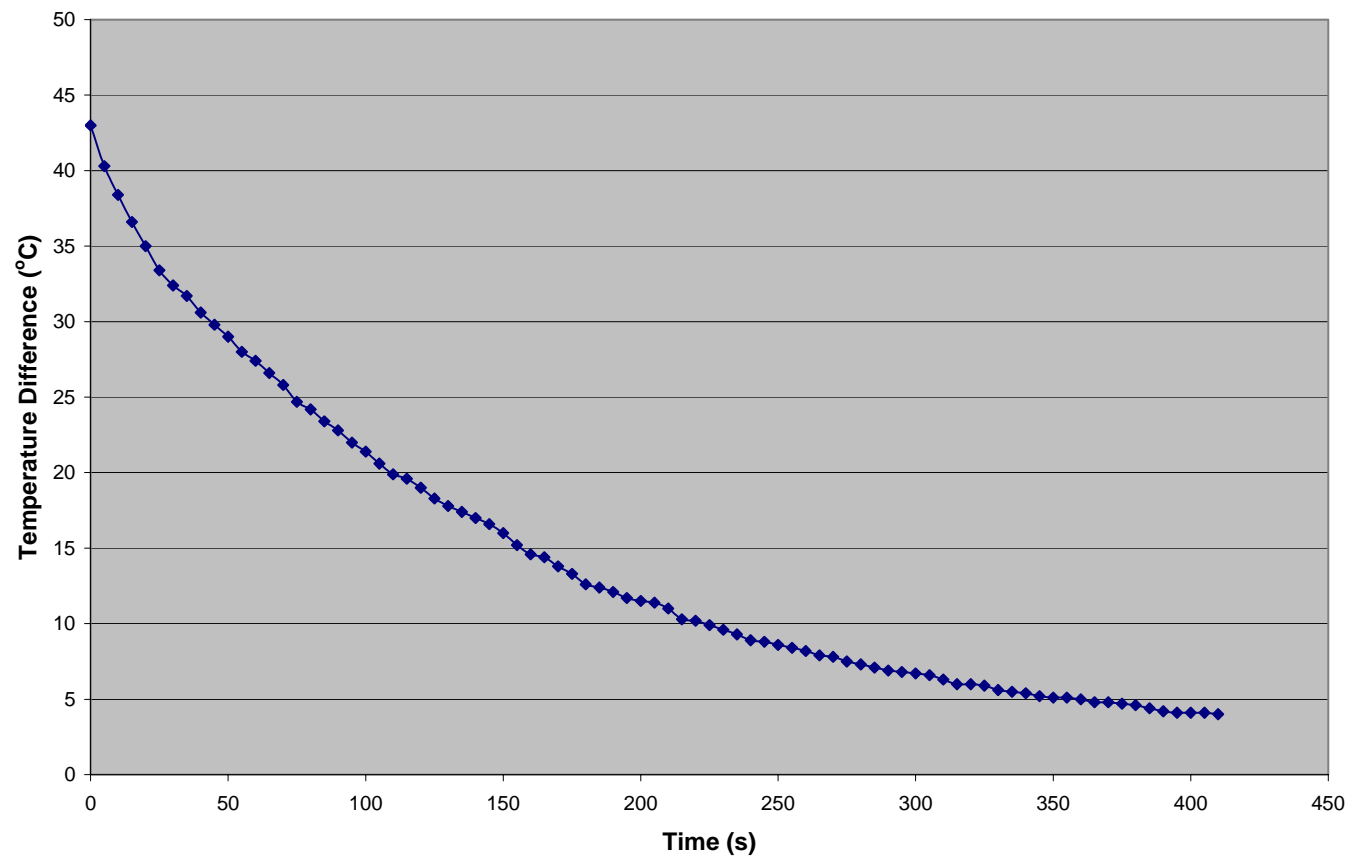

$\bullet-1.4 "$ x 1.4" Water-Filled Debond minus Defect-Free

Figure 4-86 Cylinder no 8 (5 minutes heating with $1500 \mathrm{~W}$ setting of the heater)

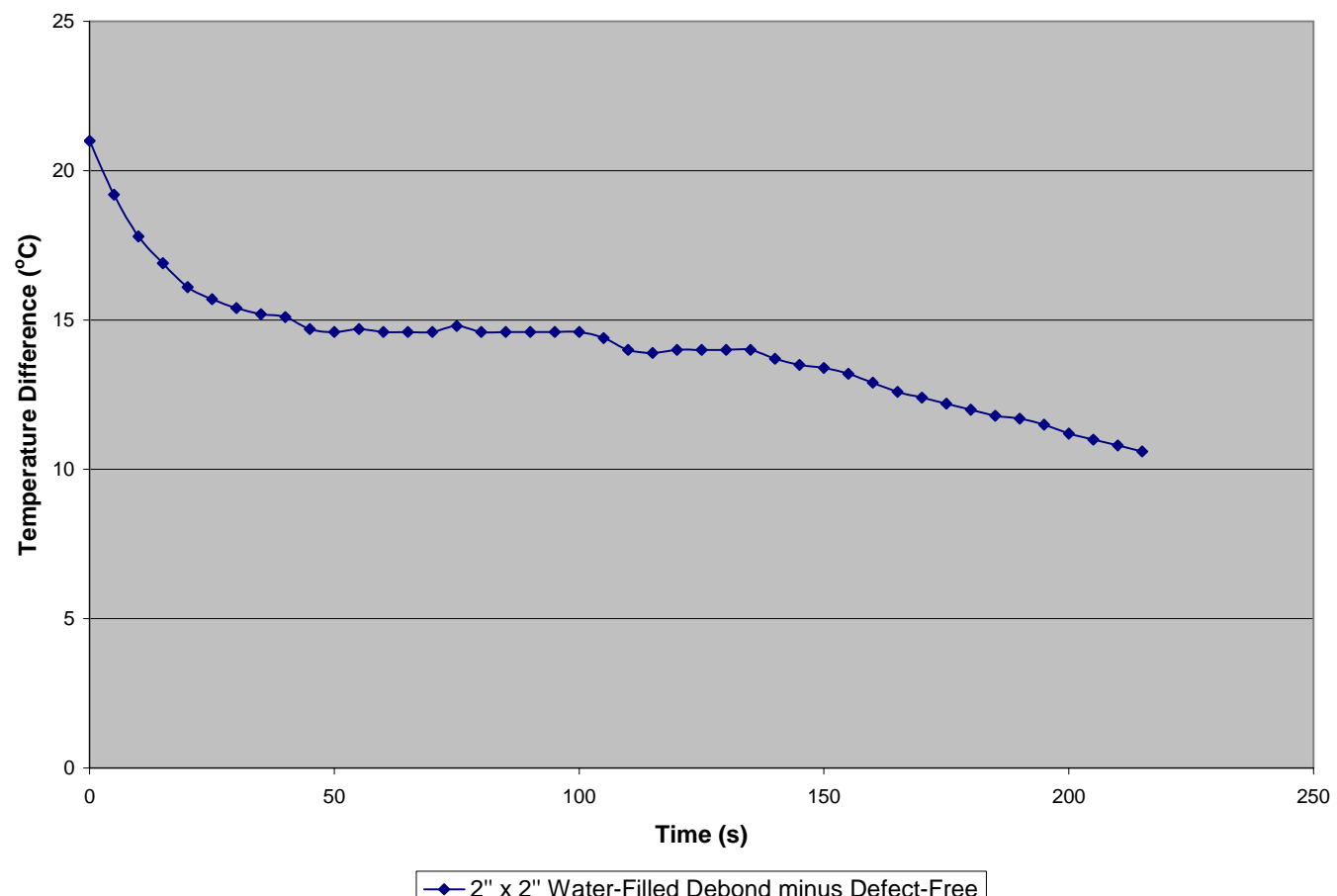

Figure 4-87 Cylinder no 9 ( 5 minutes heating with $1500 \mathrm{~W}$ setting of the heater) 


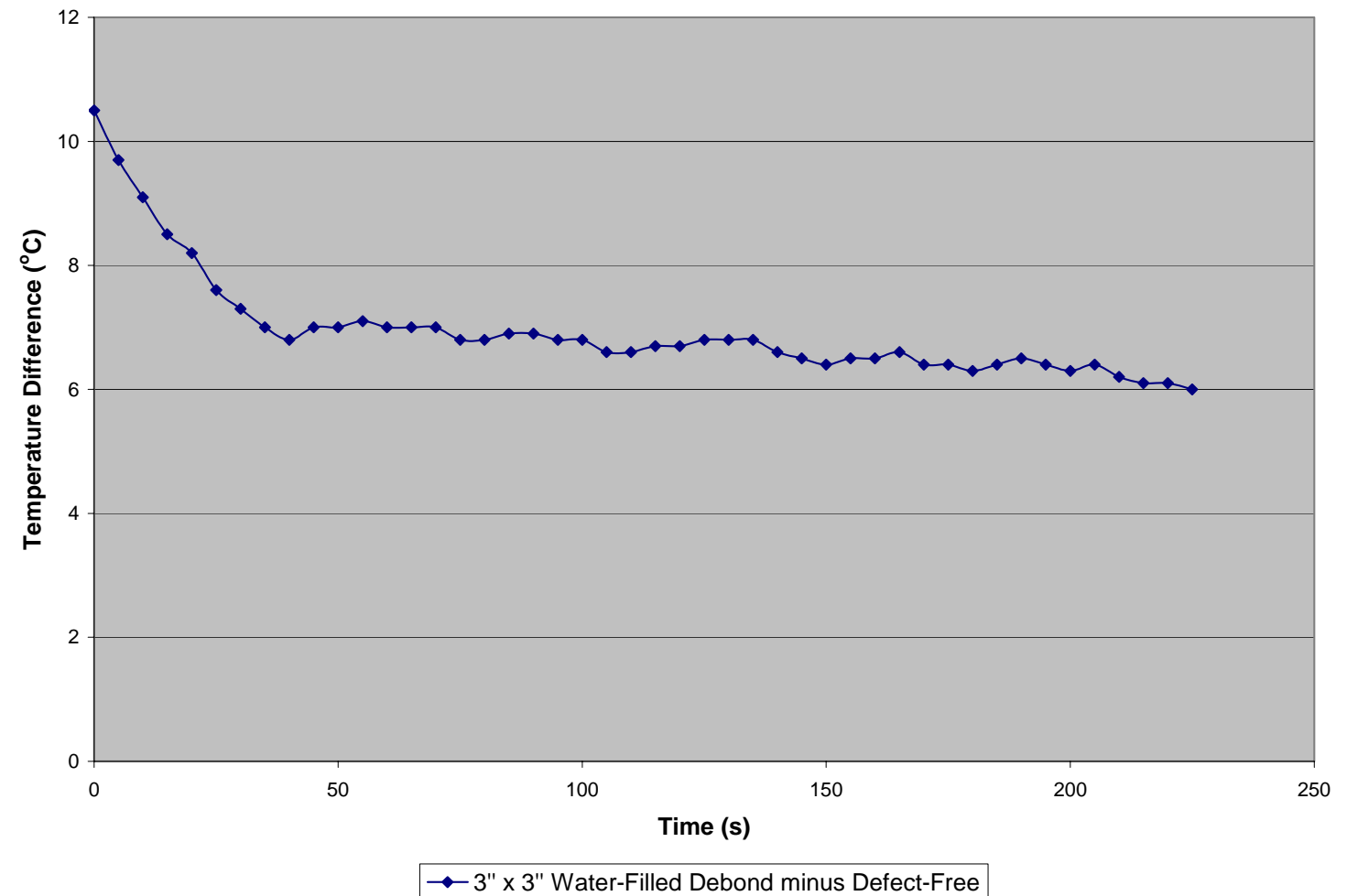

Figure 4-88 Cylinder no 10 (5 minutes heating with $1500 \mathrm{~W}$ setting of the heater)

\subsubsection{Thermal Difference versus Time Curves for CFRP Wrapped Cylinders}

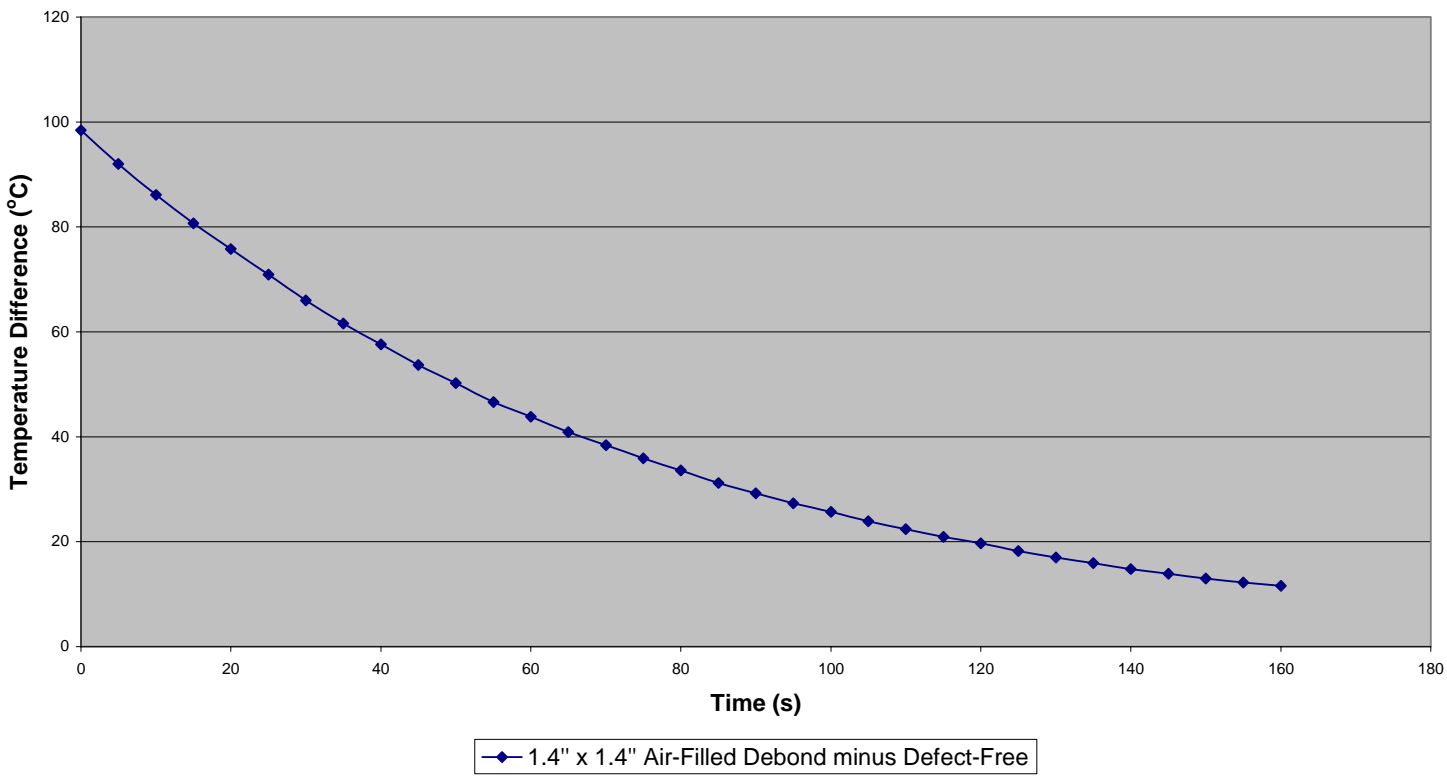

Figure 4-89 Cylinder no 15 ( 3 minutes heating with $1500 \mathrm{~W}$ setting of the heater) 


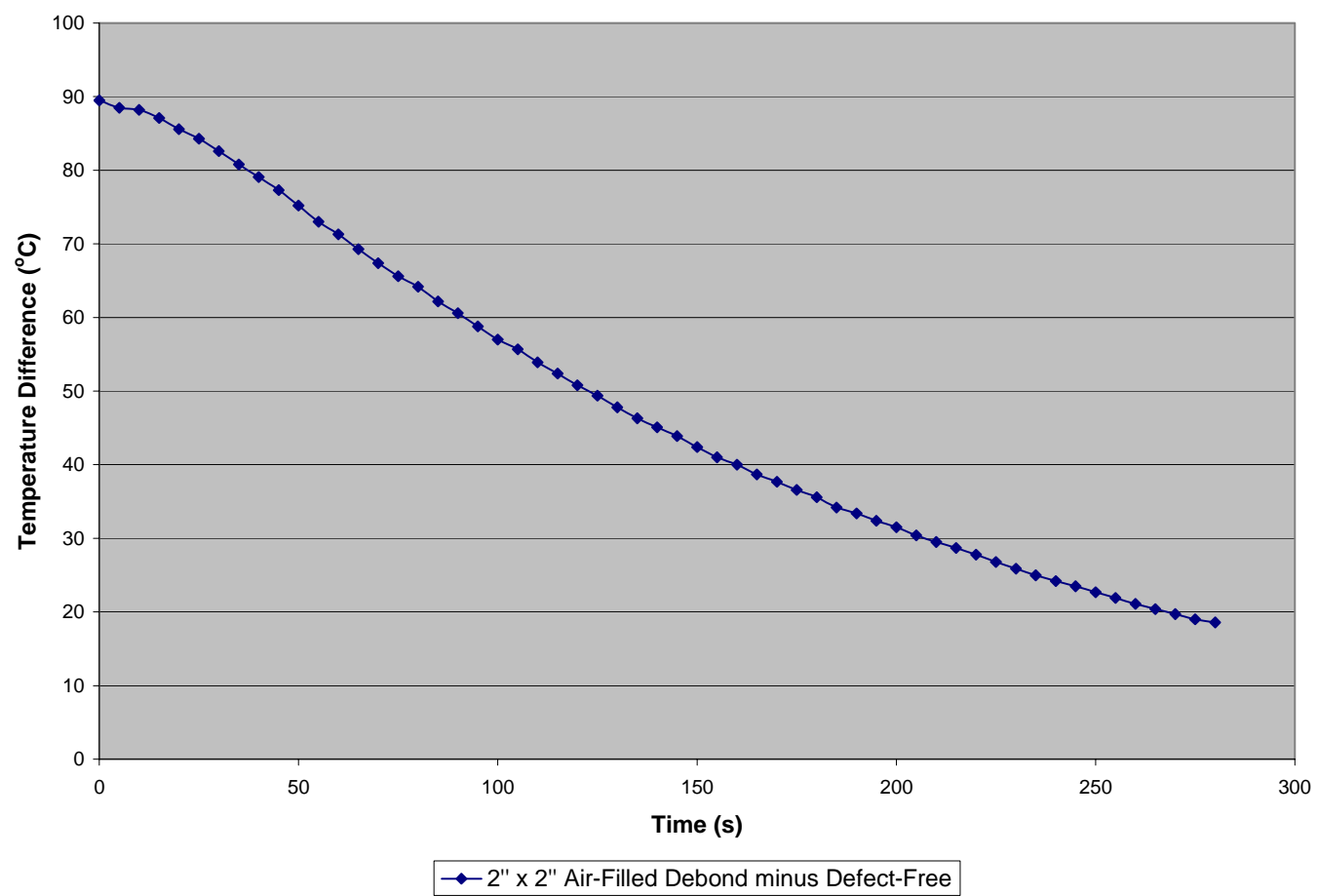

Figure 4-90 Cylinder no 16 ( 3 minutes heating with $1500 \mathrm{~W}$ setting of the heater)

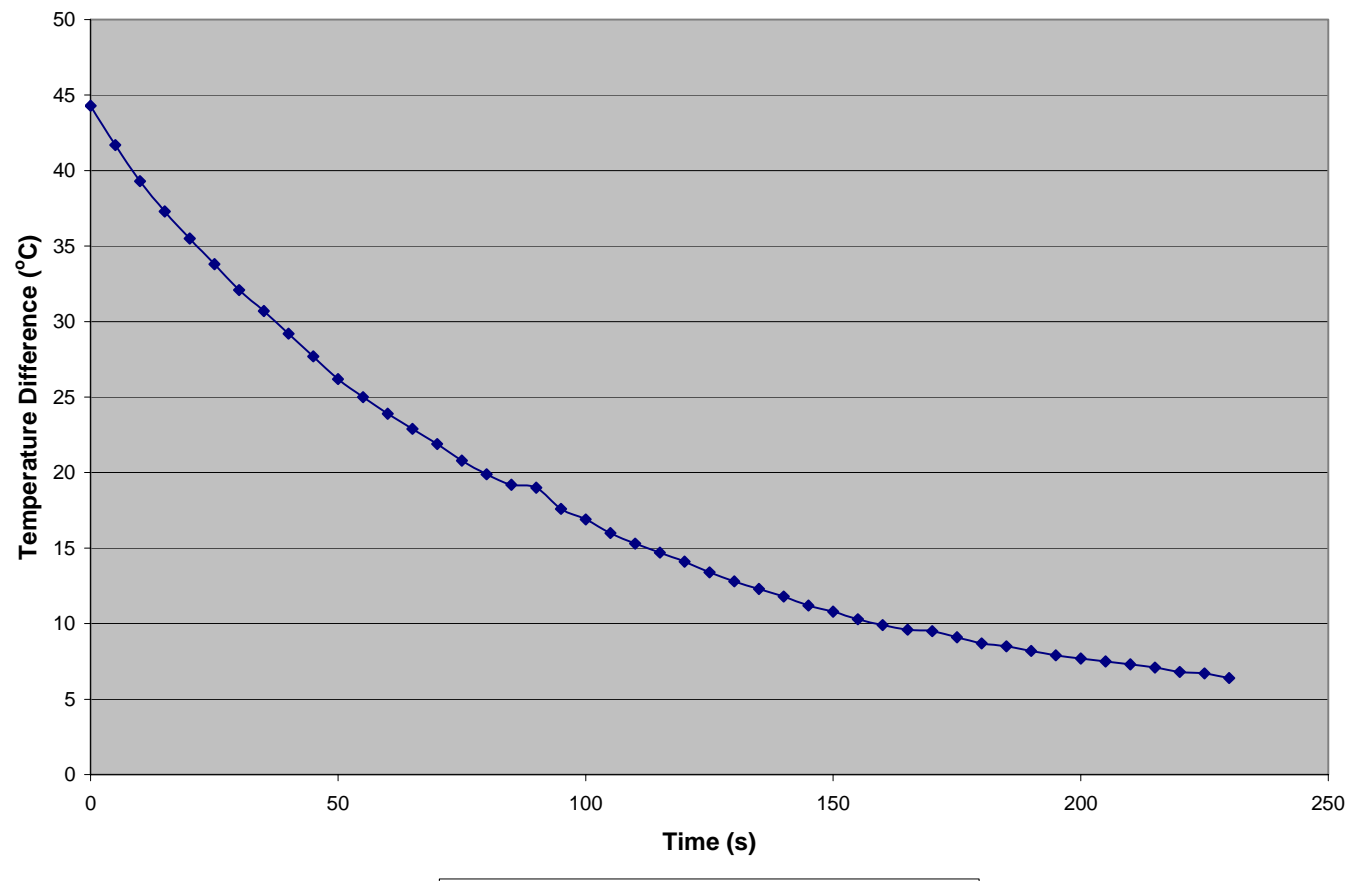

3" x 3" Air-Filled Debond minus Defect-Free

Figure 4-91 Cylinder no 17 (5 minutes heating with $750 \mathrm{~W}$ setting of the heater) 


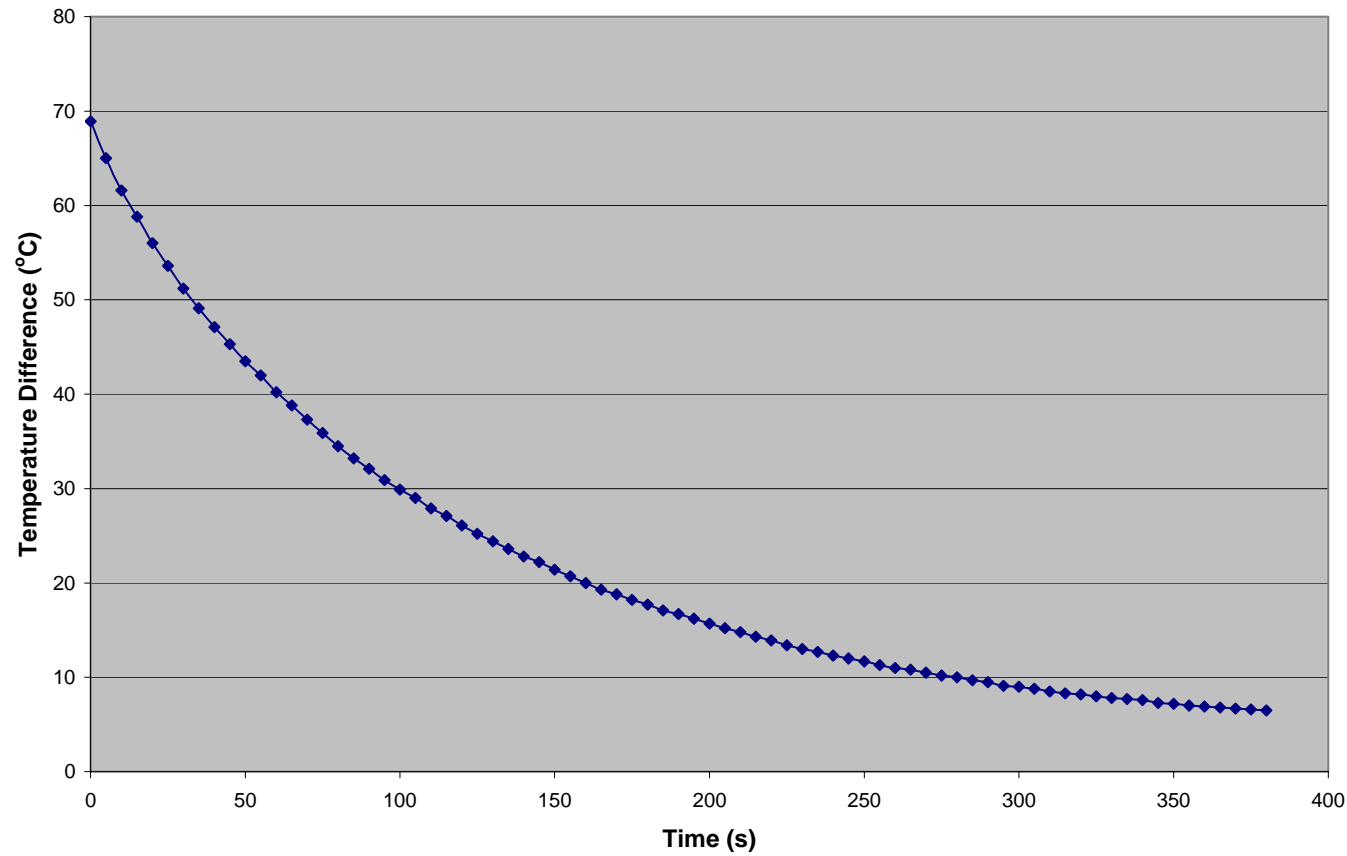

1.4" x 1.4" Water-Filled Debond minus Defect-Free

Figure 4-92 Cylinder no 22 (5 minutes heating with $1500 \mathrm{~W}$ setting of the heater)

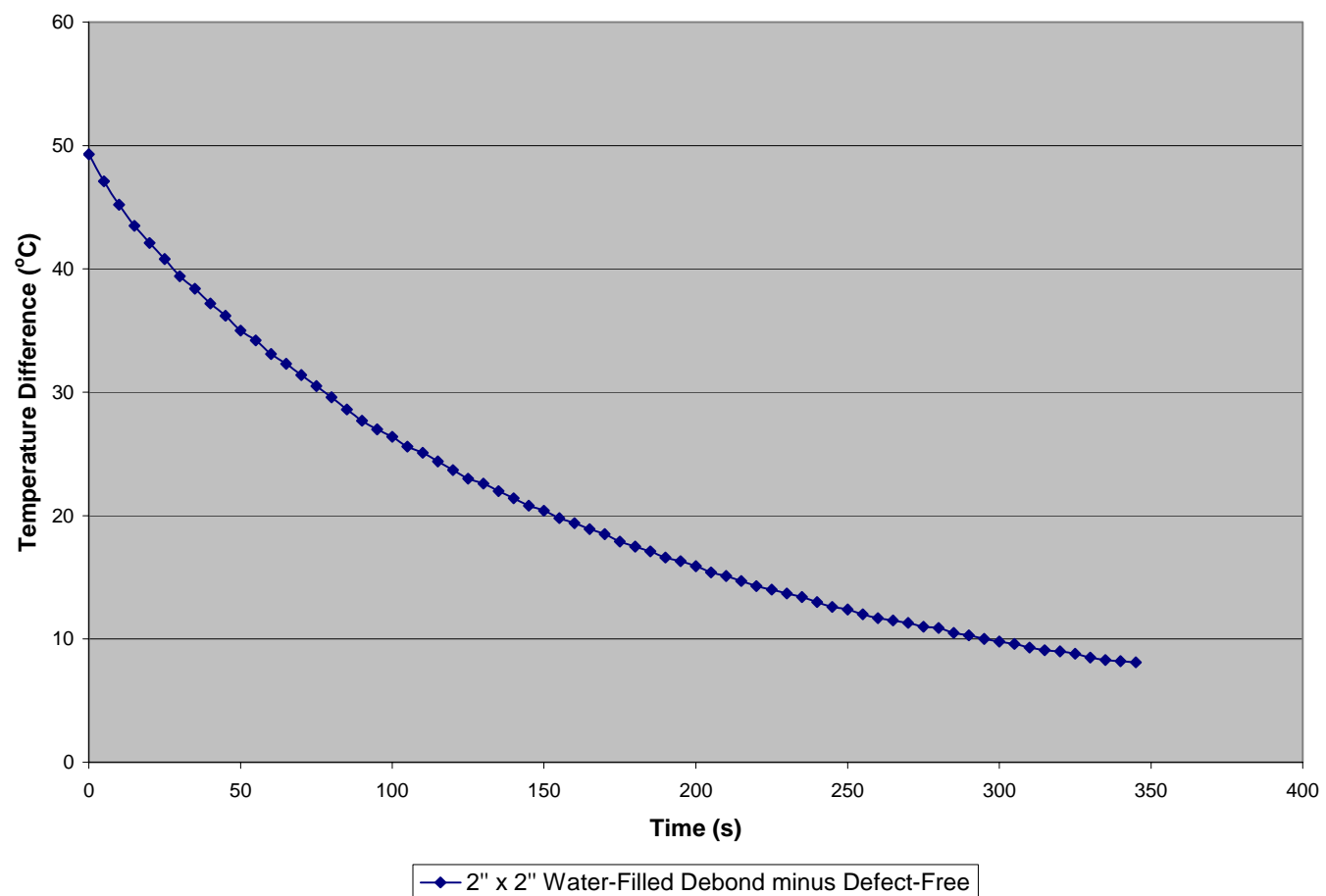

Figure 4-93 Cylinder no 23 (5 minutes heating with $1500 \mathrm{~W}$ setting of the heater) 


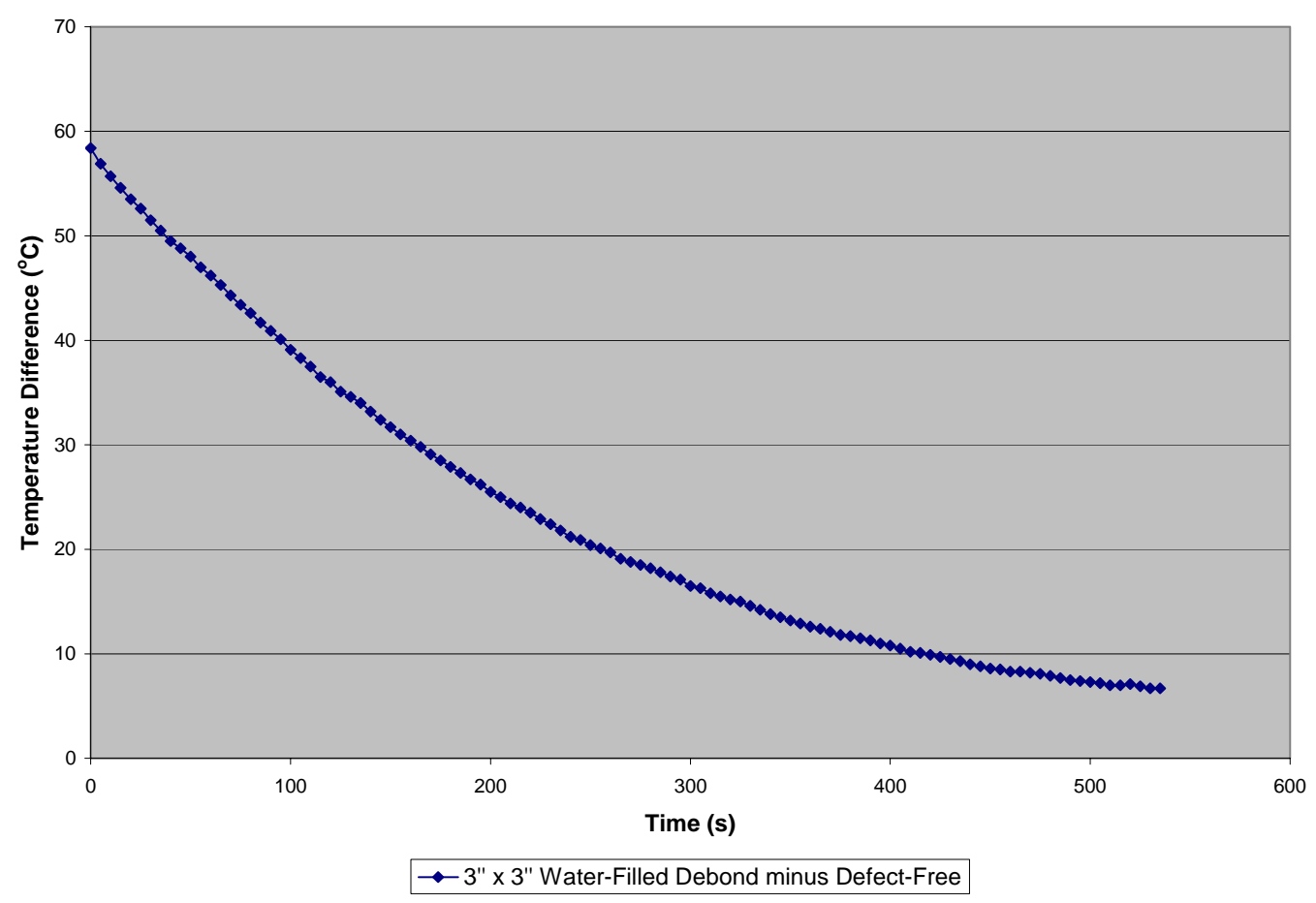

Figure 4-94 Cylinder no 24 (5 minutes heating with $1500 \mathrm{~W}$ setting of the heater)

\subsubsection{Observations}

It can be seen that cylinders wrapped with CFRP moved towards thermal equilibrium at a faster rate compared to GFRP wrapped cylinders. This is because of the values of thermal conductivity of the materials. Thermal conductivity of CFRP perpendicular to the fibers is $0.8 \mathrm{~W} \mathrm{~m}^{-1}{ }^{\circ} \mathrm{C}^{-1}$ whereas thermal conductivity of GFRP perpendicular to the fibers has a value $0.3 \mathrm{~W} \mathrm{~m}^{-1}{ }^{\circ} \mathrm{C}^{-1}$ (Maldague 1993). In the parallel direction, the thermal conductivities of CFRP and GFRP are $7.0 \mathrm{~W} \mathrm{~m}^{-1}{ }^{\circ} \mathrm{C}^{-1}$ and $0.38 \mathrm{~W}$ $\mathrm{m}^{-1}{ }^{\circ} \mathrm{C}^{-1}$, respectively (Maldague 1993). Therefore, the CFRP fabric conducts heat at a faster rate than GFRP fabric. As a result, CFRP wrapped cylinder cools at a quicker pace than GFRP wrapped cylinder after removal of heat. For example, GFRP wrapped cylinder no 1 and CFRP wrapped cylinder no 15 (both with 1.4" x 1.4" air debonds) were heated for 3 minutes with 1500 Watts power setting of the heater. As evident from the graphs, the surface temperature above the defect-free area in GFRP wrapped cylinder decreased to $32.1{ }^{\circ} \mathrm{C}$ in 390 seconds after the heating element was removed (Figure 4-54). On the other hand, surface temperature above the defect-free area in CFRP wrapped cylinder was $34.2{ }^{\circ} \mathrm{C}$ only in 160 seconds after removal of the heater (Figure 4-68). It is 
also observed that thermal "difference" curve for cylinders wrapped with GFRP with air debonds had an initial upward slope. This feature was not seen for the other cylinders (GFRP wrapped with water-filled debonds or any of the CFRP wrapped cylinders). This happens due to two reasons:

- The air-filled debonds act as thermal insulators obstructing the propagation of heat. Therefore, the area above the debond has significant amount of trapped heat.

- The GFRP wraps transmit heat at a slow rate, causing the above heat to dissipate slowly.

The region above the air-filled debond maintains a high temperature and cools down at a rate slower than the defect-free region and hence thermal difference continues to increase until maximum thermal signal is achieved. After that point, the thermal signal curve moves downward indicating the progression towards thermal equilibrium. The maximum thermal difference value for the cylinder no. 1 which was wrapped with GFRP and had 1.4" x 1.4" air-filled debond was $68.5^{\circ} \mathrm{C}$ (Figure 4-82) and it occurred in 45 seconds after the removal of the external heating. The corresponding values for the GFRP wrapped cylinder with 2" x 2 " air debond were $51.9^{\circ} \mathrm{C}$ and 55 seconds. For the 1.4 "' $\mathrm{x}$ 1.4" air-filled debond, images showing the boundary of the debond prominently were available approximately from $135^{\text {th }}$ second to $185^{\text {th }}$ second after the heating source was removed. The images showing boundary of the debond could be seen even after $390^{\text {th }}$ second as evident from the curve between thermal difference and time. In case of 2" $\mathrm{x}$ 2" air-filled debond, the best image sequence showing the boundary of the debond was obtained approximately from $120^{\text {th }}$ to $170^{\text {th }}$ after the removal of the heater. Both the above cylinders were heated for 3 minutes with 1500 Watts power setting of the heater. However, for the cylinder with the simulated 3" x 3 " air-filled debond which was heated with the same power setting but for 5 minutes, maximum temperature difference between the defective area and the sound area occurred at $10^{\text {th }}$ second after the heating cycle with a value of $75.6{ }^{\circ} \mathrm{C}$. The maximum temperature difference for the all other cylinders (i.e. irrespective of the type of wrap) occurred immediately after the removal of the heater. However, the image with the best contrast always occurred at a time later than the time of maximum thermal difference. In another observation, we see that in most of the cases the 
maximum surface temperature above the defective potion in cylinders with water-filled debonds decreases as the debond size increases. This happens because more the amount of water more is the amount of heat required to elevate the temperature (due to water's high specific heat). Also, it can be seen from comparison of the temperature difference curves for water-filled debonds wrapped with GFRP (Figures 4-86, 4-87, and 4-88) with those wrapped with CFRP (Figures 4-92, 4-93, and 4-94) that higher temperature difference is observed in case of CFRP wraps. This is because CFRP is a better thermal conductor. Also, the rate of cooling (drop in temperature per unit time) is higher in case of CFRP due to its higher thermal conductivity. The same trend is also observed in case of air-filled debonds. Also, for a particular type of wrap, it can be seen that the rate of decrease of thermal difference for water-filled debonds decreased with an increase in size of the debond. A similar trend can be observed in case of air-filled debonds also, In other words, in case of smaller debonds (air- or water-filled), thermal equilibrium is reached faster (after removal of heat) compared to larger debonds. This is because in case of

larger debonds, the heat transfer is primarily one-dimensional (through the thickness of the wrap) while for smaller debonds the effect of lateral heat transfer from the edges of the debonds is quite significant, resulting in a three-dimensional heat transfer phenomenon. However, 3" x 3" air-filled debond was not taken into consideration while arriving at this conclusion simply because the amount of heat input for the cylinders with 3" x 3" air-filled debond was different from those with the other two debond sizes.

\subsection{EFFECT OF DISCONTINUITY ON AXIAL COMPRESSIVE STRENGTH}

In this section, the results that were obtained from the crushing test of the concrete cylinders are presented. The axial compressive tests were conducted in accordance with the ASTM standards.

\subsubsection{Axial Compressive Strength of Unwrapped Specimens}

Five cylinders were tested in axial compression for determining the unwrapped compressive strength of the batch. While this batch of concrete was designed to provide a compressive strength of $4 \mathrm{ksi}$, the actual compressive strength was found to be higher. Based on the cylinder compressive test, an average value of 164.4 kips was obtained for the ultimate compressive load. Table 4-4 gives the ultimate strength for the five control 
specimens (plain concrete cylinders without wrapping). The average axial strength of 164.4 kips corresponds to a crushing strength of $5.81 \mathrm{ksi}$.

Table 4-4 Ultimate compressive strength of unwrapped cylinders

\begin{tabular}{|c|c|c|}
\hline $\begin{array}{c}\text { Cylinder } \\
\text { No }\end{array}$ & $\begin{array}{c}\text { Axial Strength } \\
\text { (kips) }\end{array}$ & $\begin{array}{c}\text { Average Axial Strength } \\
\text { (kips) }\end{array}$ \\
\hline \hline 1 & 165 & \\
\hline 2 & 167 & \multirow{2}{*}{164.4} \\
\hline 3 & 158 & \\
\hline 4 & 168 & \\
\hline 5 & 164 & \\
\hline
\end{tabular}

\subsubsection{Axial Compressive Strength of Wrapped Specimens}

The specimen wrapped with CFRP and GFRP were tested for evaluating the increase in axial strength due to wrapping. The results are summarized in Table 4-5.

Table 4-5 Ultimate compressive strength of wrapped cylinders

\begin{tabular}{|c|c|c|c|}
\hline $\begin{array}{c}\text { Cylinder } \\
\text { No }\end{array}$ & $\begin{array}{c}\text { Axial Strength } \\
\text { (kips) }\end{array}$ & Average Axial Strength (kips) & $\begin{array}{c}\text { Increase in } \\
\text { Strength }\end{array}$ \\
\hline \hline \multicolumn{2}{|c|}{ Wrapped with GFRP } \\
\hline 1 & 210 & & \multirow{2}{*}{1.33} \\
\hline 2 & 225 & 218.33 & \\
\hline 3 & 220 & Wrapped with CFRP & 1.72 \\
\hline \multicolumn{2}{|c|}{282.33} & \\
\hline 1 & 290 & & \\
\hline 3 & 275 &
\end{tabular}

\subsubsection{Axial Compressive Strength of Wrapped Specimens with Simulated Debonds}

The setup of debonds that was adopted in this research and the corresponding debonded area are given in Table 4-6. 
Table 4-6 Setup of debonds and corresponding area

\begin{tabular}{|c|c|c|c|}
\hline $\begin{array}{c}\text { Setup } \\
\text { No }\end{array}$ & Setup Type & $\begin{array}{c}\text { Area of } \\
\text { Debonds } \\
\text { (in }^{2}\end{array}$ & $\begin{array}{c}\text { Percent } \\
\text { Area of } \\
\text { Debonds } \\
\text { (\%) }\end{array}$ \\
\hline \hline 1 & $\begin{array}{c}\text { One 1.4" x 1.4" air or water-filled } \\
\text { debond on each side }\end{array}$ & 4 & 1.73 \\
\hline 2 & $\begin{array}{c}\text { One 2" x 2" air or water-filled } \\
\text { debond on each side }\end{array}$ & 8 & 3.53 \\
\hline 3 & $\begin{array}{c}\text { One 3" x 3" air or water-filled } \\
\text { debond on each side }\end{array}$ & 18 & 7.95 \\
\hline 4 & $\begin{array}{c}\text { One 2" x 2" and one 1.4" x 1.4" air or } \\
\text { water-filled debond on each side }\end{array}$ & 12 & 5.26 \\
\hline 5 & $\begin{array}{c}\text { One 3" x 3" and one 1.4" x 1.4" air or } \\
\text { water-filled debond on each side }\end{array}$ & 22 & 9.68 \\
\hline 6 & $\begin{array}{c}\text { One 3" x 3" and one 2" x 2" air or } \\
\text { water-filled debond on each side }\end{array}$ & 26 & 11.48 \\
\hline 7 & $\begin{array}{c}\text { One 3" x 3", one 2" x 2" and one 1.4" } \\
\text { x 1.4" air or water-filled debond on } \\
\text { each side }\end{array}$ & 30 & 13.22 \\
\hline
\end{tabular}

\subsubsection{Compressive Strength of GFRP Wrapped Cylinders with Air-filled Debonds}

The percent area of debond for the cylinders wrapped with GFRP with air-filled debonds and their corresponding compressive strengths are given in Table 4-7. The numbering system for the cylinders adopted here is same as described in the previous chapter.

Table 4-7 Ultimate compressive strength of GFRP wrapped cylinders with air-filled debonds

\begin{tabular}{|c|c|c|c|}
\hline $\begin{array}{c}\text { Cylinder } \\
\text { No }\end{array}$ & $\begin{array}{c}\text { Percent Area of } \\
\text { Debond (\%) }\end{array}$ & $\begin{array}{c}\text { Compressive } \\
\text { Strength (kips) }\end{array}$ & $\begin{array}{c}\text { Percent } \\
\text { Decrease in } \\
\text { Compressive } \\
\text { Strength (\%) }\end{array}$ \\
\hline \hline 1 & 1.73 & 160 & 26.7 \\
\hline 2 & 3.53 & 155 & 29.0 \\
\hline 3 & 7.95 & 152 & 30.3 \\
\hline 4 & 5.26 & 173 & 20.7 \\
\hline 5 & 9.68 & 190 & 12.9 \\
\hline 6 & 11.48 & 182 & 16.6 \\
\hline 7 & 13.22 & 142 & 34.9 \\
\hline
\end{tabular}


As seen from the table maximum decrease in compressive strength is in the case where one 3"' x 3"' air debond, one 2" x 2"' air debond and one 1.4" x 1.4" air debond are inserted on either side of the column with the percent of area of discontinuity being $13.22 \%$. This is expected as this is the cylinder with largest amount of area of FRP wrap that is not in contact with the cylinder surface. The data does show some anomolies, that is, the percent decrease values are not always follow a uniform trend.

\subsubsection{Compressive Strength of GFRP Wrapped Cylinders with Water-filled Debonds}

Table 4-8 summarizes the percent area of debond of GFRP wrapped cylinders with simulated water-filled debond setups and also the corresponding compressive strength values.

Table 4-8 Ultimate compressive strength of GFRP wrapped cylinders with water-filled debonds

\begin{tabular}{|c|c|c|c|}
\hline $\begin{array}{c}\text { Cylinder } \\
\text { No }\end{array}$ & $\begin{array}{c}\text { Percent Area of } \\
\text { Debond (\%) }\end{array}$ & $\begin{array}{c}\text { Percent } \\
\text { Compressive } \\
\text { Strength (kips) }\end{array}$ & $\begin{array}{c}\text { Decrease in } \\
\text { Compressive } \\
\text { Strength (\%) }\end{array}$ \\
\hline \hline 8 & 1.73 & 172 & 21.2 \\
\hline 9 & 3.53 & 165 & 24.4 \\
\hline 10 & 7.95 & 183 & 16.1 \\
\hline 11 & 5.26 & 148 & 32.2 \\
\hline 12 & 9.68 & 140 & 35.8 \\
\hline 13 & 11.48 & 125 & 42.7 \\
\hline 14 & 13.22 & 166 & 23.9 \\
\hline
\end{tabular}

Here also, we see that except for two specimens, i.e., cylinder no 10 and 14, other specimens show larger decrease in compressive strength with an increase in area of discontinuity. Also, comparing Tables 4-7 and 4-8, we see that for cylinders with minimum edge effect, i.e., in case of cylinders having only one debond on each side, the decrease in strength in case of cylinders (nos. 1, 2, and 3) with air-filled debonds are more than their water-filled debond counterparts (cylinder nos. 8, 9, and 10). This is due to the presence of water that withstands pressure more than air does. In other words, water-filled debonds still provide some level of confinement that is absent in case of airfilled debonds. However, such a trend could not be observed for cylinders with higher percentage debonded areas, in which case the edge effect was also more prominent due to placement of some of the debonds away from the center. Also, it can be seen from both 
Tables 4-7 and 4-8 that in several cases, the compressive strength is below the value of 164.4 kips that was obtained for unwrapped (plain concrete) cylinders.

\subsubsection{Compressive Strength of CFRP Wrapped Cylinders with Air-filled Debonds}

Table 4-9 furnishes the detail relating to the area of discontinuity and decrease in axial strength of CFRP wrapped cylinders with air-filled debonds.

Table 4-9 Ultimate compressive strength of CFRP wrapped cylinders with air-filled debonds

\begin{tabular}{|c|c|c|c|}
\hline $\begin{array}{c}\text { Cylinder } \\
\text { No }\end{array}$ & $\begin{array}{c}\text { Percent Area of } \\
\text { Debond (\%) }\end{array}$ & $\begin{array}{c}\text { Percent } \\
\text { Compressive } \\
\text { Strength (kips) }\end{array}$ & $\begin{array}{c}\text { Decrease in } \\
\text { Compressive } \\
\text { Strength (\%) }\end{array}$ \\
\hline \hline 15 & 1.73 & 250 & 11.4 \\
\hline 16 & 3.53 & 198 & 29.8 \\
\hline 17 & 7.95 & 160 & 43.3 \\
\hline 18 & 5.26 & 126 & 55.3 \\
\hline 19 & 9.68 & 172 & 39.0 \\
\hline 20 & 11.48 & 170 & 39.7 \\
\hline 21 & 13.22 & 148 & 47.5 \\
\hline
\end{tabular}

Here also we can see that as the percent area of debond increases, the compressive strength decreases. In some cases, the strength value is below 164.4 kips (plain concrete).

\subsubsection{Compressive Strength of CFRP Wrapped Cylinders with Water-filled Debonds}

Table 4-10 represents the percent area of debond of CFRP wrapped cylinders with simulated water-filled debonds and also their corresponding compressive strength values.

Table 4-10 Ultimate compressive strength of CFRP wrapped cylinders with water-filled debonds

\begin{tabular}{|c|c|c|c|}
\hline $\begin{array}{c}\text { Cylinder } \\
\text { No }\end{array}$ & $\begin{array}{c}\text { Percent Area of } \\
\text { Debond (\%) }\end{array}$ & $\begin{array}{c}\text { Percent } \\
\text { Compressive } \\
\text { Strength (kips) }\end{array}$ & $\begin{array}{c}\text { Decrease in } \\
\text { Compressive } \\
\text { Strength (\%) }\end{array}$ \\
\hline \hline 8 & 1.73 & 265 & 6.1 \\
\hline 9 & 3.53 & 281 & 0.4 \\
\hline 10 & 7.95 & 215 & 23.8 \\
\hline 11 & 5.26 & 155 & 45.0 \\
\hline 12 & 9.68 & 165 & 41.5 \\
\hline 13 & 11.48 & 138 & 51.1 \\
\hline 14 & 13.22 & 133 & 52.8 \\
\hline
\end{tabular}


Comparing the data from Tables 4-9 and 4-10, it can be inferred that cylinders with water-filled debonds fare better as long as the percentage of debonded area is small (3.53\% or less). This behavior does not hold for larger debonded areas.

\subsubsection{Graphs of Percent Area of Debonds versus Percent Decrease in Compressive Strength}

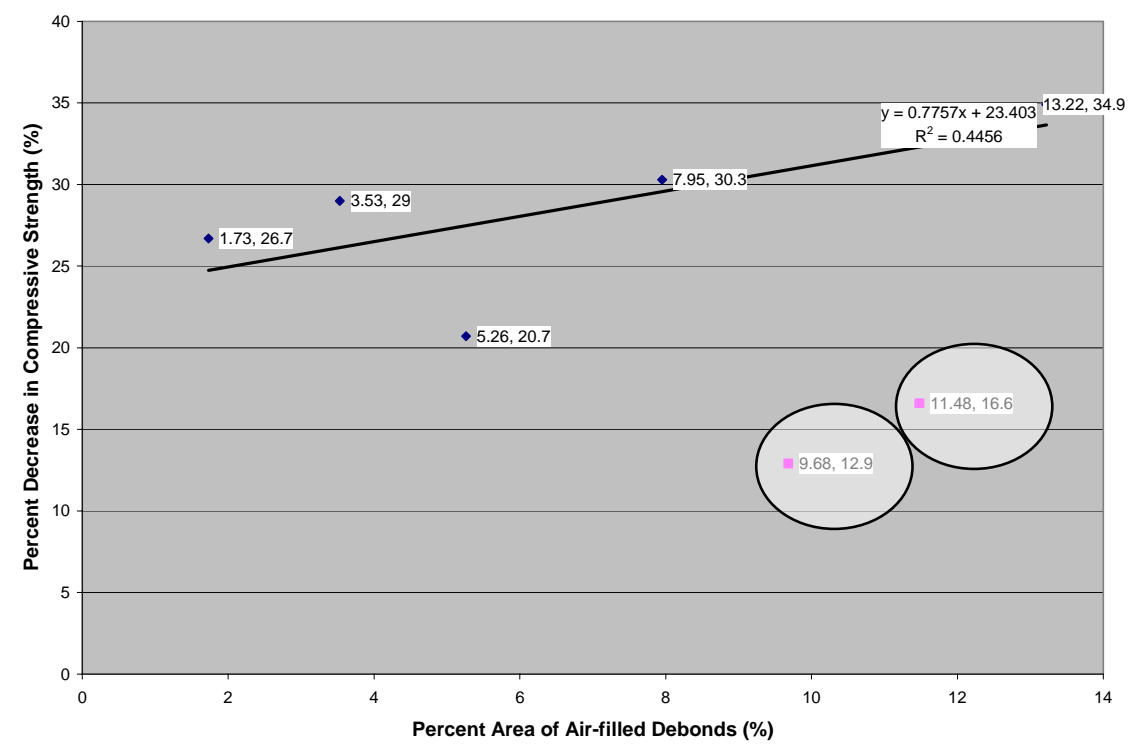

Figure 4-95 GFRP wrapped cylinders with air-filled debonds

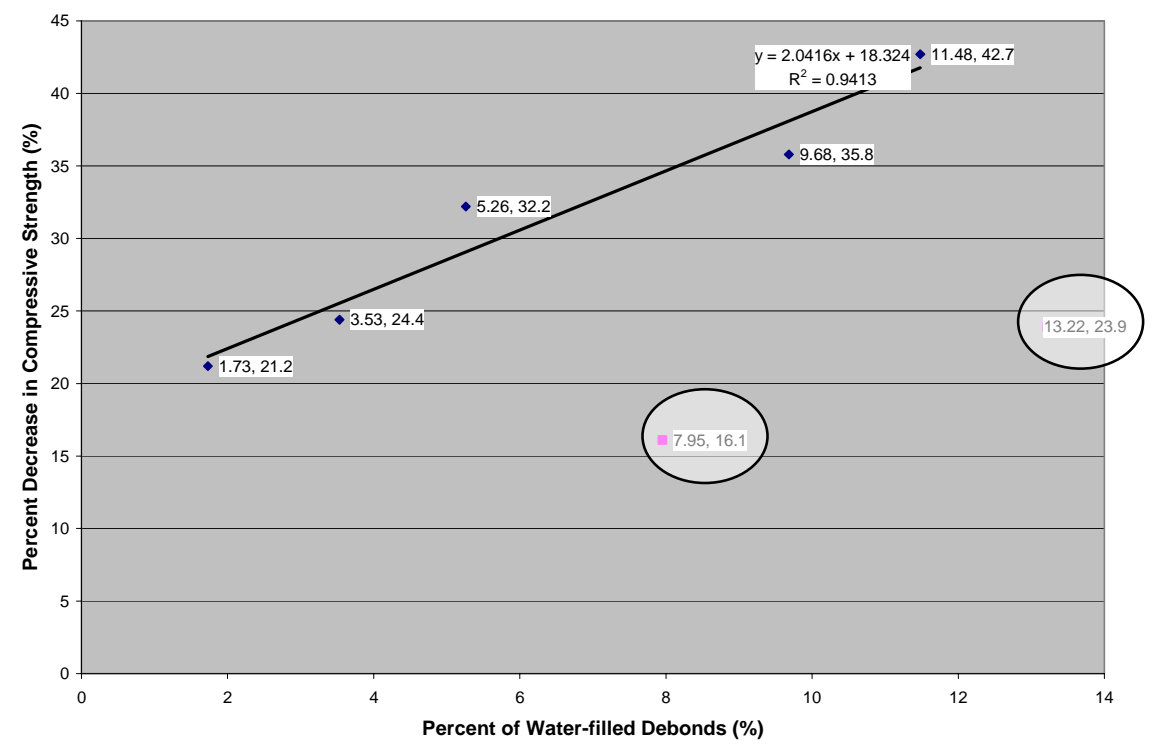

Figure 4-96 GFRP wrapped cylinders with water-filled debonds 


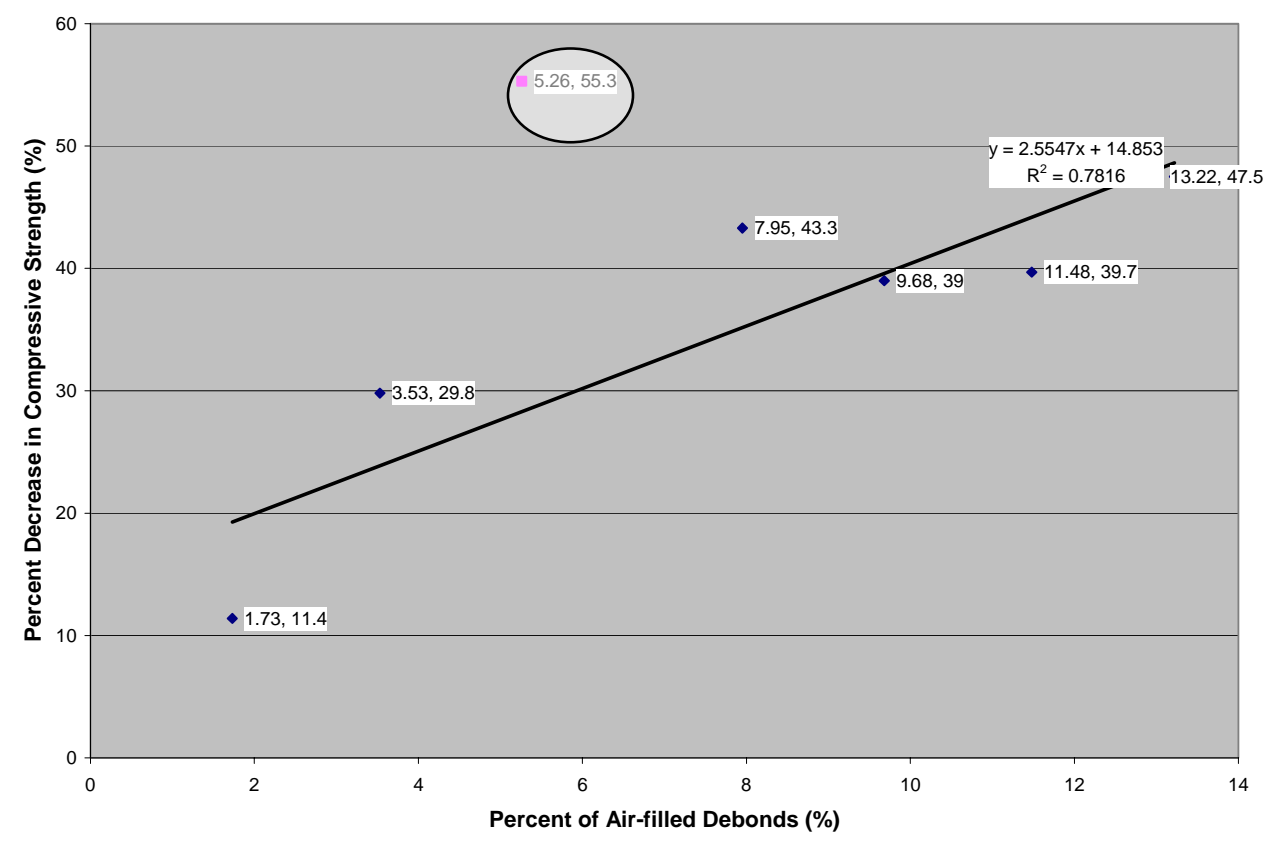

Figure 4-97 CFRP wrapped cylinders with air-filled debonds

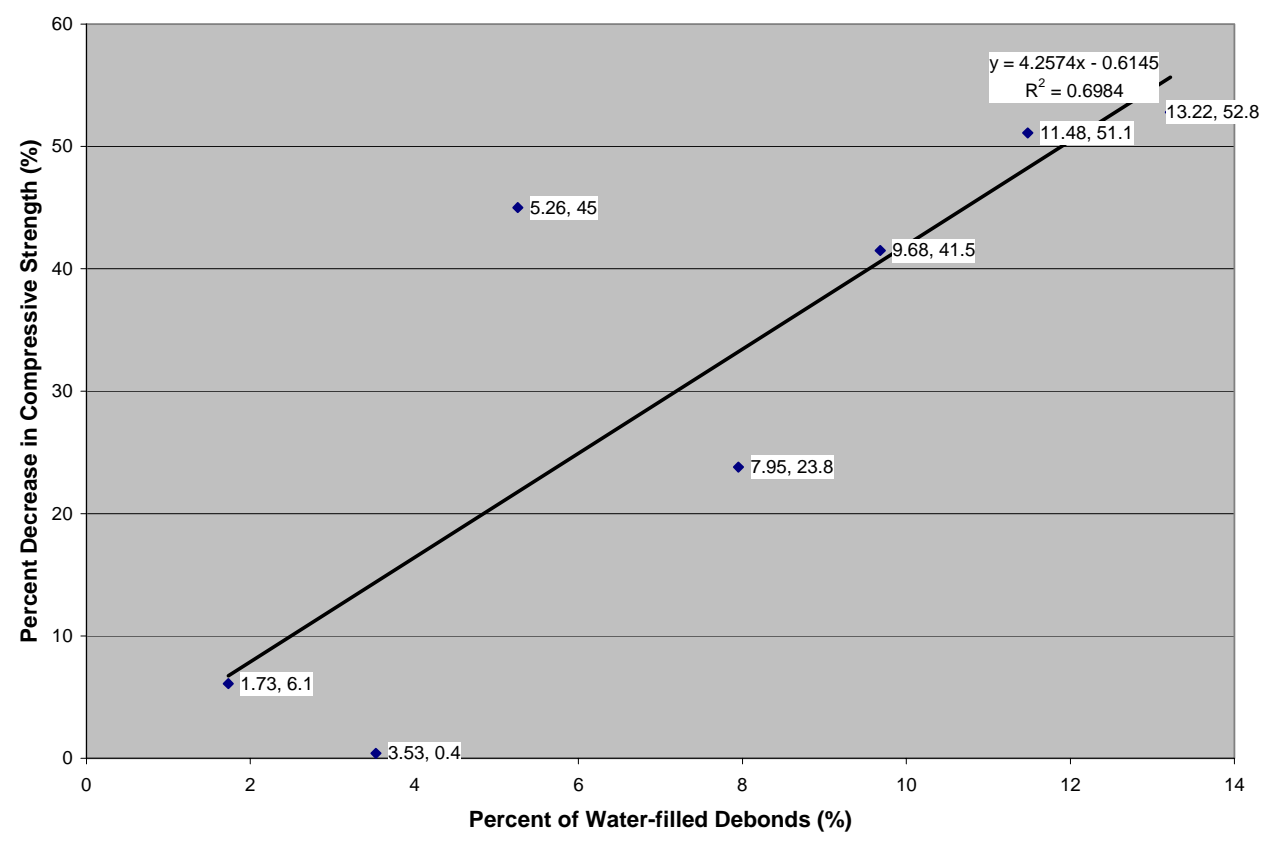

Figure 4-98 CFRP wrapped cylinders with water-filled debonds 
Table 4-11 summarizes the regression results.

Table 4-11 Regression relationships for various wrapped cylinders

\begin{tabular}{|c|c|c|c|}
\hline Specimen & Slope & Intercept & $\mathbf{R}^{\mathbf{2}}$ \\
\hline \hline GFRP wrapped cylinders with air-filled debonds & 0.7757 & 23.403 & 0.4450 \\
\hline GFRP wrapped cylinders with water-filled debonds & 2.0416 & 18.324 & 0.9413 \\
\hline CFRP wrapped cylinders with air-filled debonds & 2.5547 & 14.053 & 0.7816 \\
\hline CFRP wrapped cylinders with water-filled debonds & 4.2574 & -0.6145 & 0.6984 \\
\hline
\end{tabular}

In Figures 4-95 to 4-98, the points that are not included in the regression analysis are encircled. The $\mathrm{R}^{2}$ values in Table 4-11 are generally high indicating that the percent decrease in compressive strength and percentage area of debonds correlate well.

\subsubsection{Graphs of Percent Area of Debonds versus Percent Compressive Strength}

The graphs presented in Figures 4-99 to 4-102 show the variation of the Percent Compressive Strength to the Percent area of debond. The excluded points are shown by pink dots.

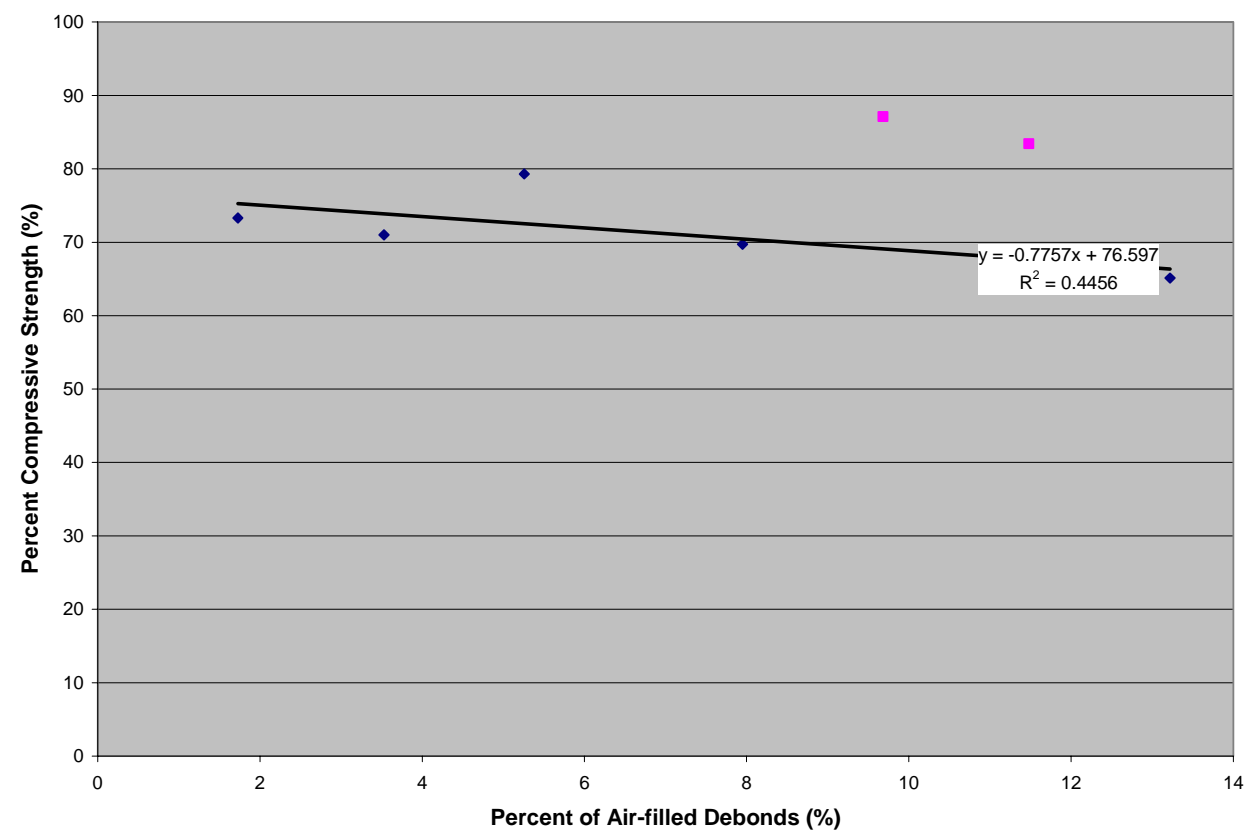

Figure 4-99 GFRP wrapped cylinders with air-filled debonds 


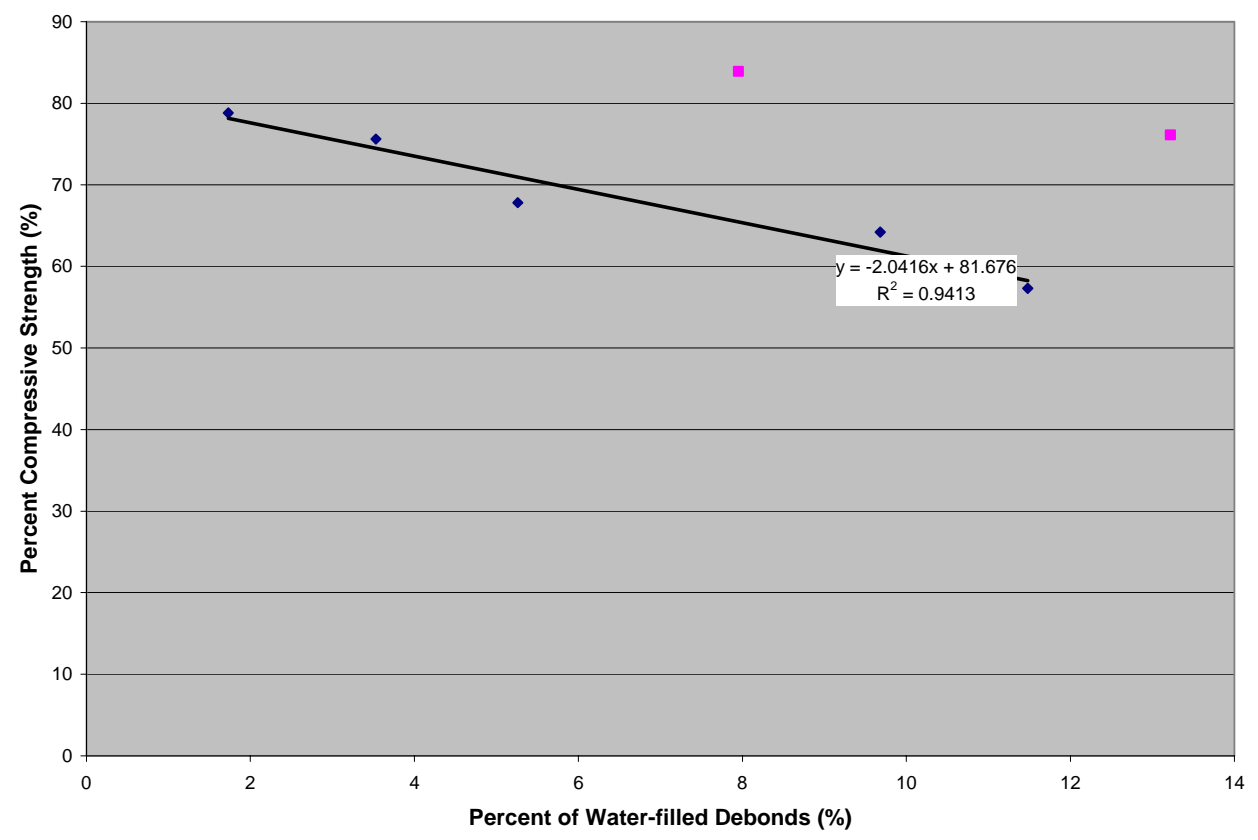

Figure 4-100 GFRP wrapped cylinders with water-filled debonds

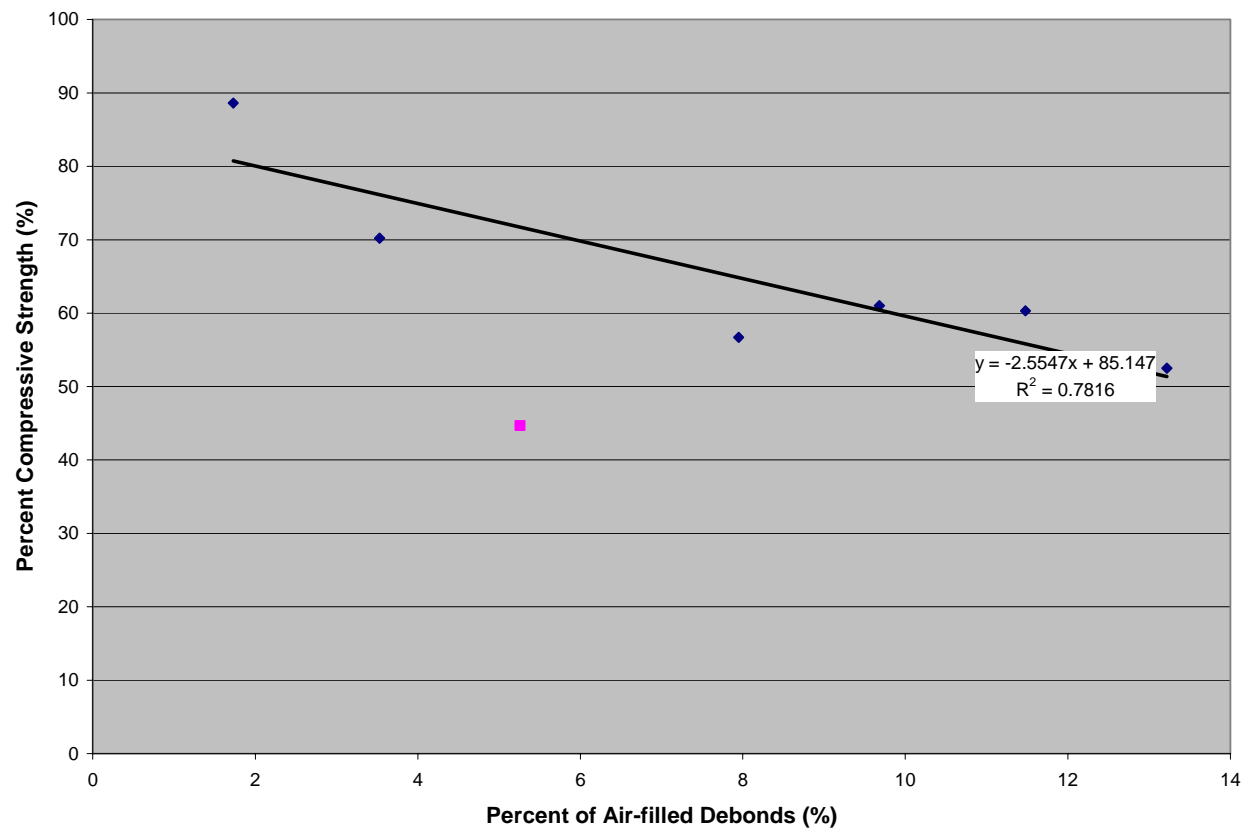

Figure 4-101 CFRP wrapped cylinders with air-filled debonds 


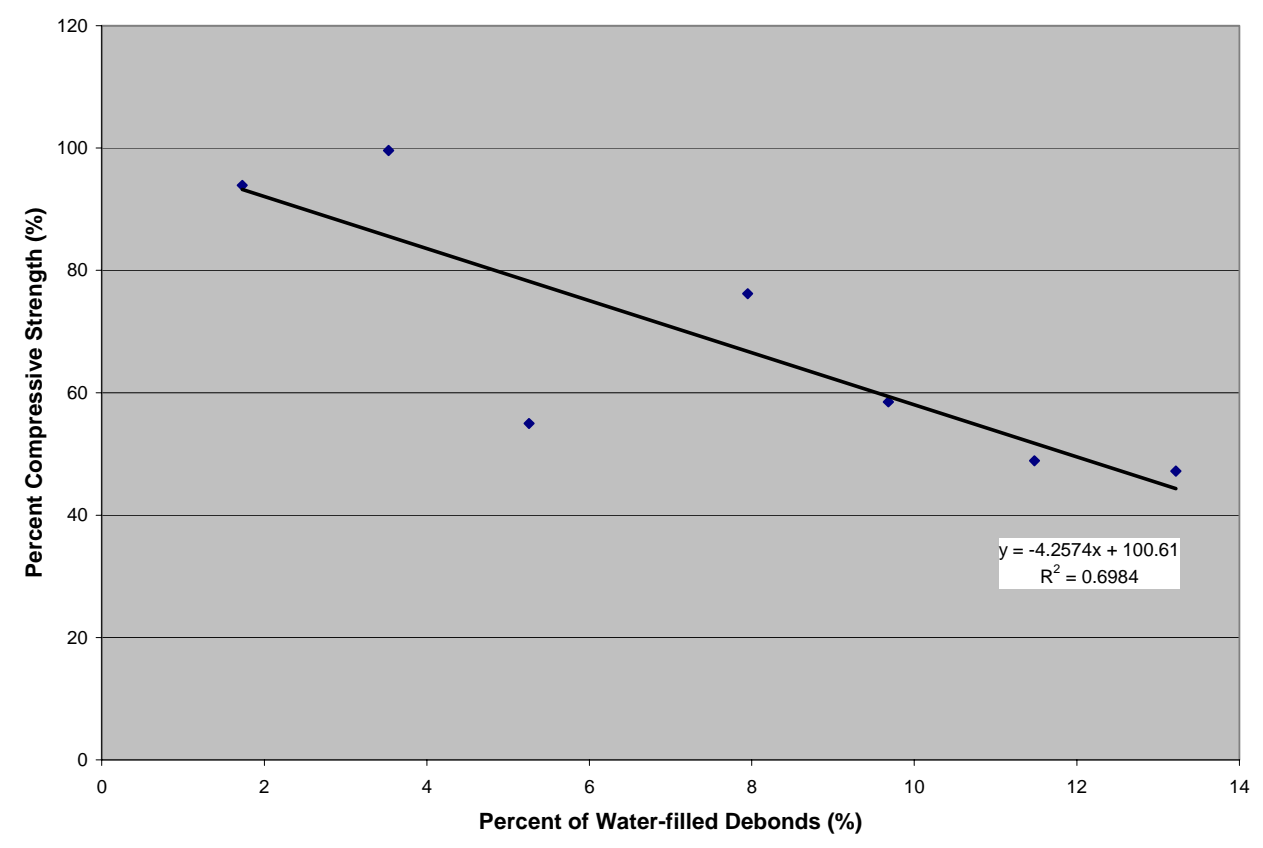

Figure 4-102 CFRP wrapped cylinders with water-filled debonds

We can see that the compressive strength decreases as percentage of debonded area increases. For larger percentage area of debonds, the compressive strength for wrapped cylinders often fell below the value for plain concrete cylinders (164.4 kips) as can be seen from Tables 4-7 to 4-10. This could be due to stress concentration effects, which needs further investigation.

\subsubsection{Theory of Confinement and Comparison between Analytical and Experimental Results}

When uniaxially loaded concrete is restrained from expanding in the radial direction, it results in increased strength of the concrete. When concrete wrapped with FRP fabrics is subjected to uniaxial compression, it is essentially being restrained triaxially. The ultimate compressive strength increases as the confining stress increases as evident from the stress strain curves for triaxial compression test (Figure 4-103). 


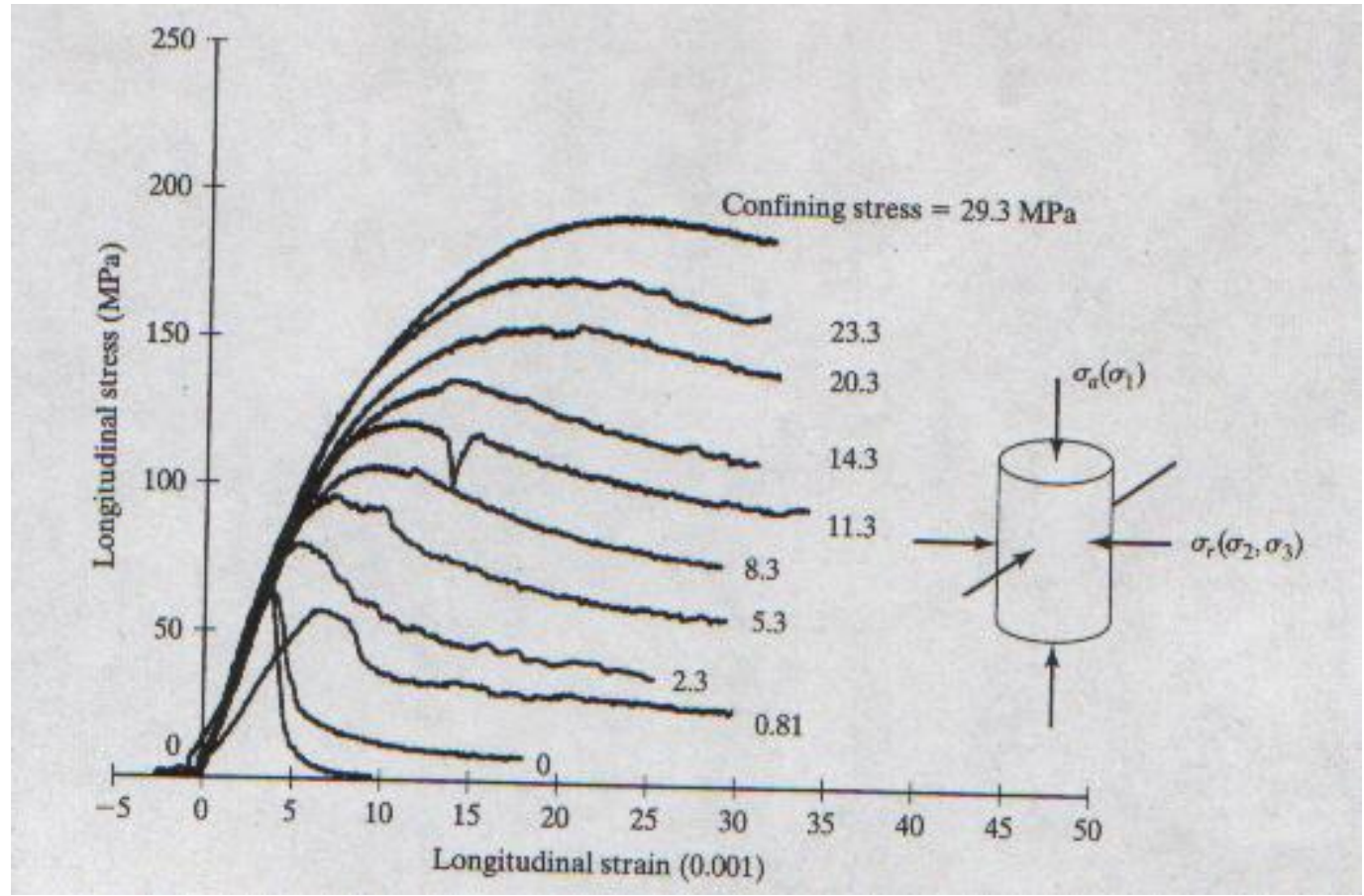

Figure 4-103 Stress strain curves for concrete in triaxial compression (Mindness et al. 2003)

The confinement action develops as the lateral expansion of concrete increases under axial load. The confinement device (e.g., FRP wraps) develops a hoop tensile stress which is in equilibrium with the radial confinement pressure that constrains the concrete from dilating laterally (De Lorenzis et al. 2003). The confinement action is shown in Figure 4-104.

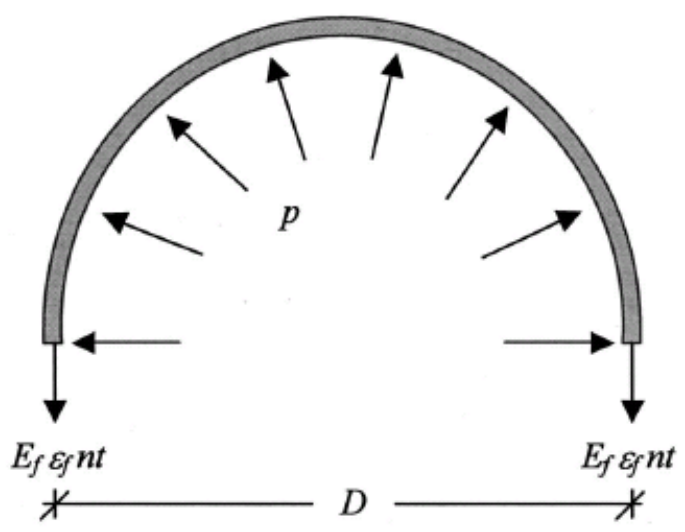

Figure 4-104 Confinement action (De Lorenzis et al. 2003) 
The lateral strain $\varepsilon_{1}$ of the concrete should be equal to circumferential strain of FRP fabric $\varepsilon_{\mathrm{f}}$ under the assumption of deformation compatibility. From principle of equilibrium, we find the lateral force $\mathrm{p}$ that acts on concrete radially.

$\mathrm{p}=\mathrm{E}_{1} \varepsilon_{1}=\mathrm{E}_{1} \varepsilon_{\mathrm{f}}$

where $E_{1}=\left(2 E_{f} n t\right) / D$

where $\mathrm{D}$ is diameter of the cylinder, $\mathrm{n}$ is the number of FRP layers, $\mathrm{t}$ is the thickness of each layer. The maximum confinement pressure $p_{u}$ that can be exerted by the confining device can be found by equating circumferential strain of FRP fabric to ultimate strain $\varepsilon_{\mathrm{fu}}$ of FRP fabric.

$\mathrm{p}_{\mathrm{u}}=\mathrm{E}_{1} \varepsilon_{\mathrm{fu}}=\left(2 \mathrm{f}_{\mathrm{fu}} \mathrm{nt}\right) / \mathrm{D}$

where $f_{f u}$ is the ultimate stress of each layer of FRP fabric. The experimental results of the study (results of concrete cylinders wrapped with CFRP fabric) are compared with analytical calculation as furnished below. GFRP wrapped cylinders were not considered here since $f_{\text {fu }}$ value was not available for GFRP fabric.

Average axial compressive load of the concrete cylinders $=164.4$ kips

Hence unconfined compressive strength $=(164.4) /\left(\Pi \times 6^{2} / 4\right)=5.81 \mathrm{ksi}$

Experimental confined compressive strength obtained for CFRP wrapped concrete

cylinders $=282.33 \mathrm{kips}$

All of the following models are listed in the paper by De Lorenzis et al. (2003).

\section{Model 1}

This model is proposed by Fardis and Khalili (1981) and confined compressive strength of concrete is given by

$$
\frac{f^{\prime}{ }_{c c}}{f^{\prime}{ }_{c o}}=1+4.1\left(\frac{p_{u}}{f^{\prime}{ }_{c o}}\right)
$$


Where $p_{u}$ is the theoretical maximum confinement pressure that can be exerted by the confinement device, $\mathrm{f}^{\prime}{ }_{c o}$ is the unconfined compressive strength and $\mathrm{f}^{\prime}{ }_{\mathrm{cc}}$ is the confined compressive strength of concrete.

$\mathrm{p}_{\mathrm{u}}=\left(2 \mathrm{f}_{\mathrm{fu}} \mathrm{nt}\right) / \mathrm{D}$

Where $\mathrm{D}$ is diameter of the cylinder, $\mathrm{n}$ is the number of FRP layers, $\mathrm{t}$ is the thickness of each layer and $f_{f u}$ is the ultimate tensile stress of FRP fabric.

In our case,

$\mathrm{D}=6$,

$\mathrm{n}=3$

$\mathrm{f}_{\mathrm{fu}}=495 \mathrm{ksi}$ (from the manufacturer)

$\mathrm{t}=0.004$ '

$\mathrm{f}^{\prime}{ }_{\mathrm{co}}=5.81 \mathrm{ksi}$

$\mathrm{p}_{\mathrm{u}}=(2 \times 495 \times 3 \times 0.004) / 6=1.98 \mathrm{ksi}$

$f^{\prime}{ }_{c c}=5.81 \times\left[1+4.1\left(\frac{1.98}{5.81}\right)\right]$

$=13.93 \mathrm{ksi}$

Hence confined strength of plain concrete cylinders $=13.93 \times\left(\Pi \times 6^{2} / 4\right)=393.86$ kips

Experimental confined compressive strength/ Analytical confined compressive strength $=282.33 / 393.86=0.717$

\section{Model 2}

This model is proposed by Miyauchi et al. (1997) and confined compressive strength of concrete is given by

$$
\frac{f^{\prime}{ }_{c c}}{f^{\prime}{ }_{c o}}=1+3.485\left(\frac{p_{u}}{f^{\prime}{ }_{c o}}\right)
$$

where the terms in the equation are already explained above

$$
f_{c c}^{\prime}=5.81 \times\left[1+3.485\left(\frac{1.98}{5.81}\right)\right]
$$

$=12.71 \mathrm{ksi}$

Hence confined strength of plain concrete cylinders $=12.71 \times\left(\Pi \times 6^{2} / 4\right)=359.31 \mathrm{kips}$

Experimental confined compressive strength/ Analytical confined compressive strength $=282.33 / 359.31=0.785$ 


\section{Model 3}

This model is proposed by Toutanji (1999) and confined compressive strength of concrete is given by

$$
\frac{f^{\prime}{ }_{c c}}{f^{\prime}{ }_{c o}}=1+3.5\left(\frac{p_{u}}{f_{c o}^{\prime}}\right)^{0.85}
$$

where the terms in the equation are already explained above

$$
\begin{aligned}
f^{\prime}{ }_{c c} & =5.81 \times\left[1+3.5\left(\frac{1.98}{5.81}\right)^{0.85}\right] \\
& =13.95 \mathrm{ksi}
\end{aligned}
$$

Hence confined strength of plain concrete cylinders $=13.95 \times\left(\Pi \times 6^{2} / 4\right)=394.36 \mathrm{kips}$ Experimental confined compressive strength/ Analytical confined compressive strength $=282.33 / 394.36=0.716$

\section{Model 4}

This model is proposed by Saaman et al. (1998) and confined compressive strength of concrete is given by

$$
\frac{f_{c c}^{\prime}}{f^{\prime}{ }_{c o}}=1+6.0\left(\frac{p_{u}^{0.7}}{f_{c o}^{\prime}}\right)
$$

where the terms in the equation are already explained above

$$
\begin{aligned}
f_{c c}^{\prime} & =5.81 \times\left[1+6.0\left(\frac{1.98^{0.7}}{5.81}\right)\right] \\
& =15.48 \mathrm{ksi}
\end{aligned}
$$

Hence confined strength of plain concrete cylinders $=15.48 \mathrm{x}\left(\Pi \times 6^{2} / 4\right)=437.61 \mathrm{kips}$ Experimental confined compressive strength/ Analytical confined compressive strength $=282.33 / 437.61=0.645$

\section{Model 5}

This model is proposed by Saafi et al. (1999) and confined compressive strength of concrete is given by

$$
\frac{f_{c c}^{\prime}}{f_{c o}^{\prime}}=1+2.2\left(\frac{p_{u}}{f_{c o}^{\prime}}\right)^{0.84}
$$


where the terms in the equation are already explained above

$$
\begin{aligned}
f_{c c}^{\prime} & =5.81 \times\left[1+2.2\left(\frac{1.98}{5.81}\right)^{0.84}\right] \\
& =10.98 \mathrm{ksi}
\end{aligned}
$$

Hence confined strength of plain concrete cylinders $=10.98 \times\left(\Pi \times 6^{2} / 4\right)=310.40 \mathrm{kips}$ Experimental confined compressive strength/ Analytical confined compressive strength $=282.33 / 310.40=0.909$

\section{Model 6}

This model is proposed by Spoelstra and Monti (1998) ("approximate") and confined compressive strength of concrete is given by

$$
\frac{f_{c c}^{\prime}}{f^{\prime}{ }_{c o}}=0.2+3\left(\frac{p_{u}}{f^{\prime}{ }_{c o}}\right)^{0.5}
$$

where the terms in the equation are already explained above

$$
\begin{aligned}
f^{\prime}{ }_{c c} & =5.81 \times\left[0.2+3\left(\frac{1.98}{5.81}\right)^{0.5}\right] \\
& =11.33 \mathrm{ksi}
\end{aligned}
$$

Hence confined strength of plain concrete cylinders $=11.33 \times\left(\Pi \times 6^{2} / 4\right)=320.29 \mathrm{kips}$ Experimental confined compressive strength/ Analytical confined compressive strength $=282.33 / 320.29=0.881$

\section{Model 7}

This model is proposed by Kono et al. (1998) and confined compressive strength of concrete is given by

$$
\frac{f^{\prime}{ }_{c c}}{f^{\prime}{ }_{c o}}=1+0.0572 \times p_{u}
$$

where the terms in the equation are already explained above

$$
\begin{aligned}
f_{c c}^{\prime} & =5.81(1+0.0572 \times 1.98) \\
& =6.46 \mathrm{ksi}
\end{aligned}
$$

Hence confined strength of plain concrete cylinders $=6.46 \times\left(\Pi \times 6^{2} / 4\right)=182.62 \mathrm{kips}$ Experimental confined compressive strength/ Analytical confined compressive strength $=282.33 / 182.62=1.54$ 
Table 4-12 Comparison between experimental and analytical compressive strength of concrete cylinders wrapped with CFRP fabric

\begin{tabular}{|c|c|c|c|c|c|c|c|c|}
\hline \multirow[t]{2}{*}{$\begin{array}{l}\mathbf{f}_{\text {co }} \\
(\mathbf{k s i})\end{array}$} & $\begin{array}{l}\mathbf{f}_{\mathrm{u}} \\
(\mathbf{k s i})\end{array}$ & \multicolumn{7}{|c|}{ Experimental Strength / Analytical Strength } \\
\hline & & $\begin{array}{l}\text { Fardis } \\
\text { and } \\
\text { Khalili }\end{array}$ & Miyauchi & Toutanji & Saaman & Saafi & $\begin{array}{c}\text { Spoelstra and } \\
\text { Monti(approximate) }\end{array}$ & Kono \\
\hline 5.81 & 495 & 0.717 & 0.785 & 0.716 & 0.645 & 0.909 & 0.881 & 1.54 \\
\hline
\end{tabular}

The experimental values were compared with the analytical models and two of the models namely, Saafi et al. (1999) and Spoelstra and Monti (1998) (approximate) provided better correlation with the experimental results. The only model that under predicted the value of confined concrete strength was that by Kono et al. (1998).

\subsubsection{Failure Modes}

This section presents sample pictures showing the failure modes of plain and FRP wrapped concrete cylinders that were tested using Universal Compression Testing Machine as a part of this research.

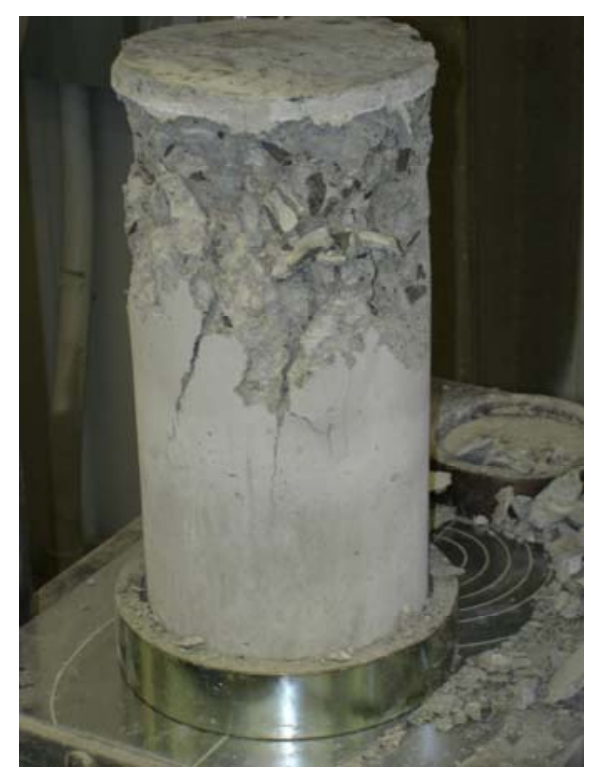

Figure 4-105 Failure mode of unwrapped concrete cylinder 


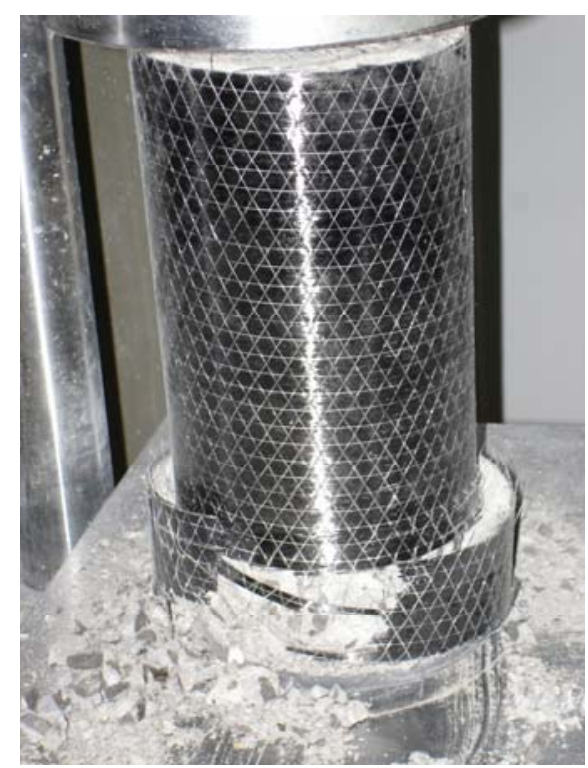

Figure 4-106 Failure mode of concrete cylinders wrapped with CFRP Fabric

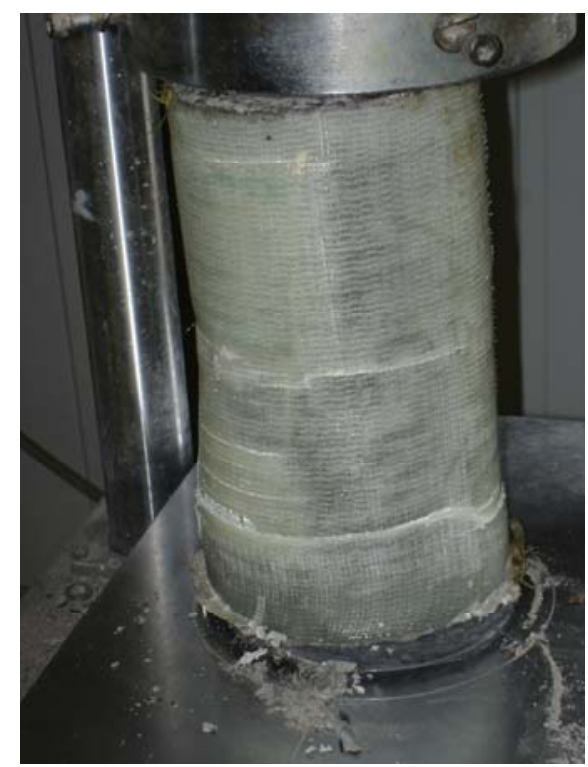

Figure 4-107 Failure mode of concrete cylinders wrapped with GFRP Fabric

\subsubsection{Conclusions}

Barring few exceptions, it can be seen from the tables and graphs that the axial compressive strength of columns decreases significantly with increase in the percentage area of debonds between the FRP wraps and the underlying concrete surface. In general, the $\mathrm{R}^{2}$ values were quite high $(0.7$ to 0.94$)$, thus it can be concluded that the two parameters correlate reasonably well. Also, for small levels of debonding, water-filled 
debonds were observed to perform better in terms of resisting pressure and providing confining action compared to air-filled debonds due to water's higher bulk modulus. Thus, for small percentage area of debonds, water-filled debonds led to higher compressive strength compared to air-filled debonds. However, this was not the case with higher percentage of debonds.

The GFRP wrapped cylinders showed a much larger percentage decrease in compressive strength compared to CFRP wrapped cylinders for small debonds. A $1.73 \%$ debond area causes over $20 \%$ reduction in compressive strength for GFRP wrapped cylinders whereas the corresponding reduction is around 10\% for CFRP wrapped cylinders. However, the percentage decrease jumps to 20 to $32 \%$ for GFRP wrapped cylinders and 45 to $55 \%$ for CFRP wrapped cylinders for 5\% debonded area. Therefore, the ACI $440.2 \mathrm{R}-02$ criterion of limiting debonds to no more than $5 \%$ of the total laminate area is not at all adequate for both GFRP and CFRP wrapped concrete columns.

Several experimental data points obtained in this research have shown that in case of GFRP and CFRP wrapped cylinders with sizable percentage of debonded area (> $3.53 \%$ ), the failure strength often fell below the strength of unwrapped (plain concrete) cylinders. This could be a result of large stress concentration occurring around the debonds. This issue needs to be investigated further in future research by testing additions FRP wrapped cylinders with large percentage of debonded areas $(>5 \%)$. 


\section{CHAPTER 5}

\section{FIELD TESTING RESULTS USING INFRARED THERMOGRAPHY}

This chapter describes the results of field testing using infrared thermography (IRT). The IRT testing was carried out in order to detect debonds and delaminations in timber piles wrapped with glass fiber reinforced polymer (GFRP) fabrics. The delaminations refer to defects within the timber piles while the debonds are discontinuities between the FRP wrap and the underlying timber piles. Detection of these subsurface defects was useful for taking remedial action such as injecting resin in defective areas.

\subsection{FIELD TRIP DURING JUNE 7-9, 2005}

During June 7 to 9, 2005, a field trip was conducted to inspect and repair a railroad bridge in Moorefield, West Virginia. The bridge number was 574 and its picture is shown in Figure 5-1. Four piles were tested during this field trip. Since water had flooded underneath the bridge (Figures 5-2(a) and 5-2(b)), it was very difficult to place the tripod at a convenient position and take the infrared images. A cofferdam was built around the piles and a submersible pump was subsequently used to drain out the water. It helped in getting larger lengths of the piles to be exposed for inspection and repair work. The piles were dried using a hot air blower before testing because water on the surfaces of the piles could lead to erroneous results (Figure 5-3).

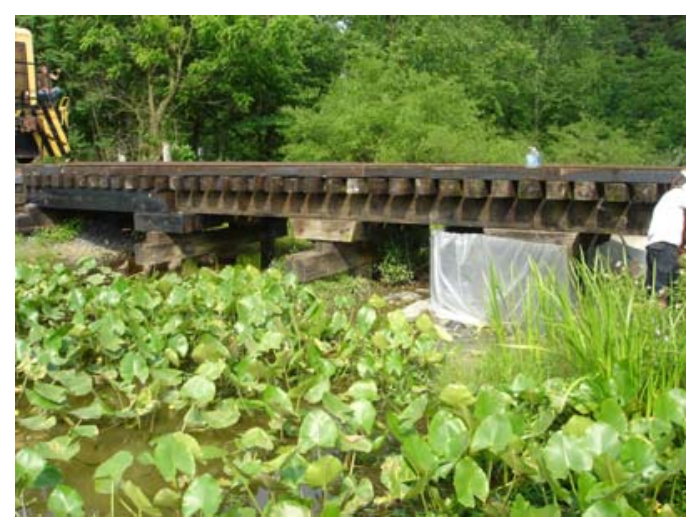

Figure 5-1 Picture of bridge \# 574 


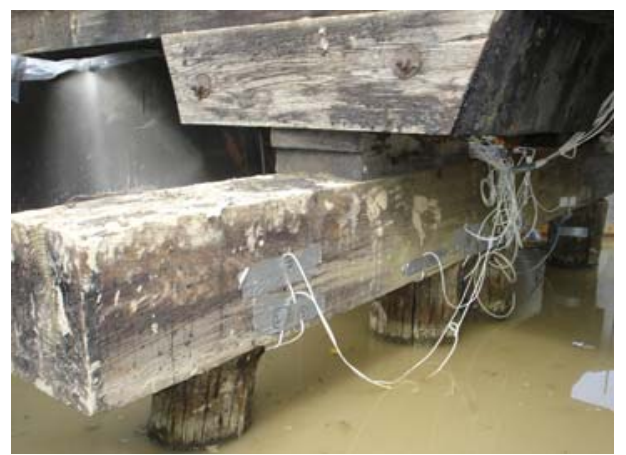

(a)

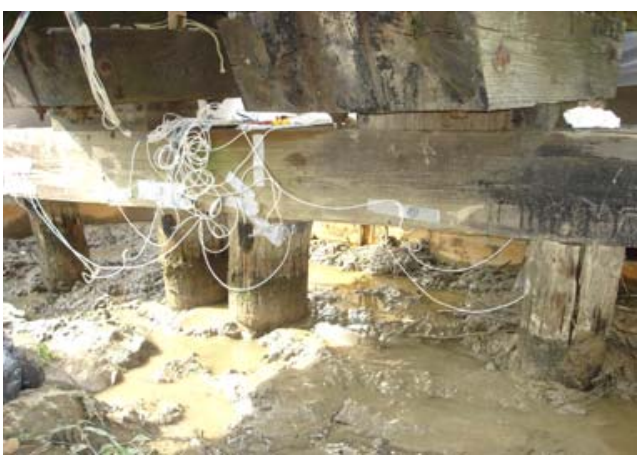

(b)

Figure 5-2 (a) Water underneath the bridge before pumping, and (b) picture after pumping

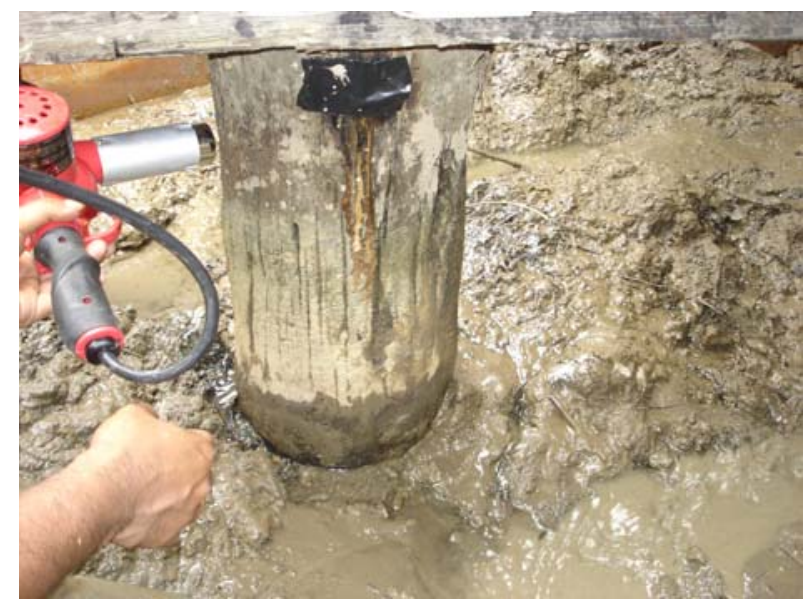

Figure 5-3 Drying the column with hot air

Figure 5-4(a) shows a digital picture of the first pile and Figure 5-4(b) shows the infrared image of the same pile. Before acquiring the infrared image, a $1500 \mathrm{~W}$ heater was used to heat the pile. The heater was held at a distance of $12 "(0.3 \mathrm{~m})$ from the pile. After heating the pile for 5 minutes, the heater was removed and the infrared image was acquired. The infrared image (Figure 5-4(b)) shows an area with higher temperature, i.e., a bright spot in the infrared image. This "hot spot" indicates existence of an air gap or void within the pile (known as a "delamination"). The temperature of the hot spot is 55.1 ${ }^{\circ} \mathrm{C}$ whereas the temperature of the adjacent area is $44.5{ }^{\circ} \mathrm{C}$. The pile was also tap tested and it also revealed a hollow air gap at the same location.

Figure 5-5(a) shows the digital picture of the second and third piles and Figure 5-5(b) shows the corresponding infrared image. Since the underneath of the bridge was 
very muddy after water was pumped out, it was possible to heat only the second pile uniformly with the heater. The temperature of the brighter region in the infrared image of the second pile (Figure 5-5(b)) is $59.1{ }^{\circ} \mathrm{C}$ whereas temperature of an adjacent area is 40.9 ${ }^{\circ} \mathrm{C}$. The brighter region (hot spot) in the infrared image indicated delamination within the timber pile. This pile was also tested by tapping with a hammer and tap testing also corroborated the results from Infrared Thermography testing.

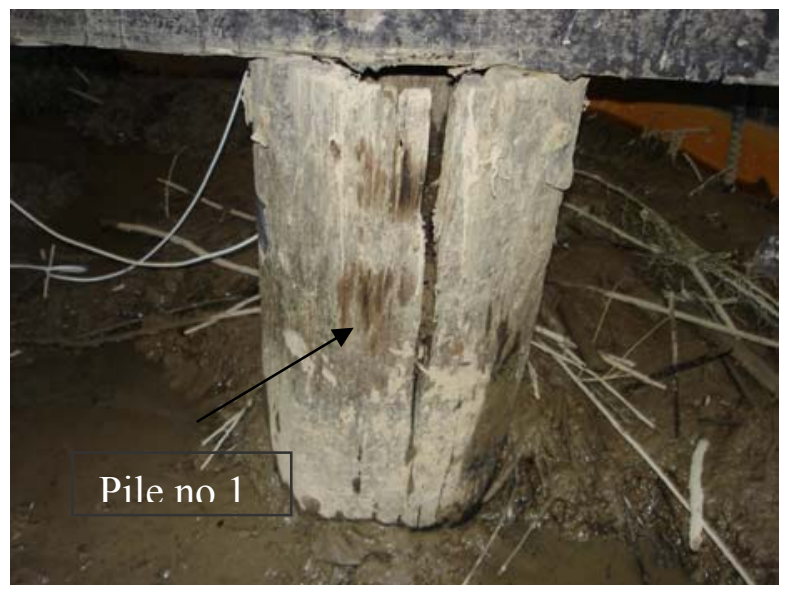

(a)

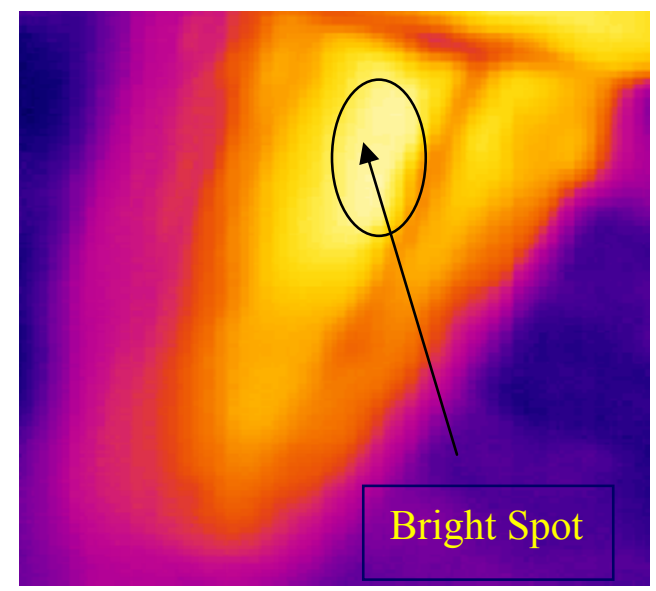

(b)

Figure 5-4 (a) Digital picture of first pile, and (b) infrared image

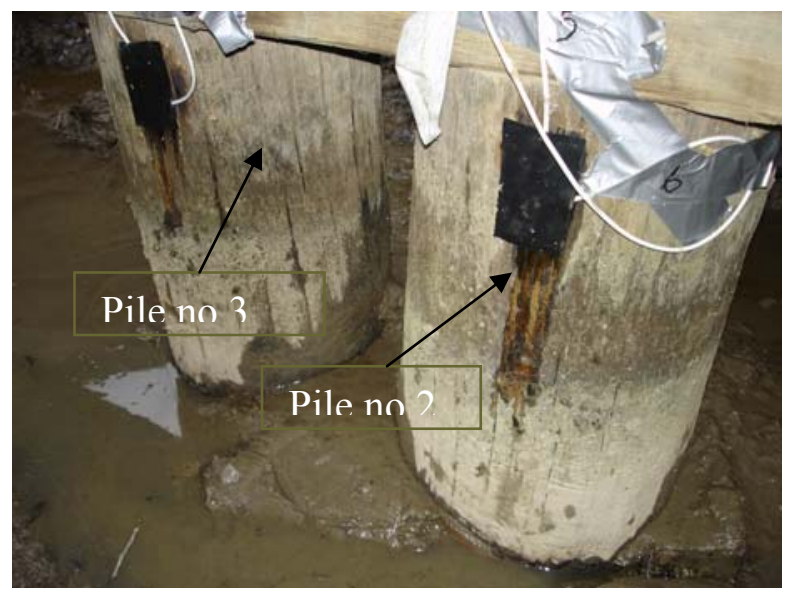

(a)

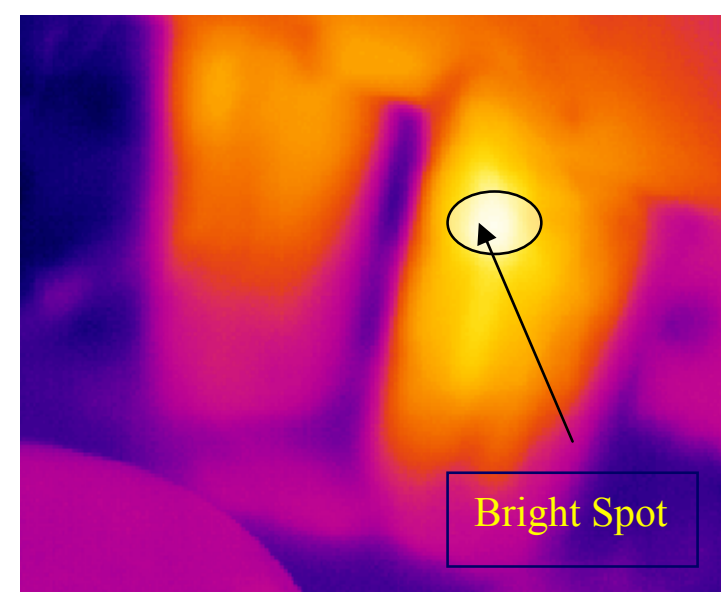

(b)

Figure 5-5 (a) Digital picture of second and third piles, and (b) infrared image

Figure 5-6(a) shows the digital picture of the fourth pile and Figure 5-6(b) shows the corresponding infrared image. In case of this pile, heating with the heater was not 
possible because of strong wind blowing in the region. The infrared image of the pile (Figure 5-6(b)), taken under the influence of solar radiation, shows that the top portion of the pile is at a higher temperature compared to the bottom portion. This is quite normal because in this case, the phenomenon of convective heat flow through the atmosphere comes into picture, which causes a increasing temperature profile in the vertical direction. Such naturally occurring thermal gradient often masks the true defects (Steele 2001).

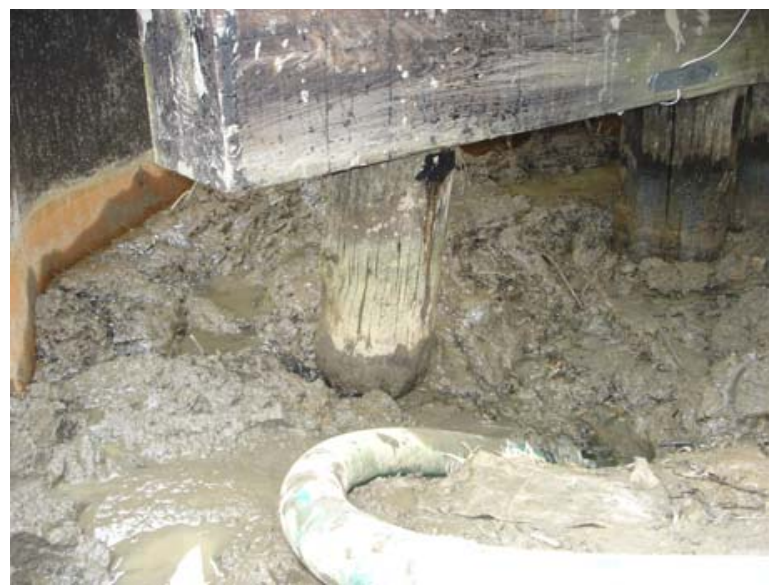

(a)

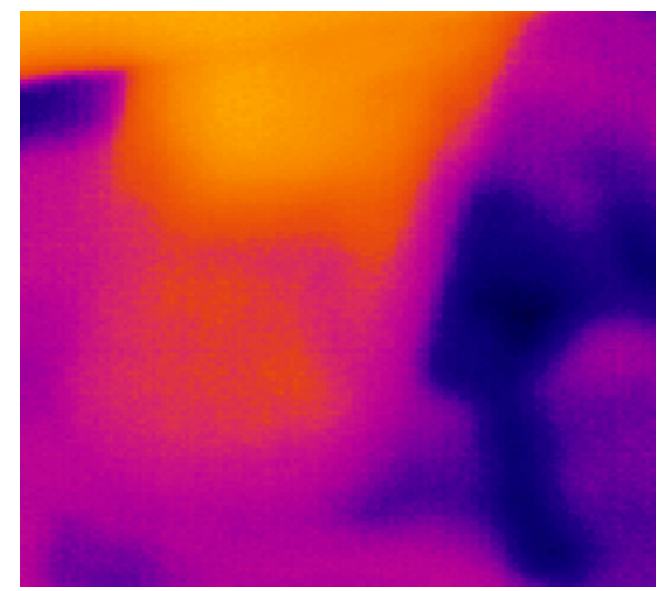

(b)

Figure 5-6 (a) Digital picture of fourth pile, and (b) infrared image

\subsection{FIELD TRIP DURING JUNE 20-23, 2005}

A second field trip was conducted to Moorefield during June 20 to June 23 to wrap the first, third, and fourth pile of Bridge\# 574 with GFRP fabric. The water was drained out as before and the mud around the piles was dug out to obtain a length of 36 inches $(0.9144 \mathrm{~m})$ for the purpose of wrapping. Infrared tests were carried out on the freshly wrapped piles (after 24 hours of curing) to detect any debonds between the wrap and the underlying timber pile. Figure 5-7 shows the basic infrared testing setup in the field. 


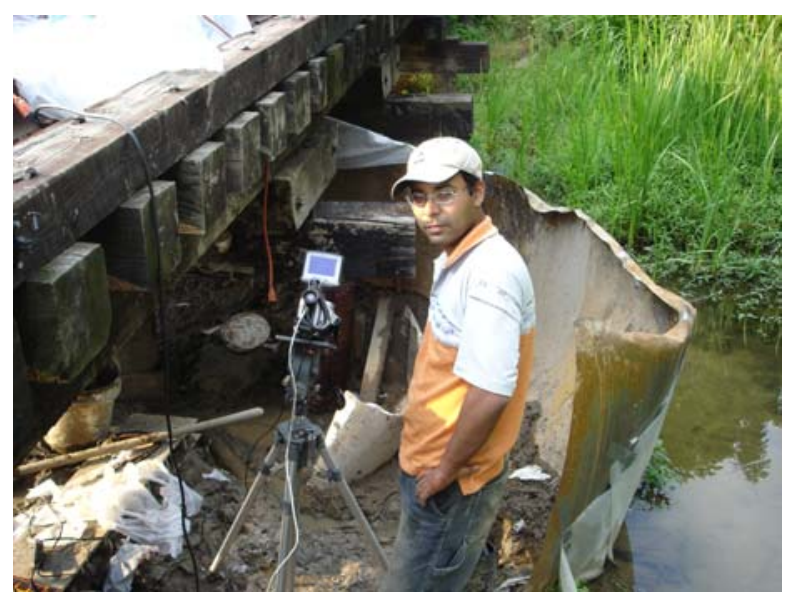

Figure 5-7 Infrared test setup in the field

For the Infrared Thermography experiments, the $1500 \mathrm{~W}$ shop heater was used as the heating source. Prior to acquiring infrared images, the piles were heated up for 5 minutes with the shop heater held at a distance of 12 inches from them. Figure 5-8(a) shows the digital picture of the first pile and Figure 5-8(b) shows the infrared image of the pile. In this infrared image (Figure 5-8(b)), a region with brighter contrast compared to the surrounding area (a "hot spot") can be seen. Temperature of this hotter region was $66.7{ }^{\circ} \mathrm{C}$ and temperature of a surrounding defect-free area was recorded to be $30.7{ }^{\circ} \mathrm{C}$. This is actually the seam of the FRP wrap and not a debond. The tap testing with a hammer also did not reveal the presence of any debond. The digital photograph of the third pile and the corresponding thermal image are shown in Figure 5-9(a) and 5-9(b), respectively. The thermal image of this pile also shows a "hot spot" which is actually the seam of the GFRP wrapping instead of a debond. The temperature of this hot spot was $68.3{ }^{\circ} \mathrm{C}$. Infrared camera measurement revealed the temperature of a surrounding defectfree region to be $37.5^{\circ} \mathrm{C}$. The tap testing result was also in harmony with the Infrared Thermography result.

The above tests showed no real debonds in the freshly wrapped piles, thus indicating that the wrapping was properly conducted. 


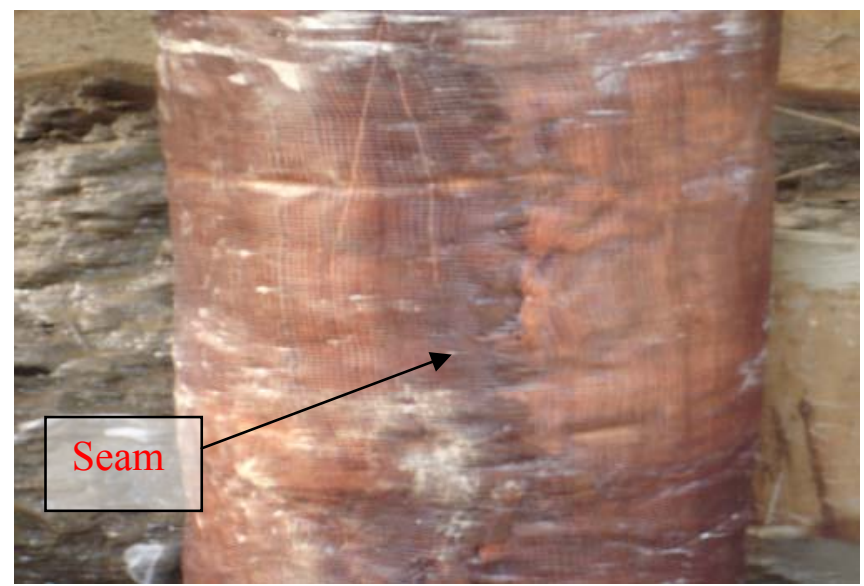

(a)

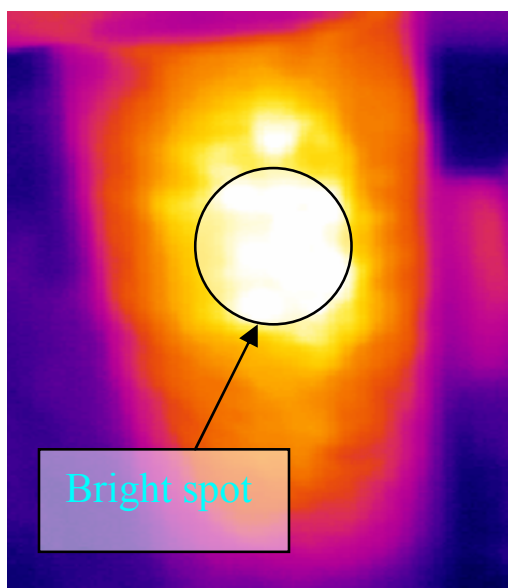

(b)

Figure 5-8 (a) Digital picture of first pile, and (b) infrared image

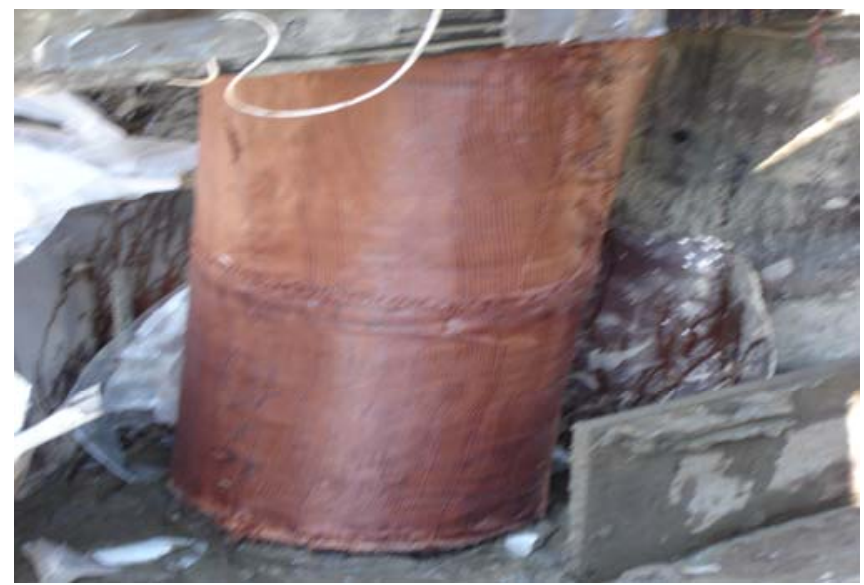

(a)

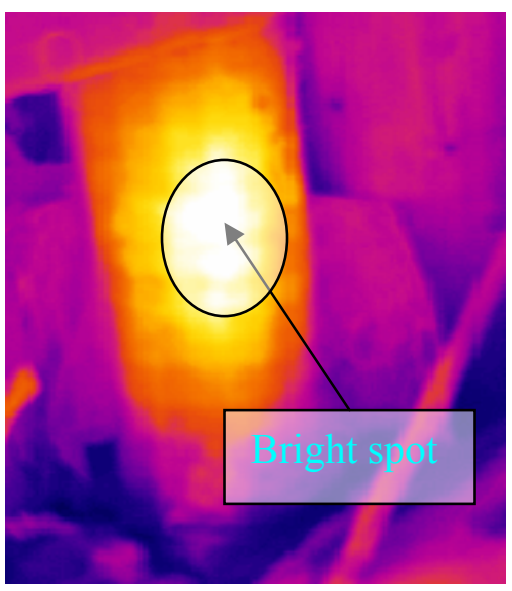

(b)

Figure 5-9 (a) Digital picture of third pile, and (b) infrared image

Figures 5-10(a) and 5-10(b) show the digital picture and the infrared image of the fourth pile. Even before the infrared test, this pile was heated up due to solar radiation. Subsequent heating with the shop heater resulted in overheating the pile and hence, no conclusive inference could be drawn from the infrared image. 


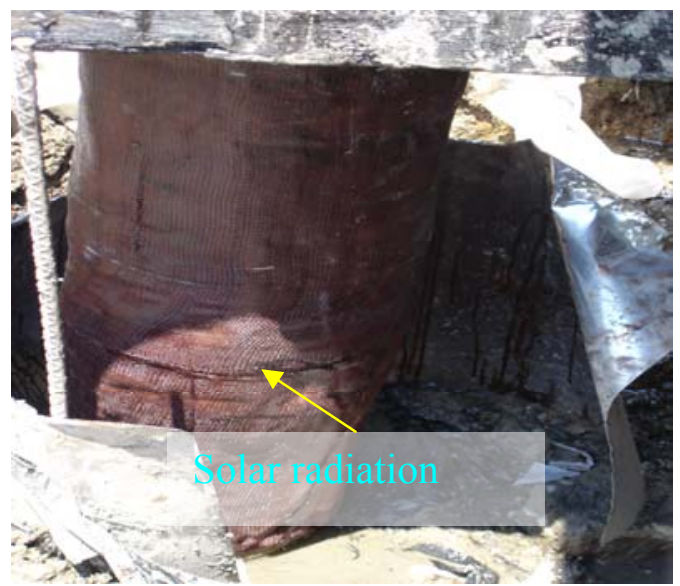

(a)

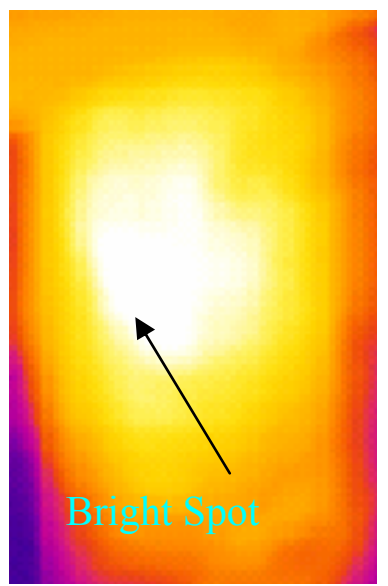

(b)

Figure 5-10 (a) Digital picture of fourth pile, and (b) infrared image

\subsection{SUMMARY}

The field testing results showed that infrared thermography was successful in detecting delaminations within the timber piles. The digital infrared images acquired from freshly wrapped piles (after 24 hours of curing) did not reveal any subsurface debonds, thus indicating that the wrapping process was conducted properly. It is obvious that infrared thermography can be a valuable tool for quality control during the wrapping process and for subsequent in-service monitoring. If debonding occurs during service, it can be detected using infrared thermography testing, and techniques such as injection of resin can fill these subsurface voids to ensure continued structural integrity of the wrapped piles. 


\section{CHAPTER 6}

\section{CONCLUSIONS AND RECOMMENDATIONS}

\subsection{CONCLUSIONS}

In summary, the following conclusions are drawn from the study:

- Digital Infrared Thermography (IRT) proved to be very effective in detecting airfilled debond of sizes 1.4" x 1.4", 2"x 2" and 3" x 3" in concrete cylinders wrapped around with Glass Fiber Reinforced Polymer (GFRP) wrap and Carbon Fiber Reinforced Polymer (CFRP) wrap. Also, water-filled debonds actually showed up as air-filled debonds ("hot spots") in the infrared images because of the relatively small thickness of the FRP wraps.

- Ground Penetrating Radar tests showed that GPR is an excellent tool for detecting water-filled debonds of the above mentioned sizes. However, GPR's performance was not satisfactory in terms of detecting air-filled debonds. Also, one of the characteristics of the $1.5 \mathrm{GHz}$ ground coupled antenna is its small footprint (small field of view compared to that of an infrared camera) which means the antenna has to go directly over the debonded area in order to indicate its presence with certainty. This means the GPR line scans have to be closely spaced in the field.

- Curves for surface temperature versus time and also thermal difference versus time were established. Maximum thermal difference for GFRP wrapped cylinders with simulated air-filled debonds did not occur immediately after the external stimulus was removed, but sometime later. For all other cylinders, maximum thermal difference was seen immediately after the removal of the heater. The relation between maximum surface temperature above the water-filled debonds and the debond sizes was inversely proportional in most of the cases, that is, larger water-filled debonds led to smaller surface temperature. This is because water has a high specific heat value, and larger debond absorbs more heat with less temperature increase. Regarding the time duration during which thermal images with good contrast were observed, it was found that the CFRP wrapped cylinders had a higher cooling rate and reached thermal equilibrium faster compared to the GFRP wrapped cylinders. This is because CFRP has higher 
thermal conductivity compared to GFRP fabrics. Moreover, the rate of decrease in thermal difference bore an inverse relationship with the size of debonds for both air-filled and water-filled debonds, i.e., larger debonds can be observed for a longer duration in the infrared image sequence.

- Regarding the influence of area of debond on the axial compressive strength of cylinders, the general trend was a decrease in compressive strength with an increase in area of debonded portion. In general, water-filled debonds performed better than air-filled debonds in terms of withstanding pressure and providing confining action because of higher bulk modulus value of water. This was true for smaller percentage of debonded area $(<3.53 \%)$ only. As the percentage of debonded area increased, the behavior became more erratic, and several data points showed that the compressive strength even dropped below the value for unwrapped (plain concrete) cylinders. This behavior may be due to stress concentration effects and needs further investigation.

- A combination GPR and IRT have satisfied the available standards for inspection methods used to detect delaminations. Section 6.2.3 of ACI 440.2R-02 states that inspection method should be able to detect delaminations that are $2 \mathrm{in}^{2}$ or greater. The debond sizes that were incorporated in this study were 2 in $^{2}$ (1.4', $\mathrm{x} 1.4^{\prime \prime}$ '), 4 in $^{2}\left(2\right.$ ' $x$ 2"') and 9 in $^{2}(3$ ' $x 3$ ' '). Results of the compression tests conducted on wrapped cylinders with embedded debonds showed that the ACI 440.2R-02 criterion of limiting debonded area to within $5 \%$ of the total laminate area is not restrictive enough for both GFRP and CFRP wrapped columns.

- From the field tests that were conducted, it was confirmed that Infrared Thermography could successfully detect the presence of subsurface anomalies in timber piles.

- GPR and IRT can complement each other to form a robust nondestructive evaluating system for inspecting FRP wrapped columns. In such columns, IRT by itself could detect both air-filled and water-filled debonds as "hot spots" without making a distinction between them. GPR, on the other hand could detect only water-filled debonds and missed all air-filled debonds. A combination of IRT and 
GPR systems can not only detect both air-filled and water-filled debonds but also provides a means of distinguishing between the two.

\subsection{RECOMMENDATIONS FOR FUTURE RESEARCH}

A number of recommendations can be put forward for future study on detection of air-filled and water-filled debonds with the help of GPR and IRT. Future study can concentrate on quantitative analysis of data acquired from these two state-of-the-art techniques in order to obtain vital information such as width, thickness, and depth of the debond. This kind of information, if extracted, can herald a new phase in the field of nondestructive testing because a precise knowledge of the width or depth of the debond will help immensely to characterize its severity and carry out the rehabilitation process in a more efficient manner. Also, the ability of GPR and IRT for detecting debonds of smaller sizes can be explored. Performance of the survey wheel in evaluating debond sizes in FRP wrapped columns can also be investigated. Use of cooling sources such as liquid $\mathrm{CO}_{2}$ and cold water for IRT testing can be explored. Heat transfer finite element modeling for cylindrical members should be used to better describe the heat transfer process between the debond and the surrounding and also to determine the effect of applied heat transfer rate on surface temperature differences.

Several experimental data points in this research study showed that the compressive strength for wrapped cylinders with sizable percentage of debonded area $(>3.53 \%)$ even dropped below the value for unwrapped (plain concrete) cylinders. This behavior may be due to stress concentration effects and needs further investigation and confirmation using compression testing of additional FRP wrapped concrete cylinders with embedded debonds. These results can have significant impact on current analysis and design procedures and guidelines for FRP wrapped concrete members. 


\section{REFERENCES}

ACI 440.2R-02 (2002). Guide for the Design and Construction of Externally Bonded FRP Systems for Strengthening Concrete Structures, American Concrete Institute, Farmington Hills, MI.

Agrawal, S. (2005). "Nondestructive Evaluation of Wooden Logs using Ground Penetrating Radar." MS Thesis, Department of Civil and Environmental Engineering, West Virginia University, Morgantown, West Virginia.

Buyukozturk, O., and Au, C. (2005).'Effect of Fiber Orientation and Ply Mix on FRP-confined Concrete." Paper available online at http://web.mit.edu/istgroup/ist/documents/ orientationPlyMix.pdf.

Clemena, G. C. (1991). "Short-Pulse Radar Methods." CRC Handbook on Nondestructive Testing of Concrete, edited by Malhotra, V.M., and Carino, N.J., CRC Press, Inc., FL, 253-273.

FLIR SYSTEMS (2002a). ThermaCAM ${ }^{T M}$ S60 Operator's Manual , Revision A, 14 June.

FLIR SYSTEMS (2002b). ThermaCAM ${ }^{T M}$ Researcher Operating Manual, Version A.

Fyfe Co. LLC (2000). http://www.fyfeco.com/products/epoxies/pdf/s.pdf

Godinez-Azcuaga, V. F., Gostautas, R. S., Finlayson, R. D., and Miller, M. (2004). "Nondestructive Evaluation of FRP Wrapped Concrete Columns and Bridges." Proceedings of Structural Materials VI- An NDT Conference, Buffalo, New York, September 14-17, 139-146.

GSSI (2006). Geophysical Survey System, Inc., http://www.geophysical.com/GSSI \%20SIR-20\%20Brochure US.pdf.

GSSI (2004). Geophysical Survey System, Inc., http://www.geophysical.com/antennas.htm.

GSSI (2002a). SIRveyor SIR-20 User's Manual, Geophysical Survey System, Inc., North Salem, NH. 
GSSI (2003). RADAN for Windows - Version 5.0 User's Manual, Geophysical Survey System, Inc., North Salem, NH.

Halabe, U. B. (1990). “Condition Assessment of Reinforced Concrete Structures Using Electromagnetic Waves.” Ph.D. Dissertation, Department of Civil Engineering, Massachusetts Institute of Technology (MIT), Cambridge, MA.

Halabe, U. B., Sotoodehnia, A., Maser, K. R., and Kausel, E. A. (1993). "Modeling the Electromagnetic Properties of Concrete." American Concrete Institute (ACI) Materials Journal, 90(6), 552-563.

Halabe, U. B., Maser, K. R., and Kausel, E. A. (1995). “Condition Assessment of Reinforced Concrete Structures using Electromagnetic Waves." American Concrete Institute (ACI) Materials Journal, 92(5), 511-523.

Hing, C. L., (2006). "Nondestructive Evaluation of Fiber Reinforced Polymer Bridge Decks Using Ground Penetrating Radar and Infrared Thermography." Ph.D. Dissertation, Department of Civil and Environmental Engineering, West Virginia University, Morgantown, West Virginia.

Jackson, D. R., Islam, M., and Alampalli, S. (2000). "Feasibility of Evaluating the Performance of Fiber Reinforced Plastic (FRP) Wrapped Reinforced Concrete Columns Using Ground Penetrating Radar (GPR), and Infrared (IR) Thermography Techniques." Proceedings of Structural Materials Technology IV - An NDT Conference, Atlantic City, NJ, February 28- March 3.

Kaplan, H. (1999). Practical Applications of Infrared Thermal Sensors and Imaging Equipment, SPIE - The International Society for Optical Engineering, Bellingham, Washington, USA.

Kreith, F., and Bohn, M. S. (1993). Principles of Heat Transfer, 5th Edition, International Thomson Publishing / PWS Publishing Company, Boston, MA, 558 - 560.

Lorenzis, L. D., and Tepfers, R. (2003). "Comparative Study of Models on Confinement of Concrete Cylinders with Fiber-Reinforced Polymer Composites." Journal of Composites for Construction, ASCE, 7(3), 219-237. 
Maierhofer, C. (2003). "Nondestructive Evaluation of Concrete Infrastructure with Ground Penetrating Radar." Journal of Materials in Civil Engineering, ASCE, 15(3), 287-297.

Maldague, X. (1993). Nondestructive Evaluation of Materials by Infrared Thermography, Springer-Verlag, London.

Maldague, X. (2000). "Applications of Infrared Thermography in Nondestructive Evaluation." Trends in Optical Nondestructive Testing (invited chapter), Pramod Rastogi ed., 591-609. (paper also available at http://www.ndt.net/v06n04.htm).

Mehta, P. K. (1986). CONCRETE Structure, Properties, and Materials, PrenticeHall, Inc., Englewood Cliffs, New Jersey 07632.

Mindess, S., Young, J. F., and Darwin, D. (2003). Concrete, Second Edition, Prentice-Hall, Inc., Englewood Cliffs, New Jersey 07632.

Rajappa, R.R., (2004). "Behaviour of FRP Wrapped Concrete Cylinders."MS Thesis, Department of Civil and Environmental Engineering, West Virginia University, Morgantown, West Virginia.

Starnes., M.A., Carino, N.J., and Kausel, E.A.(2003). "Preliminary Thermography Studies for Quality Control of Concrete Structures Strengthened with Fiber-reinforced Polymer Composites." Journal of Materials in Civil Engineering, ASCE, 15(3), 266273.

Steele III, W. E. (2001). "Detection of Subsurface Anomalies in Fiber Reinforced Polymer (FRP) Wrapped Timber Bridge Components using Infrared Thermography. MS Thesis, Department of Civil and Environmental Engineering, West Virginia University, Morgantown, WV.

Toutanji, H.A. (1999). "Stress Strain Characteristics of Concrete Columns Externally Confined with Advanced Fiber Composite Sheets." ACI Materials Journal, 96(3), 397-404.

Vasudevan, A. (2004) "Application of Digital Infrared Thermography for Nondestructive Evaluation of Composite Bridge Components." MS Thesis, Department of Civil and Environmental Engineering, West Virginia University, Morgantown, WV. 